Universidade de São Paulo - USP

Faculdade de Medicina de Ribeirão Preto - FMRP

Programa de Pós-graduação em Clínica Médica

FELIPE ARRIVA PITELLA

\title{
Avaliação Quantitativa e Qualitativa da Densidade de Transportadores Pré-Sinápticos de Dopamina em Pacientes Saudáveis e em Portadores de Doença de Parkinson: Um estudo de SPECT com [ ${ }^{99 \mathrm{~m}}$ Tc]-TRODAT-1.
}

Ribeirão Preto - SP

2017 
Felipe Arriva Pitella

\section{Avaliação Quantitativa e Qualitativa da Densidade de Transportadores Pré-Sinápticos de Dopamina em Pacientes Saudáveis e em Portadores de Doença de Parkinson: Um estudo de SPECT com [ ${ }^{99 \mathrm{~m}}$ Tc]-TRODAT-1.}

Tese de doutorado apresentada à Faculdade de Medicina de Ribeirão Preto da Universidade de São Paulo para obtenção do título de doutor em Ciências Médicas.

Área de Concentração: Clínica Médica

Orientador: Prof. Dr. Lauro Wichert Ana

Ribeirão Preto - SP

2017 
Autorizo a reprodução e divulgação total ou parcial deste trabalho, por qualquer meio convencional ou eletrônico, para fins de estudo e pesquisa, desde que citada a fonte.

\section{FICHA CATALOGRÁFICA}

Pitella, Felipe Arriva

Avaliação quantitativa e qualitativa da densidade de transportadores pré-sinápticos de dopamina em pacientes saudáveis e em portadores de doença de Parkinson: um estudo de SPECT com 99mTc-TRODAT-1. Ribeirão Preto, 2017.

238 p. : 25il. ; $30 \mathrm{~cm}$

Dissertação de Doutorado, apresentada à Faculdade de Medicina de Ribeirão Preto/USP. Área de concentração: Clínica Médica.

Orientador: Wichert-Ana, Lauro.

1. Doença de Parkinson. 2. TRODAT-1. 3. Semiquantificação. 4. SPECT. 5. Medicina nuclear. 
Nome: Pitella, Felipe Arriva

Título: Avaliação Quantitativa e Qualitativa da Densidade de Transportadores Pré-Sinápticos de Dopamina em Pacientes Saudáveis e em Portadores de Doença de Parkinson: Um estudo de SPECT com [ $\left.{ }^{99 \mathrm{~m}} \mathrm{Tc}\right]-\mathrm{TRODAT}-1$.

Tese apresentada à Faculdade de Medicina de Ribeirão Preto da Universidade de São Paulo para obtenção do título de doutor em Ciências Médicas.

Aprovado em:

\section{Banca Examinadora}

Prof(a). Dr(a).

Julgamento:

Prof(a). Dr(a).

Julgamento:

Prof(a). Dr(a).

Julgamento:

Prof(a). Dr(a).

Julgamento:

Prof(a). Dr(a).

Julgamento:
Instituição:

Assinatura

Instituição:

Assinatura:

Instituição:

Assinatura:

Instituição:

Assinatura:

Instituição:

Assinatura: 


\section{DEDICATÓRIA E AGRADECIMENTOS}

À minha família, em especial a meus pais, Fátima e Luís, e querida irmã, Lidiana, sempre presentes nos momentos mais importantes da minha vida, assim como nos pequenos momentos, que trazem significado a essa jornada.

À minha linda Karen, amiga, companheira e grande amor, com a qual compartilho sonhos e alegrias.

Aos meus amigos, que acolheram a idéia e me apoiaram direta ou indiretamente para cumprir essa meta, especialmente ao Leonardo, Ana, Emerson e Mery.

A todos que tiveram paciência por eu ter, em alguns momentos, abdicado de suas companhias para cumprir as obrigações para com este trabalho.

Aos colegas colaboradores da Seção de Medicina Nuclear e do ambulatório de doenças extrapiramidais do HCRP, particularmente Manuelina e Prof. Vitor Tumas, que realizaram com muito critério e competência a avaliação neurológica dos pacientes.

Ao meu orientador, colega de trabalho e amigo, Prof. Dr. Lauro Wichert-Ana, que além de orientar, foi incentivador para meu aprimoramento no universo acadêmico. 
"Viva como se fosse morrer amanhã. Aprenda como se fosse viver para sempre."

(Gandhi) 


\section{RESUMO}

PITElla, F. A. (2017). Avaliação Quantitativa e Qualitativa da Densidade de Transportadores Pré-Sinápticos de Dopamina em Pacientes Saudáveis e em Portadores de Doença de Parkinson: Um estudo de SPECT com [ ${ }^{99 m}$ Tc]-TRODAT-1. X f. Tese (Doutorado - Programa de pós graduação da Clínica Médica) - Faculdade de Medicina de Ribeirão Preto, Universidade de São Paulo, 2017.

Introdução: A doença de Parkinson (DP) é uma doença neurodegenerativa progressiva. A característica principal da fisiopatologia é a perda de neurônios dopaminérgicos na substância nigra pars compacta. A tomografia por emissão de fóton único (SPECT) com [ $\left.{ }^{99 \mathrm{~m}} \mathrm{Tc}\right]-$ TRODAT-1, um tropano radiomarcado que se liga a transportadores dopaminérgicos (DAT) pré-sinápticos, foi proposta para avaliar a integridade do sistema dopaminérgico nigroestriatal. Na rotina clínica, a interpretação visual de DAT-SPECT e várias técnicas de semiquantificação podem ser aplicadas. OBJETIVO: (1) caracterizar a densidade de DAT no estriado em pacientes saudáveis e com DP; (2) comparar diferentes métodos semiquantitativos de densidade de DAT no estriado. MÉTODOS: Este estudo incluiu prospectivamente 67 pacientes; 23 controles saudáveis ( 8 do sexo masculino, 15 do sexo feminino, idade $59 \pm 11$ anos) e 44 pacientes com DP idiopática em graus variados (29 homens, 15 mulheres, idade 59 \pm 7 anos). SPECT com [ $\left.{ }^{99 m} \mathrm{Tc}\right]-T R O D A T-1$ de todos os pacientes foram avaliados $\mathrm{e}$ comparados com achados clínicos. A interpretação visual e quatro abordagens de semiquantificação foram avaliadas: (1) Método manual; (2) corregistro com ressonância magnética (RM); (3) corregistro com RM corrigida para efeito de volume parcial (4) Two Box. RESULTADOS: Na avaliação qualitativa, foi encontrada alta sensibilidade $(90,91 \%$ 95,45\%), especificidade $(91,3 \%$ - 100\%) e acurácia $(92,54 \%$ - 95,52\%). A concordância intraobservador foi excelente. A concordância interobservador variou entre moderada a pobre. Os pacientes com DP apresentaram potencial de ligação (BPI) estriatal significativamente 
menor em comparação aos controles em todos os métodos semiquantitativos. Entre os métodos semiquantitativos, o mais acurado foi o manual, seguido por Two Box. O método manual poderia potencialmente reduzir os casos falsos positivos de 3 para 0 e os casos falsos negativos de 9 para 7. A reprodutibilidade dos métodos semiquantitativos foi excelente. Em geral, correlações negativas entre BPI e a severidade da DP e as escalas motoras foram encontradas, no entanto, as correlações não foram estatisticamente significantes. $\mathrm{O}$ índice de assimetria e a relação putamen/caudado apresentaram desempenho inferior ao BPI. Observouse diferença estatisticamente significante do BPI entre o grupo com discinesia e sem discinesia no corpo estriado e nos caudados. Conclusão: A avaliação qualitativa de SPECT cerebral com [ $\left.{ }^{99 \mathrm{~m}} \mathrm{Tc}\right]-T R O D A T-1$ apresenta excelente desempenho do diagnóstico diferencial entre pacientes saudáveis e com DP. A avaliação semiquantitativa é complementar a avaliação qualitativa, e pode contribuir de forma a reduzir falsos negativos ou falsos positivos.

Palavras-Chave: Doença de Parkinson, SPECT, dopamina, TRODAT-1. 


\section{ABSTRACT}

PITELlA, F. A. (2017). Quantitative and Qualitative Evaluation of Dopamine Presynaptic Transporter Density in Healthy Patients and in Patients with Parkinson's Disease: a SPECT with [ ${ }^{99 m}$ Tc]-TRODAT-1 study. X f. Doctoral thesis (Posgraduate program in Clinical Medicine) - School of Medicine, University of São Paulo, Ribeirão Preto, 2017.

Introduction: Parkinson disease (PD) is a progressive neurodegenerative disease. The pathophysiology's main hallmark is the loss of dopaminergic neurons in the substantia nigra pars compacta. Single photon emission computed tomography (SPECT) with ${ }^{99 \mathrm{~m}} \mathrm{Tc}$ TRODAT-1, a radiolabeled tropane that binds dopamine transporters (DAT), has been proposed to evaluate the integrity of the nigrostriatal dopaminergic system. In clinical routine, visual interpretation of DAT-SPECT and several semiquantification techniques can be applied. AIM: (1) to characterize DAT density in the striatum in healthy patients and with Parkinson's disease; (2) to compare different semiquantitative methods. METHODS: This study included prospectively 67 patients; 23 healthy controls ( 8 male; 15 female; age $59 \pm 11$ years old) and 44 patients with various degrees of severity of idiopathic PD (29 male; 15 female; age $59 \pm 7$ years old). SPECT with [ $\left.{ }^{99 \mathrm{~m}} \mathrm{Tc}\right]-T R O D A T-1$ of all patients were evaluated and compared with clinical findings. Visual interpretation and four semiquantification approaches were evaluated: (1) Manual method; (2) ROI automatically drawn on the coregistered Magnetic Resonance Imaging (MRI); (3) coregistered MRI corrected by partial volume effects (4) Two Box. RESULTS: In the qualitative evaluation, high sensitivity $(90.91 \%-95.45 \%)$, specificity $(91.3 \%-100 \%)$ and accuracy $(92.54 \%-95.52 \%)$ were found. Intraobserver agreement was excellent. Interobserver agreement ranged from moderate to poor. PD patients had significantly lower striatal DAT binding potential (BPI) compared to controls in all semiquantitative methods. Among the semiquantitative methods, the most 
accurate was the manual, followed by Two Box. The manual method would potentially reduce false positive cases from 3 to 0 and false negative cases from 9 to 7 . The reproducibility of semiquantitative methods was excellent. In general, negative correlations between striatal DAT binding and PD severity and motor scales were found, however, the correlations were not statistically significant. Asymmetry index and putamen/caudate ratio presented inferior performance compared to BPI. A statistically significant difference between the group with dyskinesia and without dyskinesia in the striatum and caudate BPI was found. Conclusion: Qualitative evaluation of DAT-SPECT with TRODAT-1 presents excellent differential diagnosis performance among healthy and PD patients. Semiquantitative evaluation is complementary to the qualitative evaluation, and may contribute in a way to reduce false negatives or false positives.

Palavras-Chave: Parkinson's disease, SPECT, dopamine, TRODAT-1. 


\section{LISTA DE FIGURAS}

Figura 1: Imagem esquemática da fenda sináptica dopaminérgica ......................................38

Figura 2: Imagem transversa de um SPECT com [ $\left.{ }^{99 \mathrm{~m}} \mathrm{Tc}\right]-T R O D A T-1$ de um paciente saudável. Estudo interpretado como normal

Figura 3: Imagens transversais de estudos de SPECT com $\left[{ }^{99 \mathrm{~m}} \mathrm{Tc}\right]-T R O D A T-1$ em pacientes com DP, classificados em graus: I- acometimento de um dos putâmens; IIacometimento bilateral dos putâmens; IIIa - acometimento dos putâmens e do um dos núcleos caudados; IIIb - envolvimento bilateral dos putâmens e núcleos caudados .......56

Figura 4: Fluxograma com os tipos de classificação visual das imagens de SPECT com $\left[{ }^{99 \mathrm{~m}} \mathrm{Tc}\right]-T R O D A T-1$ realizadas pelos observadores

Figura 5: Imagens axiais apresentadas no software Jetpack da estação de trabalho Extended Brilliance Workspace Philips (EBW)

Figura 6: Imagens axiais selecionadas no software Jetpack da estação de trabalho Extended Brilliance Workspace Philips (EBW) para compor imagem 2D utilizada na quantificação

Figura 7: Áreas de interesse delineadas em composição 2D das imagens axiais selecionadas no software Jetpack da estação de trabalho Extended Brilliance Workspace Philips (EBW)

Figura 8: Imagem somada 2D (A) foi suavizada através de filtro $3 \times 3$ (B), e limite externo do ROI de referência foi construído a partir de um threshold de sinal e após exclusão do couro cabeludo $(\mathrm{C})$.

Figura 9: Posicionamento das ROIs estriatais direita e esquerda (A) e estabelecimento da ROI de referência (B) no método Two Box

Figura 10: Corregistro entre o template MNI305 do Atlases do Montreal Neurological Institute (A) e o SPECT com [ ${ }^{99 \mathrm{~m}}$ Tc]-TRODAT-1 de um controle saudável (B)...........6 68

Figura 11: Etapa de extração dos parâmetros de quantificação das imagens de SPECT com [ ${ }^{99 \mathrm{~m}} \mathrm{Tc}$ ]-TRODAT-1 utilizando as VOIs baseadas em template padronizado de RM (MNI305)

Figura 12: Fluxograma com as principais etapas realizadas na avaliação semiquantitativa... 71

Figura 13: Gráficos de dispersão dos dados de potencial de ligação do grupo controle saudável.

Figura 14: Gráficos do BPI no corpo estriado e subestruturas calculados pelo método manual, sendo $\mathrm{ST}=$ estriado; $\mathrm{PU}=$ putâmen $; \mathrm{CA}=$ caudado (i) = ipsilateral; $(\mathrm{c})$ = contralateral.

Figura 15: Gráficos do BPI no corpo estriado e subestruturas calculados pelo método de corregistro com RM.

Figura 16: Gráficos do BPI no corpo estriado e subestruturas calculados pelo método de corregistro com RM-corrigida. 
Figura 17: Gráficos do BPI no corpo estriado calculados pelo método Two Box

Figura 18: Gráficos dos índices de assimetria do corpo estriado e subestruturas calculados pelo método manual.

Figura 19: Gráficos da razão entre putâmen e caudado calculados pelo método manual.......98

Figura 20: Curvas ROC do BPI para o corpo estriado (ST) ipsilateral (i) e contralateral (c) obtidos pelos métodos manual e por corregistro com RM

Figura 21: Curvas ROC do BPI para o corpo estriado (ST) ipsilateral (i) e contralateral (c) obtidos pelos métodos por corregistro com RM-corrigida e Two Box.

Figura 22: Curvas ROC dos índices de assimetria (IA) obtidos pelo método manual.......... 103

Figura 23: Curvas ROC da razão putâmen pelo caudado $(\mathrm{P} / \mathrm{C})$ obtida pelo método pelo método manual.

Figura 24: Correlação entre BPI de ST(i) e ST(c) obtidos pelo método manual com o UPDRS-3 e HYS.

Figura 25: Gráficos de dispersão do BPI do corpo estriado correlacionado ao UPDRS-3 em grupo com doença de Parkinson em fase inicial (HYS I e II). 


\section{LISTA DE TABELAS}

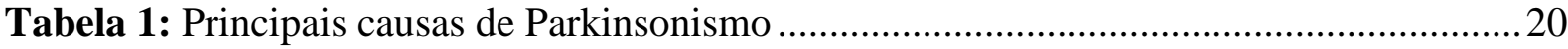

Tabela 2: Sinais motores cardinais da doença de Parkinson ...............................................2 27

Tabela 3: Principais sintomas não motores em portadores de doença de Parkinson............... 29

Tabela 4: Drogas usadas no tratamento de sintomas motores da DP ....................................32

Tabela 5: Radiofármacos aplicados no estudo da via nigroestriatal pré-sináptica...................39

Tabela 6: Radiofármacos aplicados no estudo da via nigroestriatal pós-sináptica. ................ 40

Tabela 7: Desordens parkinsonianas associadas ou não a déficit dopaminérgico estriatal .....41

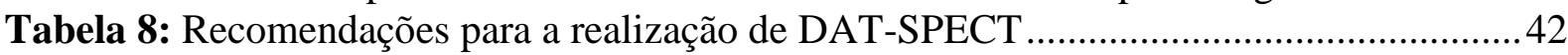

Tabela 9: Características demográficas dos participantes do estudo.......................................76

Tabela 10: Características dos pacientes com doença de Parkinson. ..................................... 77

Tabela 11: Índices semiquantitativos encontrados para o grupo controle saudável

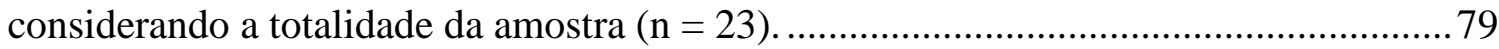

Tabela 12: Semiquantificação manual dos controles saudáveis por faixa etária......................80

Tabela 13: Correlação de idade com os potenciais de ligação do estriados, caudados e

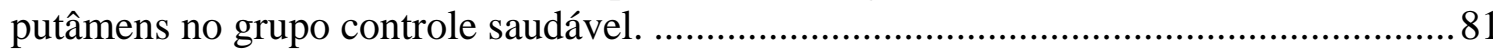

Tabela 14: Semiquantificação manual dos controles saudáveis por gênero e classe socioeconômica.

Tabela 15: Avaliação qualitativa dos SPECTs com [ $\left.{ }^{99 \mathrm{~m}} \mathrm{Tc}\right]-T R O D A T-1$ para distinção entre grupos com doença de Parkinson e controles saudáveis.

Tabela 16: Análise da concordância interobservador e intraobservador na avaliação qualitativa dos SPECTs com [ $\left.{ }^{99 \mathrm{~m}} \mathrm{Tc}\right]$-TRODAT-1.

Tabela 17: Análise da correlação da avaliação qualitativa dos SPECTs com [ $\left.{ }^{99 \mathrm{~m}} \mathrm{Tc}\right]-$ TRODAT-1 com dados clínicos.

Tabela 18: Semiquantificação de BPI em pacientes saudáveis e com DP através do método manual ( $n=67$ pacientes).

Tabela 19: Semiquantificação de BPI em pacientes saudáveis e com DP através de RM (n = 67 pacientes).

Tabela 20: Semiquantificação de BPI em pacientes saudáveis e com DP através de RMcorrigida $(n=67$ pacientes $)$.

Tabela 21: Semiquantificação de BPI em pacientes saudáveis e com DP através de Two Box ( $\mathrm{n}=67$ pacientes).

Tabela 22: Semiquantificação de IA e PU/CA em pacientes saudáveis e com DP com o método manual ( $\mathrm{n}=67$ pacientes).

Tabela 23: Resultados da curva ROC para o BPI de ST, CA e PU obtidos pelos métodos de semiquantificação.

Tabela 24: Resultados da curva ROC para os índices de assimetria e para a razão entre putâmen e caudado obtidos a partir do método de semiquantificação manual. 
Tabela 25: Avaliação intraobservador dos métodos semiquantitativos.

Tabela 26: Avaliação interobservador dos métodos semiquantitativos.

Tabela 27: Avaliação da confiabilidade do método semiquantitativo manual referentes aos índices de assimetria e razão putâmen/caudado.

Tabela 28: Correlação do BPI com variáveis clínicas para cada método.

Tabela 29: Correlação entre UPDRS-3 e o BPI em subgrupos (HYS I/II) e (HYS III/IV). .111

Tabela 30: Comparação entre médias de variáveis clínicas entre os grupos com e sem discinesia.

Tabela 31: Comparação entre médias dos potenciais de ligação dos grupos com e sem discinesia. 


\section{LISTA DE SIGLAS}

AACD Enzima Aminoácido Descarboxilase

AAL Automated Anatomical Labeling

AIM Movimento Anormal Involuntário

AMS Atrofia de Multiplos Sistemas

AUC Área sob a curva, do inglês Area Under the Curve

BPI Binding Potential Index

CA Núcleo Caudado

CEP Comitê de Ética em Pesquisa

CFT Carbometoxifluorfeniltropano

CNPq Conselho Nacional de Desenvolvimento Científico e Tecnológico

CNS Conselho Nacional da Saúde

COD Coefficient of Determination

COMT Catecol-O-amino transferase

CREB Proteína de ligação ao elemento de resposta ao AMP cíclico

CT Tomografia Computadorizada, do inglês Computed Tomography

DAT Transportador Dopaminérgico

DCB Demência Corticobasal

DICOM Digital Imaging and Comunication in Medicine

DP Doença de Parkinson

DTBZ Dihidrotetrabenazina 


\begin{tabular}{ll} 
EANM & Associação Europeia de Medicina Nuclear e Imagem Molecular \\
EBW & Extended Brilliance Workspace Philips \\
ECD & Dicloridrato de etilenocisteínadietilester \\
ERK & Cinase regulada por sinal extracelular \\
FD & Fluorodopa \\
FDG & Fluordesoxiglicose \\
GTM & Geometric Tranfer Matrix \\
HCRP & Hospital das Clínicas de Ribeirão Preto \\
HYS & Hoehn and Yahr Scale \\
IA & Índice de Assimetria \\
IBZM & Iodobenzamida \\
IC & Intervalo de Confiança \\
ICBM & International Consortium of Brain Mapping \\
ICC & Intraclass Correlation Coefficient \\
LEHR & Low Energy High Resolution \\
LID & Discinesia Induzida por Levodopa \\
MAO & Monoaminoxidase \\
MDS & Movement Disorder Society \\
MNI & Montreal Neurological Institute \\
MPTP & Netil-feniltetrahidroperidina \\
NEMA & National Electrical Manufacturer's Association \\
\hline
\end{tabular}


OMS Organização Mundial da Saúde

OSEM Ordered Subset Expectation Maximization

PU/CA Relação do Putâmen pelo Caudado

PET Positron Emission Tomography

PSP Paralisia Supranuclear Progressiva

PU Putâmen

PVE Efeito de Volume Parcial, do inglês Partial Volume Effect

RM Ressonância Magnética

ROI Área de interesse, do inglês Region of Interest

SBR Specific Binding Ratio

SD Standard Desviation

SNC Sistema Nervoso Central

SPECT Single Photon Emission Computed Tomography

ST Corpo Estriado

TCLE Termo de Consentimento Livre Esclarecido

UPDRS Unified Parkinson's Disease Rating Scale

VMAT Transportador Monoamina Vesicular

VOI Volume of Interest

VPN Valor Preditivo Negativo

VPP Valor Preditivo Positivo 


\section{SUMÁRIO}

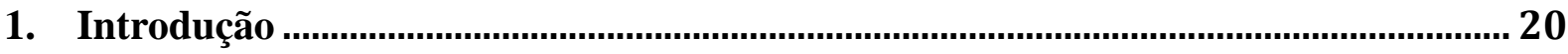

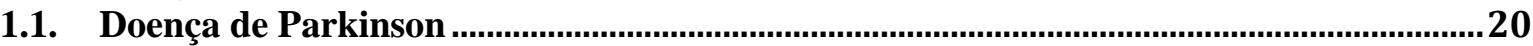

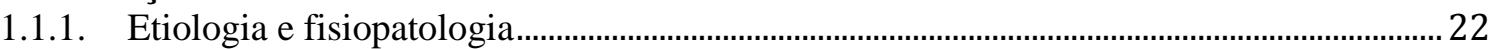

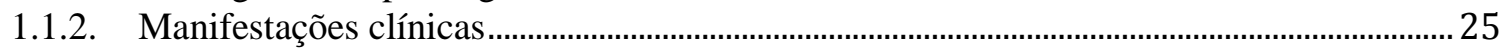

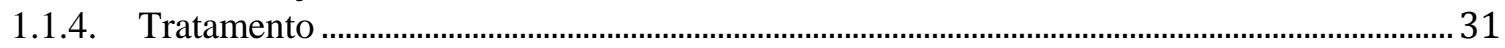

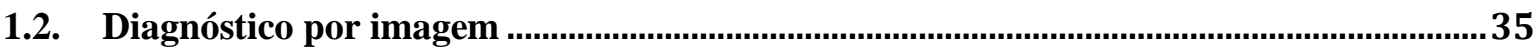

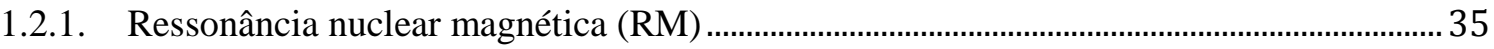

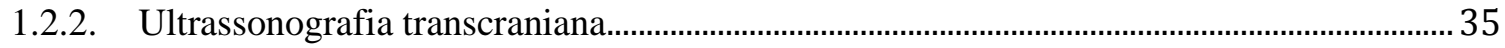

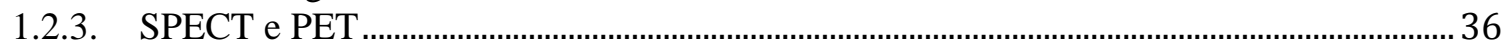

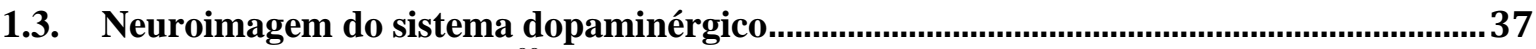

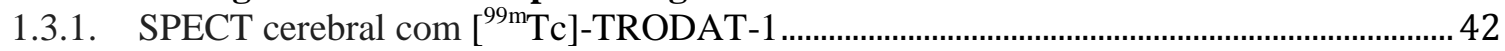

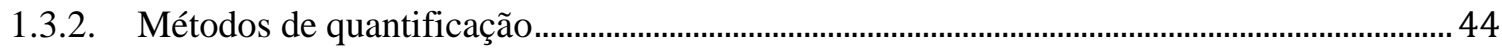

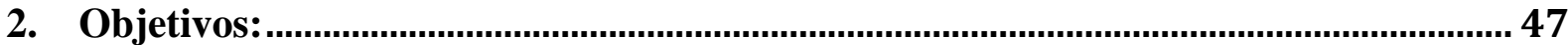

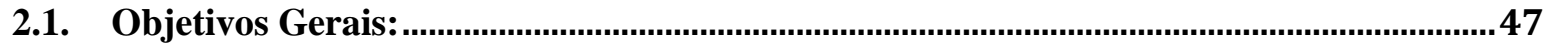



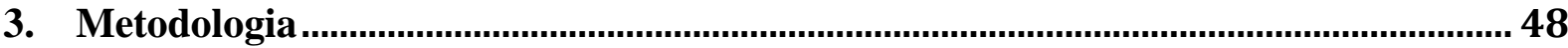

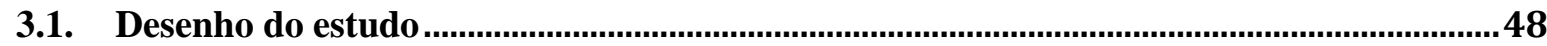

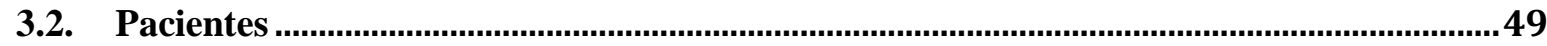

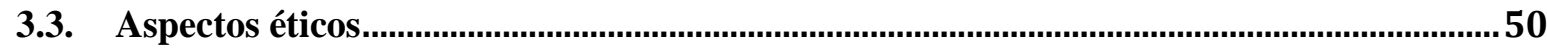

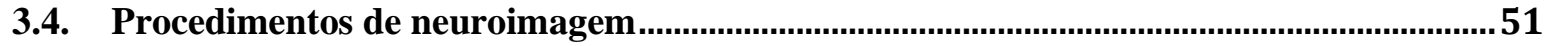

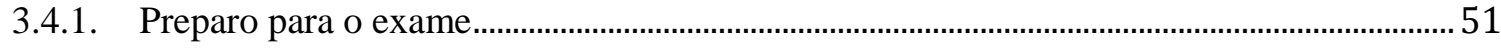

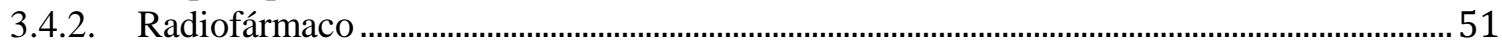

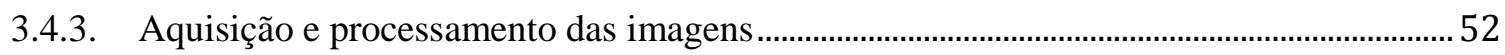

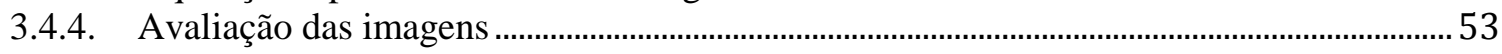

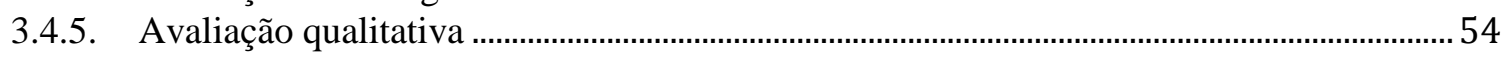

3.4.6. Avaliação semiquantitativa manual.................................................................................... 57

3.4.7. Avaliação semiquantitativa baseada em template padrão (Two Box)....................................... 62

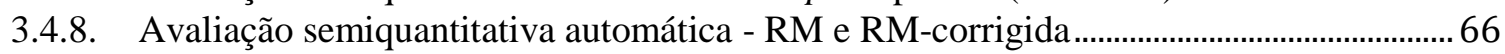

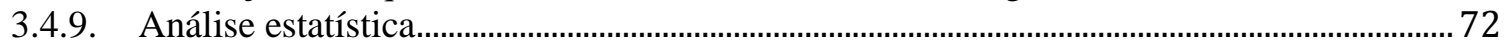

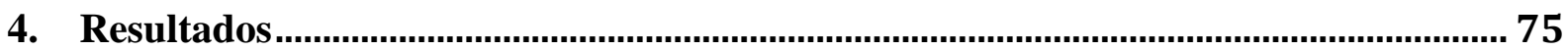

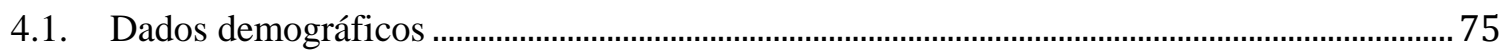

4.2. Densidade de DAT no grupo controle saudável ........................................................................ 78

4.3. Análise qualitativa do SPECT com [ ${ }^{99 \mathrm{~m}}$ Tc]-TRODAT-1 .................................................... 84

4.4. Análise e comparação dos métodos semiquantitativos............................................................ 86

4.5. Comparação da densidade de DAT nos grupos com e sem discinesia ...................................112

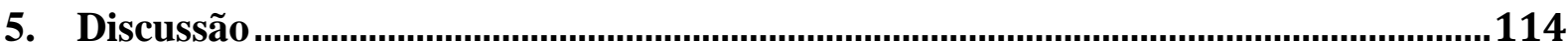

5.1. Densidade de DAT no grupo controle saudável ...................................................................114

5.2. Análise qualitativa do SPECT com [ $\left.{ }^{99 \mathrm{~m}} \mathrm{Tc}\right]-T R O D A T-1$.....................................................117 
5.3. Análise e comparação dos métodos quantitativos

5.4. Comparação da densidade de DAT nos grupos com e sem discinesia

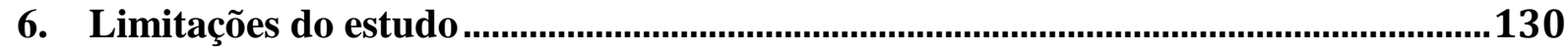

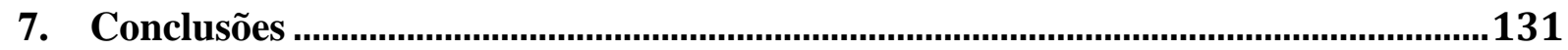

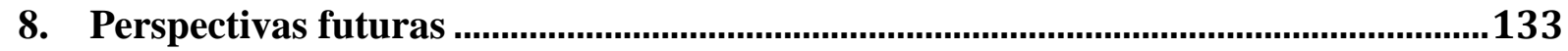

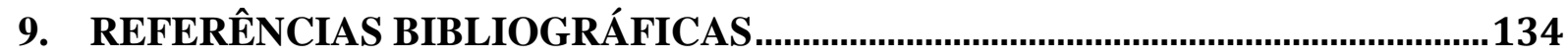

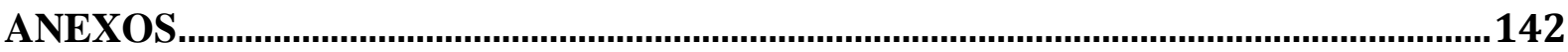

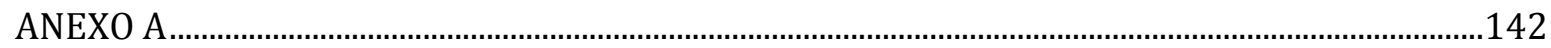

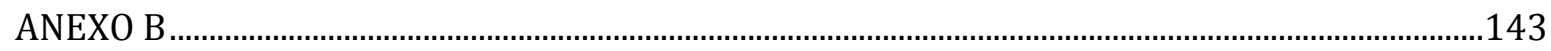

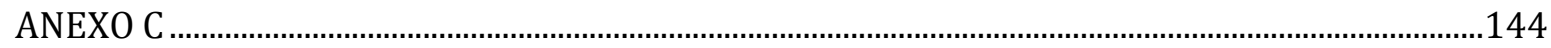

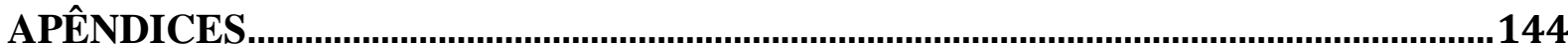

APÊNDICE 1: Termo de Consentimento Livre Esclarecido - grupo saudável................................148

APÊNDICE 2: Termo de Consentimento Livre Esclarecido - grupo DP leve......................................150

APÊNDICE 3: Termo de Consentimento Livre Esclarecido - grupo DP avançado.........................152

APÊNDICE 4: Procedimento Operacional........................................................................................154

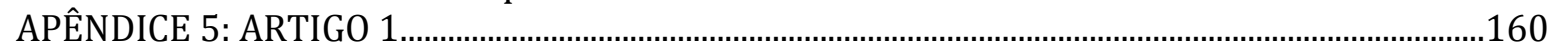

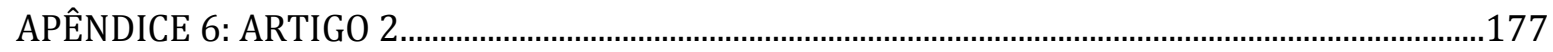

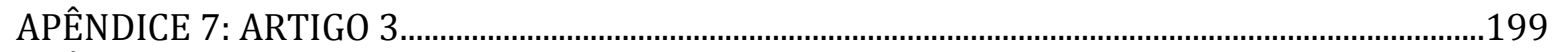

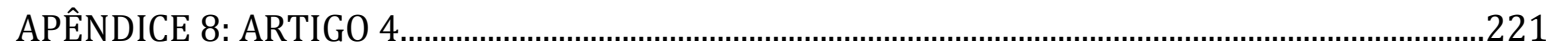




\section{Introdução}

\subsection{Doença de Parkinson}

Parkinsonismo é uma síndrome clínica caracterizada por déficits motores específicos, referidos como os sintomas cardinais na doença de Parkinson: acinesia/bradicinesia, rigidez, tremor e instabilidade postural (BARBOSA; SALLEM, 2005). Uma ampla variedade de entidades pode causar sinais e sintomas de parkinsonismo (tabela 1). Estas doenças têm em comum a desordem da via dopaminérgica nigroestriatal, que desempenha um papel central no controle de movimentos voluntários (WILKINSON; WEINTRAUB; STERN, 2012a). As causas de parkinsonismo podem ser agrupadas em: primária (ou idiopática), secundária, parkinsonismo-plus ou síndromes atípicas, e doenças neurodegenerativas hereditárias (WILKINSON; WEINTRAUB; STERN, 2012a).

Tabela 1: Principais causas de Parkinsonismo (BARBOSA; SALLEM, 2005; WILKINSON; WEINTRAUB; STERN, 2012a).

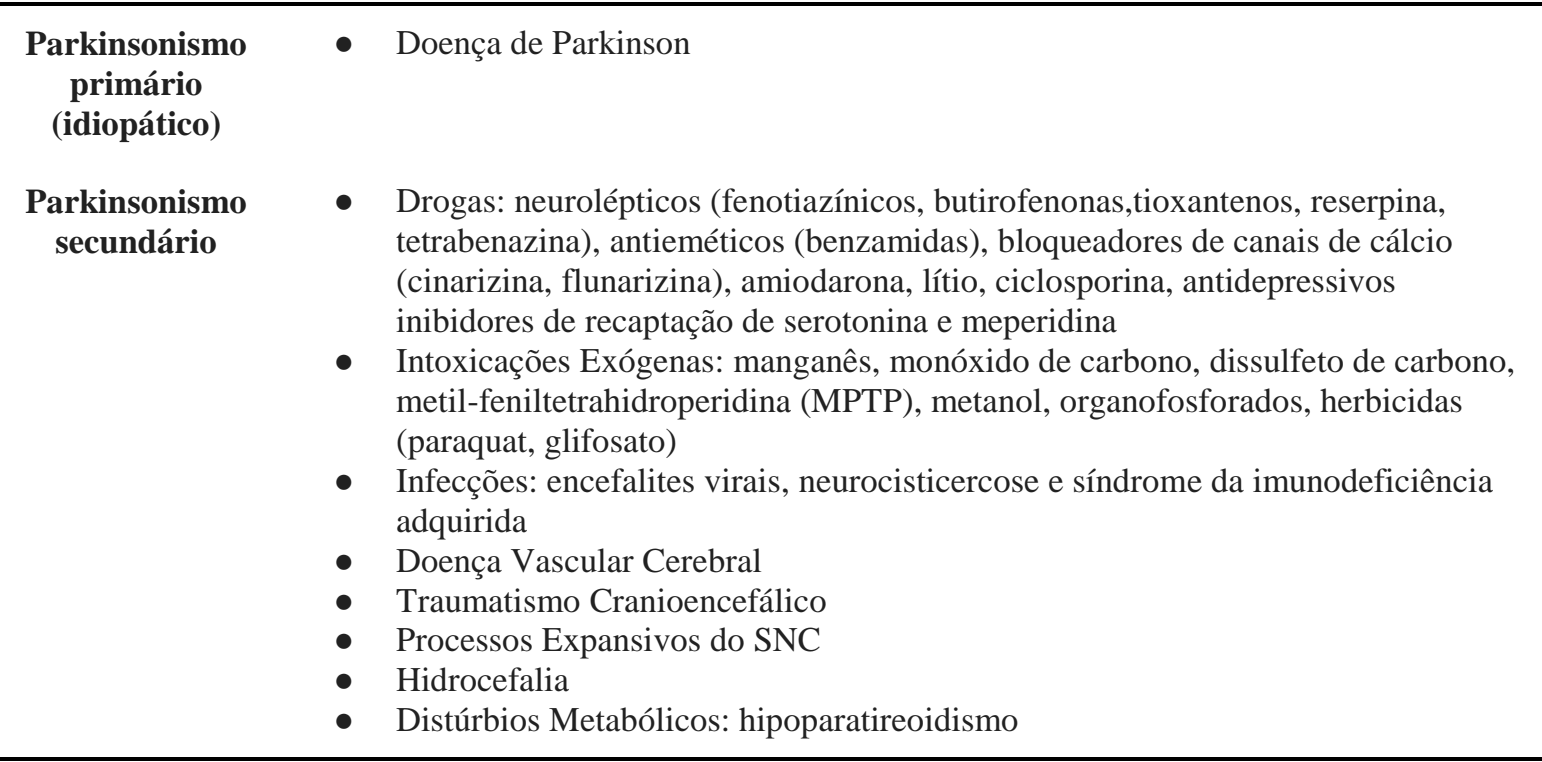


Continuação - Tabela 1: Principais causas de parkinsonismo (BARBOSA; SALLEM, 2005; WILKINSON; WEINTRAUB; STERN, 2012a).

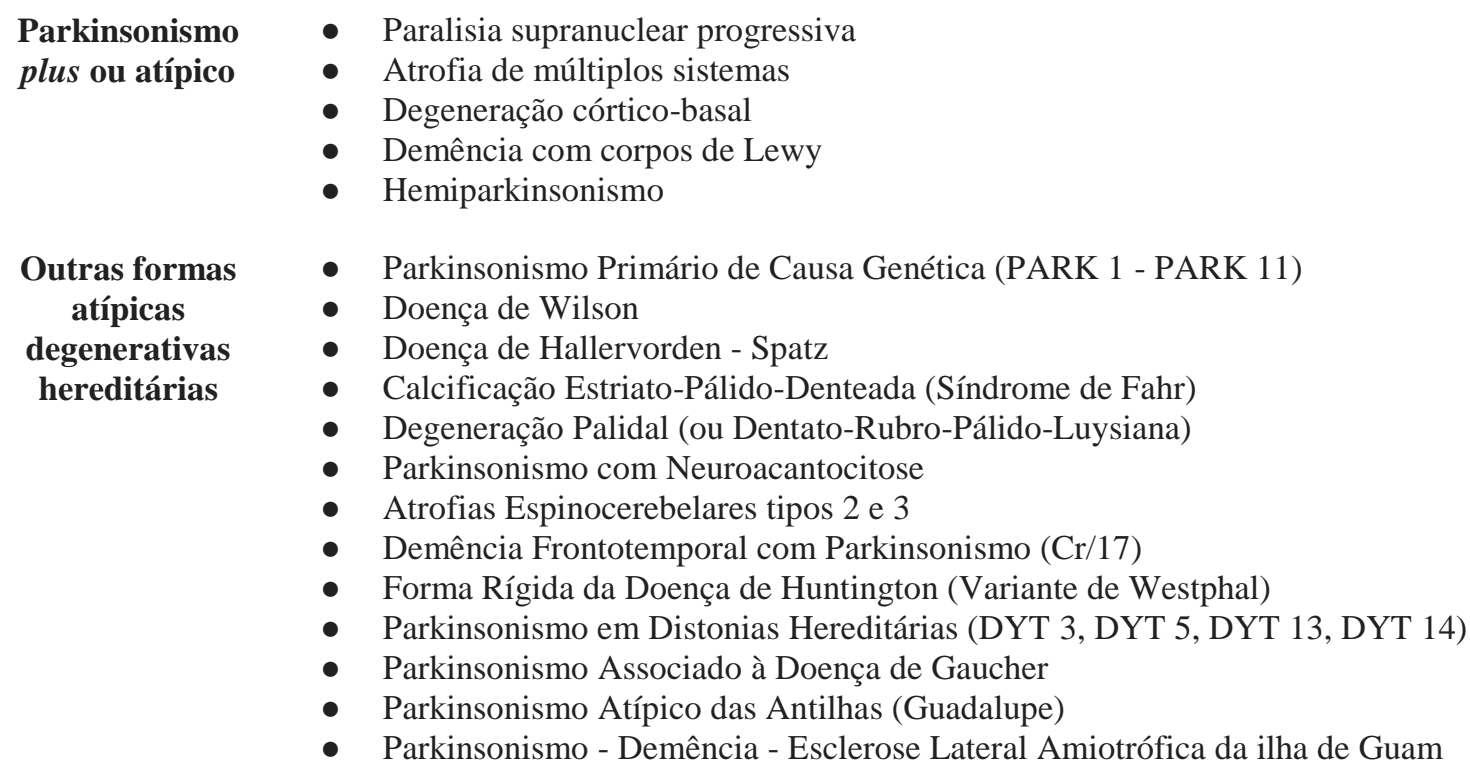

A doença de Parkinson (DP) é uma doença neurodegenerativa progressiva que afeta cerca de $1 \%$ das pessoas com mais de 60 anos e até $4 \%$ das pessoas com mais de 80 anos (GAZEWOOD; RICHARDS; CLEBAK, 2013; MUNHOZ et al., 2015).

O mérito da descrição inicial da doença de Parkinson coube a James Parkinson, médico inglês, membro do colégio real de cirurgiões, nascido em 1755 e falecido em 1824. James Parkinson publicou muitos artigos científicos dentro da área médica e nas áreas de geologia, paleontologia e sociologia. Em 1871, Parkinson publicou em Londres um ensaio intitulado "An Essay on the Shaking Palsy". Na tradução, o "ensaio sobre a paralisia agitante" se tornou a primeira descrição mundial bem definida da DP (DREW, 2016; TEIVE, 1998; WEBSITE, 2017).

O diagnóstico da DP ainda se baseia principalmente nos achados clínicos. Os sintomas cardinais, citados anteriormente, incluem bradicinesia, rigidez, tremor e instabilidade postural. 
Clinicamente há uma progressão dos sintomas e uma resposta sustentada ao tratamento com levodopa. Sintomas não motores, tais como constipação, arritmias cardíacas, distúrbios do sono e déficits cognitivos também são observados na doença (GAZEWOOD; RICHARDS; CLEBAK, 2013; MUNHOZ et al., 2015).

A incidência e a prevalência aumentam na medida em que a expectativa de vida da população se eleva, sendo raros os casos em indivíduos com menos de 50 anos de idade. $\mathrm{Na}$ maioria dos estudos, a doença de Parkinson se mostra mais frequente em homens em relação a mulheres (MARRAS; TANNER, 2012; PICILLO et al., 2017). Em uma metanálise incluindo 17 estudos relevantes com mais de 2.500 casos, a razão de incidência global entre homens e mulheres foi de 1,46 (IC 95\% 1,24-1,72). Com o aumento da faixa etária, esta relação é menos robusta, havendo uma maior variabilidade entre os estudos (MARRAS; TANNER, 2012).

Em relação à mortalidade, as taxas aumentam com a idade, elevando-se de forma acentuada após os 60 anos de idade para uma proporção de 100/100.000. Tal como a incidência e a prevalência, a taxa de mortalidade é discretamente maior em homens em relação a mulheres (MARRAS; TANNER, 2012).

\subsubsection{Etiologia e fisiopatologia}

A principal característica fisiopatológica da DP é a perda de neurônios dopaminérgicos na substância nigra pars compacta, o que leva ao esgotamento da dopamina no corpo estriado e ao acúmulo da proteína a-sinucleína no cérebro na forma de corpos de Lewy. Vários outros mecanismos patogênicos implicados na morte de células dopaminérgicas na DP são descritos, dentre eles: estresse oxidativo, excitotoxicidade, disfunção mitocondrial, neuroinflamação, agregação de proteínas, fosforilação, defeitos genéticos e toxinas (HARIKRISHNA REDDY; MISRA; MEDHI, 2014). 
Durante muitos anos, acreditou-se que a perda neuronal progressiva provocava, exclusivamente, diminuição da função dopaminérgica no eixo nigroestriatal. Entretanto, apesar deste importante déficit dopaminérgico, estudos mostram acometimento de outros sistemas neurotransmissores (sistema noradrenérgico, colinérgico, serotoninérgico, glutaminérgico, GABAérgico) na fisiopatologia dos sintomas da DP (EHGOETZ MARTENS; LEWIS, 2016; WERNECK, 2010).

Existem muitas evidências sobre a influência genética no desenvolvimento da DP. Pacientes que possuem parentes em primeiro grau com DP têm duas vezes mais chances de desenvolver a doença (MIZUNO; HATTORI; MOCHIZUKI, 2012; WERNECK, 2010). A primeira menção sobre a participação da genética na DP foi feita em 1893 por Gowers ao observar que $15 \%$ de seus pacientes tinham familiares com tremores físicos ou parkinsonismo. Em 1949, Mjönes descreveu, pela primeira vez, casos ocorridos em uma mesma família, propondo que a doença teria um traço autossômico dominante com $60 \%$ de penetração (WERNECK, 2010). Como se acredita que a DP é causada pela interação de predisposição genética e fatores ambientais, vários estudos têm tentado encontrar fatores de risco genéticos para a DP (MIZUNO; HATTORI; MOCHIZUKI, 2012). Apesar de alguns resultados conflitantes, diversos genes foram implicados na causa da doença (MIZUNO, HATTORI, MOCHIZUKI, 2012).

Além dos fatores genéticos, fatores externos também têm sido estudados. A hipótese de que o tabagismo e o uso de cafeína são inversamente associados com o risco de desenvolver DP é largamente aceita, embora alguns resultados conflitantes tenham sido relatados (MIZUNO; HATTORI; MOCHIZUKI, 2012). A associação com neurotoxinas, tais como pesticidas e herbicidas, é variável nos vários estudos, muitas vezes dependentes de gênero e país. Muitos especialistas em DP acreditam que a morte neuronal nigral é iniciada pela interação ambiental de neurotoxinas com a predisposição genética. Tal interação provavelmente induz à disfunção mitocondrial e ao estresse oxidativo, que por sua vez podem induzir disfunções no proteossoma 26S e no sistema de autofagia, associado aos lisossomos, 
provocando o acúmulo de proteínas tóxicas e agregados de proteínas, particularmente de $\alpha$ sinucleína (MIZUNO; HATTORI; MOCHIZUKI, 2012).

Em 2003, Braak e colaboradores sugeriram que o processo degenerativo na DP começa nas regiões caudais do tronco encefálico e do bulbo olfatório, progredindo na direção caudal-rostral. O envolvimento do SNC ocorre, segundo esta hipótese, no terceiro de um processo de seis estágios que começa nos núcleos motores dorsais dos nervos glossofaríngeo e vago e no bulbo olfatório (BRAAK et al., 2004; MUNHOZ et al., 2015). De forma mais detalhada, no estágio 1 ocorre o comprometimento do núcleo motor dorsal dos nervos glossofaríngeo e vago, além da zona reticular intermediária e do núcleo olfatório anterior, constituindo assim um processo neurodegenerativo quase que totalmente localizado nas fibras dopaminérgicas que inervam o putâmen dorso-lateral. No estágio 2, existe o comprometimento adicional dos núcleos da rafe, núcleo reticular gigantocelular e do complexo do lócus cerúleos. No estágio 3, observa-se o acometimento da parte compacta da substância negra do mesencéfalo. Já nos estágios 4 e 5 há comprometimentos das regiões prosencefálicas, do mesocórtex temporal e de áreas de associação do neocórtex e neocórtex pré-frontal, respectivamente. No estágio 6, ocorre o comprometimento de áreas de associação do neocórtex, áreas pré-motoras e área motora primária (SOUZA et al., 2011).

A visão de DP como uma doença multissistêmica, não restrita ao trato nigrostriatal, não é nova, porém o estudo citado de Braak e colaboradores não apenas mostrou que o processo degenerativo começa em estruturas não dopaminérgicas do cérebro, tronco ou mesmo no sistema autônomo periférico, mas também influenciou a forma como interpretamos os sinais aparentemente inespecíficos que podem ser detectados no curso da doença. Outro aspecto inovador desta hipótese é que a doença se apresenta de forma sequencial e previsível. Assim, quando o processo afeta o SNC, componentes de outras estruturas do tronco encefálico já estão afetadas. Este conceito, no entanto, não escapa à crítica de estudos patológicos em que $6 \%$ a $43 \%$ dos casos descritos não se enquadram perfeitamente neste modelo, especialmente no aspecto sequencial (MUNHOZ et al., 2015). Além disso o estudo 
de Braak e colaboradores falha por vezes em estabelecer a correlação clínica entre essas alterações e manifestações motoras ou não-motoras (BRAAK et al., 2004; MUNHOZ et al., 2015).

Com o objetivo de correlacionar as manifestações clínicas com as alterações patológicas, outras teorias são descritas. Em contraste com a teoria ascendente em que a degeneração neuronal ocorre a partir do sistema neuronal periférico para o sistema nervoso central, outros autores descrevem evidências de que isso ocorre de forma paralela. Sugere-se que sintomas precoces não motores apareceriam antes dos sintomas clássicos motores devido a um limiar mais baixo para que estes primeiros ocorram. Este fato seria decorrente de uma reserva funcional do sistema dopaminérgico associado ao controle de movimentos (ENGELENDER; ISACSON, 2017). Independentemente da falta de consonância dos estudos patológicos em DP, a literatura é unânime em caracterizar sua distribuição como progressiva e difusa, não restrita ao sistema motor (MUNHOZ et al., 2015).

Fica evidente deste modo, que apesar dos avanços, novos estudos ainda são necessários para melhor estabelecer a fisiopatologia da doença.

\subsubsection{Manifestações clínicas}

A perda de neurônios nigrais na DP ocorre lentamente ao longo das décadas que precedem o início dos sintomas. Até $80 \%$ dos neurônios dopaminérgicos são perdidos antes do aparecimento dos sinais e sintomas cardinais da doença de Parkinson (WILKINSON; WEINTRAUB; STERN, 2012a). Portanto não é surpreendente que a DP comece insidiosamente e seja anunciada por um pródromo de sintomas inespecíficos, tais como fraqueza subjetiva, incoordenação ou dificuldade de escrever. Muitos vão se queixar de dor ou tensão em um ombro ou braço, fazendo com que o paciente procure um ortopedista antes de um neurologista. O início típico dos sintomas na DP e que deve aumentar a suspeita clínica 
ocorre no contexto de uma doença de início insidioso, assimétrico e lentamente progressiva. Fatigabilidade fácil, mal-estar, depressão, distúrbios do sono, perda de olfato e constipação são exemplos de sintomas não motores que podem aparecer anos antes dos primeiros sinais motores (WILKINSON; WEINTRAUB; STERN, 2012a). Identificar esses sintomas não motores e não específicos é fundamental para um diagnóstico mais precoce.

Os sinais e sintomas da DP precoce podem ser inespecíficos e levam a um amplo diagnóstico diferencial, incluindo outras doenças neurodegenerativas (ex: síndromes parkinsonianas atípicas, doença de Wilson etc), miastenia gravis, doença cerebrovascular e distúrbios do movimento. Em muitos casos, o diagnóstico só ficará evidente à medida que os sinais motores se desenvolvem (WILKINSON; WEINTRAUB; STERN, 2012b).

\subsubsection{Sinais e sintomas motores}

O parkinsonismo ou síndrome parkinsoniana é um dos mais frequentes tipos de distúrbio do movimento e apresenta-se com 4 componentes básicos: acinesia/bradicinesia, rigidez, tremor e instabilidade postural (tabela 2). Pelo menos dois desses componentes são necessários para a caracterização da síndrome (BARBOSA; SALLEM, 2005). 
Tabela 2: Sinais motores cardinais da doença de Parkinson (BARBOSA; SALLEM, 2005; FERNANDEZ, 2015; WILKINSON; WEINTRAUB; STERN, 2012b).

\begin{tabular}{l|l|}
\hline \multicolumn{1}{c}{ Sinal motor } & \multicolumn{1}{c}{ Descrição } \\
\hline Acinesia / bradicinesia & $\begin{array}{l}\text { Pobreza de movimentos e lentidão na iniciação e } \\
\text { execução de atos motores voluntários }\end{array}$ \\
Rigidez & $\begin{array}{l}\text { Estado de hipertonicidade involuntária com } \\
\text { resistência invariável ao movimento passivo. }\end{array}$ \\
Tremor & $\begin{array}{l}\text { Movimento de oposição rítmica e alternada, mais } \\
\text { frequentemente do indicador e polegar, oscilando } \\
\text { com uma freqüência característica de 4-6 Hz ("tremor } \\
\text { de repouso"). }\end{array}$ \\
Instabilidade postural & $\begin{array}{l}\text { Estado de perda dos reflexos de readaptação } \\
\text { posturais. }\end{array}$ \\
\hline
\end{tabular}

A acinesia é a ausência ou falha do movimento, enquanto bradicinesia se aplica mais especificamente à lentidão na execução dos movimentos. Estes termos são utilizados para definir a dificuldade e lentidão que os pacientes com DP têm em iniciar e executar um movimento. Estas condições se manifestam de diferentes formas (BARBOSA; SALLEM, 2005; WILKINSON; WEINTRAUB; STERN, 2012b): atraso no início do movimento motor,rápida fadiga com movimentos voluntários, redução da expressão facial (hipomimia), diminuição da expressão gestual corporal, dificuldade em executar ações sequenciais ou simultâneas, sialorréia, festinação, acinesia súbita ou congelamento (freezing), cinesia paradoxal, micrografia, marcha em bloco, disartria hipocinética, hipofonia e disdiadococinesia.

A rigidez é o estado de hipertonicidade involuntária com resistência invariável ao movimento passivo. Pode ocorrer em todos os grupos musculares (WILKINSON; WEINTRAUB; STERN, 2012b). As características de hipertonia plástica incluem a resistência à movimentação do membro afetado de forma contínua ou intermitente (fenômeno da "roda denteada"), acometimento preferencial da musculatura flexora, e exacerbação dos 
reflexos tônicos segmentares (reação paradoxal de Wesphal ou reflexo local de postura de Foix-Thévenard) (BARBOSA; SALLEM, 2005; WILKINSON; WEINTRAUB; STERN, 2012b).

O tremor da DP é descrito como "tremor de repouso" porque está presente em repouso (4-6 ciclos/s) e geralmente reduz em intensidade com a movimentação voluntária do segmento afetado. $\mathrm{O}$ tremor pode ser intensificado com a ativação contralateral dos membros, com ativação mental e durante o processo de caminhar. Ela desaparece no sono e piora com stress ou ansiedade. Em cerca de $75 \%$ dos pacientes é a primeira manifestação motora, normalmente com início unilateral na região distal de um membro (BARBOSA; SALLEM, 2005; WILKINSON; WEINTRAUB; STERN, 2012b).

A instabilidade postural é tipicamente o último dos quatro sinais cardinais a aparecer e refere-se principalmente à perda dos reflexos de readaptação posturais, levando a quedas e problemas com a marcha. Esse distúrbio, que não é comum em fases iniciais de evolução da DP, pode agravar-se de tal modo a determinar quedas frequentes, o que faz com que este sinal cardinal seja um dos mais incapacitantes (BARBOSA; SALLEM, 2005; WILKINSON; WEINTRAUB; STERN, 2012b).

\subsubsection{Sinais e sintomas não motores}

O padrão e a progressão dos sintomas não motores parecem coincidir com a localização dos agregados de proteínas no sistema nervoso. A proteína $\alpha$-sinucleína forma aglomerados chamados corpos de Lewy, que foram encontrados em neurônios nas partes do cérebro que controlam o movimento, mas também em todo o córtex e no sistema nervoso periférico. Há indícios de que os corpos de Lewy estão associados a sintomas não-motores e danos a partes do sistema nervoso que dependem de neurotransmissores diferentes da dopamina (BOURZAC, 2016). Desse modo, outros sistemas neurotransmissores (sistema noradrenérgico, colinérgico, serotoninérgico, glutaminérgico, GABAérgico) envolvidos na 
fisiopatologia dos sintomas da DP são descritos (EHGOETZ MARTENS; LEWIS, 2016; WERNECK, 2010).

A maioria dos pacientes com DP apresentam sintomas não motores (tabela 3). O impacto funcional e de qualidade de vida dos sintomas não motores é muito significativo, igualando ou mesmo superando aquele imposto pelos sintomas motores da DP (MUNHOZ et al., 2015)

Tabela 3: Principais sintomas não motores em portadores de doença de Parkinson (BOURZAC, 2016; MELO; BARBOSA; CARAMELLI, 2007; MUNHOZ et al., 2015; NICARETTA; PEREIRA; PIMENTEL, 1998; WILKINSON; WEINTRAUB; STERN, 2012b).

\begin{tabular}{llc}
\hline \multicolumn{1}{c}{ Sintoma } & \multicolumn{1}{c}{ Descrição } & \multicolumn{1}{c}{ Prevalência } \\
\hline Distúrbios do sono & Sonambulismo e dificuldade em distinguir o sonho da realidade & $42-58 \%$ \\
Perda ponderal & Perda leve a moderada de peso & $21-30 \%$ \\
Anosmia/hiposmia & Perda parcial ou total do olfato & $50-75 \%$ \\
Psicose / alucinações & ilusões visuais, auditivas e outras alucinações & $10-40 \%$ \\
Depressão & Similar a outras formas de depressão & $20-68 \%$ \\
Ansiedade & $\begin{array}{l}\text { Ansiedade generalizada, ataques de pânico e transtorno obsessivo } \\
\text { compulsivo, constantemente associada a alterações motoras }\end{array}$ & $40 \%$ \\
Distúrbios autonômicos & $\begin{array}{l}\text { Livedo reticularis, oleosidade, intolerância ao calor, sudorese } \\
\text { excessiva, distúrbios vasomotores, hipotensão } \\
\text { ortostática, hipotensão pós-prandial, dispnéia, } \\
\text { disfagia, sialorréia, constipação intestinal, } \\
\text { disfunção vesical e impotência sexual. }\end{array}$ & $50-79 \%$ \\
Demência & $\begin{array}{l}\text { Dificuldade com funções de memória, linguagem e problemas } \\
\text { emocionais }\end{array}$ \\
\hline
\end{tabular}

Uma pesquisa incluindo 1.072 pacientes com DP usando um questionário estruturado e realizada na Itália mostrou que $98,6 \%$ dos pacientes apresentavam ao menos um dos sintomas não motores estudados, notadamente psiquiátricos, sensoriais e relacionados ao 
sono. Estes sintomas podem ocorrer em qualquer momento no decorrer da doença, no entanto, alguns são geralmente relatados nos estágios iniciais, tais como distúrbios do sono, distúrbios olfatórios e constipação. Outras tendem a ocorrer nos estágios tardios, tais como psicose e déficits cognitivos. Um terceiro grupo destes sintomas não tem uma relação clara com estágios da doença, incluindo depressão e formas de disautonomia (MUNHOZ et al., 2015).

\subsubsection{Acurácia do diagnóstico clínico}

Embora uma melhor compreensão da DP tenha sido adquirida nos últimos anos com o reconhecimento de várias características pré-motoras e biomarcadores potenciais, seu diagnóstico ainda é principalmente baseado em achados clínicos motores (FERNANDEZ, 2015).

Dois estudos clinicopatológicos publicados no início dos anos 90 mostraram uma acurácia do diagnóstico clínico da doença de Parkinson idiopática de 76 \% (HUGHES et al., 1992; RAJPUT; ROZDILSKY; RAJPUT, 1991). Outro estudo posterior, com metodologia comparável, mostrou um aumento da acurácia no diagnóstico para 90 \% (HUGHES et al., 2001; HUGHES; DANIEL; LEES, 2001), fato que coincide com aumento do conhecimento dos neurologistas sobre a doença e sobre os pontos fundamentais no diagnóstico diferencial com outras síndromes parkinsonianas, ao mesmo tempo que surge critérios operacionais consensuais para o diagnóstico de doença de Parkinson, paralisia supranuclear progressiva, degeneração corticobasal e atrofia de múltiplos sistemas (HUGHES et al., 2002).

Outro estudo sugere que a acurácia do diagnóstico clínico aumenta quando realizado por neurologista especialista em distúrbios do movimento. Uma revisão de 143 casos de parkinsonismo avaliados clinicamente por especialistas em doenças do movimento e submetidos a análise neuropatológica descreve um valor preditivo positivo de 98,6 \%, com uma sensibilidade de 91,1\% (HUGHES et al., 2002).

Por outro lado, uma metanálise com artigos publicados entre 1988 e agosto de 2014 
reportou resultados diferentes (RIZZO et al., 2016). Neste trabalho foram selecionados 20 estudos, incluindo 11 utilizando exame patológico como padrão-ouro. Incluindo apenas esses 11 estudos, a acurácia diagnóstica combinada foi de 80,6\% (IC 95\%, 75,2\% - 85,3\%). A acurácia foi de 73,8\% (IC 95\%, 67,8\% -79,6\%) para o diagnóstico clínico realizado principalmente por não especialistas na área. A acurácia do diagnóstico clínico realizado por especialistas em transtornos de movimento subiu de 79,6\% (IC 95\%, 46\% - 95,1\%) da avaliação inicial para 83,9\% (IC 95\%, 69,7\% - 92,6\%) após o seguimento. Utilizando os critérios diagnósticos do Banco de Cérebros de Londres (anexo A) (HUGHES et al., 1992), a acurácia diagnóstica combinada foi de 82,7\% (IC 95\%, 62,6\% - 93\%) (RIZZO et al., 2016). Considerando este cenário, a aplicação de biomarcadores e de exames por imagem ganha relevância, especialmente em casos duvidosos, como por exemplo em quadros com resposta ao tratamento dopaminérgico menos definida.

\subsubsection{Tratamento}

A terapia farmacológica envolve a administração isolada ou conjunta de algumas classes de medicamentos. Cada droga apresenta vantagens e desvantagens na sua aplicação, sendo as principais descritas na tabela 4. 
Tabela 4: Drogas usadas no tratamento de sintomas motores da DP (GAZEWOOD; RICHARDS; CLEBAK, 2013; POEWE; MAHLKNECHT, 2012; ROSSO et al., 2010).

\begin{tabular}{|c|c|c|c|}
\hline $\begin{array}{c}\text { Droga / classe da } \\
\text { droga }\end{array}$ & Exemplos & Vantagens & Desvantagens \\
\hline Levodopa & $\begin{array}{l}\text { Carbidopa/levodopa } \\
\text { (Sinemet); } \\
\text { benserazida/levodopa } \\
\text { (Prolopa, Madopar) }\end{array}$ & $\begin{array}{l}\text { Droga mais efetiva, melhora } \\
\text { as incapacidades motoras, } \\
\text { prolonga a capacidade de } \\
\text { realizar atividades diárias. }\end{array}$ & $\begin{array}{l}\text { Complicações motoras: } \\
\text { discinesias, distonia, } \\
\text { confusão mental, psicose, } \\
\text { sedação }\end{array}$ \\
\hline $\begin{array}{l}\text { Agonistas } \\
\text { dopaminérgicos }\end{array}$ & $\begin{array}{l}\text { Não ergolínicos: } \\
\text { pramipexol (Mirapex), } \\
\text { ropinirole (Requip) } \\
\text { Ergolínicos: } \\
\text { bromocriptina } \\
\text { (Parlodel), pergolida } \\
\text { (Permax) }\end{array}$ & $\begin{array}{l}\text { Uso como monoterapia em } \\
\text { doença inicial ou em } \\
\text { associação com a levodopa } \\
\text { para tratamento de } \\
\text { complicações motoras. } \\
\text { Menor risco de desenvolver } \\
\text { complicações motoras. }\end{array}$ & $\begin{array}{l}\text { Efeitos adversos } \\
\text { dopaminérgicos, } \\
\text { neuropsiquiátricos, } \\
\text { sonolência diurna. No } \\
\text { caso dos ergolínicos: risco } \\
\text { de fibrose pulmonar, } \\
\text { fibrose de valva cardíaca e } \\
\text { eritromelalgia. }\end{array}$ \\
\hline $\begin{array}{l}\text { Inibidores da } \\
\text { monoamina-oxi-dase } \\
\text { B (MAO-B) }\end{array}$ & $\begin{array}{l}\text { Selegiline (Eldepryl), } \\
\text { rasagiline (Azilect) }\end{array}$ & $\begin{array}{l}\text { Uso como monoterapia em } \\
\text { doença inicial ou em } \\
\text { complicações motoras em } \\
\text { doença na fase tardia. } \\
\text { Dose única diária. Boa } \\
\text { tolerância. }\end{array}$ & $\begin{array}{l}\text { Metabólitos podem causar } \\
\text { efeitos adversos. Risco de } \\
\text { síndrome serotoninérgica. }\end{array}$ \\
\hline $\begin{array}{l}\text { Inibidores da } \\
\text { catecol-O-amino } \\
\text { transferase (COMT) }\end{array}$ & $\begin{array}{l}\text { Entacapone (Comtan), } \\
\text { tolcapone (Tasmar) }\end{array}$ & $\begin{array}{l}\text { Usada para tratar } \\
\text { complicações motoras; reduz } \\
\text { período OFF; discreta } \\
\text { melhora da realização de } \\
\text { tarefas diárias e na qualidade } \\
\text { de vida. }\end{array}$ & $\begin{array}{l}\text { Efeitos adversos } \\
\text { dopaminérgicos; } \\
\text { descoloração da urina. } \\
\text { Diarréia explosiva e } \\
\text { toxicidade hepática } \\
\text { associadas a tolcapone. }\end{array}$ \\
\hline $\begin{array}{l}\text { Agonistas } \\
\text { dopaminérgicos } \\
\text { injetáveis }\end{array}$ & Apomorfina (Apokyn) & $\begin{array}{l}\text { Reduz período OFF em } \\
\text { doença avançada. }\end{array}$ & $\begin{array}{l}\text { Requer iniciação em } \\
\text { ambiente hospitalar e } \\
\text { injeções subcutâneas. }\end{array}$ \\
\hline $\begin{array}{l}\text { Inibidor da N-metil- } \\
\text { D-aspar- tato }\end{array}$ & Amantadina & $\begin{array}{l}\text { Tratamento de discinesias na } \\
\text { doença em fase tardia }\end{array}$ & $\begin{array}{l}\text { Efeitos adversos } \\
\text { cognitivos, livedo } \\
\text { reticularis, edema, } \\
\text { desenvolvimento de } \\
\text { tolerância. }\end{array}$ \\
\hline Anticolinérgicos & $\begin{array}{l}\text { Benzotropina; } \\
\text { biperideno (Akineton); } \\
\text { tri-hexifinidil (Artane) }\end{array}$ & $\begin{array}{l}\text { Tratamento de tremores em } \\
\text { pacientes com idade }<60 \\
\text { anos sem déficit cognitivo }\end{array}$ & $\begin{array}{l}\text { Uso limitado pelos efeitos } \\
\text { anticolinérgicos }\end{array}$ \\
\hline
\end{tabular}


A levodopa, aprovada em 1970 (DREW, 2016), corresponde ao precursor imediato da dopamina e, ao contrário dela, atravessa a barreira hematoencefálica, sendo então convertida em dopamina pela enzima L-aminoácido aromático descarboxilase (BRAVO; NASSIF, 2006). Usualmente é administrada com carbidopa, que inibe o metabolismo periférico da levodopa, permitindo que esta atinja concentrações terapêuticas para entrar no cérebro com menores efeitos adversos (GAZEWOOD; RICHARDS; CLEBAK, 2013).

A terapia combinada com carbidopa-levodopa continua a ser o tratamento mais eficaz. Se não for eficaz, pode ser necessário considerar outro diagnóstico. Carbidopa-levodopa melhora o tremor, rigidez e a bradicinesia, particularmente nos estágios iniciais da DP. É bem tolerada, tem ação de início rápido, reduz o risco de morte, e tem baixo custo. No entanto, o uso prolongado de levodopa é freqüentemente complicado por flutuações e discinesias significativamente incapacitantes (FERNANDEZ, 2015; THANVI; LO; ROBINSON, 2007b).

Os sintomas não motores podem ter grande impacto na qualidade de vida dos pacientes com DP. Deste modo, reconhecer e tratar estes sintomas é de fundamental importância. Dentre os principais medicamentos pode-se citar: metilfenidato para fatigabilidade; sildenafil para impotência sexual (distúrbio autonômico); clozapina para psicose manifestada por alucinações visuais e auditivas; antidepressivos para depressão; rivastigmina para demência; etc (GAZEWOOD; RICHARDS; CLEBAK, 2013).

Os tratamentos farmacológicos atualmente disponíveis para DP podem controlar os sintomas motores da doença desde os estágios iniciais, mas não retardam ou param a progressão da doença. Vários estudos clínicos têm investigado numerosos compostos com uma enorme variedade de mecanismos de ação (HARIKRISHNA REDDY; MISRA; MEDHI, 2014). Porém, uma compreensão mais clara do que impulsiona o desenvolvimento da DP pode ajudar na busca por tratamentos que venham a retardar ou parar a evolução desta (GRAYSON, 2016).

Tratamentos complementares como a terapia ocupacional e fisioterapia podem ajudar os pacientes a manter a família, a vida social e laboral, e devem ser oferecidos principalmente 
àqueles que têm dificuldade em realizar tarefas da vida diária. Já os tratamentos cirúrgicos, tal como a estimulação cerebral profunda do núcleo subtalâmico e o globo pálido, têm como objetivos básicos melhorar a sintomatologia e reduzir os efeitos colaterais da terapêutica farmacológica. Independentemente da técnica, objetivos ou o estado clínico do paciente, é consenso que a estimulação cerebral profunda não retarda a progressão da doença (FERNANDEZ, 2015).

\subsubsection{Discinesias levodopa-induzidas}

As taxas de incidência relatadas de discinesia induzida por levodopa (LID) mostram um amplo intervalo, entre $9 \%$ a $80 \%$. LID são clinicamente heterogêneas, comumente presentes como coréia ou coreoatetose, embora mioclonias, balismo e outras formas de movimentos anormais também sejam descritos. A LID geralmente aparece pela primeira vez no lado mais afetado pela DP e nos membros inferiores antes dos membros superiores (THANVI; LO; ROBINSON, 2007b). Os fatores de risco para LID incluem a idade de início do DP, gravidade da doença, duração do tratamento com levodopa e dose da medicação, indicando que tanto a perda progressiva de neurônios dopaminérgicos como a exposição à levodopa desempenham papéis no estabelecimento da LID (MOSHAROV; BORGKVIST; SULZER, 2015a).

Os mecanismos causadores da LID não são claros. Vários mecanismos possíveis foram propostos. Sugere-se que a estimulação pulsátil dos receptores pós-sinápticos devido à administração intermitente de levodopa leva a mudanças em proteínas e genes, causando alterações na via de saída estriatal, de tal modo a promover discinesias (THANVI; LO; ROBINSON, 2007b). Alguns autores demonstraram evidência de que a denervação dopaminérgica pré-sináptica na DP desempenha um papel no desenvolvimento da LID (THANVI; LO; ROBINSON, 2007b). 


\subsection{Diagnóstico por imagem}

\subsubsection{Ressonância nuclear magnética (RM)}

Anormalidades estruturais na DP são sutis ou ausentes, e alterações não específicas, tais como atrofia do putâmen, são encontradas em menos de $20 \%$ dos casos (BOOTH et al., 2015a; HOLTBERND; EIDELBERG, 2014; JON STOESSL, 2011). Com o advento da ressonância magnética de alto campo, aquisições volumétricas e sequências mais sofisticadas, o papel da imagem estrutural no diagnóstico de distúrbios parkinsonianos está se tornando mais importante. A ressonância magnética pode ajudar a excluir lesões estruturais, como tumores de gânglios da base, hemorragias, vasculopatia, hidrocefalia e calcificação, todos associados ao parkinsonismo (BROOKS, 2012). Imagens de tensão difusional e ressonância funcional para avaliar conectividade cerebral, espectroscopia para avaliar metabólitos cerebrais e análise volumétrica para avaliar anormalidades corticais, podem ser aplicadas (BAGLIERI et al., 2013), e auxiliam no diagnóstico diferencial, e potencialmente na avaliação prognóstica, monitoração terapêutica (BAGLIERI et al., 2013; BROOKS, 2012).

\subsubsection{Ultrassonografia transcraniana}

Vários artigos relataram aumento da ecogenicidade na substância nigra utilizando ecografia transcraniana não invasiva. Somado a ecogenicidade normal dos gânglios da base, este achado tem um elevado valor preditivo positivo para diagnóstico de DP (BOOTH et al., 2015b). Contudo, aumento da ecogenicidade também é observado em indivíduos com tremor e não se altera ao longo da evolução da DP (JON STOESSL, 2011). Além disso cerca de 20 $\%$ dos indivíduos caucasianos e $60 \%$ dos asiáticos não podem ser estudados devido a uma janela acústica temporal inadequada (BOOTH et al., 2015b). Assim seu papel é ainda controverso (JON STOESSL, 2011), não havendo dados suficientes na literatura para embasar uma recomendação (GAZEWOOD; RICHARDS; CLEBAK, 2013). 


\subsubsection{SPECT e PET}

Além do valor diagnóstico, as imagens funcionais auxiliam no entendimento da fisiopatologia subjacente às síndromes parkinsonianas e fornecem um meio sensível para detectar doenças subclínicas e avaliar o grau e a evolução da doença (BROOKS, 2012). A tomografia por emissão de pósitrons (PET) apresenta maior sensibilidade, particularmente devido a maior resolução espacial $(2-3 \mathrm{~mm})$, fato que permite aquisição das imagens em menor tempo. A tomografia por emissão de fóton único (SPECT) é uma modalidade menos sensível, porém amplamente disponível, capaz de avaliar perfusão cerebral e ligação a receptores (BROOKS, 2012).

Técnicas de imagem molecular utilizam biomarcadores dopaminérgicos como principal ferramenta na investigação clínica das desordens de movimento, tendo em vista a importância do sistema nigroestriatal na fisiopatologia da doença de Parkinson (MEYER; FRINGS; HELLWIG, 2014; MEYER; HELLWIG, 2014; NIETHAMMER; FEIGIN; EIDELBERG, 2012; OUNG et al., 2015). No entanto, muitos outros sistemas neuroquímicos podem ser avaliados, tais como serotoninérgico, adrenérgico, colinérgico e noradrenérgico, além de atividade neuroinflamatória e deposição de proteínas (ex: placas amiloides) (BROOKS; PAVESE, 2011; NIETHAMMER; FEIGIN; EIDELBERG, 2012; PAVESE; BROOKS, 2009; QAMHAWI et al., 2015). Dentre estes outros estudos, os mais comuns são o estudo da perfusão e metabolismo cerebral.

A PET com $\left[{ }^{18} \mathrm{~F}\right]$-fluordesoxiglicose (FDG) estuda o metabolismo glicolítico cerebral, refletindo a atividade sináptica regional. Nos distúrbios parkinsonianos, métodos de covariância espacial têm permitido estabelecer padrões de doença e de características clínicas, que podem ser utilizados para identificar o diagnóstico, progressão da doença e efeitos terapêuticos (NIETHAMMER; FEIGIN; EIDELBERG, 2012). A perfusão cerebral e o metabolismo glicolítico tendem a se apresentar de forma semelhante em diversas doenças neurodegenerativas. Em DP, o padrão clássico consiste no aumento metabólico pálido- 
talâmico e pontino e reduções relativas no córtex pré-motor, área motora suplementar e regiões de associação parietal (NIETHAMMER; FEIGIN; EIDELBERG, 2012).

\subsection{Neuroimagem do sistema dopaminérgico}

A dopamina pertence à família de catecolaminas de neurotransmissores. Além da dopamina, essa família inclui a norepinefrina e a epinefrina. O aminoácido neutro tirosina é o precursor de todas as catecolaminas A primeira etapa na síntese de dopamina consiste na conversão da tirosina em levodopa (1 -3,4-diidroxifenilalanina ou levodopa) por oxidação da posição 3 no anel de benzeno. Essa reação é catalisada pela enzima tirosina hidroxilase (TH). A próxima e última etapa consiste na conversão da 1-DOPA em dopamina pela enzima aminoácido aromático descarboxilase (AADC). Nos neurônios dopaminérgicos, o produto final da via de síntese das catecolaminas é a dopamina. A seguir, esta é transportada para o interior de vesículas secretoras para armazenamento e liberação. São necessárias duas bombas moleculares separadas para o transporte da dopamina nas vesículas sinápticas. Uma ATPase de prótons concentra prótons na vesícula, criando um gradiente eletroquímico caracterizado por $\mathrm{pH}$ intravesicular baixo (isto é, concentração elevada de prótons) e um interior eletropositivo da vesícula. Esse gradiente é explorado por um antiportador de prótons, o transportador de monoaminas vesicular (VMAT), que permite o deslocamento de prótons ao longo do gradiente (para fora da vesícula) enquanto efetua o transporte simultâneo de dopamina para dentro da vesícula, contra o seu gradiente de concentração (STANDAERT; GALANTER, 2009).

As células dopaminérgicas localizadas na substância nigra são projetadas até o corpo neoestriado, composto pelo putâmen e o núcleo caudado. Uma vez presente no corpo estriado, a dopamina armazenada em vesículas intracelulares na região pré-sináptica somente é liberada para o meio intra-sináptico mediante a passagem de um potencial de ação através deste axônio. Após sua liberação para a fenda sináptica, a dopamina interage com os receptores pós 
e pré-sinápticos, sendo então metabolizadas ou recapturadas de volta para o terminal présináptico através dos transportadores dopaminérgicos (DAT) (figura 1). Sendo assim os DAT apresentam vital importância nas funções dopaminérgicas, de forma a modular a atividade motora e cognitiva (SHIH et al., 2006b; WENG et al., 2004; YEH et al., 2012).

A avaliação da integridade nigroestriatal é realizada utilizando-se radiotraçadores de três alvos moleculares pré-sinápticos diferentes (AACD, VMAT e DAT) ou de receptores pós sinápticos. Embora estes raçadores forneçam resultados diagnósticos similares, há evidências que estes alvos são regulados de forma distinta em DP. No início dos sintomas, por exemplo, a síntese de dopamina parece estar positivamente regulada, enquanto a expressão de DAT parece ser negativamente regulada (BROOKS; PAVESE, 2011; PAVESE; BROOKS, 2009).

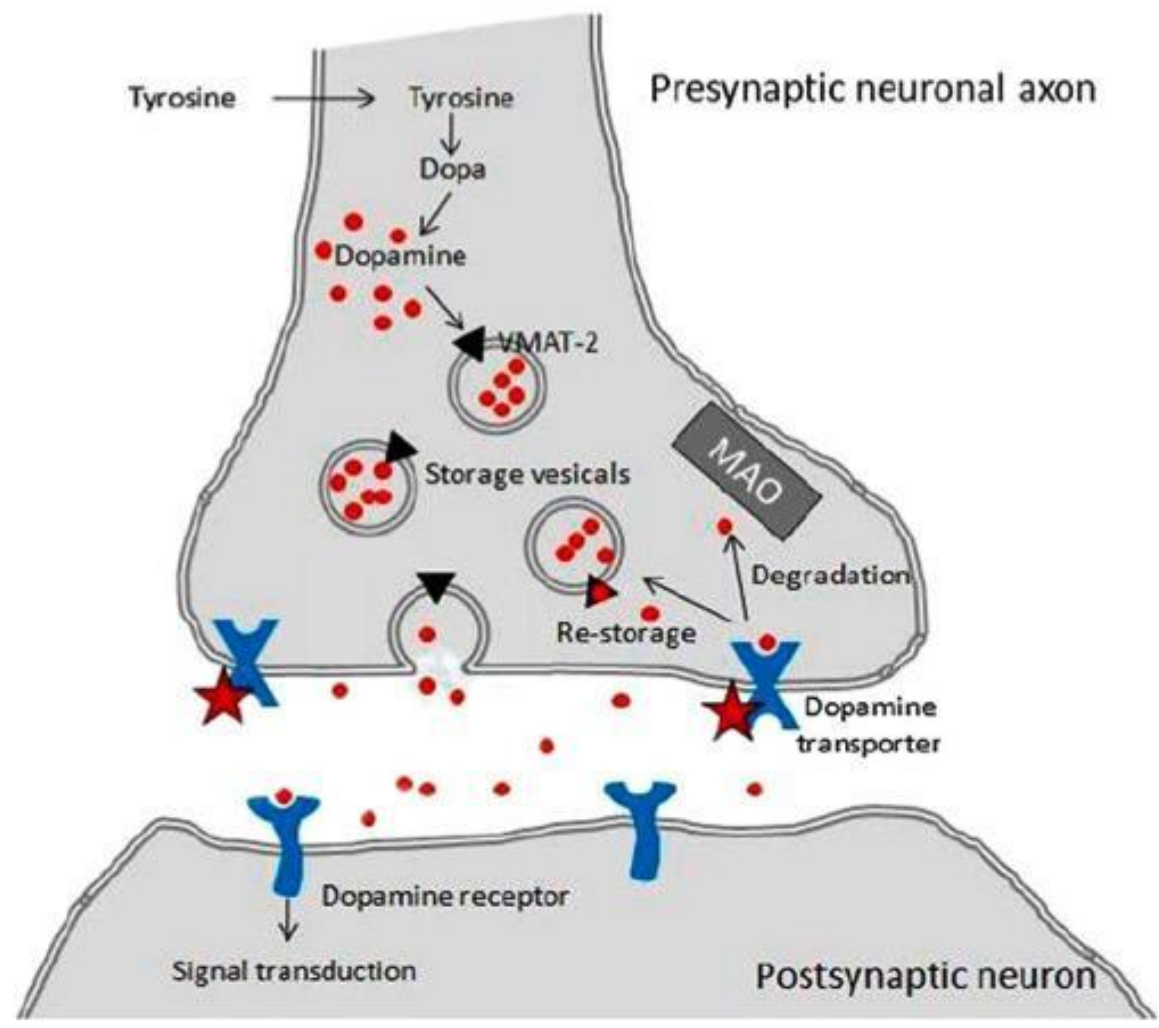

Figura 1: Imagem esquemática da fenda sináptica dopaminérgica (DJANG et al., 2012). 
Foram propostos vários radiotraçadores diferentes para imagens do sistema dopaminérgico (tabela 5 e 6 ).

Tabela 5: Radiofármacos aplicados no estudo da via nigroestriatal pré-sináptica (BROOKS; PAVESE, 2011; DJANG et al., 2012; PAVESE; BROOKS, 2009; SHIH et al., 2006a; VAN LAERE et al., 2010).

\begin{tabular}{|c|c|c|c|}
\hline $\begin{array}{l}\text { Marcador biológicos pré- } \\
\text { sinápticos }\end{array}$ & $\begin{array}{l}\text { Técnica de } \\
\text { neuroimagem }\end{array}$ & Radionuclídios & Fármaco \\
\hline $\begin{array}{l}\text { Metabolismo de levodopa: } \\
\text { (a) captação dentro de neurônios } \\
\text { dopaminérgicos } \\
\text { (b) metabolismo de AACD } \\
\text { (c) armazenamento de }{ }^{18} \mathrm{~F}- \\
\text { dopamina }\end{array}$ & PET & {$\left[{ }^{18} \mathrm{~F}\right]$} & dopa \\
\hline \multirow{8}{*}{$\begin{array}{l}\text { Transportador dopaminérgico } \\
\text { (DAT) }\end{array}$} & PET & {$[11 \mathrm{C}$} & CFT \\
\hline & & {$\left[{ }^{18} \mathrm{~F}\right]$} & CFT \\
\hline & & {$\left[{ }^{11} \mathrm{C}\right]$} & $\begin{array}{l}\text { RTI-32 / cocaína / } \\
\text { metilfenidato }\end{array}$ \\
\hline & & {$\left[{ }^{3} \mathrm{H}\right]$} & WIN 35,428 \\
\hline & PET e SPECT & {$\left[{ }^{18} \mathrm{~F}\right] /\left[{ }^{11} \mathrm{C}\right] /\left[{ }^{123} \mathrm{I}\right]$} & FP-CIT \\
\hline & & {$\left[{ }^{123} \mathrm{I}\right] /\left[{ }^{11} \mathrm{C}\right]$} & $\beta$-CIT altropano \\
\hline & SPECT & {$\left[{ }^{123} \mathrm{I}\right]$} & $\begin{array}{l}\text { FP-CIT / PE2I ou RTI-32 / } \\
\beta \text {-CIT }\end{array}$ \\
\hline & & {$\left[{ }^{99 \mathrm{~m}} \mathrm{Tc}\right]$} & TRODAT-1 \\
\hline $\begin{array}{l}\text { Transportador de monoaminas } \\
\text { vesicular (VMAT) }\end{array}$ & PET & {$\left[{ }^{11} \mathrm{C}\right]$} & dihidrotetrabenazina \\
\hline
\end{tabular}


Tabela 6: Radiofármacos aplicados no estudo da via nigroestriatal pós-sináptica (BROOKS; PAVESE, 2011; DJANG et al., 2012; PAVESE; BROOKS, 2009; SHIH et al., 2006a; VAN LAERE et al., 2010).

\begin{tabular}{|l|lll}
\hline $\begin{array}{c}\text { Marcador biológicos pós- } \\
\text { sinápticos }\end{array}$ & \multicolumn{2}{c}{$\begin{array}{c}\text { Técnica de } \\
\text { neuroimagem }\end{array}$} & \multicolumn{2}{c}{ Radionuclídios } & \multicolumn{1}{c}{ Fármaco } \\
\hline Receptores pós-sinápticos & PET & $\left.{ }^{[1} \mathrm{C}\right]$ & racloprida \\
& & {$\left[{ }^{11} \mathrm{C}\right]$} & faliprida \\
& {$\left[{ }^{11} \mathrm{C}\right]$} & FLB 457 \\
& {$\left[{ }^{11} \mathrm{C}\right]$} & SCH23390 \\
& & & DMFP \\
& SPECT & {$\left[{ }^{18} \mathrm{~F}\right]$} & Iodobenzamida (IBZM) \\
& & {$\left[{ }^{123} \mathrm{I}\right]$} & epideprida \\
\hline
\end{tabular}

O SPECT da densidade dos transportadores dopaminérgicos (DAT-SPECT) permite a diferenciação de causas neurodegenerativas de parkinsonismo, onde tipicamente os pacientes terão um estudo anormal, de outros distúrbios de movimento ou tremor, em que tipicamente o estudo será normal (BOOTH et al., 2015a). A tabela 7 situa as desordens parkinsonianas quanto a presença ou ausência de déficit dopaminérgico estriatal. 
Tabela 7: Desordens parkinsonianas associadas ou não a déficit dopaminérgico estriatal (BROOKS, 2016).

\begin{tabular}{ll}
\multicolumn{1}{c}{$\begin{array}{c}\text { Desordens parkinsonianas associadas a } \\
\text { déficit dopaminérgico estriatal }\end{array}$} & \multicolumn{1}{c}{$\begin{array}{c}\text { Desordens parkinsonianas sem déficit } \\
\text { dopaminérgico estriatal }\end{array}$} \\
\hline Doença de Parkinson & Tremores essenciais e distônicos \\
Atrofia de múltiplos sistemas & Parkinsonismo secundário \\
Paralisia supranuclear progressiva & Infecção (toxoplasmose) \\
Demência corticobasal & Hidrocefalia \\
Demência por corpos de Lewy & Atrofia palidal \\
Doença de pequenos vasos & Distonia responsiva à dopa \\
Doença de Huntington & Parkinsonismo-distonia ligada a X \\
Parkinsonismo - Demência - Esclerose Lateral & Parkinsonismo psicogênico \\
Amiotrófica da ilha de Guam & \\
\hline
\end{tabular}

Outro papel potencial para o DAT-SPECT é o monitoramento da progressão da doença em doentes com e sem tratamento. A perda nigrostriatal em pacientes com DP está estimada em pelo menos $8 \%$ ao ano, substancialmente mais elevada do que a perda fisiológica de neurônios nigroestriatais, estimada em $5 \%$ por década. Entretanto, por não haver uma correlação direta comprovada entre o declínio progressivo da densidade do DAT e o desfecho clínico, o papel do DAT-SPECT para avaliar a eficácia de terapias neuroprotetoras em ensaios clínicos, por exemplo, tem sido questionado (BOOTH et al., 2015a).

Por fim, outra possível aplicação do DAT-SPECT está na detecção subclínica da doença de Parkinson, embora não exista uma clara definição de qual seria esse grupo de risco que deveria ser submetido ao rastreamento.

As principais recomendações para DAT-SPECT estão resumidas na tabela 8 . 
Tabela 8: Recomendações para a realização de DAT-SPECT (DJANG et al., 2012; VAN LAERE et al., 2010).

Avaliação de pacientes com suspeita de uma síndrome parkinsoniana

Diagnóstico diferencial entre síndromes parkinsonianas com e sem perda dopaminérgica pré-sináptica

Diagnóstico precoce de síndrome parkinsoniana

Diagnóstico diferencial entre demência de Alzheimer e demência por corpos de Lewy

Quadros com apenas 1 de 3 sinais cardinais para DP com ou sem assimetria, presença de 2 sinais cardinais sem bradicinesias, resposta pobre a levodopa e falta de progressão da doença, são indicativos clínicos para a solicitação do exame (BOOTH et al., 2015a).

\subsubsection{SPECT cerebral com $\left[{ }^{99 \mathrm{~m}}\right.$ Tc]-TRODAT-1}

O [ $\left.{ }^{99 m} \mathrm{Tc}\right]-T R O D A T-1$ é um tropano radiomarcado que se liga a transportadores de dopamina (DAT), que apresenta elevada ação farmacocinética (máxima captação estriatal entre 3-4h após a injeção), excelentes características físicas para a aquisição de imagens em gama-câmara e relativo baixo valor comercial. Este é capaz de avaliar a densidade dos DAT no corpo estriado, sendo aplicado principalmente na detecção/diagnóstico diferencial da doença de Parkinson (SHIH et al., 2006b; WENG et al., 2004; YEH et al., 2012), embora esteja também associado a outras desordens cuja patogênese está relacionada ao sistema dopaminérgico, tais como outras desordens do movimento (BROOKS, 2012; BROOKS; PAVESE, 2011; SHIH et al., 2006b; TATSCH, 2008). O campo de pesquisa em $\left[{ }^{99 \mathrm{~m}} \mathrm{Tc}\right]-$ TRODAT-1 é bastante amplo, sendo utilizado na avaliação de várias doenças com finalidades diversas, desde objetivando melhor compreender a fisiopatologia destas doenças, até investigar as potenciais aplicações diagnósticas e prognósticas do DAT-SPECT com $\left[{ }^{99 \mathrm{~m}} \mathrm{Tc}\right]-$ TRODAT-1. Pode-se citar avaliação das síndromes parkinsonianas atípicas (BOOTH et al., 
2015b; HOLTBERND; EIDELBERG, 2014; HUGHES et al., 1992; LIN et al., 2010; LIZARRAGA et al., 2016; SCHERFLER et al., 2005), distúrbios do sono (PEDROSO et al., 2013), déficit de atenção e de aprendizado (KRAUSE et al., 2005, 2003; SZOBOT et al., 2011), esquizofrenia (CHEN et al., 2011; SCHMITT et al., 2012), outros distúrbios neuropsicológicos (HOEXTER et al., 2012; HOU et al., 2012), síndrome de Tourette (LIU et al., 2010; LIZARRAGA et al., 2016), intoxicação a mercúrio (LIN et al., 2011), avaliação de usuários de cocaína (CRITS-CHRISTOPH et al., 2008), etc.

A avaliação do estudo com [ $\left.{ }^{99 \mathrm{~m}} \mathrm{Tc}\right]-$ TRODAT-1 para fins diagnósticos pode ser realizada de forma qualitativa e semiquantitativa (BROOKS, 2012; BROOKS; PAVESE, 2011; SHIH et al., 2006b; TATSCH, 2008). Vários estudos mostram excelentes resultados com leitores treinados utilizando somente a interpretação visual. Na interpretação visual, a forma estriatal, extensão, simetria e intensidade de captação diferenciam o estado normal de anormal. O estriado normal em imagens transaxiais deve apresentar uma forma de crescente ou de vírgula, e deve ter bordas bem delineadas e simétricas. O nível de atividade estriatal deve ser comparada com a atividade de fundo. A cabeça do caudado e o putâmen devem ter alto contraste com o fundo em todas as escalas e para pacientes de todas as idades. Alguma diminuição na ligação do estriado, tanto no caudado quanto no putâmen ocorre com o envelhecimento normal (5\% a 7\% por década), porém esta é pequena e não deve interferir com a interpretação (DJANG et al., 2012; KAASINEN et al., 2015; VAN LAERE et al., 2010).

Tipicamente pacientes com DP mostram uma degeneração assimétrica nigroestriatal na inspeção visual, com uma redução da densidade de transportadores dopaminérgicos no corpo estriado preferencialmente do lado contralateral ao predomínio dos sintomas, iniciando a partir do putâmen para o caudado (BOOTH et al., 2015a; MEYER; FRINGS; HELLWIG, 2014; MEYER; HELLWIG, 2014). Este déficit é correlacionado a severidade dos sintomas e duração da doença. Níveis reduzidos de DAT em um estudo basal e uma subsequente redução mais pronunciada em um estudo de controle, também são colocadas como fatores preditores 
de um incapacidade motora mais importante, déficit cognitivo, psicose e depressão (MEYER; HELLWIG, 2014). Déficit simétrico pode ocorrer em formas genéticas de parkinsonismo como a parkina (PARK2) (BOOTH et al., 2015a).

A avaliação semiquantitativa, por sua vez, também mostra bons resultados. As vantagens potenciais da semiquantificação incluem: medição mais objetiva dos índices de ligação estriatal; capacidade de obter um resultado quantitativo que possa ser correlacionado com a perda dopaminérgica pré-sináptica; detecção de mudanças sutis nos DAT; interpretações mais assertivas em caso de dúvidas na análise visual. Contudo apesar do fato de a semiquantificação parecer simples, variações consideráveis interobservadores podem ocorrer, particularmente devido a erros na delimitação das áreas de interesse ou na reorientação do cérebro, que pode levar a falsas interpretações.

\subsubsection{Métodos de quantificação}

$\mathrm{Na}$ literatura uma grande variedade de abordagens quantitativas é encontrada. Apesar da quantificação absoluta a partir da imagem de SPECT possibilitar uma estimativa mais acurada da concentração radioisotópica sobre uma estrutura de interesse, sua eficiência é comprometida por parâmetros de aquisição não ideais, efeitos de espalhamento e atenuação, volume sensível do objeto e pelo efeito de volume parcial (COT SANZ, 2003; RITT et al., 2011), sendo de difícil correção em muitos casos. Avaliações semiquantitativas são preferíveis na rotina clínica devido a sua exequibilidade.

O processo de semiquantificação baseado em áreas de interesse (ROI) tem como principal desafio a construção dessas ROIs de modo a apresentarem dimensões adequadas e posicionamento correto sobre as estruturas do corpo estriado. A experiência do avaliador passa a ser um fator determinante na construção destas ROIs para quantificação.

O método manual de quantificação é um dos mais amplamente utilizados devido a sua 
versatilidade e praticidade, Este envolve o desenho manual de uma ROI irregular que compreenda todo o corpo estriado ou suas subestruturas, e outra sobre uma região de referência, representativa da radiação de "fundo" (background). Esta metodologia permite calcular o índice de potencial de ligação (BPI, binding potential index) através de uma razão entre os valores obtidos através das ROIs (TOSSICI-BOLT et al., 2006, 2011; VERHOEFF et al., 1993).

No entanto, o desenho e o posicionamento manual das ROIs são dependentes do observador, o que pode gerar uma grande variabilidade na análise intraobservadores e interobservadores. A variabilidade na construção de ROI de forma manual pode ser minimizada quando estas são baseadas em modelos anatômicos ou modelos padronizados (templates) (TOSSICI-BOLT et al., 2006, 2011; VERHOEFF et al., 1993).

A construção de ROIs templates podem ser baseadas em modelos geométricos padronizados com tamanho e formato semelhantes às estruturas do corpo estriado (VAN LAERE et al., 2006) ou utilizando ROIs com geometrias regulares e amplas dimensões, como é o caso do método semiquantitativo Two Box (TOSSICI-BOLT et al., 2006). Outra abordagem é baseada na construção de ROIs a partir de imagens estruturais de ressonância magnética (RM) ou tomografia computadorizada (CT, computed tomography), que possam ser corregistradas sobre as imagens de SPECT do corpo estriado. A construção de ROIs ou volumes de interesse (VOI, volume of interest) a partir dessas imagens estruturais proporcionam método de quantificação muitas vezes mais acurados (SCHERFLER et al., 2005; SEPPI; SCHOCKE, 2005).

Com o objetivo de avaliar a acurácia, precisão e reprodutibilidade de diferentes métodos semiquantitativos de imagens de SPECT do corpo estriado, Santos, LA realizou 23 aquisições de SPECT utilizando um simulador antropomórfico estriatal preenchido com diferentes concentrações de atividade de ${ }^{99 \mathrm{~m}} \mathrm{Tc}$. Cinco métodos baseados em ROIs, dedicados para a quantificação de SPECT do corpo estriado foram avaliados: ROIs desenhadas sobre as imagens de SPECT (Manual), ROIs com dimensões padronizadas (método Two Box e Three 
Box); e baseado em imagens estruturais (RM e CT). Foram avaliados a acurácia, reprodutibilidade e variabilidade intra e interobservadores (SANTOS, 2015). O autor concluiu que os cinco métodos semiquantitativos demonstraram ser eficientes na realização de leituras proporcionais dos índices de potencial de ligação, mesmo quando aplicados a imagens de diferentes concentrações de atividade. Contudo, os métodos de quantificação relativa Manual e Three Box demonstraram não ser reprodutíveis nas avaliações intra e interobservadores quando comparados às outras técnicas semiquantitativas desenvolvidas, reduzindo sua confiabilidade, apesar da prática e rápida aplicação. Os efeitos de variabilidade foram menos expressivos nos demais métodos $\mathrm{Na}$ avaliação de subestruturas do corpo estriado (putâmen e caudado), os métodos estruturais (RM e CT) foram mais acurados, demonstrando uma crescente eficiência em representar parâmetros semiquantitativos diante da diminuição dos índices nominais de preenchimento. Na investigação do corpo estriado, o método Two Box apresentou a melhor performance diante todos os métodos avaliados (SANTOS, 2015).

Apesar de ser grande a diversidade de métodos e propostas de quantificação de imagens de SPECT do corpo estriado, a implementação dessas técnicas na prática clínica é restrita. Dentre as possíveis causas para este fato pode-se citar a falta de replicabilidade, a falta de padronização e a necessidade de investimento, uma vez que a grande maioria destas plataformas são oferecidas de forma comercial. 


\section{Objetivos:}

\subsection{Objetivos Gerais:}

2.1.1. Criar um banco de dados de imagens de SPECT cerebral da densidade de transportadores dopaminérgicos pré-sinápticos através do uso do radiofármaco [ ${ }^{99 \mathrm{~m}}$ Tc $]-$ TRODAT-1;

2.1.2. Caracterizar a densidade de DAT no corpo estriado dos pacientes saudáveis e em portadores de doença de Parkinson;

2.1.3. Comparar diferentes métodos de semiquantificação da densidade de transportadores dopaminérgicos no corpo estriado.

\subsection{Objetivos Específicos:}

2.2.1. Determinar o limiar semiquantitativo de normalidade ao SPECT com [ $\left.{ }^{99 \mathrm{~m}} \mathrm{Tc}\right]-\mathrm{TRODAT}-1$ entre os voluntários saudáveis e os pacientes com DP;

2.2.2. Determinar os parâmetros de sensibilidade e especificidade da avaliação qualitativa e dos diferentes métodos de semiquantificação no SPECT com [ $\left.{ }^{99 \mathrm{~m}} \mathrm{Tc}\right]-T R O D A T-1$ (validação clínica) para um equipamento de SPECT-CT Philips BrightView XCT;

2.2.3. Avaliar diferentes índices semiquantitativos e correlacionar o potencial de ligação no corpo estriado com dados clínicos;

2.2.4. Avaliar a reprodutibilidade inter e intra-sujeito na avaliação qualitativa e semiquantitativa do SPECT com [ ${ }^{99 \mathrm{~m}}$ Tc]-TRODAT-1.

2.2.5. Correlacionar a densidade de DAT no corpo estriado com a presença ou ausência de discinesias. 


\section{Metodologia}

\subsection{Desenho do estudo}

Após inclusão prospectiva dos pacientes no estudo, estes foram alocados em dois grupos (pacientes com doença de Parkinson e controles saudáveis). As imagens foram analisadas por métodos qualitativo e semiquantitativos de forma cega por dois avaliadores, a fim de se estabelecer acurácia, sensibilidade, especificidade e reprodutibilidade dos métodos.

Etapa 1: Planejamento Metodológico: definição dos métodos de análise das imagens de SPECT cerebral com [ ${ }^{99 \mathrm{~m}} \mathrm{Tc}$ ]-TRODAT-1, assim como dos parâmetros recomendados para aquisição e reconstrução das imagens, e dos protocolos de quantificação, através de revisão sistemática da literatura e de resultados obtidos em estudos no próprio serviço com um simulador morfológico (SANTOS, 2015; TREVISAN, 2015).

Etapa 2: Recrutamento e avaliação clínica dos pacientes com DP e dos controles saudáveis.

Etapa 3: Aquisição e processamento das imagens de SPECT cerebral com [ ${ }^{99 \mathrm{~m}} \mathrm{Tc}$ ]TRODAT-1.

Etapa 4: Avaliação qualitativa e aplicação dos métodos de quantificação auxiliado por softwares free source.

Etapa 5: Análise dos parâmetros qualitativos e semiquantitativos calculados por cada método. 


\subsection{Pacientes}

Foram incluídos neste estudo prospectivo, 67 pacientes voluntários, 23 saudáveis ( 9

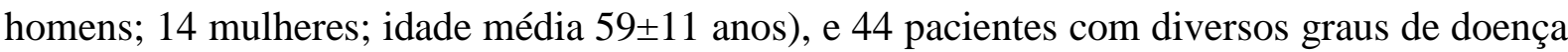
de Parkinson idiopática (29 homens; 15 mulheres; idade média 59 \pm 7 anos; duração média dos sintomas 10 \pm 6 anos, intervalo de duração dos sintomas 1-21 anos) encaminhados pelo ambulatório de doenças extrapiramidais do ambulatório do Hospital das Clínicas da Faculdade de Medicina de Ribeirão Preto da Universidade de São Paulo (HC-FMRP-USP).

No grupo de voluntários saudáveis foram excluídos pacientes com: demência moderadamente grave e grave; doença de Parkinson ou com síndrome parkinsoniana; desordens neuropsiquiátricas (esquizofrenia, hiperatividade e déficit de atenção, depressões sintomáticas e outras que podem cursar com alterações no sistema dopaminérgico); uso abusivo de álcool ou drogas; outras lesões orgânicas cerebrais conhecidas; antecedente de acidentes vasculares cerebrais; claustrofobia; uso crônico de medicações psicotrópicas; uso de medicações que interferem sabidamente na ligação do TRODAT-1 ao DAT; história de trauma com perda da consciência; tabagismo. Os pacientes foram submetidos a avaliação clínica sumária.

Os portadores de Parkinson necessariamente apresentavam diagnóstico clínico confirmado por neurologista especialista na área. Foram utilizados os critérios diagnósticos do Banco de Cérebros de Londres (UK-PDS Brain Bank Society-Sponsored Revision of the Unified Parkinson's Disease Rating Scale) (GOETZ, 2012; GOETZ et al., 2008).

Para a estratificação dos pacientes foi utilizada a escala de Hoehn e Yahr (HYS) (anexo B). A mesma estabelece padrões típicos de progressão dos déficits motores, e têm como vantagens a simples e fácil aplicação, além da possibilidade de ser administrada aos pacientes com ou sem o uso de terapia dopaminérgica. Pacientes nos estágios de 1 a 3 são considerados como portadores de incapacidades leves a moderadas, enquanto nos estágios 4 e 
5 são considerados como portadores de incapacidades graves (BHIDAYASIRI; TARSY, 2012; SCHENKMAN et al., 2001)(SCHENKMAN et al., 2001).

A graduação motora do paciente foi realizada por neurologista especialista em desordens de movimento através da parte 3 da escala unificada da avaliação da doença de Parkinson (UPDRS), originalmente desenvolvida nos anos 1980 e modificada em 2001 pela Movement Disorder Society (MDS). O MDS-UPDRS foi publicado pela primeira vez na Inglaterra no ano de 2008 (GOETZ, 2012; GOETZ et al., 2008; STEBBINS; GOETZ, 1998). Cada tópico da escala é ancorado em cinco respostas: 0 - normal; 1 - leve; 2 - discreto; 3 = moderado ; 4 = grave (GOETZ, 2012; GOETZ et al., 2008; STEBBINS; GOETZ, 1998). Como se vê, quanto maior a pontuação, mais avançados são os sintomas.

Análise posterior do poder do estudo em diferenciar entre grupos com e sem DP atingiu um valor de até $100 \%$, demonstrando que a casuística foi adequada para os objetivos propostos.

\subsection{Aspectos éticos}

O estudo foi aprovado pela Unidade de Pesquisa Clínica e pelo Comitê de Ética em Pesquisa (CEP) do HCRP. Todos os pacientes voluntários assinaram consentimento livre e esclarecido (apêndices 1, 2 e 3) para a realização dos exames. Cada grupo assinou TCLE específico, sendo um destinado ao grupo de pacientes saudáveis, um para portadores de Parkinson inicial, e outro para Parkinson avançado. Este estudo recebeu apoio da Fundação de Apoio à Pesquisa do Estado de São Paulo - FAPESP (concessão de auxílio à pesquisa 2015/50089-3).

A privacidade do paciente foi garantida pelas seguintes medidas: (a) identificação do paciente na planilha de dados da pesquisa por números; (b) todas as informações de identificação dos pacientes presentes nas imagens de SPECT cerebral com [ ${ }^{99 \mathrm{~m}} \mathrm{Tc}$ ]-TRODAT1 de todos os voluntários foram anonimizados. Este estudo está em conformidade com as 
"Diretrizes e Normas Regulamentadoras de Pesquisas envolvendo Seres Humanos" Resolução No. 466/2012 do Conselho Nacional de Saúde (CNS), que dispõe sobre pesquisas envolvendo seres humanos.

\subsection{Procedimentos de neuroimagem}

\subsubsection{Preparo para o exame}

Pacientes foram avaliados quanto aos critérios de inclusão e de exclusão. Orientou-se a realização de uma dieta com restrição de proteínas durante um período de 24 horas antecedendo o exame, tanto para os pacientes portadores de DP, quanto para os controles saudáveis, conforme protocolo estabelecido na rotina clínica do HCRP. Em guidelines internacionais é recomendado a suspensão de algumas medicações (metilfenidato, bupropiona, efedrina, fentanil, anestésicos, anfetamina e cocaína) por 5 meias-vidas (BOOIJ; KEMP, 2008; DJANG et al., 2012), porém, para evitar qualquer interferência na captação ao transportador dopaminérgico, nenhum paciente com DP ou controle saudável em uso de uma destas medicações foi incluído na amostra. Estudos mostram que, ao contrário do que ocorre com traçadores de receptores dopaminérgicos pós sinápticos (VAN LAERE et al., 2010), a levodopa não influencia de forma significativa na captação de TRODAT-1 ou de outros traçadores pré-sinápticos dopaminérgicos (DJANG et al., 2012; FERNAGUT et al., 2010), deste modo não foi orientada a suspensão da droga.

\subsubsection{Radiofármaco}

O radiofármaco [ $\left.{ }^{99 \mathrm{~m}} \mathrm{Tc}\right]-$ TRODAT-1 foi preparado a partir de um kit pré formulado 
liofilizado fornecido pelo Institute of Nuclear Energy Research (Lung-Tan, Taiwan). O kit foi reconstituído com $1.110 \mathrm{MBq}(44 \mathrm{mCi})$ de [ $\left.{ }^{99 \mathrm{~m}} \mathrm{Tc}\right]$-pertecnetato de sódio recém eluído em 5 $\mathrm{ml}$ de solução salina e incubado a $100^{\circ} \mathrm{C}$ por 30 minutos para completar a marcação. Após resfriar para a temperatura ambiente, foi realizado controle de qualidade da pureza radioquímica (> 90\%), determinada por método cromatográfico.

\subsubsection{Aquisição e processamento das imagens}

Tomografia por emissão de pósitron único (SPECT) foi realizada 4 horas após a administração intravenosa de [ ${ }^{99 \mathrm{~m}} \mathrm{Tc}$ ]-TRODAT-1, com dose preconizada de 740-1110 MBq (média de 865,8 \pm 74 ). As imagens cintilográficas foram obtidas em um gama câmara circular modelo BrightView XCT (Philips Medical Systems Inc., Cleveland, OH, USA) composta por duas cabeças detectoras. Os dados foram coletados utilizando um colimador para baixas energias e alta resolução (low energy high resolution - LEHR) e um raio de rotação inferior a $20 \mathrm{~cm}$. Em um modo de aquisição step-and-shoot foram coletadas 64 projeções, em uma órbita circular de $180^{\circ}$ por cabeça, com um tempo de aquisição por projeção de $30 \mathrm{~s}$, em uma matriz de 128 x 128 pixels, um fator de ampliação de x1 e pixels isotrópicos de 2,13 mm. Os dados foram adquiridos a partir de uma janela simétrica de energia com largura de $15 \%$, centralizada em um fotopico de $140 \mathrm{keV}$. Os parâmetros de aquisição e reconstrução das imagens foram definidos através de revisão da literatura e de resultados obtidos em estudos no próprio serviço com um simulador morfológico (SANTOS, 2015; TREVISAN, 2015). A aplicação de diferentes protocolos de aquisição e reconstrução pode interferir nos resultados finais da quantificação, sendo necessário estabelecer o mais adequado para o equipamento disponível no serviço (DICKSON et al., 2010). Todos os pacientes realizaram SPECT com $\left[{ }^{99 \mathrm{~m}} \mathrm{Tc}\right]-$ TRODAT-1.

As condições adequados para a realização do SPECT e a qualidade final das imagens 
foram garantidas por parâmetros indicados pelo fabricante e pela realização de controles de qualidade estabelecidos por protocolos internacionais. Os testes de uniformidade intrínseca e extrínseca, centro de rotação, resolução espacial, sensibilidade tomográfica e os demais testes de controle de qualidade de periodicidade mensal e semestral tiveram seus resultados analisados e adequados aos valores recomendados pelas normas NEMA (NEMA Standards Publication NU 1-2007: Performance Measurements of Gamma Cameras, 2007).

Os dados adquiridos foram reconstruídos em um terminal Extended Brilliance Workspace Philips (EBW), utilizando um algoritmo iterativo (Ordered Subset Expectation Maximization - OSEM) de 8 iterações e 4 subsets. As imagens de SPECT foram corrigidas para os efeitos de degradação do sinal devido a atenuação dos fótons de raio gama através do método de correção uniforme desenvolvido por Chang (Chang's Method), com coeficiente de atenuação linear de $0,12 \mathrm{~cm}^{-1}$. Um filtro Butterworth de 2 ordem e frequência de corte de 0,22 ciclos/pixel foi utilizado para eliminação dos sinais de alta frequência das imagens, incrementando assim a razão sinal-ruído. Em seguida, as imagens foram armazenadas em formato DICOM 3.0.

Dados gerais sobre o paciente, preparação do radiofármaco, administração do traçador, controles de qualidade do equipamento e do radiofármaco, parâmetros de aquisição e parâmetros de reconstrução foram registrados devidamente em documento de procedimento operacional padrão (apêndice 4). O mesmo auxiliou no estabelecimento de uma sistemática de realização dos exames de forma adequada, de modo a garantir a confiabilidade dos dados adquiridos..

\subsubsection{Avaliação das imagens}

As análises visuais e semiquantitativas foram realizadas cegamente por dois médicos nucleares com experiência em neuroimagem (observador A e B). Foi procedido treinamento 
prévio para o uso dos softwares de quantificação. Um destes realizou duas leituras com pelo menos 1 semana de intervalo entre elas (avaliação A1 e A2). A leitura do segundo observador foi chamada de B1 para fins de comparação.

Para a análise os pacientes foram randomizados, sendo identificados por um número aleatório (1 a 67). Com o objetivo de avaliação interobservador, métodos automáticos (RM e RM-corrigida) foram realizados em computadores distintos.

Antes de qualquer interpretação, a qualidade das imagens adquiridas foram rotineiramente verificadas através do sinograma e do modo cine no raw projection (aquisição bruta), a fim de assegurar que não houve movimento que pudesse causar algum artefato. $\mathrm{O}$ alinhamento também foi verificado. Um eventual desalinhamento promovendo uma assimetria artificial posicional pode interferir na interpretação (DJANG et al., 2012).

Os métodos de quantificação aplicados neste estudo foram definidos por dados da literatura e por aplicação prévia dos mesmo em estudo com fantoma antropomórfico realizado na Seção de Medicina Nuclear do HC-FMRP-USP (SANTOS, 2015; TREVISAN, 2015). Os critérios de escolha foram baseados essencialmente na exequibilidade dos métodos em uma rotina prática, com potenciais bons resultados, utilizando plataformas de livre acesso.

\subsubsection{Avaliação qualitativa}

As imagens foram avaliadas em uma estação de trabalho Extended Brilliance Workspace Philips (EBW), dedicada à pesquisa na Seção de Medicina Nuclear do HC-FMRPUSP. Três escalas lineares de cor foram utilizadas: inverse (branco e preto), cool e thermal. $\mathrm{Na}$ avaliação qualitativa 1 , as imagens de cada paciente foram consideradas pelos observadores como normais (figura 2) ou alteradas. 


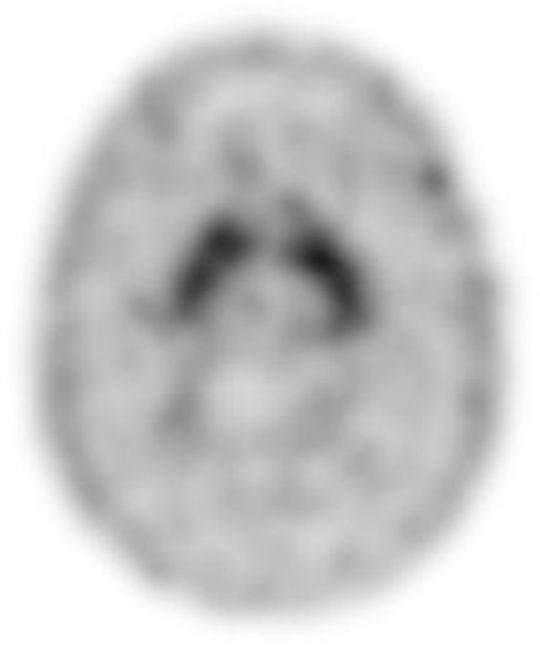

Figura 2: Imagem transversa de um SPECT com [ $\left.{ }^{99 \mathrm{~m}} \mathrm{Tc}\right]-T R O D A T-1$ de um paciente saudável. Estudo interpretado como normal.

$\mathrm{Na}$ avaliação qualitativa 2 exames foram classificados em graus de acordo com o tipo de alteração observada: 0 - normal; I - acometimento de um dos putâmens; II acometimento bilateral dos putâmens; III - acometimento dos putâmens e do (s) núcleo (s) caudado (s) (BENAMER et al., 2000; OTTAVIANI et al., 2006). Na avaliação qualitativa 3, estabelecida a partir de uma modificação da classificação de Benamer, o padrão de imagem III foi subdividido em IIIa, com envolvimento de um dos núcleos caudados, e IIIb, com envolvimento bilateral dos núcleos caudados (figura 3). 


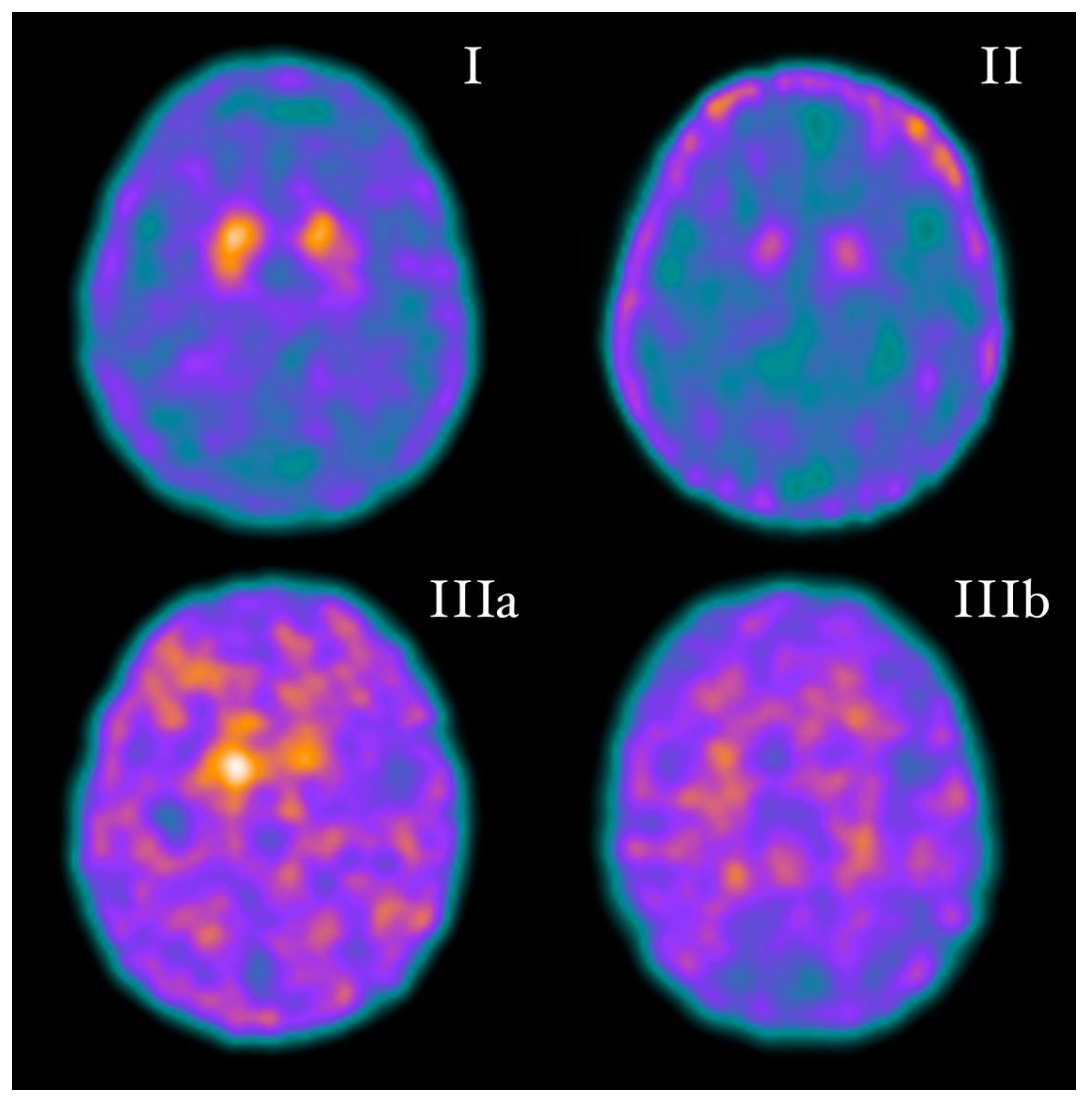

Figura 3: Imagens transversais de estudos de SPECT com [ ${ }^{99 \mathrm{~m}}$ Tc]-TRODAT-1 em pacientes com DP, classificados em graus: I- acometimento de um dos putâmens; II- acometimento bilateral dos putâmens; IIIa acometimento dos putâmens e do um dos núcleos caudados; IIIb - envolvimento bilateral dos putâmens e núcleos caudados.

O fluxograma a seguir (figura 4) evidencia os critérios utilizados na avaliaçãoo qualitativa. 


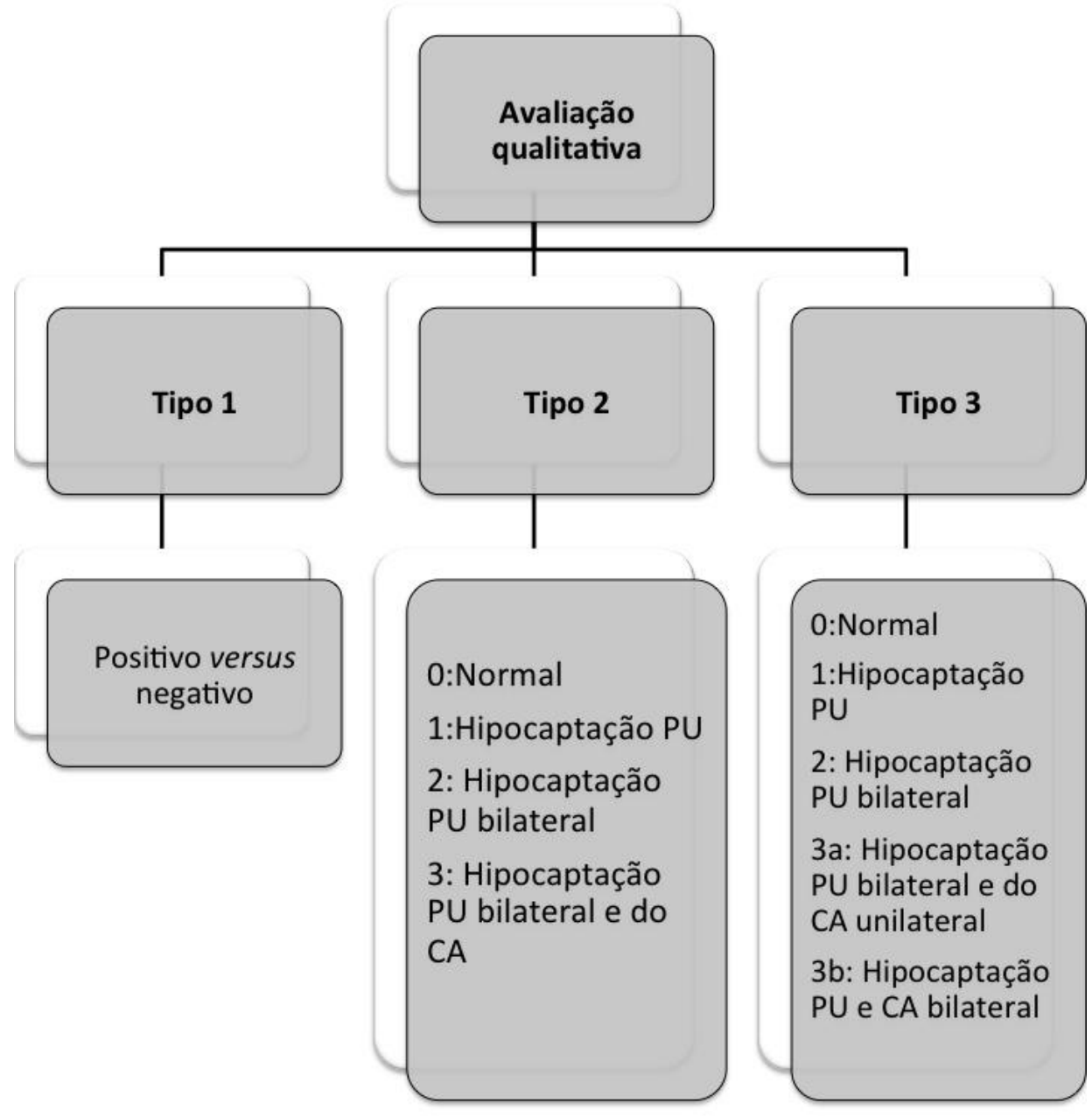

Figura 4: Fluxograma com os tipos de classificação visual das imagens de SPECT com [ ${ }^{99 m}$ Tc]-TRODAT-1 realizadas pelos observadores, sendo $\mathrm{PU}=$ putâmen, e $\mathrm{CA}=$ núcleo caudado.

\subsubsection{Avaliação semiquantitativa manual}

Os dados adquiridos foram avaliados em uma estação de trabalho Extended Brilliance Workspace Philips $(E B W)$, dedicada à pesquisa na Seção de Medicina Nuclear do HC-FMRPUSP. Para tanto utilizou-se o software Jetpack, que disponibiliza aplicativo de quantificação 
semi-automatizada de imagens de SPECT do corpo estriado denominado Brain Dopamine Transport. Ao selecionar a imagem de SPECT reconstruída, inicialmente o aplicativo apresenta de forma sequencial as imagens transversais do estudo (figura 5).

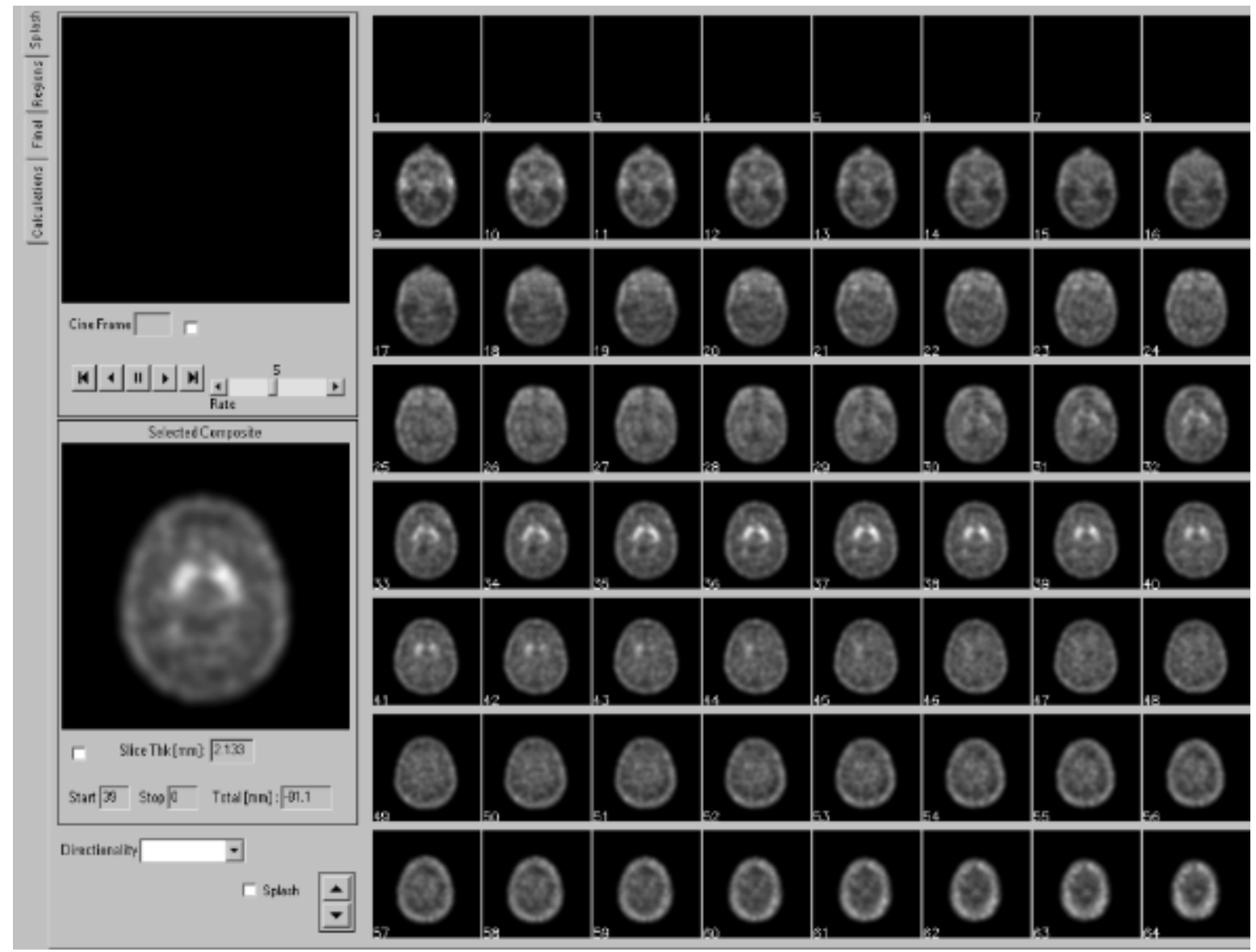

Figura 5: Imagens axiais apresentadas no software Jetpack da estação de trabalho Extended Brilliance Workspace Philips (EBW).

A seguir o observador seleciona a sequência de imagens representativas do corpo estriado, que irão integrar a imagem composta 2D utilizada na semiquantificação. A escolha destas imagens está baseada na definição visual de quais apresentam maior captação do 
radiofármaco no corpo estriado e melhor relação alvo/não-alvo. Na literatura o número de imagens somadas varia entre duas a seis conforme a metodologia aplicada por autor específico (ASENBAUM et al., 1997; BADIAVAS et al., 2011; DAVID MOZLEY et al., 2000; HUANG et al., [s.d.]; HWANG et al., 2004; KAASINEN et al., 2015; OTTAVIANI et al., 2006; WENG et al., 2004; YIN et al., 2014). A composição final é feita somando-se as imagens. No caso do método aplicado neste estudo a imagem resultante foi integrada por 5 cortes transversais e sequenciais com maior número de contagens por pixel (figura 6).

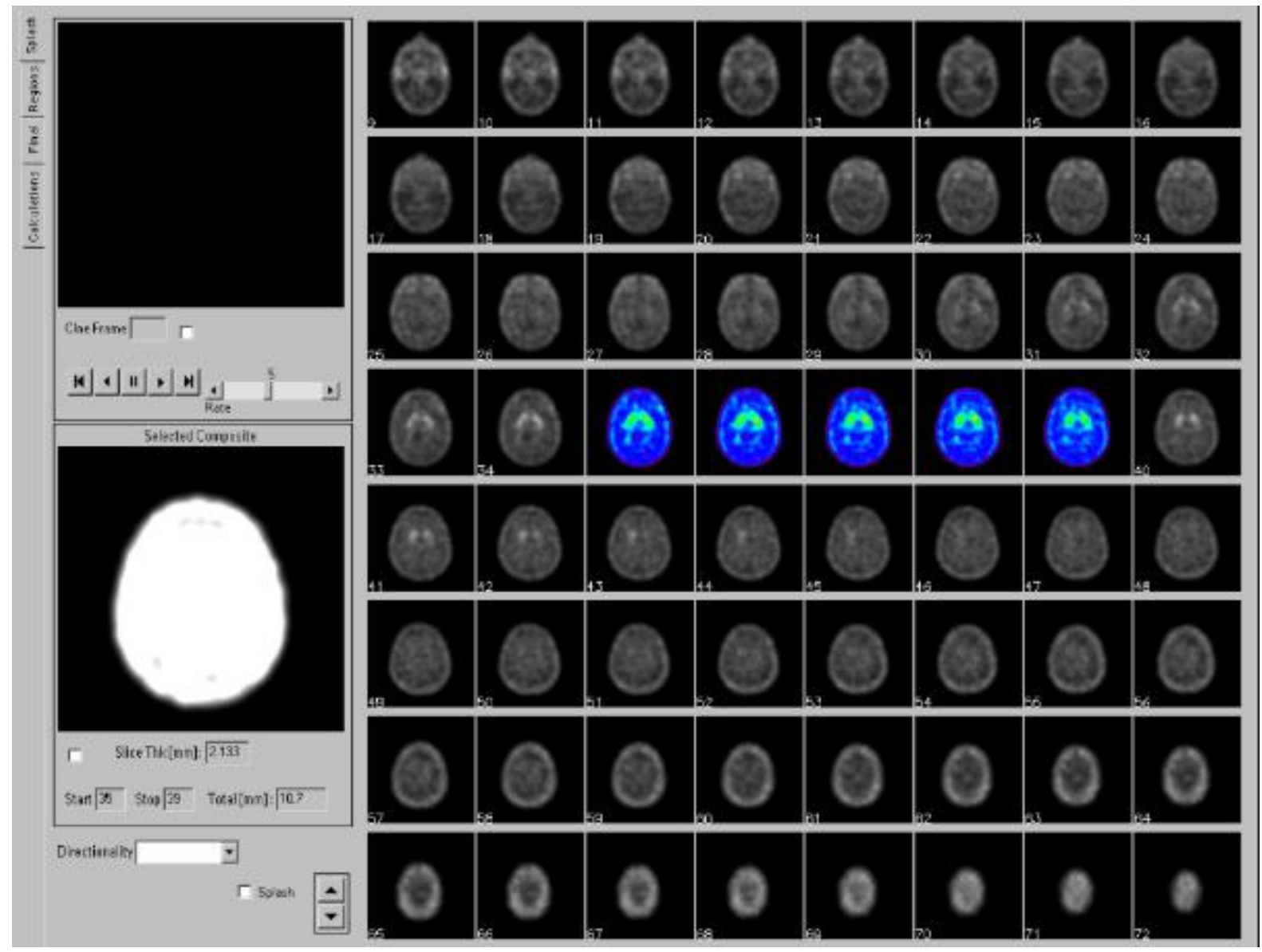

Figura 6: Imagens axiais selecionadas no software Jetpack da estação de trabalho Extended Brilliance Workspace Philips (EBW) para compor imagem 2D utilizada na quantificação. 
Após a escolha de 5 imagens representativas dos corpos estriados e a soma destas, foi realizada a segmentação de regiões de interesse (ROIs) para posterior quantificação (figura 7), sendo definidas as seguintes regiões de interesse: núcleos caudados (CA), putâmens (PU), corpos estriados (ST) e o lobo occipital (O). A ROI no lobo occipital corresponde a ROI de referência, construída sobre uma região de baixa densidade de contagens na imagem. Após a construção de todas as ROIs, correspondentes a cada estrutura, o aplicativo integra o número de contagens registradas no interior de cada região de interesse, assim como o número total de pixels que constituem cada ROI.

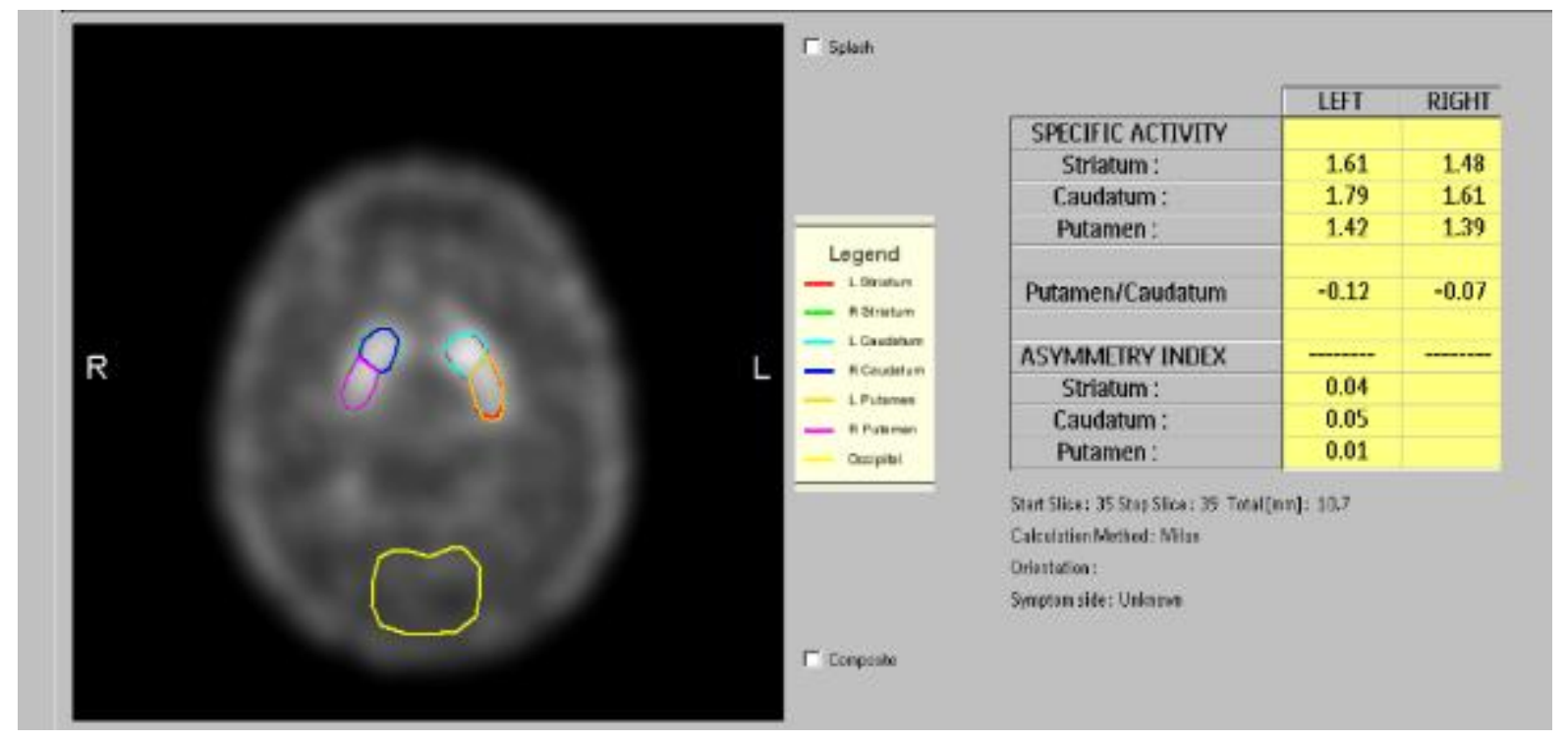

Figura 7: Áreas de interesse delineadas em composição 2D das imagens axiais selecionadas no software Jetpack da estação de trabalho Extended Brilliance Workspace Philips (EBW).

Automaticamente o software Jetpack gera valores de potencial de ligação, relação entre putâmen e caudado, e índices de assimetria. Para os cálculos e correlação com a lateralização dos sintomas e com os demais dados clínicos, optou-se por transportar os valores médios de contagens por pixel em cada estrutura para uma tabela Excel. 
Uma vez coletados os valores médios de contagem por pixel para cada área de interesse, os índices a seguir foram calculados (WENG et al., 2004): potencial de ligação (BPI) para cada estrutura, ipsilateral e contralateral à lateralização dos sintomas motores; índice de assimetria (IA) dos estriados, putâmens (PU) e núcleos caudados (CA); e razão entre putâmen e núcleos caudado (PU/CA), ipsilateral e contralateral à lateralização dos sintomas motores. Foram aplicadas as fórmulas abaixo:

$$
B P I=\frac{R O I-\text { ROIref }}{\text { ROIref }}
$$

Onde ROI e ROIref são as médias de contagens por píxel encontradas pelas ROIs de interesse e ROI de referência, respectivamente.

$$
I A=2 X \frac{R O I i-R O I C}{R O I i+R O I C}
$$

Onde ROIi e ROIc são as médias de contagens por pixel encontradas pelas ROIs de interesse ipsilaterais e contralaterais ao lado de predomínio dos sintomas motores, respectivamente.

$$
\frac{P U}{C A}=\frac{(P U-R O I r e f)}{(C A-\text { ROIref })}
$$

Onde PU e CA são as médias de contagens por píxel encontradas pelas ROIs de interesse nos putâmens e núcleos caudados, respectivamente. A ROIref é a média de contagens por pixel no lobo occipital. 


\subsubsection{Avaliação semiquantitativa baseada em template padrão (Two Box)}

O método de quantificação Two Box, proposto por Tossici-Bolt e colaboradores (TOSSICI-BOLT et al., 2006), é baseado na utilização de um template de ROIs padronizadas na coleta de parâmetros de quantificação em imagens bidimensionais de SPECT do corpo estriado. O desenvolvimento de protocolos de quantificação aplicados a medicina nuclear como o Two Box visa minimizar a subjetividade do profissional especialista na avaliação quantitativa, com a finalidade de aumentar a acurácia do estudo, ao mesmo tempo que simplifica este processo. A utilização de ROIs com amplas dimensões que possam registrar as contagens em uma região de interesse e as contagens ao seu redor é uma forma de garantir que a máxima densidade de contagens originadas de uma região específica possa ser integralmente registrada e posteriormente corrigida. Nesta abordagem o avaliador é capaz de corrigir a informação de contagens médias por pixel nas estruturas de interesse para o efeito de volume parcial (PVE), que pode subestimar o número de contagens observadas em pequenos volumes, gerando um viés na quantificação.

O software QuantiSPECT (GE Healthcare), indisponível no HCRP, oferece o aplicativo Two Box Method, dedicado a quantificação de imagens de cintilografia do corpo estriado por meio de templates de ROIs padronizadas. Para este estudo, plataformas abertas foram utilizadas com a mesma finalidade. As etapas deste processo são esclarecidas a seguir.

As principais etapas deste método incluem a construção de uma imagem bidimensional (2D) a partir da somatória das imagens transversais que contenham contagens do corpo estriado (I); a construção da ROI de referência (II); o posicionamento das ROIs trapezoidais pré-construídas sobre os corpos estriados na imagem 2D (III); e o cálculo do parâmetro de semiquantificação Specific Binding Ratio (SBR) (IV), um análogo do potencial de ligação, definido como uma razão entre as contagens na área de interesse e a de referência (TOSSICI-BOLT et al., 2006). 
I. Uma imagem em 2D foi construída a partir da soma de 20 imagens axiais sequenciais, selecionadas por um especialista. Nesta etapa foi aplicado o software ImageJ (National Institutes of Health Bethesda, Maryland, USA) (SCHNEIDER; RASBAND; ELICEIRI, 2012), específico para processamento e análise de imagens. O procedimento foi realizado para todos os SPECTs com [ $\left.{ }^{99 \mathrm{~m}} \mathrm{Tc}\right]-$ TRODAT-1 adquiridos.

II. Construção da ROI de referência (figura 8) no software Multi Image Analysis GUI - MANGO Versão 3.2.7 (Research Imaging Institute, University Texas Health Science Center at San Antonio - UTHSCSA). A imagem 2D foi carregada no software e suavizada através de filtro de médias 3x3 aplicado 20 vezes com a finalidade de reduzir as flutuações estatísticas do sinal nesta região de referência. Os limites da ROI de referência foram estabelecidos utilizando uma limiarização (threshold) de cerca de 50\% do sinal do máximo valor de contagens registrado na área de captação não específica (não estriatal). A seguir o limite da ROI de referência foi deslocado (aproximadamente $20 \mathrm{~mm}$ ou 6 pixels) de modo a excluir o couro cabeludo, que gera significativo efeito de volume parcial. O principal motivo da escolha da região de referência incorporando todo o cérebro (com a exclusão da região estriatal) se deve a grande heterogeneidade de captação no ROI estriatal e nas várias subregiões na matéria cinzenta entre sujeitos. Esta escolha reduz a variabilidade e melhora a contagem estatística (TOSSICI-BOLT et al., 2006). 


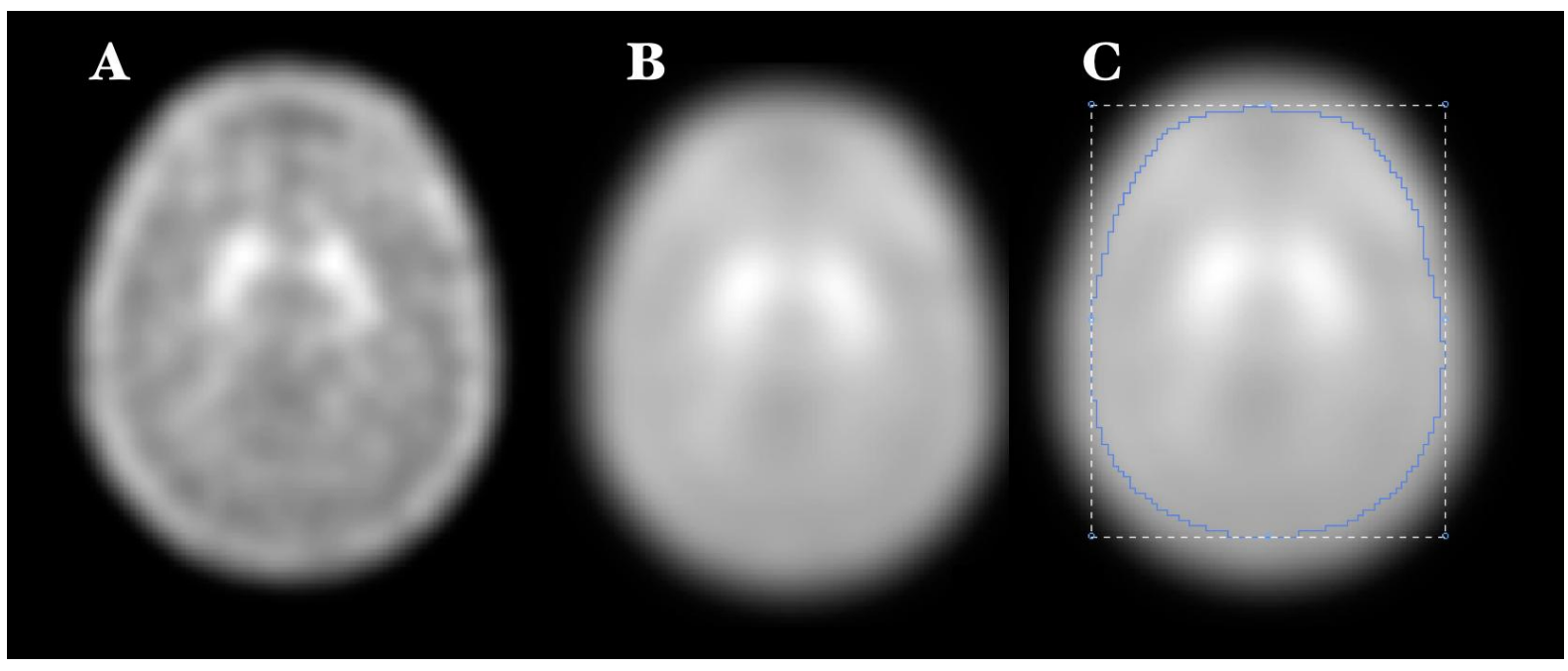

Figura 8: Imagem somada 2D (A) foi suavizada através de filtro $3 \times 3$ (B), e limite externo do ROI de referência foi construído a partir de um threshold de sinal e após exclusão do couro cabeludo (C).

III. Posicionamento das duas ROIs trapezoidais de dimensões padronizadas (aproximadamente 44,8 x 38,4 $\mathrm{mm}$ ) na região estriatal, previamente construídas em software Multi Image Analysis GUI - MANGO Versão 3.2.7 (Research Imaging Institute, University Texas Health Science Center at San Antonio - UTHSCSA). Seguiu-se a inserção do limite externo da ROI de referência de modo a excluir o couro cabeludo. A definição final da ROI de referência se deu a partir da exclusão das contagens provenientes da ROI estriatal e do couro cabeludo (figura 9).

IV. Obtenção dos valores de contagem média das ROIs estriatais direita e esquerda e da ROI de referência (figura 9). Estes valores foram armazenados em planilha eletrônica no formato *.xls (Microsoft Excel) para cálculo do SBR. 


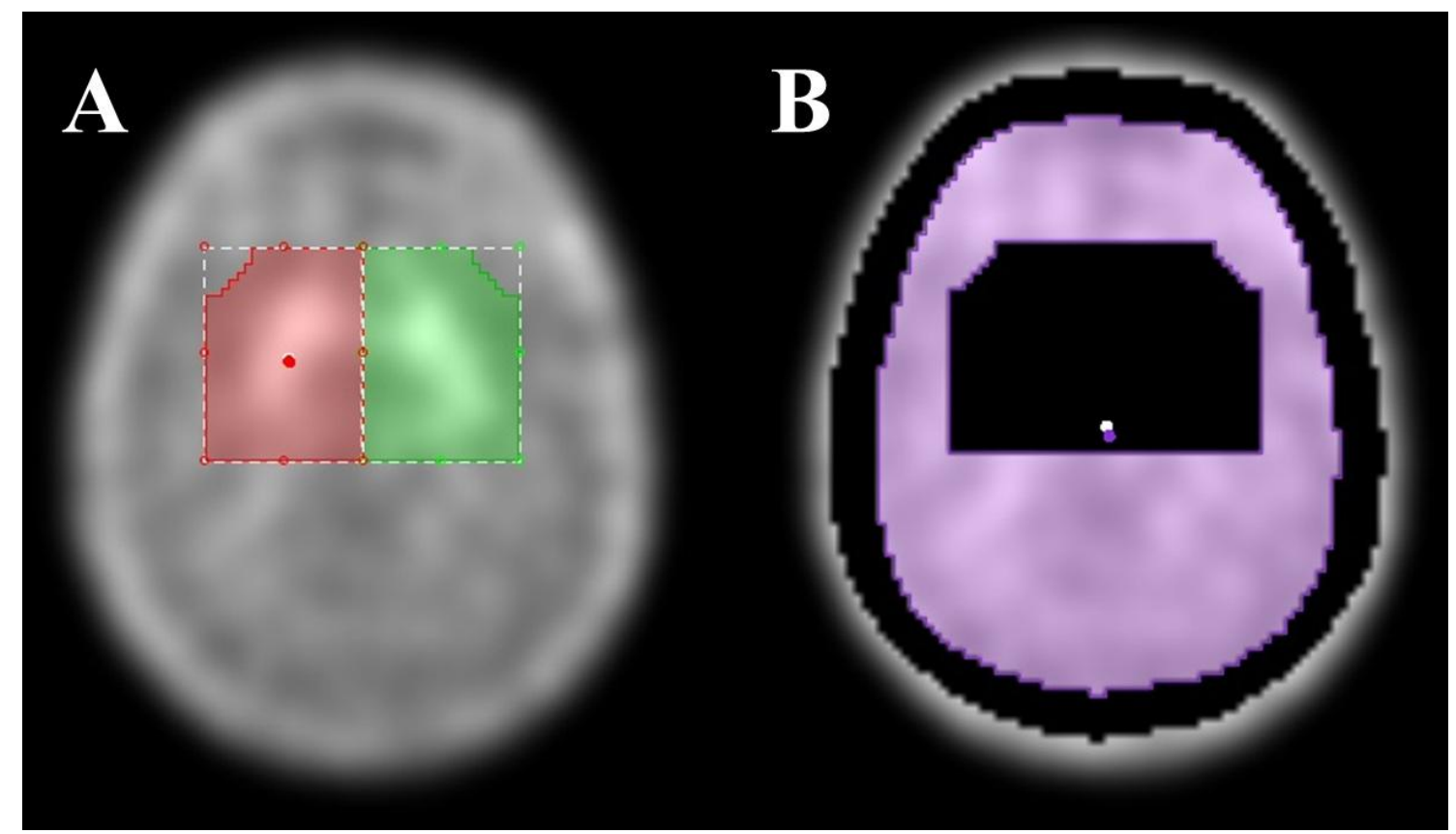

Figura 9: Posicionamento das ROIs estriatais direita e esquerda (A) e estabelecimento da ROI de referência (B) no método Two Box (fonte: arquivo do autor).

O SBR foi quantificado a partir da seguinte equação:

$$
S B R=\frac{\operatorname{Cesp}}{\text { Cref }}
$$

O SBR pode ser associado ao BPI através de um fator de ponderação entre os volumes $\mathrm{V}_{\mathrm{ROI}}$ e $\mathrm{V}_{\mathrm{ST}}$, conforme descrito na equação:

$$
S B R=B P I \times \frac{V R O i}{V S T}
$$

Onde Cesp corresponde a concentração de contagens exclusivamente originada do 
corpo estriado, Cref corresponde a concentração de contagens do ROI de referência; $V_{S T}$. é o volume de cada corpo estriado (volume padrão de $11.2 \mathrm{ml}$ foi assumido no algorítmo) (TOSSICI-BOLT et al., 2006); e $V_{R O I}$ é o volume da ROI de interesse utilizada sobre o corpo estriado, a qual equivale ao produto entre área da ROI geométrica e o número de imagens transversais utilizadas na construção da imagem bidimensional.

O método Two Box não permite individualizar os putâmens e os núcleos caudados para quantificação, deste modo foram calculados os valores de SBR apenas para os corpos estriados.

\subsubsection{Avaliação semiquantitativa automática - RM e RM-corrigida}

As modalidades SPECT e RM permitem a criação de templates genéricos, que podem ser utilizados para quantificação (BADIAVAS et al., 2011). Templates genéricos são preferíveis em relação ao paciente-específico principalmente pela aplicabilidade e praticidade. Um algoritmo de registro de imagens e quantificação automatizado e especialmente desenvolvido para este fim pode ter grande utilidade na rotina prática diária do especialista em medicina nuclear (BADIAVAS et al., 2011).

No presente estudo, um método totalmente automatizado foi aplicado na semiquantificação das imagens de SPECT com [ ${ }^{99 \mathrm{~m}}$ Tc]-TRODAT-1 utilizando a informação estrutural da RM. Este método foi originalmente desenvolvido por Lee e colaboradores, os quais criaram um algoritmo de registro de imagens de SPECT e RM baseado em intensidades de imagem para melhorar a precisão (LEE et al., 2007).

As principais etapas envolvidas neste processo correspondem a obtenção de um template padronizado de RM a partir do Atlases do Montreal Neurological Institute (MNI) (I); corregistro das imagens de SPECT com o template de RM (II); extração dos valores da média de contagens por voxel, registrados por cada VOI estriatal oferecida pelo atlas Automated 
Anatomical Labeling - AAL e quantificação automatizada dos valores de BPI (III); correção para o efeito de volume parcial por cada VOI analisada (IV). A seguir são descritas as etapas em maiores detalhes:

I. A etapa inicial consistiu na busca de um template padronizado de RM e a obtenção das áreas de interesse delineadas a partir desse template. O template selecionado estabelecido nas coordenadas MNI foi o MNI305 (figura 10), construído com base na média de 305 exames de ressonância magnética normais (BRETT et al., 2002). O mesmo foi adotado como padrão internacional pelo International Consortium of Brain Mapping (ICBM) (BRETT et al., 2002). Conforme já citado anteriormente, alguns autores recomendam o uso de um template genérico ao invés de paciente-específico, principalmente pela aplicabilidade e praticidade (BADIAVAS et al., 2011). Há ainda a problemática do custo envolvido neste processo, tanto no âmbito de pesquisa quanto em termos de saúde populacional, visto que o exame de RM é oneroso.

II. As imagens de SPECT foram corregistradas por um algoritmo de informação mútua normalizada com o template MNI305. Para esta finalidade foi utilizada a toolbox para Matlab R2013.b (The MathWorks Inc., Natick, MA, USA), Statistical Parametric Mapping (SPM8) (Wellcome Department of Cognitive Neurology, London, UK), que permite que a eficiência de corregistro seja avaliada de forma qualitativa. 

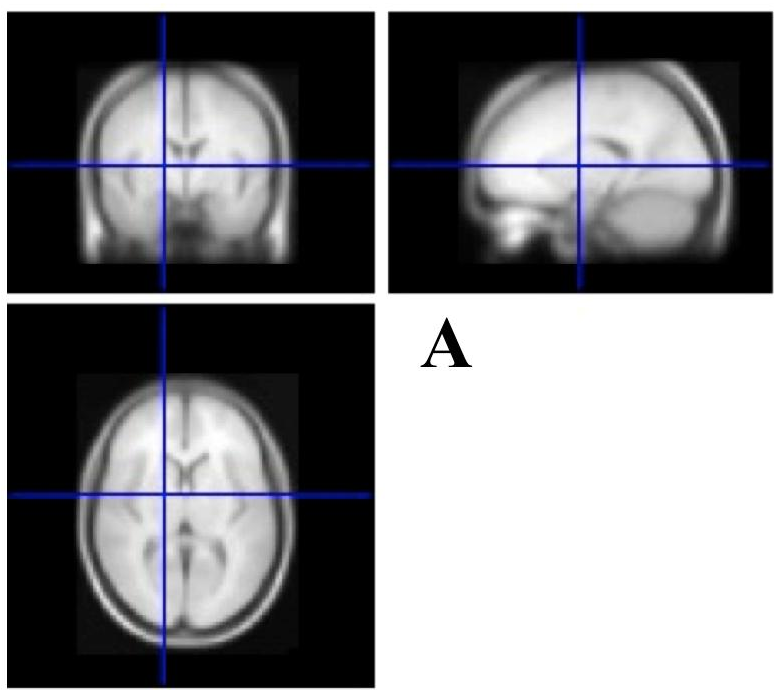

A
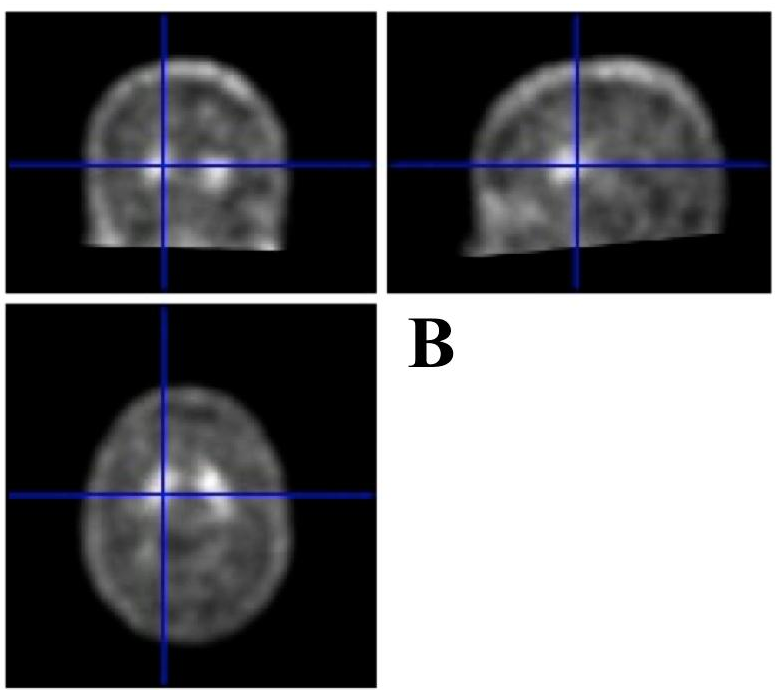

B

Figura 10: Corregistro entre o template MNI305 do Atlases do Montreal Neurological Institute (A) e o SPECT com [ $\left.{ }^{99 \mathrm{~m}} \mathrm{Tc}\right]$-TRODAT-1 de um controle saudável (B).

III. A extração dos dados (figura 11) foi realizada através da toolbox para SPM, MarsBar (MARSeille Boîte À Région d'Intérêt) (BRETT et al., 2002). Os valores de contagens por voxel de cada estrutura foram armazenados na forma de matriz e utilizados para calcular os valores de BPI. 

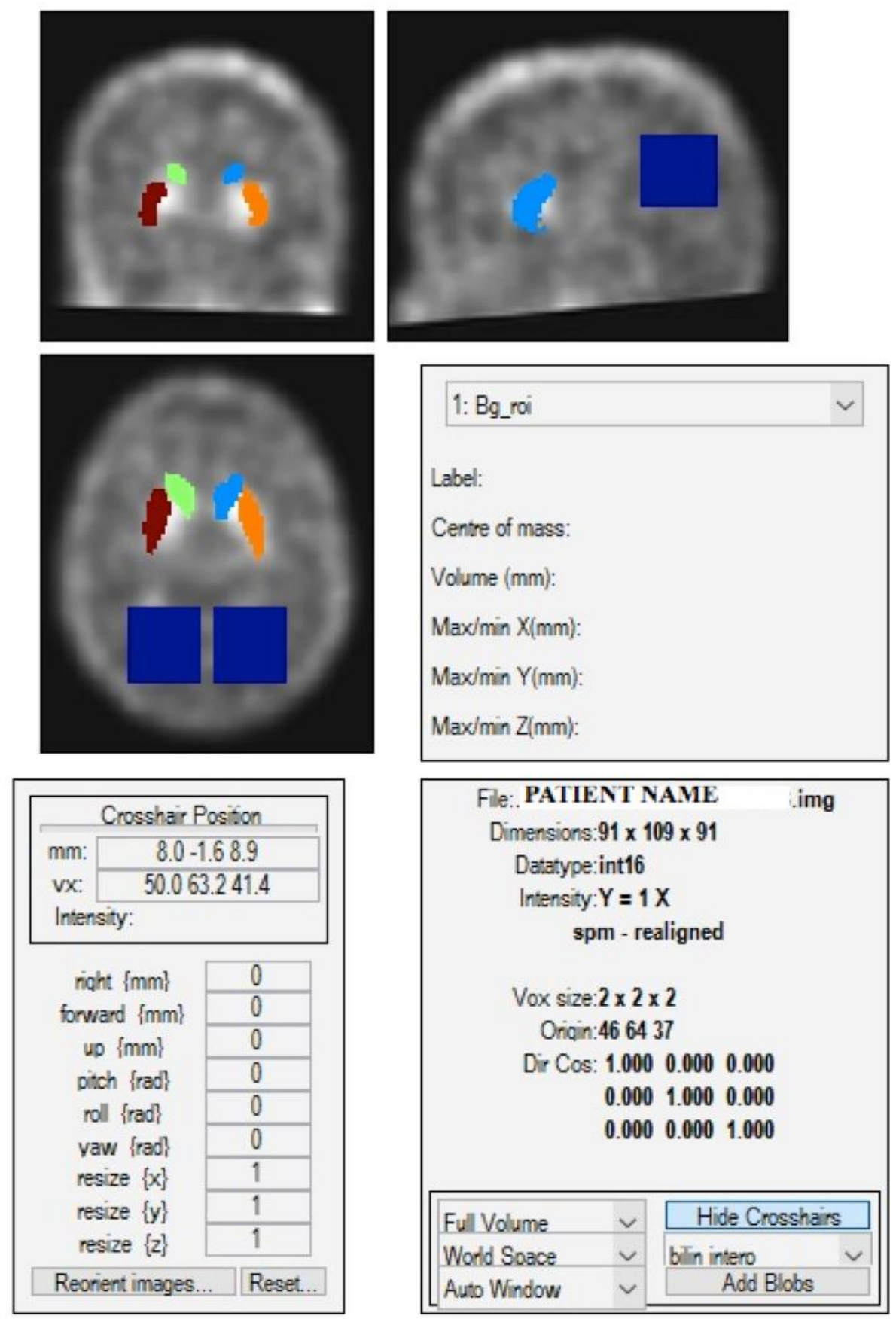

Figura 11: Etapa de extração dos parâmetros de quantificação das imagens de SPECT com [ $\left.{ }^{99 \mathrm{~m}} \mathrm{Tc}\right]-$ TRODAT-1 utilizando as VOIs baseadas em template padronizado de RM (MNI305). 
IV. A correção de volume parcial sobre os dados extraídos de cada estrutura foi realizada por meio de um método de transferência de matriz geométrica (GTM, Geometric Tranfer Matrix), no qual é possível estimar a contribuição das contagens de cada compartimento vizinho sobre o volume de interesse a ser analisado.

Para RM e RM-corrigida foi calculado o BPI dos corpos estriados e individualmente dos núcleos caudados e putâmens.

A figura 12 mostra um fluxograma das avaliações semiquantitativas realizadas neste estudo e as principais etapas envolvidas em cada processo. 


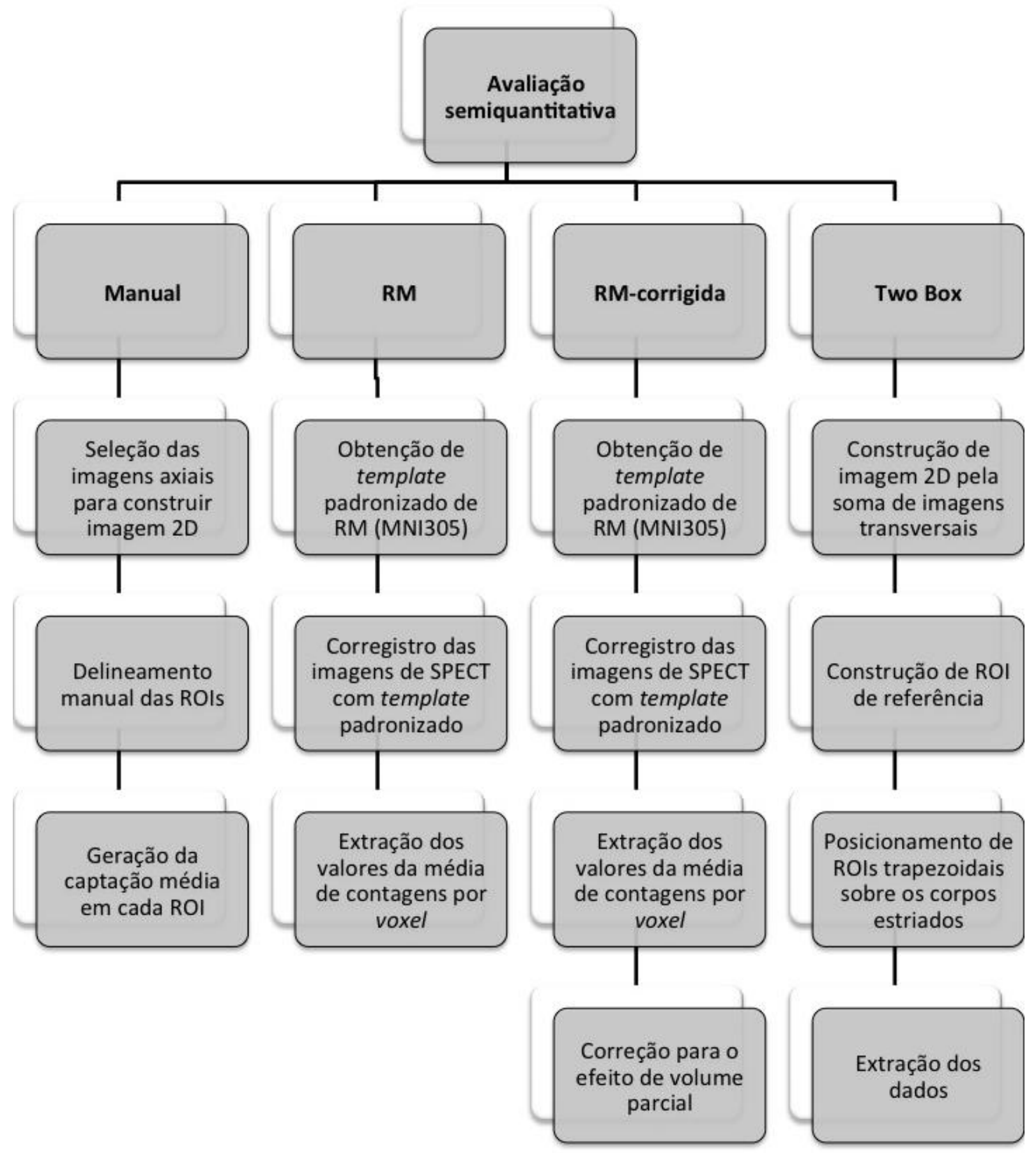

Figura 12: Fluxograma com as principais etapas realizadas na avaliação semiquantitativa. 


\subsubsection{Análise estatística}

A análise estatística foi dividida em etapas, de tal modo a cumprir os objetivos e responder às perguntas propostas neste estudo.

\subsubsection{Densidade de DAT no grupo controle saudável}

Foi realizada uma comparação dos índices semiquantitativos entre grupos, por sexo, idade (por faixa etária) e classe social. Foram utilizados métodos não-paramétricos de MannWhitney e Kruskal-Wallis para avaliação do BPI das estruturas, devido a presença de amostras não normais, testadas pelo Shapiro-Wilk test. Os demais índices (PU/CA e IA), que seguiam uma distribuição normal, foram testados por test-t para grupos independentes ou ANOVA. Uma correlação linear foi realizada entre BPI e a idade. O software estatístico aplicado foi o SPSS v17.0 (IBM Corporation, Armonk, NY, USA). Os índices utilizados nesta correlação foram obtidos pela avaliação manual do primeiro observador (A1)

\subsubsection{Análise qualitativa do SPECT com $\left[{ }^{99 \mathrm{~m}} \mathrm{Tc}\right]-\mathrm{TRODAT}-1$}

Uma tabela $2 \times 2$ foi utilizada para determinar a sensibilidade, especificidade, valores preditivos e acurácia das avaliações qualitativas para o diagnóstico de Parkinson. Dentre os portadores de DP foi realizada uma correlação de Spearman entre a avaliação qualitativa, dividida em categorias, e os parâmetros: tempo de duração da doença, UPDRS, HYS e idade de aparecimento dos sintomas. A concordância intraobservador e interobservadores foi aferida pelo coeficiente kappa ( $0 \leq \kappa \leq 1$ ) e kappa ponderado. O coeficiente kappa e a correlação de Spearman foram realizados pelo software estatístico SPSS v17.0 (IBM Corporation, Armonk, NY, USA). 


\subsubsection{Análise e comparação dos métodos semiquantitativos}

\subsection{Comparação entre médias dos grupos DP e controle}

Para a comparação entre as médias dos grupos (DP e controle) foram ajustados modelos de regressão linear simples e múltiplos. Nos modelos múltiplos foram utilizadas as variáveis sexo, idade e escolaridade como covariáveis. O software utilizado foi o SAS 9.3. Esta análise foi realizada para cada índice avaliado pelos quatro métodos de semiquantificação empregados no estudo (manual, RM, RM-corrigida e Two Box). Foi considerado um intervalo de confiança de $95 \%$ e um valor- $p<0,05$ como significante.

Para fins de comparação, foi definido de forma arbitrária, que o corpo estriado direito do grupo saudável seria comparado ao corpo estriado contralateral ao lado de predomínio dos sintomas motores no grupo com DP. Por sua vez, o corpo estriado esquerdo do grupo controle foi comparado ao corpo estriado ipsilateral ao lado de predomínio dos sintomas no grupo com DP.

\subsection{Definição de limiar de normalidade dos índices}

Curvas ROC foram geradas através do software $\mathrm{R}$ version 3.3.3. O limiar de normalidade (threshold) foi estabelecido após definição de melhor relação entre sensibilidade e especificidade dentre os pontos gerados pela curva ROC. O racional da definição do limiar foi o de evitar falsos positivos, de modo a escolher aquele valor abaixo do qual todos ou a maioria dos pacientes fossem doentes, sem que houvesse uma perda muito grande de casos de DP pela sua não identificação.

\subsection{Análise de confiabilidade}

A confiabilidade dos métodos de quantificação foi avaliada pelo coeficiente de correlação intra-classe (ICC, do inglês Intraclass Correlation Coeficient). A correlação 
aumenta quanto mais próximo o ICC for de 1 , sendo classificada como pobre $(<0,4)$, moderada $(0,4-0,75)$ e excelente $(>0,75)$ (FLEISS; LEVIN; PAIK, 2013). O software utilizado foi o SAS 9.3. Foi realizada uma análise de concordância interobservador e intraobservador para cada método, individualmente para cada índice quantitativo obtido.

\subsection{Correlação com parâmetros clínicos}

Os potenciais de ligação pelos diferentes métodos foram correlacionados com os parâmetros: tempo de duração da doença, UPDRS e HYS. Foi realizada uma correlação não paramétrica de Spearman, que varia entre -1 e +1 , sendo +1 , uma correlação perfeita positiva entre as duas variáveis; -1, uma correlação negativa perfeita entre as duas variáveis; e 0 , as duas variáveis não dependem linearmente uma da outra. O software estatístico aplicado foi o SPSS v17.0 (IBM Corporation, Armonk, NY, USA).

\subsubsection{Comparação da densidade de DAT nos grupos com e sem discinesia}

De forma complementar, a diferença das médias do grupo com e sem discinesia foi avaliada a partir de um modelo de regressão linear simples ajustado. As seguintes variáveis foram analisadas: idade (anos), escolaridade, tempo de duração da doença (anos), idade de início dos sintomas (anos), UPDRS, dose diária de levodopa (mg), número de tomadas ao dia de levodopa, duração do efeito da levodopa (horas); valor do potencial de ligação no corpo estriado, caudado e putâmen. Os valores de potencial de ligação utilizados nesta correlação foram obtidos pela avaliação manual do primeiro observador (A1). Foi considerado um intervalo de confiança de $95 \%$ e um valor-p $<0,05$ como significante. O software utilizado foi o SAS 9.3. 


\section{Resultados}

\subsection{Dados demográficos}

O grupo de voluntários saudáveis foi composto por 23 indivíduos ( 9 homens; 14 mulheres; idade média $59 \pm 11$ anos). O grupo com DP foi composto por 44 pacientes com

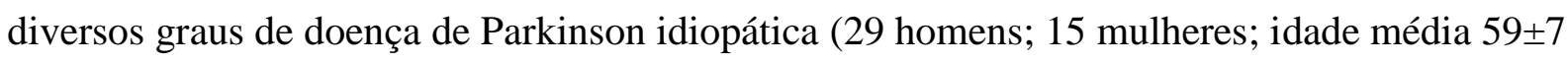
anos), com duração média dos sintomas de $10 \pm 6$ anos. Houve um claro predomínio de homens na amostra de portadores de DP, fato esperado devido a maior prevalência da doença no sexo masculino (MARRAS; TANNER, 2012; PICILLO et al., 2017). A maioria dos pacientes se consideravam caucasianos (100\% dos controles saudáveis e 90,09\% dos portadores de DP) e apresentavam dominância manual à direita (100\% dos controles normais e $86,3 \%$ dos grupo com DP). Apenas 1 paciente com DP era tabagista atual. A tabela 9 sumariza as características demográficas dos pacientes do grupo controle saudável e dos portadores de DP.

A avaliação socioeconômica dos grupos foi realizada através do "Critério Brasil 2015 e atualização da distribuição de classes para 2016" (PILLI et al., 2016). Para a análise, foram definidos como classe $\mathrm{B}$ os indivíduos pertencentes a B1 e B2, e como classe C, aqueles pertencentes a $\mathrm{C} 1$ e $\mathrm{C} 2$. O grupo controle foi composto por pacientes das classes socioeconômicas A, B e C (22\%, 43\% e 35\% dos casos, respectivamente). O grupo com DP foi composto por indivíduos das classes socioeconômicas A, B, C e D (5\%, 39\% 55\% e 2\%). A maioria dos pacientes controles e com DP eram pertencentes das classes B e C. A variável escolaridade, que corresponde a um dos tópicos avaliados pelo Critério Brasil, foi considerada também como variável independente na análise (BRUCKI et al., 2003). 
Tabela 9: Características demográficas dos participantes do estudo.

\begin{tabular}{|c|c|c|c|}
\hline & & $\begin{array}{l}\text { Grupo controle } \\
\qquad(n=23)\end{array}$ & $\begin{array}{l}\text { Grupo DP } \\
(n=44)\end{array}$ \\
\hline \multirow[t]{2}{*}{ Sexo } & Homens (n) & 9 & 29 \\
\hline & Mulheres (n) & 14 & 15 \\
\hline Idade & Média \pm desvio padrão & $59 \pm 11$ anos & $59 \pm 7$ anos \\
\hline \multirow[t]{3}{*}{ Raça } & Caucasiano (n) & 23 & 40 \\
\hline & Pardo (n) & 0 & 2 \\
\hline & Afrodescendente (n) & 0 & 2 \\
\hline \multirow{6}{*}{$\begin{array}{l}\text { Classe } \\
\text { socioeconômica } \\
\text { (Critério Brasil) }\end{array}$} & $A(n)$ & 5 & 2 \\
\hline & B1 (n) & 3 & 1 \\
\hline & $\mathrm{B} 2(\mathrm{n})$ & 7 & 16 \\
\hline & C1 (n) & 3 & 13 \\
\hline & $\mathrm{C} 2(\mathrm{n})$ & 5 & 11 \\
\hline & $\mathrm{D}(\mathrm{n})$ & 0 & 1 \\
\hline Escolaridade & Média \pm desvio padrão & $9,09 \pm 6,99$ anos & $5,98 \pm 4,11$ anos \\
\hline \multirow[t]{3}{*}{ Dominância manual } & Direita (n) & 23 & 38 \\
\hline & Esquerda (n) & 0 & 5 \\
\hline & Ambidestro (n) & 0 & 1 \\
\hline \multirow[t]{2}{*}{ Tabagismo } & $\operatorname{Sim}(n)$ & 0 & 1 \\
\hline & Não (n) & 23 & 43 \\
\hline
\end{tabular}

Dentre os pacientes com DP, 11 estavam em monoterapia com carbidopa-levodopa, 1 estava em uso de agonista dopaminérgico associado a amantadina (sem uso de levodopa), 
enquanto 32 estavam em uso de terapia combinada). Todos os pacientes responderam ao tratamento com benefícios motores. Nenhum dos pacientes utilizava medicações que pudessem interferir na captação estriatal de [ $\left.{ }^{99 \mathrm{~m}} \mathrm{Tc}\right]-T R O D A T-1$ (DJANG et al., 2012; FERNAGUT et al., 2010). Todos os portadores de DP foram classificados de acordo com a escala de Hoehn and Yahr (HYS), que varia entre I a IV (média de 2,16 $\pm 0,65$; intervalo 1-4). Foi aplicada a parte 3 da escala motora UPDRS (Unified Parkinson's Disease Rating Scale), com média de 29,74 $\pm 17,79$; intervalo de 9-74 (GOETZ et al., 2008; HUGHES et al., 1992, 2002). As características dos pacientes com referência a DP estão descritas na tabela 10.

Tabela 10: Características dos pacientes com doença de Parkinson.

\begin{tabular}{lcc}
\hline & & Grupo DP $(\mathbf{n}=\mathbf{4 4})$ \\
\hline Idade & Média \pm desvio padrão & $59 \pm 7$ anos \\
Idade de início dos sintomas & Média \pm desvio padrão & $50,47 \pm 10,2$ anos \\
Tempo de doença & Média \pm desvio padrão & $9,55 \pm 5,57$ anos \\
Lateralização dos sintomas & Direita (n) & 17 \\
UPDRS & Esquerda (n) & 27 \\
HYS & Média \pm desvio padrão & $29,74 \pm 17,79$ \\
& I & 5 \\
II & 28 \\
III & IV & 10 \\
\hline
\end{tabular}


Dentre os 44 pacientes com DP selecionados para este estudo, $21(47,7 \%)$ apresentavam discinesia, enquanto 23 não mostraram qualquer movimento involuntário anormal. O predomínio dos sintomas motores foi lateralizado para a direita em $17(38,6 \%)$ e à esquerda em 27 pacientes $(61,4 \%)$.

\subsection{Densidade de DAT no grupo controle saudável}

O grupo controle foi composto por 23 indivíduos, sendo 9 homens, 14 mulheres, idade média $59 \pm 11$ anos, escolaridade média de $9 \pm 7$ anos, 5 da classe social A, 10 classe social B, e 8 da classe social $\mathrm{C}$, caucasianos, não tabagistas, destros. Para a avaliação dos índices semiquantitativos foi considerada a avaliação A1 do método semiquantitativo manual.

No grupo dos controles saudáveis foi encontrado um valor médio de potencial de ligação do corpo estriado direito de $1,21 \pm 0,25(0,74-1,77)$, e do corpo estriado esquerdo de $1,18 \pm 0,22(0,78$ - 1,68). O potencial de ligação obtido foi em média cerca de $18 \%$ maior nos núcleos caudados em relação aos putâmens, com média de PU/CA entre 0,85 a 0,87. Considerando todas as estruturas avaliadas, o valor mínimo de potencial de ligação na amostra foi de 0,71 no putâmen e o máximo de 1,95 no caudado. $O$ índice de assimetria observado, tanto para o corpo estriado como para as sub regiões, foi variável, entre $-0,19$ a 0,19 para ST, com máximo valor negativo de $-0,38$ para PU, e máximo valor positivo de 0,27 para CA. Valores negativos de IA mostram maior BPI na estrutura à direita, enquanto valores positivos de IA indicam maior BPI à esquerda. Os resultados evidenciaram não haver predomínio preferencial de densidade de DAT em algum lado (tabela 11). 
Tabela 11: Índices semiquantitativos encontrados para o grupo controle saudável considerando a totalidade da amostra $(\mathrm{n}=23)$.

\begin{tabular}{lccccccc}
\hline Variável & Média & SD & Mínimo & Q1 & Mediana & Q3 & Máximo \\
\hline ST (i) & 1,18 & 0,22 & 0,78 & 1,05 & 1,12 & 1,27 & 1,68 \\
ST (c) & 1,21 & 0,25 & 0,74 & 1,01 & 1,22 & 1,32 & 1,77 \\
PU (i) & 1,09 & 0,23 & 0,71 & 0,90 & 1,07 & 1,32 & 1,55 \\
PU (c) & 1,14 & 0,28 & 0,73 & 0,97 & 1,08 & 1,26 & 1,91 \\
CA (i) & 1,31 & 0,27 & 0,88 & 1,13 & 1,25 & 1,44 & 1,84 \\
CA (c) & 1,33 & 0,29 & 0,80 & 1,12 & 1,29 & 1,51 & 1,95 \\
PU/CA (i) & 0,85 & 0,18 & 0,57 & 0,73 & 0,85 & 0,96 & 1,33 \\
PU/CA (c) & 0,87 & 0,17 & 0,65 & 0,75 & 0,83 & 0,91 & 1,36 \\
IA & $-0,01$ & 0,08 & $-0,19$ & $-0,07$ & $-0,04$ & 0,05 & 0,19 \\
IA (PU) & $-0,03$ & 0,12 & $-0,38$ & $-0,11$ & $-0,04$ & 0,03 & 0,22 \\
IA (CA) & $-0,01$ & 0,14 & $-0,30$ & $-0,12$ & $-0,03$ & 0,10 & 0,27 \\
\hline Legend: & & & & & & & \\
\hline
\end{tabular}

Legenda: $\mathrm{ST}$ = estriado; $\mathrm{PU}=$ putâmen; $\mathrm{CA}$ = caudado; $(\mathrm{i})=$ ipsilateral; $(\mathrm{c})=$ contralateral; $\mathrm{IA}$ = índice de assimetria; $\mathrm{PU} / \mathrm{CA}$ = razão entre putâmen e caudado; $\mathrm{Q} 1$ = quartil 1; Q3 = quartil 3; SD = desvio padrão

A tabela 12 sumariza a média e o desvio padrão dos BPI obtidos pelo método tradicional manual na totalidade dos casos controles saudáveis, estratificados pela faixa etária. 
Tabela 12: Semiquantificação manual dos controles saudáveis por faixa etária

\section{Faixa etária}

\begin{tabular}{|c|c|c|c|c|c|}
\hline Variável & $\begin{array}{l}40 \text { a } 49 \text { anos } \\
(n=5)\end{array}$ & $\begin{array}{l}50 \text { a } 59 \text { anos } \\
(n=8)\end{array}$ & $\begin{array}{l}60 \text { a } 69 \text { anos } \\
(n=6)\end{array}$ & $\begin{array}{l}70 \text { a } 79 \text { anos } \\
(n=4)\end{array}$ & valor-p \\
\hline ST (i) & $\begin{array}{l}1,24 \pm 0,18 \\
(1,12-1,56)\end{array}$ & $\begin{array}{l}1,15 \pm 0,20 \\
(0,94-1,61)\end{array}$ & $\begin{array}{l}1,06 \pm 0,21 \\
(0,78-1,41)\end{array}$ & $\begin{array}{l}1,08 \pm 0,65 \\
(1,12-1,68)\end{array}$ & 0,15 \\
\hline ST (c) & $\begin{array}{l}1,32 \pm 0,20 \\
(1,14-1,66)\end{array}$ & $\begin{array}{l}1,15 \pm 0,19 \\
(0,92-1,48)\end{array}$ & $\begin{array}{l}1,08 \pm 0,23 \\
(0,74-1,42)\end{array}$ & $\begin{array}{l}1,09 \pm 0,68 \\
(1,01-1,77)\end{array}$ & 0,19 \\
\hline PU (i) & $\begin{array}{l}1,19 \pm 0,23 \\
(0,90-1,46)\end{array}$ & $\begin{array}{l}1,05 \pm 0,22 \\
(0,81-1,42)\end{array}$ & $\begin{array}{l}0,95 \pm 0,19 \\
(0,71-1,18)\end{array}$ & $\begin{array}{l}1,02 \pm 0,60 \\
(1,08-1,55)\end{array}$ & 0,12 \\
\hline PU (c) & $\begin{array}{l}1,19 \pm 0,22 \\
(1,01-1,56)\end{array}$ & $\begin{array}{l}1,06 \pm 0,26 \\
(0,73-1,51)\end{array}$ & $\begin{array}{l}1,02 \pm 0,18 \\
(0,73-1,26)\end{array}$ & $\begin{array}{l}1,13 \pm 0,71 \\
(1,08-1,91)\end{array}$ & 0,11 \\
\hline CA (i) & $\begin{array}{l}1,37 \pm 0,19 \\
(1,18-1,66)\end{array}$ & $\begin{array}{l}1,25 \pm 0,25 \\
(0,99-1,79)\end{array}$ & $\begin{array}{l}1,22 \pm 0,32 \\
(0,88-1,84)\end{array}$ & $\begin{array}{l}1,19 \pm 0,72 \\
(1,17-1,84)\end{array}$ & 0,22 \\
\hline CA (c) & $\begin{array}{l}1,55 \pm 0,23 \\
(1,35-1,95)\end{array}$ & $\begin{array}{l}1,26 \pm 0,19 \\
(1,11-1,61)\end{array}$ & $\begin{array}{l}1,20 \pm 0,31 \\
(0,80-1,70)\end{array}$ & $\begin{array}{l}1,12 \pm 0,71 \\
(0,97-1,73)\end{array}$ & 1,13 \\
\hline PU/CA (i) & $\begin{array}{l}0,87 \pm 0,19 \\
(0,62-1,15)\end{array}$ & $\begin{array}{l}0,86 \pm 0,23 \\
(0,60-1,33)\end{array}$ & $\begin{array}{r}0,80 \pm 0,20 \\
(0,57-1,05)\end{array}$ & $\begin{array}{l}0,69 \pm 0,39 \\
(0,80-0,96)\end{array}$ & 0,92 \\
\hline PUCA (c) & $\begin{array}{l}0,76 \pm 0,04 \\
(0,72-0,80)\end{array}$ & $\begin{array}{l}0,85 \pm 0,22 \\
(0,66-1,36)\end{array}$ & $\begin{array}{l}0,88 \pm 0,16 \\
(0,65-1,10)\end{array}$ & $\begin{array}{l}0,81 \pm 0,47 \\
(0,87-1,18)\end{array}$ & 0,20 \\
\hline IA & $\begin{array}{l}-0,06 \pm 0,03 \\
{[-0,11-(-0,02)]}\end{array}$ & $\begin{array}{l}-0,002 \pm 0,11 \\
(-0,19-0,19)\end{array}$ & $\begin{array}{l}-0,01 \pm 0,07 \\
(-0,13-0,06)\end{array}$ & $\begin{array}{r}0,007 \pm 0,09 \\
(-0,05-0,14)\end{array}$ & 0,62 \\
\hline IA (PU) & $\begin{array}{l}-0,002 \pm 0,09 \\
(-0,12-0,12)\end{array}$ & $\begin{array}{l}-0,003 \pm 0,10 \\
(-0,13-0,22)\end{array}$ & $\begin{array}{l}-0,07 \pm 0,16 \\
(-0,38-0,09)\end{array}$ & $\begin{array}{l}-0,08 \pm 0,10 \\
(-0,21-0,04)\end{array}$ & 0,51 \\
\hline IA (CA) & $\begin{array}{c}-0,12 \pm 0,11 \\
(-0,24-0,06)\end{array}$ & $\begin{array}{c}-0,01 \pm 0,16 \\
(-0,30-0,18)\end{array}$ & $\begin{array}{c}0,02 \pm 0,14 \\
(-0,12-0,24)\end{array}$ & $\begin{array}{c}0,07 \pm 0,13 \\
(-0,03-0,27)\end{array}$ & 0,24 \\
\hline
\end{tabular}

Legenda: $\mathrm{ST}=$ estriado; $\mathrm{PU}=$ putâmen; $\mathrm{CA}=$ caudado; $(\mathrm{i})=$ ipsilateral; $(\mathrm{c})=$ contralateral; $\mathrm{IA}=$ índice de assimetria; $\mathrm{PU} / \mathrm{CA}=$ razão entre putâmen e caudado 
Houve uma redução percentual de $8 \%$ e $13 \%$ na média dos corpos estriados (esquerdo e direito, respectivamente) entre a faixa etária de 40 a 49 anos e a faixa etária de 50 a 59 anos. Uma nova redução percentual de $8 \%$ e $6 \%$ foi observada entre a faixa etária de 50 a 59 anos e a de 60 a 69 anos, respectivamente Esta tendência não se manteve entre os grupos de 60 a 69 anos e 70 a 79 anos, em que foi observado um discreto aumento percentual (cerca de $1 \%$ ) naqueles com idade mais avançada. Considerando as últimas duas décadas (pacientes entre 60 a 79 anos), a queda percentual do potencial de ligação do estriado comparando-se a faixa etária de 50 a 59 anos foi de $7 \%$ e $6 \%$. Esta tendência de queda do potencial de ligação com o aumento da faixa etária não foi confirmada pela análise de correlação linear (tabela 13).

Tabela 13: Correlação de idade com os potenciais de ligação do estriados, caudados e putâmens no grupo controle saudável.

\begin{tabular}{lccccccc}
\hline \multicolumn{1}{l}{} & ST(i) & ST(c) & PU(i) & \multicolumn{1}{c}{ PU(c) } & \multicolumn{2}{c}{ CA(i) } & \multicolumn{1}{c}{ CA(c)) } \\
\hline $\begin{array}{l}\text { Coeficiente de } \\
\text { correlação (R) }\end{array}$ & -0.06 & $-0,17$ & $-0,03$ & 0,05 & $-0,1$ & -0.23 \\
valor-p & 0,77 & 0,42 & 0,85 & 0,79 & 0,64 & 0.27 \\
\hline
\end{tabular}

Legenda: $\mathrm{ST}=$ estriado; $\mathrm{PU}=$ putâmen; $\mathrm{CA}=$ caudado; $\mathrm{IA}=$ índice de assimetria; $\mathrm{PU} / \mathrm{CA}=$ razão do putâmepelo caudado; (i) = ipsilateral; (c) = contralateral

Os gráficos de dispersão para os potenciais de ligação do corpo estriado (figura 13) corroboram com a análise descritiva de discreta redução com o aumento da idade, porém sem significância estatística nesta amostra. 

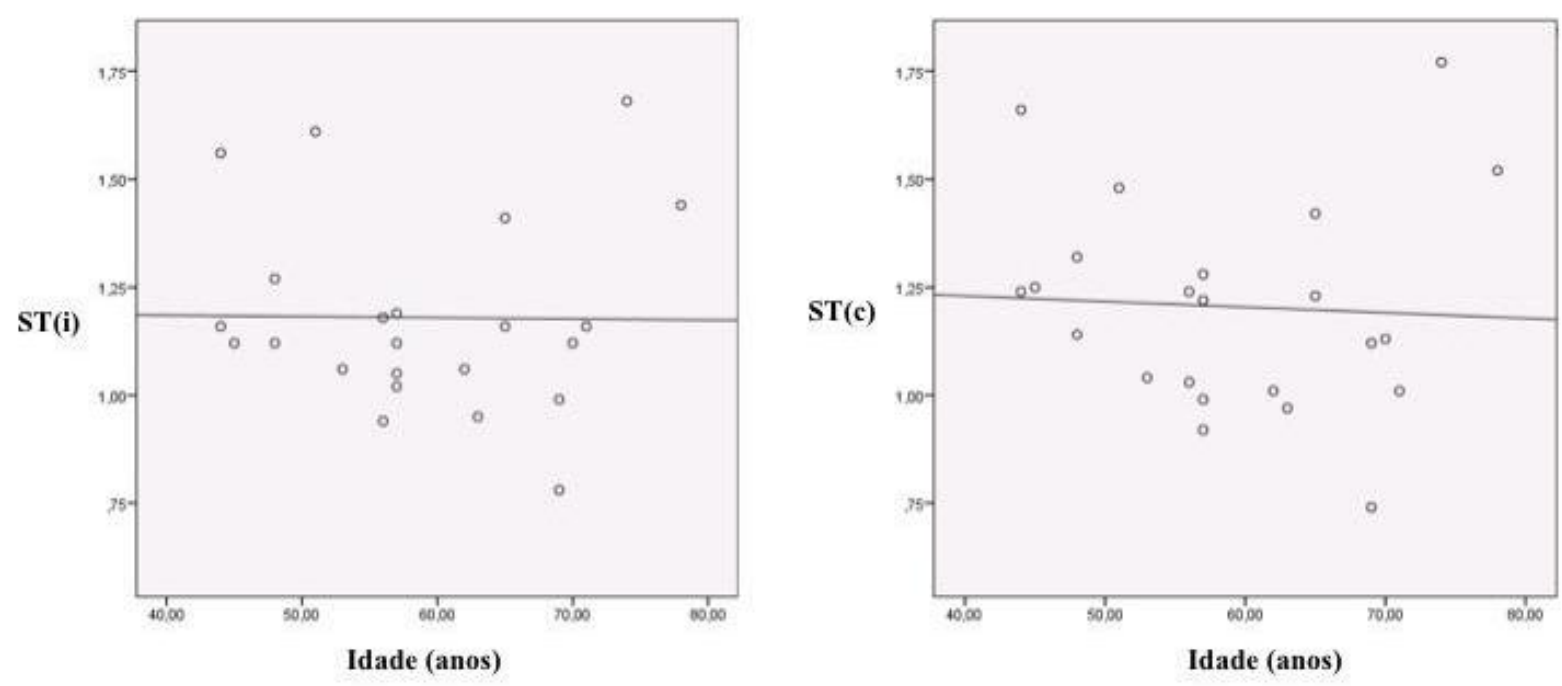

Figura 13: Gráficos de dispersão dos dados de potencial de ligação do grupo controle saudável, sendo ST(i), correspondente ao BPI do estriado esquerdo, e ST(c), BPI correspondente ao estriado direito.

A análise por gênero e classe socioeconômica, calculada a partir do "Critério Brasil 2015 e atualização da distribuição de classes para 2016" (PILLI et al., 2016), não encontrou diferenças entre os subgrupos (tabela 14). 
Tabela 14: Semiquantificação manual dos controles saudáveis por gênero e classe socioeconômica.

\begin{tabular}{|c|c|c|c|c|c|c|c|}
\hline & \multicolumn{2}{|c|}{ Gênero } & \multicolumn{5}{|c|}{ Classe socioeconômica } \\
\hline & $\begin{array}{l}\text { Homens } \\
(n=9)\end{array}$ & $\begin{array}{l}\text { Mulheres } \\
(n=14)\end{array}$ & valor-p & $\begin{array}{l}A \\
(n=5)\end{array}$ & $\begin{array}{l}B \\
(n=10)\end{array}$ & $\begin{array}{l}C \\
(n=8)\end{array}$ & valor-p \\
\hline ST (i) & $\begin{array}{l}1,22 \pm 0,24 \\
(0,94-1,68)\end{array}$ & $\begin{array}{l}1,16 \pm 0,21 \\
(0,78-1,61)\end{array}$ & 0,77 & $\begin{array}{l}1,17 \pm 0,25 \\
(0,99-1,61)\end{array}$ & $\begin{array}{l}1,10 \pm 0,21 \\
(0,78-1,56)\end{array}$ & $\begin{array}{l}1,28 \pm 0,21 \\
(1,06-1,68)\end{array}$ & 0,23 \\
\hline ST (c) & $\begin{array}{l}1,25 \pm 0,27 \\
(0,99-1,77)\end{array}$ & $\begin{array}{l}1,18 \pm 0,24 \\
(0,74-1,66)\end{array}$ & 0,77 & $\begin{array}{l}1,24 \pm 0,14 \\
(1,12-1,48)\end{array}$ & $\begin{array}{l}1,14 \pm 0,25 \\
(0,74-1,66)\end{array}$ & $\begin{array}{l}1,27 \pm 0,29 \\
(0,92-1,77)\end{array}$ & 0,51 \\
\hline PU (i) & $\begin{array}{l}1,08 \pm 0,24 \\
(0,81-1,55)\end{array}$ & $\begin{array}{c}-0,02 \pm 0,09 \\
(0,71-1,46)\end{array}$ & 0,85 & $\begin{array}{l}1,06 \pm 0,22 \\
(0,88-1,42)\end{array}$ & $\begin{array}{l}1,05 \pm 0,25 \\
(0,71-1,46)\end{array}$ & $\begin{array}{l}1,16 \pm 0,23 \\
(0,86-1,55)\end{array}$ & 0,56 \\
\hline $\mathbf{P U}(\mathbf{c})$ & $\begin{array}{l}1,19 \pm 0,33 \\
(0,85-1,91)\end{array}$ & $\begin{array}{l}1,1 \pm 0,25 \\
(0,73-1,56)\end{array}$ & 0,75 & $\begin{array}{l}1,10 \pm 0,17 \\
(0,97-1,39)\end{array}$ & $\begin{array}{l}1,10 \pm 0,27 \\
(0,73-1,56)\end{array}$ & $\begin{array}{l}1,21 \pm 0,36 \\
(0,73-1,91)\end{array}$ & 0,64 \\
\hline CA (i) & $\begin{array}{l}1,41 \pm 0,30 \\
(1,04-1,84)\end{array}$ & $\begin{array}{l}1,24 \pm 0,24 \\
(0,88-1,79)\end{array}$ & 0,57 & $\begin{array}{l}1,35 \pm 0,29 \\
(1,05-1,79)\end{array}$ & $\begin{array}{l}1,19 \pm 0,22 \\
(0,88-1,66)\end{array}$ & $\begin{array}{l}1,44 \pm 0,29 \\
(1,17-1,84)\end{array}$ & 0,13 \\
\hline $\mathbf{C A}(\mathbf{c})$ & $\begin{array}{l}1,37 \pm 0,28 \\
(0,97-1,73)\end{array}$ & $\begin{array}{l}1,31 \pm 0,30 \\
(0,80-1,95)\end{array}$ & 0,59 & $\begin{array}{l}1,43 \pm 0,12 \\
(1,29-1,61)\end{array}$ & $\begin{array}{l}1,24 \pm 0,32 \\
(0,80-1,95)\end{array}$ & $\begin{array}{l}1,39 \pm 0,31 \\
(0,97-1,73)\end{array}$ & 0,24 \\
\hline PU/CA (i) & $\begin{array}{l}0,78 \pm 0,16 \\
(0,57-1,05)\end{array}$ & $\begin{array}{l}0,89 \pm 0,19 \\
(0,59-1,33)\end{array}$ & 0,14 & $\begin{array}{l}0,79 \pm 0,13 \\
(0,62-0,98)\end{array}$ & $\begin{array}{l}0,90 \pm 0,21 \\
(0,59-1,33)\end{array}$ & $\begin{array}{l}0,82 \pm 0,18 \\
(0,57-1,15)\end{array}$ & 0,51 \\
\hline PU/CA (c) & $\begin{array}{l}0,88 \pm 0,18 \\
(0,65-1,18)\end{array}$ & $\begin{array}{l}0,86 \pm 0,18 \\
(0,66-1,36)\end{array}$ & 0,83 & $\begin{array}{l}0,77 \pm 0,05 \\
(0,74-0,86)\end{array}$ & $\begin{array}{r}0,91 \pm 0,20 \\
(0,72-1,36)\end{array}$ & $\begin{array}{l}0,88 \pm 0,19 \\
(0,65-1,18)\end{array}$ & 0,35 \\
\hline IA & $\begin{array}{l}-0,01 \pm 0,09 \\
(-0,19-0,19)\end{array}$ & $\begin{array}{l}-0,15 \pm 0,09 \\
(-0,19-0,19)\end{array}$ & 0,85 & $\begin{array}{l}-0,07 \pm 0,10 \\
(-0,19-0,08)\end{array}$ & $\begin{array}{l}-0,02 \pm 0,05 \\
(-0,08-0,06)\end{array}$ & $\begin{array}{l}0,02 \pm 0,09 \\
(-0,05-0,19)\end{array}$ & 0,12 \\
\hline IA (PU) & $\begin{array}{l}-0,07 \pm 0,14 \\
(-0,38-0,22)\end{array}$ & $\begin{array}{l}-0,08 \pm 0,06 \\
(-0,21-0,00)\end{array}$ & 0,13 & $\begin{array}{c}-0,04 \pm 0,05 \\
(-0,12-0,02)\end{array}$ & $\begin{array}{l}-0,04 \pm 0,13 \\
(-0,38-0,09)\end{array}$ & $\begin{array}{l}-0,02 \pm 0,13 \\
(-0,21-0,22)\end{array}$ & 0,88 \\
\hline IA (CA) & $\begin{array}{l}0,03 \pm 0,15 \\
(-0,30-0,24)\end{array}$ & $\begin{array}{l}0,03 \pm 0,13 \\
(-0,12-0,27)\end{array}$ & 0,28 & $\begin{array}{c}-0,07 \pm 0,15 \\
(-0,30-0,10)\end{array}$ & $\begin{array}{l}-0,02 \pm 0,14 \\
(-0,17-0,24)\end{array}$ & $\begin{array}{l}0,04 \pm 0,14 \\
(-0,24-0,27)\end{array}$ & 0,41 \\
\hline
\end{tabular}

Legenda: $\mathrm{ST}$ = estriado; $\mathrm{PU}=$ putâmen; $\mathrm{CA}=$ caudado; $\mathrm{IA}$ = índice de assimetria; PU/CA = razão do putâmen pelo caudado; (i) = ipsilateral; (c) = contralateral. 


\subsection{Análise qualitativa do SPECT com [ ${ }^{99 \mathrm{~m}}$ Tc]-TRODAT-1}

Em uma primeira análise, os SPECTs com [ $\left.{ }^{99 \mathrm{~m}} \mathrm{Tc}\right]-T R O D A T-1$ foram considerados como positivos ou negativos para doença. Na avaliação qualitativa do observador A foi encontrada sensibilidade de $93,18 \%$ a $90,91 \%$, especificidade de $100 \%$ a 95,65\%, valor preditivo positivo de $100 \%$ a $97,56 \%$, valor preditivo negativo de $88,46 \%$ a $84,62 \%$, e acurácia de 95,52\% a 92,54 \%. Na avaliação do observador B foi encontrada sensibilidade de $95,45 \%$, especificidade de $91,30 \%$, valor preditivo positivo de $95,45 \%$, valor preditivo negativo de 91,30 \%, e acurácia de 94,03\%. Nas 3 avaliações foram encontradas elevadas sensibilidade, especificidade e acurácia. Os valores preditivos positivos foram maiores em relação aos negativos (tabela 15 ).

Tabela 15: Avaliação qualitativa dos SPECTs com $\left[{ }^{99 \mathrm{~m}}\right.$ Tc]-TRODAT-1 para distinção entre grupos com doença de Parkinson e controles saudáveis.

\begin{tabular}{llll}
\hline & Avaliação A1 & \multicolumn{1}{c}{ Avaliação A2 } & \multicolumn{1}{c}{ Avaliação B1 } \\
\hline Sensibilidade & $93,18 \%$ & $90,91 \%$ & $95,45 \%$ \\
Especificidade & $100,00 \%$ & $95,65 \%$ & $91,30 \%$ \\
VPP & $100,00 \%$ & $97,56 \%$ & $95,45 \%$ \\
VPN & $88,46 \%$ & $84,62 \%$ & $91,30 \%$ \\
Acurácia & $95,52 \%$ & $92,54 \%$ & $94,03 \%$ \\
\hline
\end{tabular}

Legenda: A1 = avaliação 1 do primeiro observador; A2 - avaliação 2 do primeiro observador; $\mathrm{B}$ = avaliação do segundo observador; VPP = valor preditivo positivo; VPN = valor preditivo negativo

Houve discordância intraobservador em 5,97 \% dos casos na avaliação qualitativa binária (positivo e negativo), e de 10,44 \% na avaliação qualitativa com padrões de imagem classificados em graus ( 0 a 3). Por sua vez, houve discordância interobservador em 10,44 \% dos casos na avaliação qualitativa binária (positivo e negativo), e de 35,82 \% na avaliação 
qualitativa com padrões de imagem classificados em graus ( 0 a 3). A tabela 16 evidencia uma forte concordância intraobservador representada pelo coeficiente kappa $(>0,80)$; uma moderada concordância interobservador (kappa =0,60 - 0,79) quando considerada a avaliação binária; e uma fraca concordância interobservador quando considerada a classificação qualitativa em graus, aumentando com a ponderação (MCHUGH, 2012).

Tabela 16: Análise da concordância interobservador e intraobservador na avaliação qualitativa dos SPECTs com $\left[{ }^{99 \mathrm{~m}} \mathrm{Tc}\right]-T R O D A T-1$.

\begin{tabular}{|c|c|c|c|}
\hline $\begin{array}{l}\text { Tipo de avaliação } \\
\text { qualitativa }\end{array}$ & $\begin{array}{l}\text { Coeficiente de } \\
\text { concordância }\end{array}$ & $\begin{array}{l}\text { Concordância } \\
\text { intraobservador } \\
\text { (A1 X A2) }\end{array}$ & $\begin{array}{l}\text { Concordância } \\
\text { interobservador } \\
\text { (A1 X B1) }\end{array}$ \\
\hline Avaliação tipo I & kappa index & $\begin{array}{l}0,87 \\
(\mathrm{IC} 95 \% 0,75 ; 0,99)\end{array}$ & $\begin{array}{l}0,77 \\
(\mathrm{IC} 95 \% 0,61 ; 0,93)\end{array}$ \\
\hline \multirow{2}{*}{$\begin{array}{l}\text { Avaliação tipo II } \\
\text { (BENAMER et al., } \\
\text { 2000) }\end{array}$} & kappa index & $\begin{array}{l}0,82 \\
(\text { IC } 95 \% 0,71 ; 0,93)\end{array}$ & $\begin{array}{l}0,49 \\
(\text { IC } 95 \% 0,36 ; 0,63)\end{array}$ \\
\hline & $\begin{array}{l}\text { kappa index } \\
\text { ponderado }\end{array}$ & $\begin{array}{l}0,92 \\
\text { (IC } 95 \% 0,87 ; 0,97)\end{array}$ & $\begin{array}{l}0,64 \\
\text { (IC 95\% 0,51; 0,77) }\end{array}$ \\
\hline
\end{tabular}

Legenda: $\mathrm{A} 1$ = avaliação 1 do primeiro observador; $\mathrm{A} 2$ - avaliação 2 do primeiro observador; $\mathrm{B}=$ avaliação do segundo observador; avaliação tipo I = binária (positivo X negativo); avaliação tipo II = classificação em graus ( 0 a 3 )

A tabela 17 mostra a correlação das avaliações qualitativas II e III com a idade de aparecimento dos sintomas do paciente, com o tempo de duração da doença, HYS e com o UPDRS-3. A correlação de Spearman mostrou uma tendência de associação positiva das avaliações qualitativas do tipo II e tipo III com o tempo de duração de doença, HYS e UPDRS-3, porém não foi comprovada significância estatística. A única correlação estatisticamente significante foi a associação negativa de entre o tempo de duração da doença e a avaliação qualitativa do tipo III (Benamer-modificado). 
Tabela 17: Análise da correlação da avaliação qualitativa dos SPECTs com [ ${ }^{99 \mathrm{~m}}$ Tc]-TRODAT-1 com dados clínicos.

\begin{tabular}{|c|c|c|c|}
\hline & & Avaliação qualitativa II & Avaliação qualitativa III \\
\hline \multirow{2}{*}{$\begin{array}{l}\text { Idade de aparecimento dos } \\
\text { sintomas }\end{array}$} & Coeficiente $\mathbf{R}$ & 0,07 & $-0,17$ \\
\hline & valor-p & 0.96 & 0.25 \\
\hline \multirow[t]{2}{*}{ Tempo de duração da doença } & Coeficiente $\mathbf{R}$ & 0,15 & 0,33 \\
\hline & valor-p & 0,32 & $0,02 *$ \\
\hline \multirow[t]{2}{*}{ HYS } & Coeficiente $\mathbf{R}$ & 0,53 & 0,16 \\
\hline & valor-p & 0,73 & 0,28 \\
\hline \multirow[t]{2}{*}{ UPDRS-3 } & Coeficiente $\mathbf{R}$ & 0,21 & 0,27 \\
\hline & valor-p & 0,16 & 0,07 \\
\hline
\end{tabular}

Legenda: $\mathrm{R}$ = coeficiente de correlação; HYS = Hoehn and Yahr scale; UPDRS-3 = parte motora da Unified Parkinson's Disease Rating Scale. * valor-p $<0,05$

\subsection{Análise e comparação dos métodos semiquantitativos}

\subsubsection{Comparação entre médias dos grupos DP e controle}

Os modelos de regressão evidenciaram uma redução estatisticamente significante (valor-p < 0,05) do potencial de ligação no corpo estriado e em subestruturas no grupo de pacientes com DP em relação ao grupo saudável em todos os métodos aplicados (manual, RM, RM-corrigida e Two Box). Os resultados se mantiveram quando aplicados os modelos de regressão múltiplos, em que foram considerados sexo, idade e escolaridade como covariáveis. As tabelas 18, 19, 20 e 21 mostram a comparação entre médias dos índices de potencial de ligação dos grupos (DP e controle) avaliados para cada método. 
Tabela 18: Semiquantificação de BPI em pacientes saudáveis e com DP através do método manual ( $\mathrm{n}=67$ pacientes).

\begin{tabular}{|c|c|c|c|c|c|c|c|c|c|c|}
\hline & \multicolumn{6}{|c|}{ Modelo de regressão simpes } & \multicolumn{4}{|c|}{$\begin{array}{c}\text { Modelo de regressão ajustado (idade, sexo, } \\
\text { escolaridade) }\end{array}$} \\
\hline & DP & $\begin{array}{l}\text { Pacientes } \\
\text { saudáveis }\end{array}$ & $\begin{array}{c}\text { DP - } \\
\text { saudáveis }\end{array}$ & $\underset{\text { IC95 }}{L I}$ & $\begin{array}{c}\text { LS } \\
\text { IC95 }\end{array}$ & $p$-valor & $\begin{array}{c}\text { DP - } \\
\text { saudáveis }\end{array}$ & $\begin{array}{c}\text { LI } \\
\text { IC95 }\end{array}$ & $\begin{array}{c}\text { LS } \\
\text { IC95 }\end{array}$ & p-valor \\
\hline ST(i) & $\begin{array}{l}0.24 \pm 0.12 \\
(0.00-0.62)\end{array}$ & $\begin{array}{l}0.49 \pm 0.17 \\
(0.15-0.80)\end{array}$ & -0.25 & -0.32 & -0.18 & $<0.01 * *$ & -0.25 & -0.33 & -0.18 & $<0.01 * *$ \\
\hline $\mathbf{S T}(\mathbf{c})$ & $\begin{array}{l}0.22 \pm 0.10 \\
(0.05-0.58)\end{array}$ & $\begin{array}{l}0.46 \pm 0.16 \\
(0.17-0.71)\end{array}$ & -0.24 & -0.31 & -0.18 & $<0.01 * *$ & -0.25 & -0.32 & -0.19 & $<0.01 * *$ \\
\hline $\mathbf{P U}(\mathbf{i})$ & $\begin{array}{c}0.25 \pm 0.14 \\
(-0.02-0.63)\end{array}$ & $\begin{array}{l}0.55 \pm 0.21 \\
(0.19-1.10)\end{array}$ & -0.31 & -0.39 & -0.22 & $<0.01 * *$ & -0.31 & -0.40 & -0.23 & $<0.01 * *$ \\
\hline $\mathbf{P U}(\mathbf{c})$ & $\begin{array}{c}0.21 \pm 0.10 \\
(-0.01-0.45)\end{array}$ & $\begin{array}{l}0.39 \pm 0.18 \\
(0.08-0.68)\end{array}$ & -0.18 & -0.25 & -0.11 & $<0.01 * *$ & -0.19 & -0.25 & -0.12 & $<0.01 * *$ \\
\hline CA(i) & $\begin{array}{l}0.23 \pm 0.14 \\
(0.01-0.61)\end{array}$ & $\begin{array}{l}0.42 \pm 0.19 \\
(0.06-0.75)\end{array}$ & -0.19 & -0.27 & -0.11 & $<0.01 * *$ & -0.20 & -0.28 & -0.11 & $<0.01 * *$ \\
\hline $\mathbf{C A}(\mathbf{c})$ & $\begin{array}{l}0.22 \pm 0.15 \\
(-0.09-0.71)\end{array}$ & $\begin{array}{l}0.53 \pm 0.20 \\
(0.14-0.84)\end{array}$ & -0.31 & -0.39 & -0.22 & $<0.01 * *$ & -0.32 & -0.41 & -0.23 & $<0.01 * *$ \\
\hline
\end{tabular}

Legenda: DP: Doença de Parkinson; LI = limite inferior; LS = limite superior; $\mathrm{IC}=$ intervalo de confiança; $\mathrm{ST}=$ corpo estriado; $\mathrm{PU}=$ putâmen; $\mathrm{CA}=$ núcleo caudado; $\mathrm{IA}=$ índice de assimetria; PU/CA = razão de PU por CA; (i) = ipsilateral; (c) = contralateral. Os valores foram descritos como média \pm desvio padrão (intervalo). ${ }^{*} p$-valor $<0.05 * * p$-valor $<0.01$ 
Tabela 19: Semiquantificação de BPI em pacientes saudáveis e com DP através de RM ( $\mathrm{n}=67$ pacientes).

\begin{tabular}{|c|c|c|c|c|c|c|c|c|c|c|}
\hline & \multicolumn{6}{|c|}{ Modelo de regressão simpes } & \multicolumn{4}{|c|}{$\begin{array}{c}\text { Modelo de regressão ajustado (idade, sexo, } \\
\text { escolaridade) }\end{array}$} \\
\hline & DP & $\begin{array}{l}\text { Pacientes } \\
\text { saudáveis }\end{array}$ & $\begin{array}{c}\text { DP - } \\
\text { Pacientes } \\
\text { saudáveis }\end{array}$ & $\begin{array}{c}\text { LI } \\
\text { IC95 }\end{array}$ & $\begin{array}{l}\text { LS } \\
\text { IC95 }\end{array}$ & p-valor & $\begin{array}{c}\text { DP - } \\
\text { Pacientes } \\
\text { saudáveis }\end{array}$ & $\begin{array}{c}\mathrm{LI} \\
\text { IC95 }\end{array}$ & $\begin{array}{l}\text { LS } \\
\text { IC95 }\end{array}$ & $p$-valor \\
\hline ST(i) & $\begin{array}{l}0.50 \pm 0.31 \\
(0.04-1.47)\end{array}$ & $\begin{array}{l}1.18 \pm 0.22 \\
(0.78-1.68)\end{array}$ & -0.68 & -0.82 & -0.53 & $<0.01 * *$ & -0.70 & -0.86 & -0.54 & $<0.01 * *$ \\
\hline ST(c) & $\begin{array}{l}0.43 \pm 0.25 \\
(0.03-1.16)\end{array}$ & $\begin{array}{l}1.21 \pm 0.25 \\
(0.74-1.77)\end{array}$ & -0.77 & -0.90 & -0.64 & $<0.01 * *$ & -0.81 & -0.95 & -0.67 & $<0.01 * *$ \\
\hline $\mathbf{P U}(\mathbf{i})$ & $\begin{array}{l}0.42 \pm 0.31 \\
(0.03-1.47)\end{array}$ & $\begin{array}{l}1.09 \pm 0.23 \\
(0.71-1.55)\end{array}$ & -0.67 & -0.82 & -0.52 & $<0.01 * *$ & -0.69 & -0.85 & -0.53 & $<0.01 * *$ \\
\hline $\mathbf{P U}(\mathbf{c})$ & $\begin{array}{l}0.37 \pm 0.25 \\
(0.01-1.10)\end{array}$ & $\begin{array}{l}1.14 \pm 0.28 \\
(0.73-1.91)\end{array}$ & -0.77 & -0.90 & -0.63 & $<0.01 * *$ & -0.81 & -0.95 & -0.67 & $<0.01 * *$ \\
\hline CA(i) & $\begin{array}{l}0.62 \pm 0.35 \\
(0.01-1.51)\end{array}$ & $\begin{array}{l}1.31 \pm 0.27 \\
(0.88-1.84)\end{array}$ & -0.69 & -0.86 & -0.52 & $<0.01 * *$ & -0.71 & -0.81 & -0.53 & $<0.01 * *$ \\
\hline $\mathrm{CA}(\mathbf{c})$ & $\begin{array}{l}0.52 \pm 0.30 \\
(0.02-1.30)\end{array}$ & $\begin{array}{l}1.33 \pm 0.29 \\
(0.80-1.95)\end{array}$ & -0.81 & -0.96 & -0.65 & $<0.01 * *$ & -0.84 & -1.00 & -0.67 & $<0.01 * *$ \\
\hline
\end{tabular}

Legenda: DP: Doença de Parkinson; LI = limite inferior; LS = limite superior; $\mathrm{IC}=$ intervalo de confiança; $\mathrm{ST}=$ corpo estriado; PU = putâmen; CA = núcleo caudado; (i) = ipsilateral; (c) = contralateral. Os valores foram descritos como média \pm desvio padrão (intervalo). $* p$-valor $<0.05 * * p$-valor $<0.01$ 
Tabela 20: Semiquantificação de BPI em pacientes saudáveis e com DP através de RM-corrigida ( $\mathrm{n}=67$ pacientes).

\begin{tabular}{|c|c|c|c|c|c|c|c|c|c|c|}
\hline & \multicolumn{6}{|c|}{ Modelo de regressão simpes } & \multicolumn{4}{|c|}{$\begin{array}{c}\text { Modelo de regressão ajustado (idade, sexo, } \\
\text { escolaridade) }\end{array}$} \\
\hline & DP & $\begin{array}{l}\text { Pacientes } \\
\text { saudáveis }\end{array}$ & $\begin{array}{l}\text { DP - } \\
\text { saudáveis }\end{array}$ & $\underset{\text { IC95 }}{\text { LI }}$ & $\begin{array}{c}\text { LS } \\
\text { IC95 }\end{array}$ & $p$-valor & $\begin{array}{l}\text { DP - } \\
\text { saudáveis }\end{array}$ & $\underset{\text { IC95 }}{\text { LI }}$ & $\begin{array}{c}\text { LS } \\
\text { IC95 }\end{array}$ & $p$-valor \\
\hline ST(i) & $\begin{array}{l}0.90 \pm 0.19 \\
(0.54-1.52)\end{array}$ & $\begin{array}{l}1.30 \pm 0.26 \\
(0.77-1.78)\end{array}$ & -0.40 & -0.51 & -0.28 & $<0.01 * *$ & -0.41 & -0.53 & -0.29 & $<0.01 * *$ \\
\hline $\mathbf{S T}(\mathbf{c})$ & $\begin{array}{l}0.86 \pm 0.16 \\
(0.59-1.41)\end{array}$ & $\begin{array}{l}1.22 \pm 0.24 \\
(0.77-1.62)\end{array}$ & -0.37 & -0.46 & -0.27 & $<0.01 * *$ & -0.38 & -0.48 & -0.28 & $<0.01 * *$ \\
\hline PU(i) & $\begin{array}{l}0.81 \pm 0.24 \\
(0.42-0.64)\end{array}$ & $\begin{array}{l}1.31 \pm 0.35 \\
(0.75-2.26)\end{array}$ & -0.50 & -0.64 & -0.35 & $<0.01 * *$ & -0.52 & -0.66 & -0.37 & $<0.01 * *$ \\
\hline $\mathbf{P U}(\mathbf{c})$ & $\begin{array}{l}0.74 \pm 0.18 \\
(0.40-1.07)\end{array}$ & $\begin{array}{c}0.96 \pm 0.28 \\
(0.45-1.48)\end{array}$ & -0.21 & -0.32 & -0.10 & $<0.01 * *$ & -0.22 & -0.33 & -0.11 & $<0.01 * *$ \\
\hline CA(i) & $\begin{array}{l}0.99 \pm 0.24 \\
(0.56-1.63)\end{array}$ & $\begin{array}{l}1.28 \pm 0.34 \\
(0.59-1.82)\end{array}$ & -0.29 & -0.43 & -0.14 & $<0.01 * *$ & -0.30 & -0.46 & -0.15 & $<0.01 * *$ \\
\hline $\mathbf{C A}(\mathbf{c})$ & $\begin{array}{l}0.98 \pm 0.27 \\
(0.37-1.84)\end{array}$ & $\begin{array}{l}1.50 \pm 0.37 \\
(0.76-2.06)\end{array}$ & -0.53 & -0.68 & -0.37 & $<0.01 * *$ & -0.55 & -0.72 & -0.38 & $<0.01 * *$ \\
\hline
\end{tabular}

Legenda: DP: Doença de Parkinson; LI = limite inferior; LS = limite superior; $\mathrm{IC}=$ intervalo de confiança; $\mathrm{ST}=$ corpo estriado; $\mathrm{PU}=$ putâmen; $\mathrm{CA}=$ núcleo caudado; IA = índice de assimetria; PU/CA = razão de PU por CA; (i) = ipsilateral; (c) = contralateral. Os valores foram descritos como média \pm desvio padrão (intervalo). * $p$-valor $<0.05 * * p$-valor $<0.01$ 
Tabela 21: Semiquantificação de BPI em pacientes saudáveis e com DP através de Two Box (n = 67 pacientes).

\begin{tabular}{|c|c|c|c|c|c|c|c|c|c|c|}
\hline & \multicolumn{6}{|c|}{ Modelo de regressão simpes } & \multicolumn{4}{|c|}{$\begin{array}{c}\text { Modelo de regressão ajustado (idade, sexo, } \\
\text { escolaridade) }\end{array}$} \\
\hline & DP & $\begin{array}{l}\text { Pacientes } \\
\text { saudáveis }\end{array}$ & $\begin{array}{c}\text { DP - Pacientes } \\
\text { saudáveis }\end{array}$ & $\begin{array}{c}\text { LI } \\
\text { IC95 }\end{array}$ & $\begin{array}{c}\text { LS } \\
\text { IC95 }\end{array}$ & $p$-valor & $\begin{array}{c}\text { DP - } \\
\text { Pacientes } \\
\text { saudáveis }\end{array}$ & $\begin{array}{c}\text { LI } \\
\text { IC95 }\end{array}$ & $\begin{array}{c}\text { LS } \\
\text { IC95 }\end{array}$ & $p$-valor \\
\hline ST(i) & $\begin{array}{c}0.74 \pm 0.49 \\
(-0.38-2.02)\end{array}$ & $\begin{array}{l}1.58 \pm 0.52 \\
(0.52-2.65)\end{array}$ & -0.83 & -1.09 & -0.58 & $<0.01 * *$ & -0.83 & -1.09 & -0.56 & $<0.01 * *$ \\
\hline $\mathbf{S T}(\mathbf{c})$ & $\begin{array}{c}0.68 \pm 0.50 \\
(-0.62-1.68)\end{array}$ & $\begin{array}{l}1.65 \pm 0.50 \\
(0.62-2.65)\end{array}$ & -0.98 & -1.22 & -0.72 & $<0.01 * *$ & -1.01 & -1.27 & -0.74 & $<0.01 * *$ \\
\hline
\end{tabular}

Legenda: DP: Doença de Parkinson; LI = limite inferior; LS = limite superior; IC = intervalo de confiança; ST = corpo estriado; (i) = ipsilateral; (c) = contralateral Os valores foram descritos como média \pm desvio padrão (intervalo). *p-valor $<0.05 * * p$-valor $<0.01$ 
Considerando o método manual (tabela 18), em média a redução percentual do BPI entre os grupos controles e com DP variou entre $53 \%$ (no núcleo caudado ipsilateral) a $68 \%$ (no putâmen contralateral), e superior a $50 \%$ em todos os demais métodos. Foi observado um predomínio do déficit de BPI contralateral ao lado de predomínio dos sintomas motores. A diferença entre as médias de BPI foi maior no método Two Box, seguido do método manual.

No método manual o desvio padrão dos índices calculados foi maior no grupo de pacientes com DP, conforme o esperado, visto que a heterogeneidade nas imagens deste grupo é maior. Contudo, este dado não foi reproduzido nos demais métodos. Enquanto no método Two Box o desvio padrão foi semelhante entre os grupos, na semiquantificação por corregistro com RM e RM-corrigida o desvio padrão foi nitidamente maior no grupo controle.

Gráficos boxplot dispostos nas figuras 14 a 17 mostram a diferença do BPI entre os grupos controle saudável e DP para cada método. 

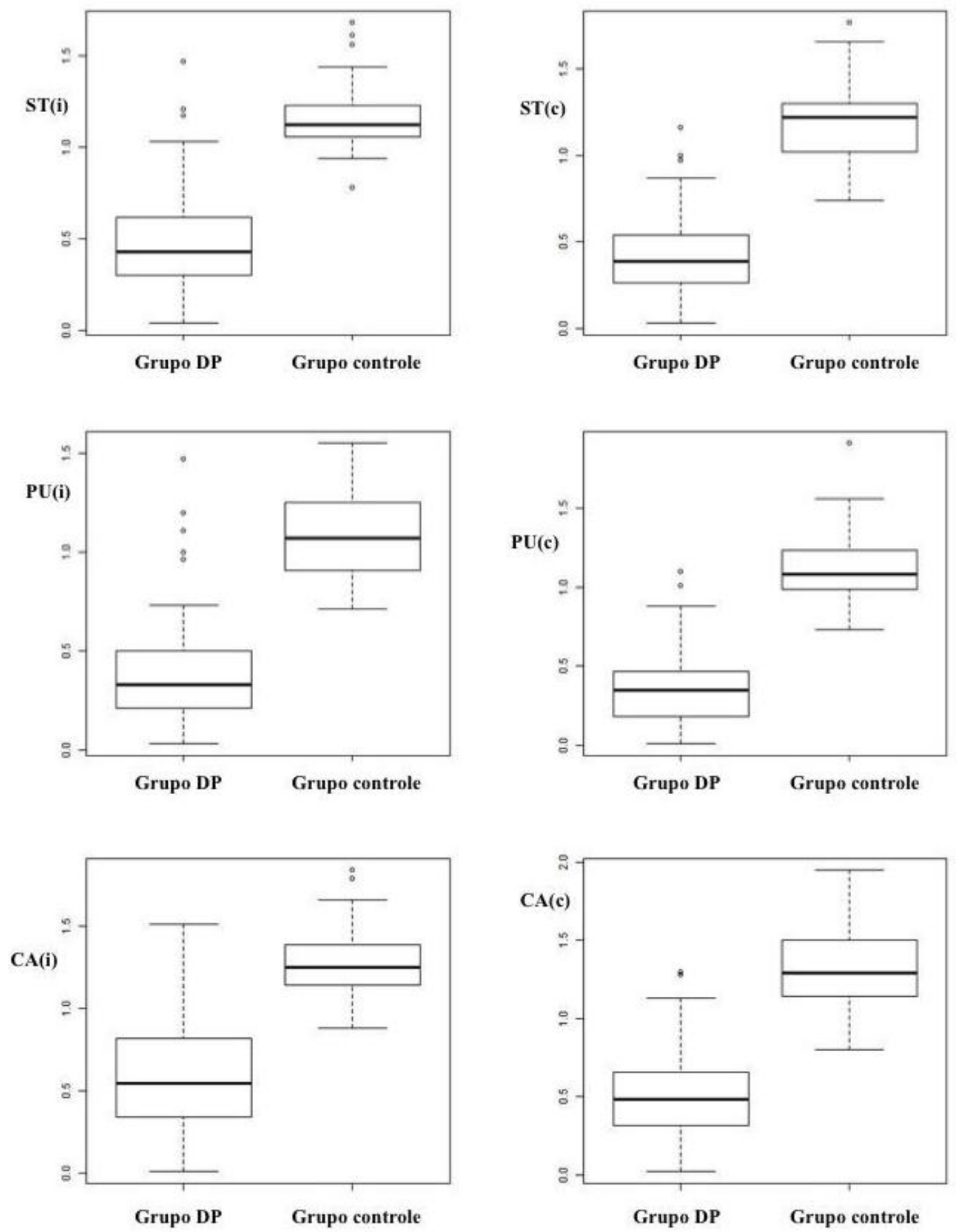

Figura 14: Gráficos do BPI no corpo estriado e subestruturas calculados pelo método manual, sendo ST = estriado; $\mathrm{PU}=$ putâmen; $\mathrm{CA}=$ caudado; $(\mathrm{i})=$ ipsilateral; $(\mathrm{c})=$ contralateral. 

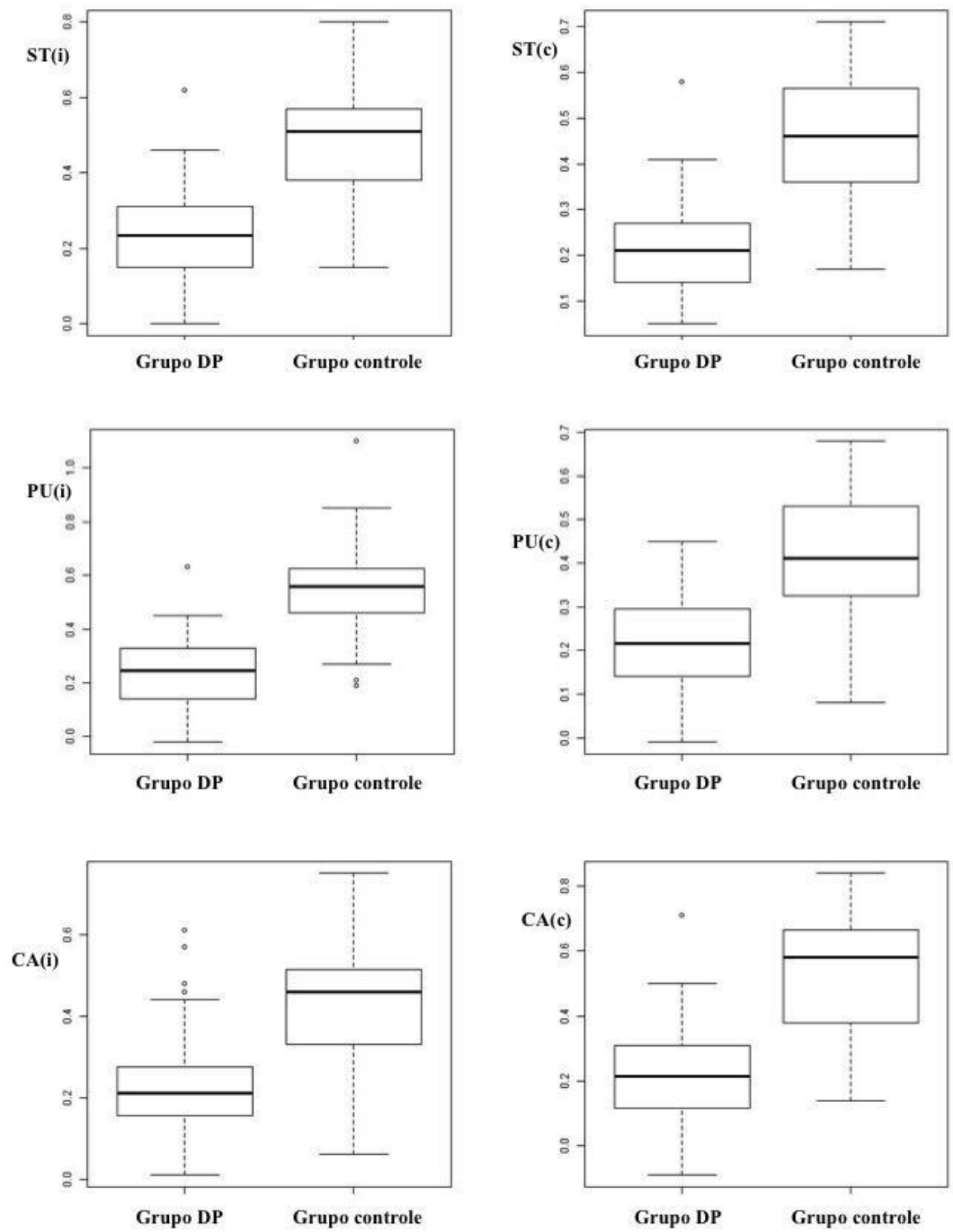

Figura 15: Gráficos do BPI no corpo estriado e subestruturas calculados pelo método de corregistro com RM. 

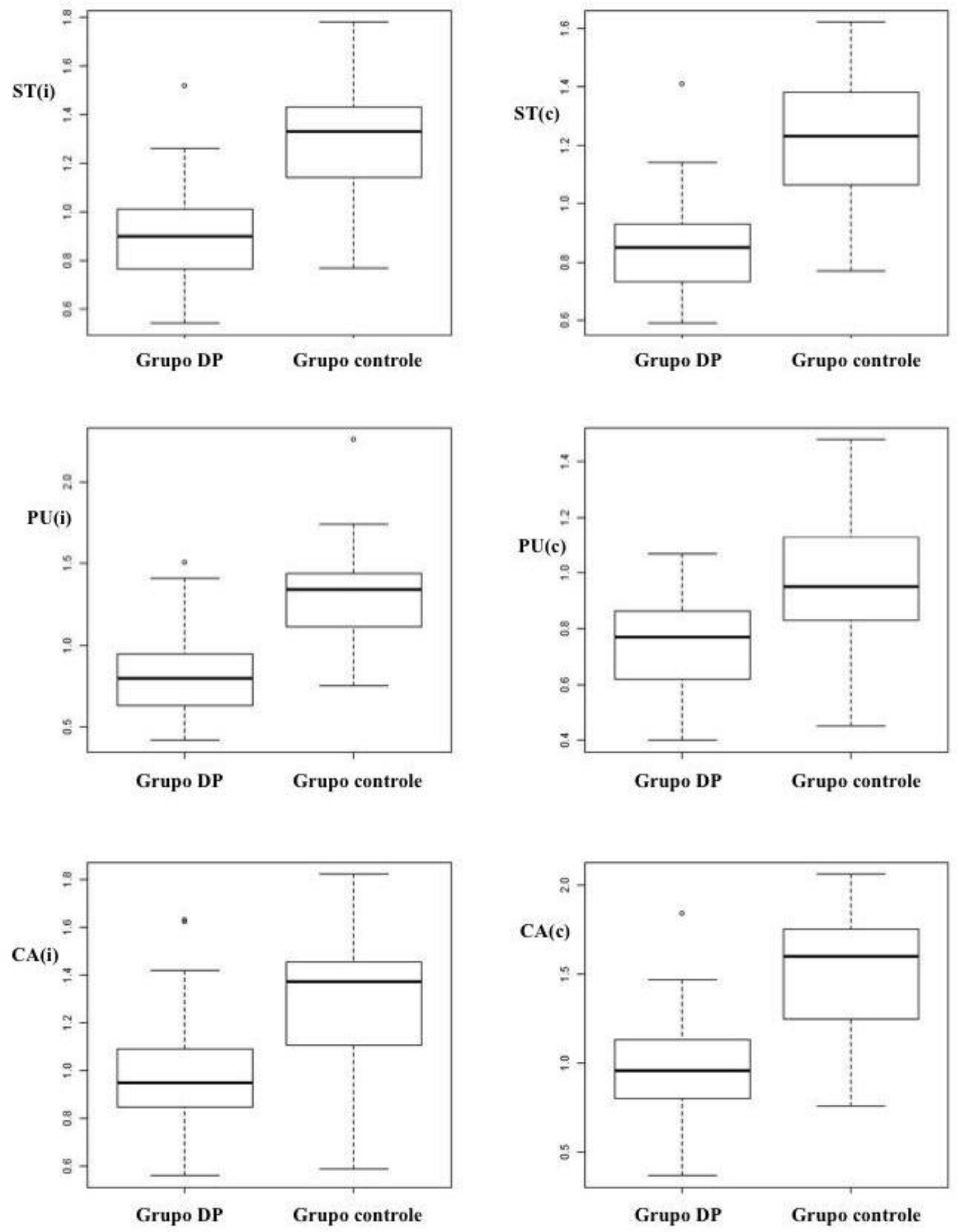

Figura 16: Gráficos do BPI no corpo estriado e subestruturas calculados pelo método de corregistro com RMcorrigida. 

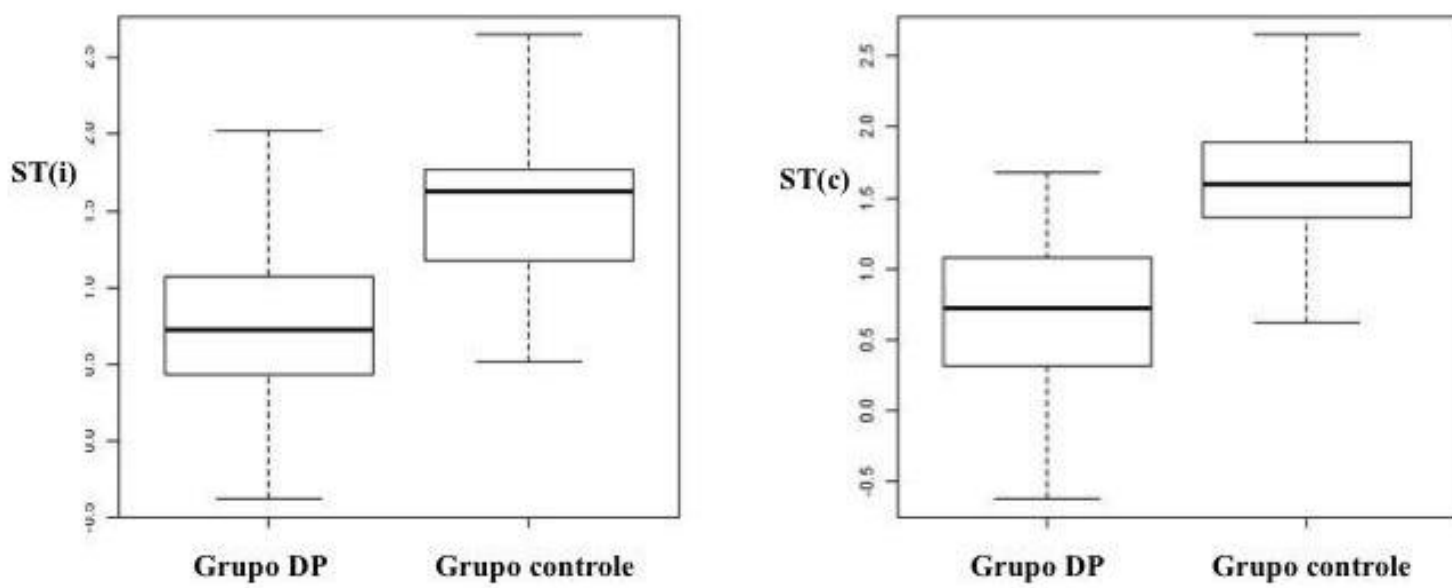

Figura 17: Gráficos do BPI no corpo estriado calculados pelo método Two Box, sendo ST = estriado; PU = putâmen; $\mathrm{CA}=$ caudado; $(\mathrm{i})=$ ipsilateral; $(\mathrm{c})=$ contralateral.

Os índices para avaliação da assimetria e da razão entre putâmen e caudado foram estudados exclusivamente através do método manual com a finalidade de avaliar sua aplicabilidade (tabela 22). 
Tabela 22: Semiquantificação de IA e PU/CA em pacientes saudáveis e com DP com o método manual ( $\mathrm{n}=67$ pacientes).

\begin{tabular}{|c|c|c|c|c|c|c|c|c|c|c|}
\hline & \multicolumn{6}{|c|}{ Modelo de regressão simpes } & \multicolumn{4}{|c|}{$\begin{array}{c}\text { Modelo de regressão ajustado (idade, sexo, } \\
\text { escolaridade) }\end{array}$} \\
\hline & DP & $\begin{array}{l}\text { Pacientes } \\
\text { saudáveis }\end{array}$ & $\begin{array}{c}\text { DP - } \\
\text { Pacientes } \\
\text { saudáveis }\end{array}$ & $\begin{array}{c}\text { LI } \\
\text { IC95 }\end{array}$ & $\begin{array}{c}\text { LS } \\
\text { IC95 }\end{array}$ & p-valor & $\begin{array}{c}\text { DP - } \\
\text { Pacientes } \\
\text { saudáveis }\end{array}$ & $\begin{array}{c}\text { LI } \\
\text { IC95 }\end{array}$ & $\begin{array}{c}\text { LS } \\
\text { IC95 }\end{array}$ & p-valor \\
\hline PU/CA (i) & $\begin{array}{c}0.74 \pm 0.38 \\
(0.23-2.33)\end{array}$ & $\begin{array}{c}0.85 \pm 0.18 \\
(0.57-1.33)\end{array}$ & -0.11 & -0.28 & 0.05 & 0.20 & -0.11 & -0.30 & 0.06 & 0.20 \\
\hline PU/CA (c) & $\begin{array}{c}0.76 \pm 0.46 \\
(0.14-2.88)\end{array}$ & $\begin{array}{c}0.87 \pm 0.17 \\
(0.65-1.36)\end{array}$ & 0.10 & -0.30 & 0.09 & 0.30 & -0.16 & -0.37 & 0.04 & 0.11 \\
\hline IA & $\begin{array}{c}0.12 \pm 0.40 \\
(0.09-1.19)\end{array}$ & $\begin{array}{c}-0.01 \pm 0.08 \\
(-0.19-0.19)\end{array}$ & 0.14 & 0.01 & 0.27 & $0.02 *$ & 0.18 & 0.01 & 0.36 & $<0.04 *$ \\
\hline IA (PU) & $\begin{array}{c}0.13 \pm 0.48 \\
(-0.87-1.64)\end{array}$ & $\begin{array}{c}-0.03 \pm 0.12 \\
(-0.38-0.22)\end{array}$ & 0.17 & 0.01 & 0.32 & $0.03 *$ & 0.25 & 0.03 & 0.46 & $<0.02 *$ \\
\hline IA (CA) & $\begin{array}{c}0.15 \pm 0.53 \\
(-1.69-1.59)\end{array}$ & $\begin{array}{l}-0.01 \pm 0.14 \\
(-0.30-0.27)\end{array}$ & 0.16 & -0.01 & 0.33 & 0.06 & 0.16 & -0.08 & 0.42 & 0.1 \\
\hline
\end{tabular}

Legenda: $\mathrm{ICC}=$ Coeficiente de Correlação Intra-classe; $\mathrm{LI}=$ limite inferior; $\mathrm{LS}=$ limite superior; $\mathrm{IC}=$ intervalo de confiança; $\mathrm{IA}=$ índice de assimetria; $\mathrm{PU} / \mathrm{CA}=$ razão de PU por CA; (i) = ipsilateral; (c) = contralateral. Os valores foram descritos como média \pm desvio padrão (intervalo). * $p$-valor $<0.05 * * p$-valor $<0.01$ 
Uma diferença estatisticamente significante foi observada para os índices de assimetria dos estriados e dos putâmens entre os grupos. O mesmo não foi observado para os caudados (figura 18).
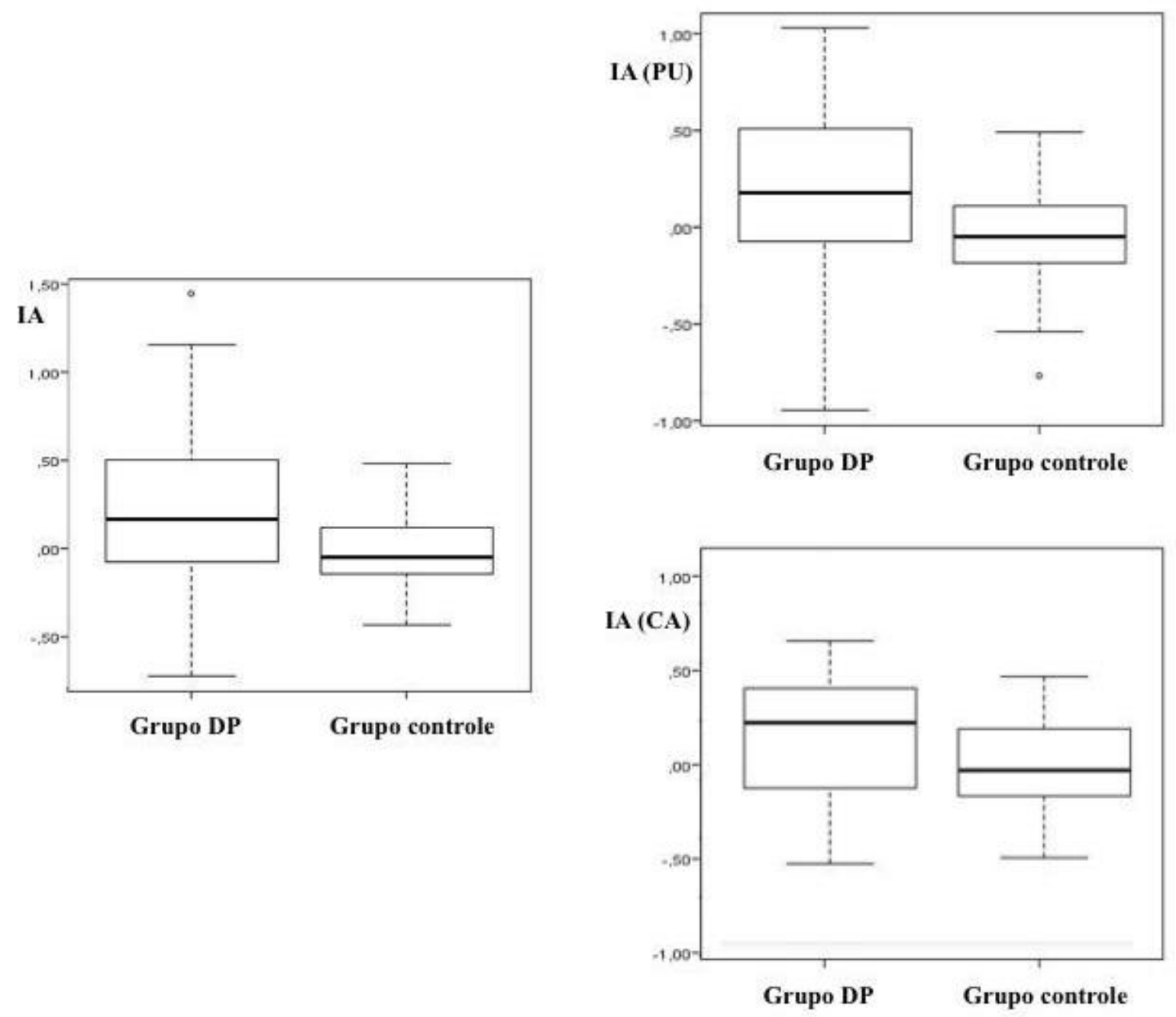

Figura 18: Gráficos dos índices de assimetria do corpo estriado e subestruturas calculados pelo método manual, sendo $\mathrm{PU}=$ putâmen; $\mathrm{CA}=$ caudado.

Embora tenha sido encontrada uma média maior nos índices de assimetria no grupo 
com DP, com valor- $p$ inferior a 0,05 para IA e IA(PU), a diferença entre as médias em termos absolutos foi pequena, tendo em vista a baixa amplitude dos valores. O desvio padrão foi elevado no grupo DP e menor no grupo controle.

Quanto às razões PU/CA(i) e PU/CA(c), apesar da média inferior no grupo com DP, este resultado não foi acompanhado de significância estatística (figura 19).
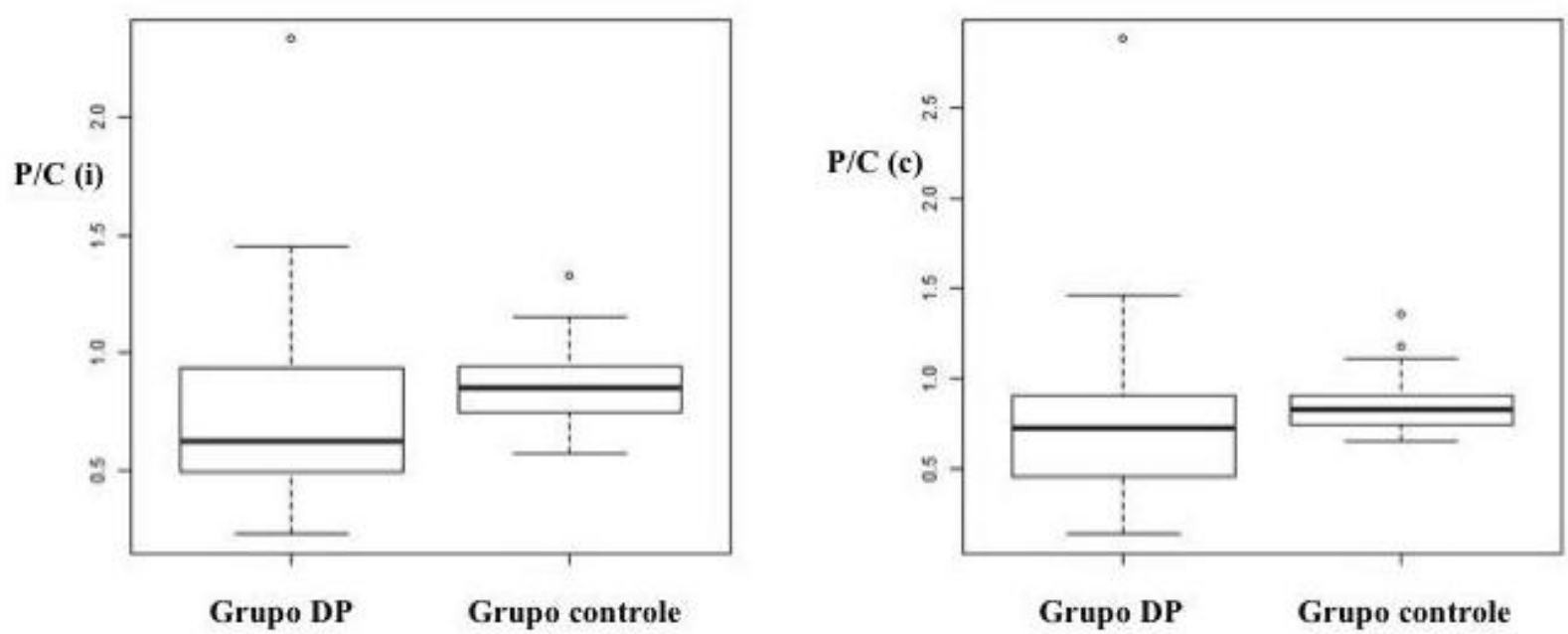

Figura 19: Gráficos da razão entre putâmen e caudado calculados pelo método manual, sendo $\mathrm{P}=$ putâmen; $\mathrm{C}=$ caudado; $(\mathrm{i})=$ ipsilateral; $(\mathrm{c})=$ contralateral.

\subsubsection{Definição de limiar de normalidade dos índices}

As curvas ROC forneceram diversos valores de sensibilidade e especificidade para cada índice calculado pelos diferentes métodos. A sensibilidade e a especificidade para a identificação do grupo de pacientes com e sem DP são dependentes do limiar adotado arbitrariamente. Para o potencial de ligação, o limiar deve ser entendido como cutoff acima do qual existe maior probabilidade de identificação do grupo de não doentes. Através de BPI obtidos pelo métodos semiquantitativos, as curvas ROC (figuras 20 e 21) geradas mostraram uma elevada sensibilidade e especificidade para identificação dos não doentes. 

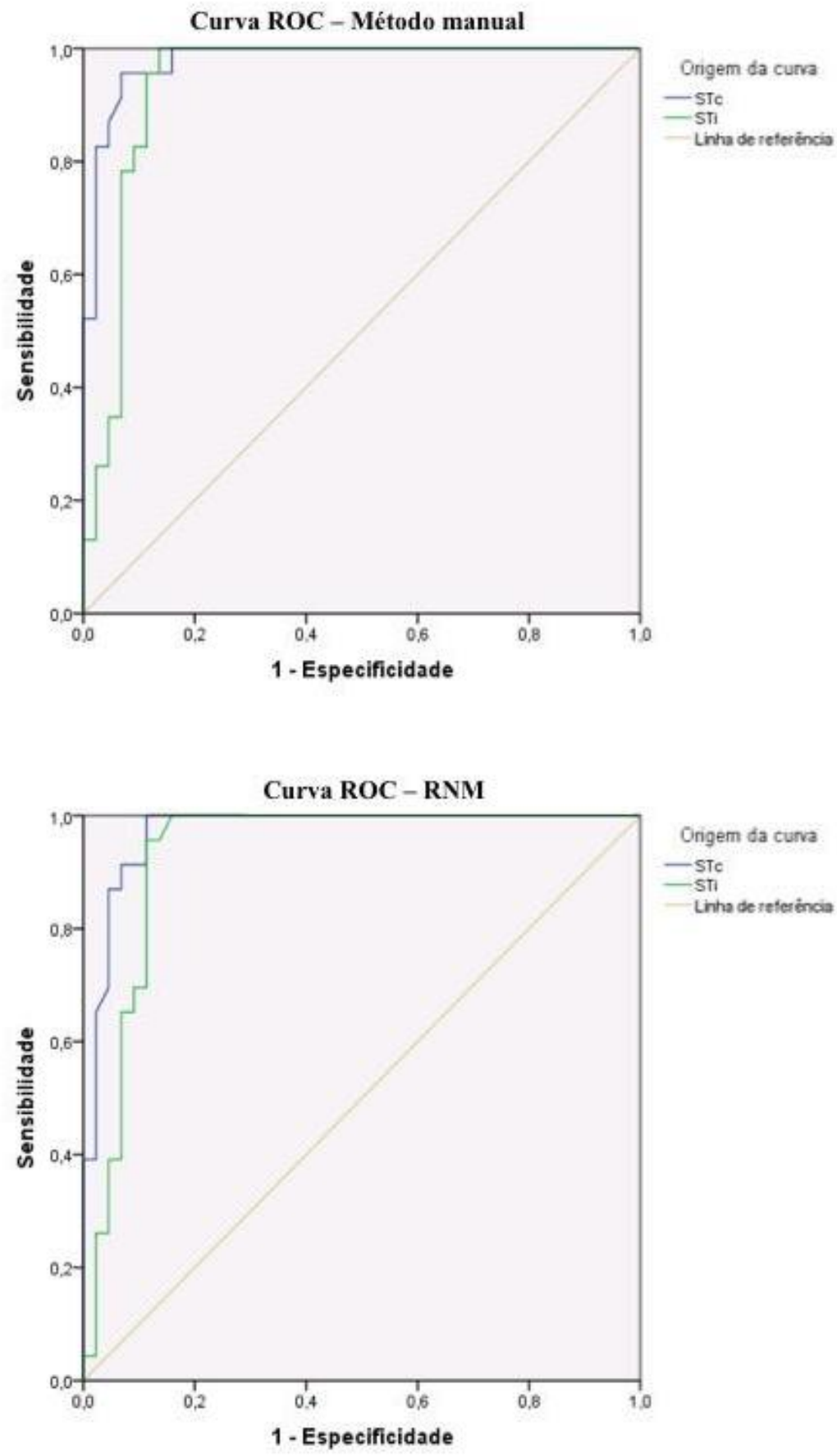

Figura 20: Curvas ROC do BPI para o corpo estriado (ST) ipsilateral (i) e contralateral (c) obtidos pelos métodos manual e por corregistro com RM 

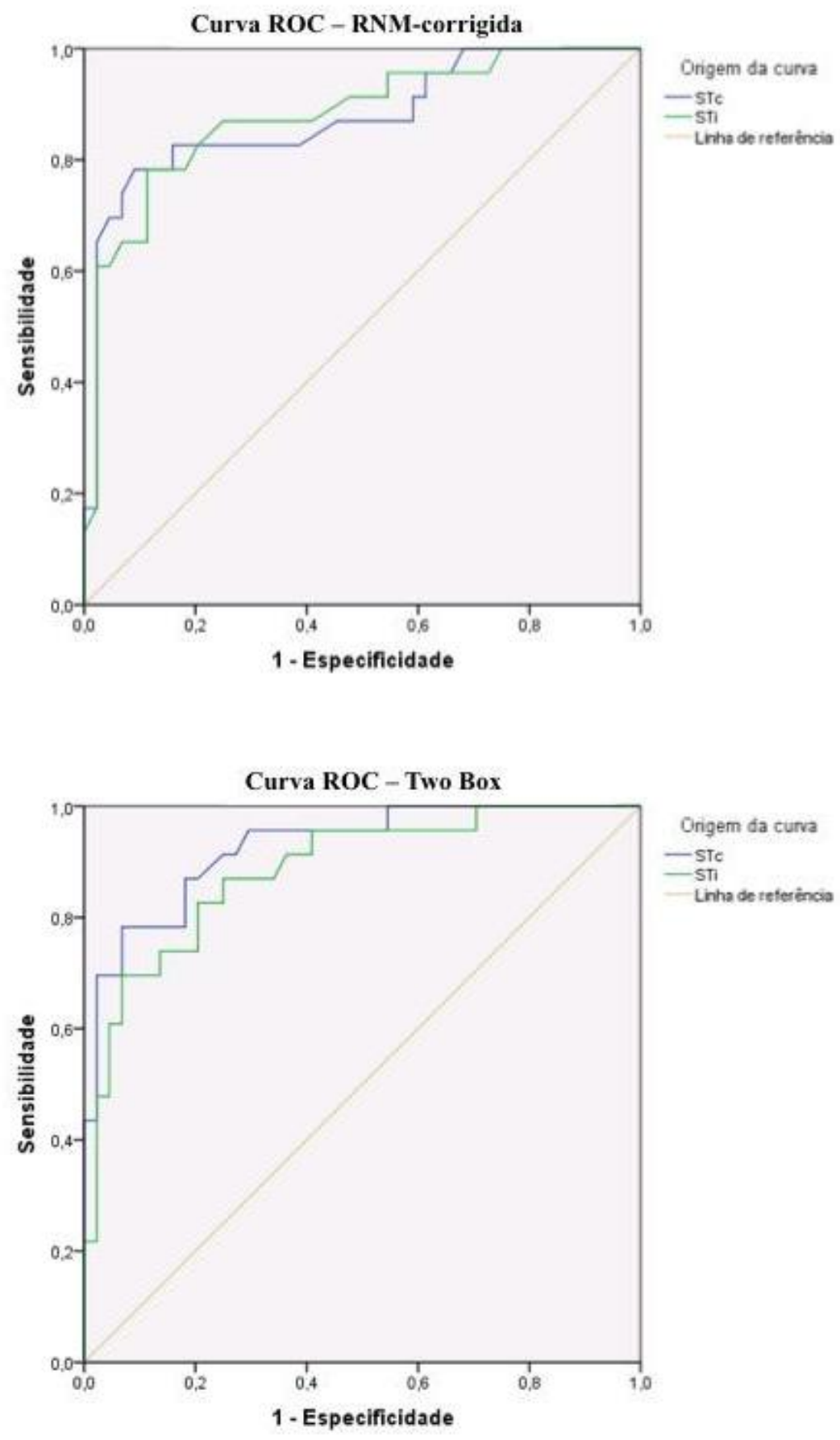

Figura 21: Curvas ROC do BPI para o corpo estriado (ST) ipsilateral (i) e contralateral (c) obtidos pelos métodos por corregistro com RM-corrigida e Two Box. 
A tabela 23 mostra o limiar, sensibilidade e especificidade determinada pelo liminar e área abaixo da curva para cada índice de potencial de ligação. Dentre os métodos, a mais acurado foi o método semiquantitativo manual, seguido pelo Two Box. Para o método manual, a sensibilidade variou entre $95 \%$ e $100 \%$ entre os índices de BPI, e a especificidade variou entre $84 \%$ a $88 \%$, considerando o limiar de normalidade (threshold) adotado. A sensibilidade foi menor nos métodos automáticos (RM e RM-corrigida) considerando o cutoff adotado, sendo em geral, inferior a $80 \%$, dado que representa um número maior de falsos positivos comparando-se aos demais métodos.

A AUC obtida a partir das curvas ROC, que traduz o desempenho do teste, se mostrou satisfatória para todos os índices, especialmente com a aplicação do método manual. O desempenho dos índices de BPI foi bom para a semiquantificação com RM e Two Box, com discreta superioridade para o segundo, variando entre 0,77 a 0,88 e 0,88 a 0,93 , respectivamente. $\mathrm{O}$ método de corregistro com RM-corrigido apresentou resultados discretamente inferiores, variando entre 0,74 a 0,81 . Para o método manual, os resultados foram muito bons, com AUC entre 0,92 a 0,98 . O IC $95 \%$ foi menor para o método manual em relação aos demais. 
Tabela 23: Resultados da curva ROC para o BPI de ST, CA e PU obtidos pelos métodos de semiquantificação.

\begin{tabular}{|c|c|c|c|c|c|c|c|}
\hline & & ST(c) & ST(i) & $\mathbf{P U}(\mathbf{c})$ & $\mathbf{P U}(\mathbf{i})$ & $\mathbf{C A}(\mathbf{c})$ & CA(i) \\
\hline \multirow[t]{4}{*}{ Manual } & Cutoff & 0,74 & 0,78 & 0,73 & 0,74 & 0,8 & 0,88 \\
\hline & Sensibilidade & 1 & 1 & 1 & 0,957 & 1 & 1 \\
\hline & Especificidade & 0,841 & 0,864 & 0,886 & 0,886 & 0,841 & 0,773 \\
\hline & $\begin{array}{l}\text { AUC } \\
(\text { IC 95\%) }\end{array}$ & $\begin{array}{l}0,98 \\
(0,94 ; 1,00)\end{array}$ & $\begin{array}{l}0,94 \\
(0,87 ; 0,99)\end{array}$ & $\begin{array}{l}0,97 \\
(0,93 ; 1,00)\end{array}$ & $\begin{array}{l}0,93 \\
(0,86 ; 0,99)\end{array}$ & $\begin{array}{l}0,96 \\
(0,92 ; 0,99)\end{array}$ & $\begin{array}{l}0,92 \\
(0,86 ; 0,98)\end{array}$ \\
\hline \multirow[t]{4}{*}{$\mathbf{R M}$} & Cutoff & 0,35 & 0,37 & 0,33 & 0,46 & 0,34 & 0,4 \\
\hline & Sensibilidade & 0,783 & 0,783 & 0,739 & 0,783 & 0,826 & 0,739 \\
\hline & Especificidade & 0,932 & 0,886 & 0,864 & 0,955 & 0,795 & 0,841 \\
\hline & $\begin{array}{l}\text { AUC } \\
(\text { IC 95\%) }\end{array}$ & $\begin{array}{l}0,88 \\
(0,79 ; 0,96)\end{array}$ & $\begin{array}{l}0,87 \\
(0,76 ; 0,96)\end{array}$ & $\begin{array}{l}0,80 \\
(0,65 ; 0,93)\end{array}$ & $\begin{array}{l}0,88 \\
(0,79 ; 0,96)\end{array}$ & $\begin{array}{l}0,88 \\
(0,79 ; 0,96)\end{array}$ & $\begin{array}{l}0,77 \\
(0,64 ; 0,90)\end{array}$ \\
\hline \multirow{4}{*}{$\begin{array}{l}\text { RM } \\
\text { corrigida }\end{array}$} & Cutoff & 0,72 & 1,13 & 0,83 & 1,1 & 1,21 & 1,14 \\
\hline & Sensibilidade & 0,783 & 0,783 & 0,783 & 0,78 & 0,783 & 0,739 \\
\hline & Especificidade & 0,909 & 0,886 & 0,682 & 0,91 & 0,841 & 0,818 \\
\hline & $\begin{array}{l}\text { AUC } \\
\text { (IC 95\%) }\end{array}$ & $\begin{array}{l}0,87 \\
(0,78 ; 0,96)\end{array}$ & $\begin{array}{l}0,87 \\
(0,78 ; 0,96)\end{array}$ & $\begin{array}{l}0,74 \\
(0,58 ; 0,96)\end{array}$ & $\begin{array}{l}0,88 \\
(0,79 ; 0,96)\end{array}$ & $\begin{array}{l}0,87(0,77 \\
0,95)\end{array}$ & $\begin{array}{l}0,74 \\
(0,60 ; 0,88)\end{array}$ \\
\hline \multirow[t]{4}{*}{ Two Box } & Cutoff & 1,12 & 1,13 & - & - & - & - \\
\hline & Sensibilidade & 0,87 & 0,826 & - & - & - & - \\
\hline & Especificidade & 0,82 & 0,795 & - & - & - & - \\
\hline & $\begin{array}{l}\text { AUC } \\
\text { (IC 95\%) }\end{array}$ & $\begin{array}{l}0,93 \\
(0,85 ; 0,98)\end{array}$ & $\begin{array}{l}0,88 \\
(0,79 ; 0,96)\end{array}$ & - & - & - & - \\
\hline
\end{tabular}

Legenda: $\mathrm{ST}=$ estriado; $\mathrm{PU}=$ putâmen; $\mathrm{CA}=$ caudado; $(\mathrm{i})=$ ipsilateral; $(\mathrm{c})=$ contralateral, AUC = Area under the curve. 
No caso dos índices de assimetria, obtidos pela semiquantificação manual, como o grupo com DP apresentou uma tendência de maiores valores em relação ao grupo controle, o limiar estabelecido a partir da curva ROC (figura 22) considera que resultados acima deste denotaria uma maior probabilidade de ser referente a paciente portador de DP. Por outro lado, conforme verificado na comparação de médias, indivíduos com DP apresentaram uma tendência a apresentar uma menor relação PU/CA em comparação aos controles saudáveis. Deste modo, o limiar foi estabelecido pela curva ROC (figura 23) para indicar a doença no caso de valores abaixo do mesmo.

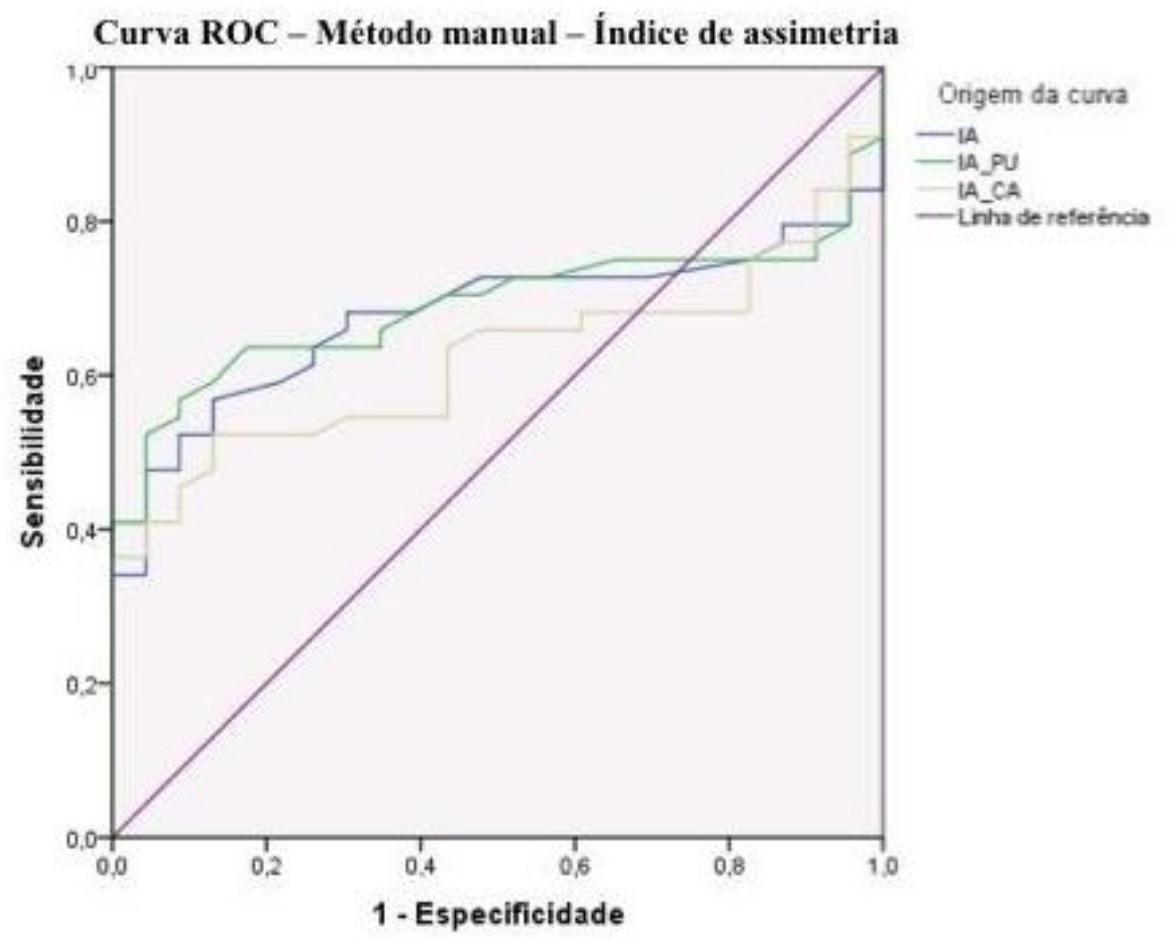

Figura 22: Curvas ROC dos índices de assimetria (IA) obtidos pelo método manual. 


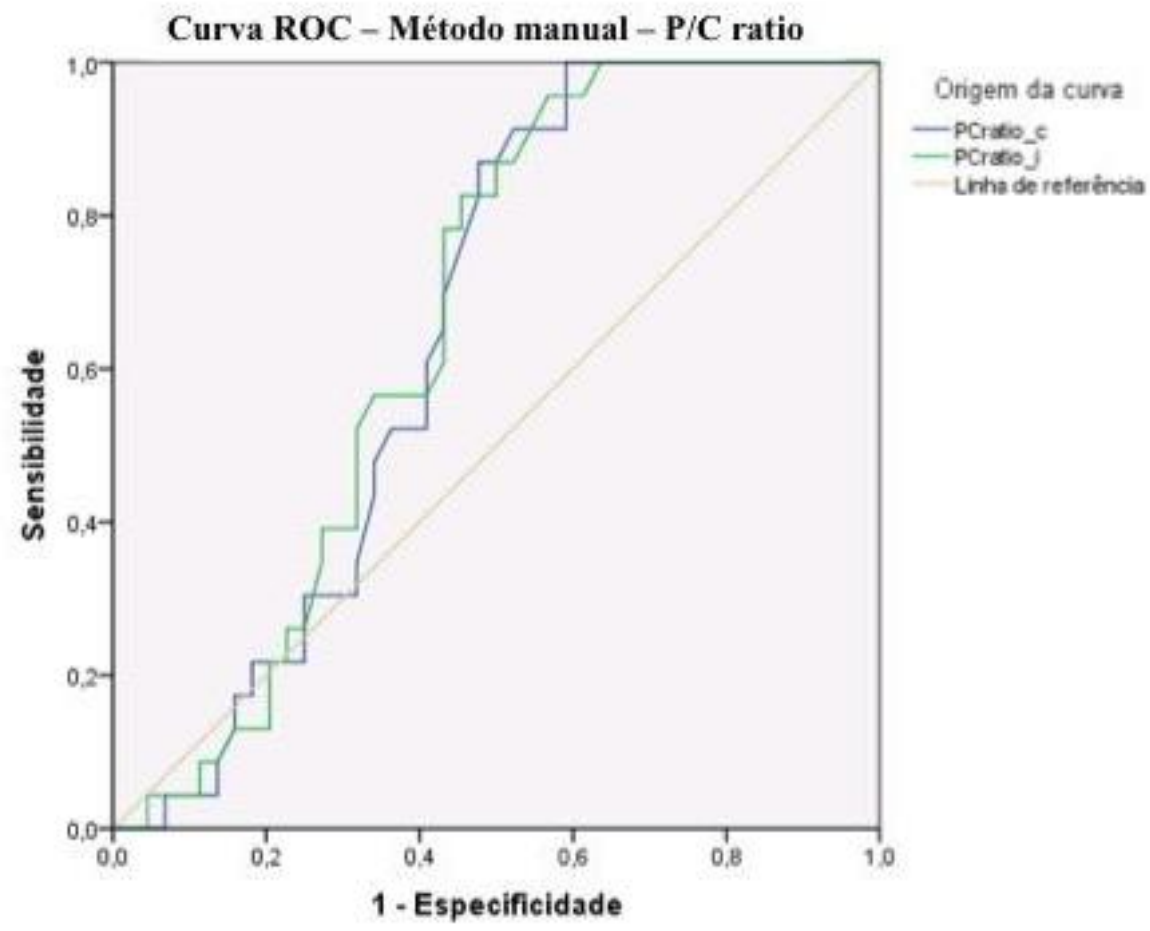

Figura 23: Curvas ROC da razão putâmen pelo caudado $(\mathrm{P} / \mathrm{C})$ obtida pelo método pelo método manual.

As curvas ROC geraram um valor de AUC não satisfatório $(<0,75)$ para IA, IA(PU), IA(CA), PU/CA(i) e PU/CA(c). Neste cenário optou-se por definir limiares (tabela 24) em que $100 \%$ dos pacientes com IA acima do cutoff estabelecido seriam portadores de DP. Do mesmo modo, pacientes com valor de PU/CA abaixo do cutoff estabelecido seriam portadores de DP. 
Tabela 24: Resultados da curva ROC para os índices de assimetria e para a razão entre putâmen e caudado obtidos a partir do método de semiquantificação manual.

\begin{tabular}{llllll}
\hline & IA & IA(PU) & IA(CA) & PU/CA(i) & PU/CA(c) \\
\hline Cutoff & 0,2 & 0,22 & 0,3 & 0,65 & 0,57 \\
Sensibilidade & 0,34 & 0,49 & 0,36 & 1 & 1 \\
Especificidade & 1 & & & & 0,36 \\
$\begin{array}{l}\text { AUC } \\
\text { (IC 95\%) }\end{array}$ & $0,67(0,54 ;$ & $0,68(0,56 ;$ & $0,62(0,49 ;$ & $0,65(0,52 ;$ & $0,66(0,53 ;$ \\
\hline
\end{tabular}

Legenda: $\mathrm{ST}=$ estriado; $\mathrm{PU}=$ putâmen; $\mathrm{CA}=$ caudado; $(\mathrm{i})=$ ipsilateral; $(\mathrm{c})$ = contralateral; $\mathrm{IA}$ = índice de assimetria; $\mathrm{PU} / \mathrm{CA}=$ razão entre putâmen e caudado; $\mathrm{AUC}=$ Area under the curve.

Os resultados mostram que, na presença de IA, IA(PU) e IA(CA) superiores, respectivamente, a 0,2, 0,22 e 0,3, todos os indivíduos eram portadores de DP. O ensaio evidenciou ainda, que valores de PU/CA(i) e PU/CA(c) inferiores a 0,65 e 0,57, respectivamente, identificaram apenas indivíduos com DP.

\subsubsection{Análise de confiabilidade}

Considerando os potenciais de ligação, na avaliação intraobservador (tabela 25), ou seja, entre A1 e A2, para todos os métodos foi encontrado um ICC próximo a 1,0. Na avaliação interobservador, ou seja, entre A1 e B1 (tabela 26), a concordância também foi excelente, com ICC para os índices analisados semelhante entre os métodos de corregistro com RM, RM-corrigida e Two Box, sendo observada discreta vantagem para o Two Box. O método manual apresentou uma confiabilidade menor dentre os métodos, com ICC variando entre 0,76 na quantificação do CA(i), até 0,87 para ST(i), ST(c) e PU(i). 
Tabela 25: Avaliação intraobservador dos métodos semiquantitativos.

\begin{tabular}{|c|c|c|c|c|c|c|c|c|c|c|c|c|}
\hline & \multicolumn{3}{|c|}{ Manual } & \multicolumn{3}{|c|}{$\mathbf{R M}$} & \multicolumn{3}{|c|}{ RM-corrigida } & \multicolumn{3}{|c|}{ Two Box } \\
\hline & ICC & $\begin{array}{c}\text { LI } \\
\text { IC95\% }\end{array}$ & $\begin{array}{c}\text { LS } \\
\text { IC95\% }\end{array}$ & ICC & $\begin{array}{c}\text { LI } \\
\text { IC95\% }\end{array}$ & $\begin{array}{c}\text { LS } \\
\text { IC95\% }\end{array}$ & ICC & $\begin{array}{c}\text { LI } \\
\text { IC95\% }\end{array}$ & $\begin{array}{c}\text { LS } \\
\text { IC95\% }\end{array}$ & ICC & $\begin{array}{c}\text { LI } \\
\text { IC95\% }\end{array}$ & $\begin{array}{c}\text { LS } \\
\text { IC95\% }\end{array}$ \\
\hline ST(i) & 0.98 & 0.97 & 0.99 & 0.9994 & 0.999 & 0.9996 & 0.9996 & 0.9993 & 0.9997 & 0.972 & 0.956 & 0.983 \\
\hline ST(c) & 0.98 & 0.96 & 0.99 & 0.9995 & 0.9992 & 0.9997 & 0.9996 & 0.9993 & 0.9997 & 0.977 & 0.963 & 0.986 \\
\hline PU(i) & 0.98 & 0.96 & 0.99 & 0.9993 & 0.9989 & 0.9996 & 0.9993 & 0.9988 & 0.9995 & - & - & - \\
\hline $\mathbf{P U}(\mathbf{c})$ & 0.97 & 0.94 & 0.98 & 0.9993 & 0.9989 & 0.9996 & 0.9994 & 0.999 & 0.9996 & - & - & - \\
\hline $\mathbf{C A}(\mathbf{i})$ & 0.96 & 0.94 & 0.98 & 0.9996 & 0.9993 & 0.9997 & 0.9997 & 0.9995 & 0.9998 & - & - & - \\
\hline $\mathbf{C A}(\mathbf{c})$ & 0.96 & 0.94 & 0.98 & 0.9991 & 0.9986 & 0.9995 & 0.9991 & 0.9985 & 0.9994 & - & - & - \\
\hline
\end{tabular}

Legenda: $\mathrm{ICC}=$ Coeficiente de Correlação Intra-classe; LI = limite inferior; $\mathrm{LS}=$ limite superior; IC = intervalo de confiança; $\mathrm{ST}=$ corpo estriado; PU = putâmen; CA = núcleo caudado; IA = índice de assimetria; PU/CA = razão de PU por CA; (i) = ipsilateral; (c) = contralateral. 
Tabela 26: Avaliação interobservador dos métodos semiquantitativos.

\begin{tabular}{|c|c|c|c|c|c|c|c|c|c|c|c|c|}
\hline & \multicolumn{3}{|c|}{ Manual } & \multicolumn{3}{|c|}{$\mathbf{R M}$} & \multicolumn{3}{|c|}{ RM-corrigida } & \multicolumn{3}{|c|}{ Two Box } \\
\hline & ICC & $\begin{array}{c}\text { LI } \\
\text { IC95\% }\end{array}$ & $\begin{array}{c}\text { LS } \\
\text { IC95\% }\end{array}$ & ICC & $\begin{array}{c}\text { LI } \\
\text { IC95\% }\end{array}$ & $\begin{array}{c}\text { LS } \\
\text { IC95\% }\end{array}$ & ICC & $\begin{array}{c}\text { LI } \\
\text { IC95\% }\end{array}$ & $\begin{array}{c}\text { LS } \\
\text { IC95\% }\end{array}$ & ICC & $\begin{array}{c}\text { LI } \\
\text { IC95\% }\end{array}$ & $\begin{array}{c}\text { LS } \\
\text { IC95\% }\end{array}$ \\
\hline $\mathbf{S T}(\mathbf{i})$ & 0.87 & 0.8 & 0.92 & 0.931 & 0.891 & 0.957 & 0.936 & 0.899 & 0.96 & 0.94 & 0.9 & 0.96 \\
\hline ST(c) & 0.87 & 0.79 & 0.92 & 0.95 & 0.919 & 0.969 & 0.946 & 0.914 & 0.967 & 0.94 & 0.9 & 0.96 \\
\hline $\mathbf{P U}(\mathbf{i})$ & 0.87 & 0.8 & 0.92 & 0.904 & 0.848 & 0.94 & 0.898 & 0.84 & 0.936 & - & - & - \\
\hline $\mathbf{P U}(\mathbf{c})$ & 0.86 & 0.78 & 0.91 & 0.883 & 0.817 & 0.926 & 0.841 & 0.754 & 0.899 & - & - & - \\
\hline $\mathbf{C A}(\mathbf{i})$ & 0.76 & 0.64 & 0.84 & 0.929 & 0.887 & 0.955 & 0.918 & 0.87 & 0.949 & - & - & - \\
\hline $\mathbf{C A}(\mathbf{c})$ & 0.81 & 0.71 & 0.88 & 0.907 & 0.853 & 0.941 & 0.889 & 0.826 & 0.93 & - & - & - \\
\hline
\end{tabular}

Legenda: ICC = Coeficiente de Correlação Intra-classe; LI = limite inferior; LS = limite superior; IC = intervalo de confiança; ST = corpo estriado; PU = putâmen; CA = núcleo caudado; IA = índice de assimetria; PU/CA = razão de PU por CA; (i) = ipsilateral; (c) = contralateral. 
Por outro lado, considerando apenas o método manual, a confiabilidade intraobservador para cálculo da razão PU/CA e dos índices de assimetria foi satisfatória, exceto para o cálculo do IA(PU), em que se observou uma pobre confiabilidade. Quanto a confiabilidade interobservador, foi pobre para todos os índices (limítrofe para IA(PU), porém com um IC95\% elevado).

Tabela 27: Avaliação da confiabilidade do método semiquantitativo manual referentes aos índices de assimetria e razão putâmen/caudado.

\begin{tabular}{lllllll}
\hline & \multicolumn{3}{c}{ Avaliação interobservador } & \multicolumn{3}{c}{ Avaliação intraobservador } \\
\hline & ICC & LI IC95\% & LS IC95\% & ICC & LI IC95\% & LS IC95\% \\
PU/CA (i) & 0,12 & $-0,12$ & 0,35 & 0,66 & 0,51 & 0,78 \\
PU/CA (c) & $-0,03$ & $-0,27$ & 0,21 & 0,49 & 0,28 & 0,65 \\
IA & 0,35 & $-0,05$ & 0,60 & 0,73 & 0,56 & 0,83 \\
IA (PU) & 0,47 & 0,14 & 0,67 & 0,02 & $-0,61$ & 0,38 \\
IA (CA) & 0,20 & $-0,28$ & 0,51 & 0,51 & 0,20 & 0,70 \\
\hline
\end{tabular}

Legenda: LI = limite inferior; LS = limite superior; IC = intervalo de confiança; ICC = coeficiente de correlação intraclasse; $\mathrm{PU}=$ putâmen; $\mathrm{CA}$ = caudado; $\mathrm{IA}=$ índice de assimetria; $\mathrm{PU} / \mathrm{CA}$ = razão do putâmen pelo caudado; (i) = ipsilateral; (c) = contralateral.

Valores negativos de ICC embora não teoricamente possíveis, podem ser observados na prática como resultado de uma análise estatística. A interpretação nestes casos é de uma pobre correlação (GIRAUDEAU, 1996).

\subsubsection{Correlação com parâmetros clínicos}

Os potenciais de ligação pelos diferentes métodos foram correlacionados com os parâmetros: tempo de duração da doença, UPDRS e HYS (tabela 28). 
Tabela 28: Correlação do BPI com variáveis clínicas para cada método.

\begin{tabular}{|c|c|c|c|c|c|c|c|c|c|}
\hline & & \multicolumn{2}{|c|}{ Manual } & \multicolumn{2}{|c|}{$\mathbf{R M}$} & \multicolumn{2}{|c|}{ RM-corrigida } & \multicolumn{2}{|c|}{ Two Box } \\
\hline & & $\mathbf{R}$ & valor-p & $\mathbf{R}$ & valor-p & $\mathbf{R}$ & valor-p & $\mathbf{R}$ & valor-p \\
\hline \multirow{6}{*}{$\begin{array}{l}\text { Tempo de } \\
\text { duração da } \\
\text { doença }\end{array}$} & ST(i) & $-0,352$ & $0,01 *$ & $-0,212$ & 0,16 & $-0,205$ & 0,18 & $-0,325$ & $0,03^{*}$ \\
\hline & $\mathrm{ST}(\mathrm{c})$ & $-0,256$ & 0,09 & $-0,090$ & 0,56 & $-0,072$ & 0,64 & $-0,222$ & 0,14 \\
\hline & PU(i) & $-0,348$ & $0,02 *$ & $-0,325$ & $0,03 *$ & $-0,328$ & $0,03 *$ & - & - \\
\hline & $\mathbf{P U}(\mathbf{c})$ & $-0,199$ & 0,19 & $-0,131$ & 0,39 & $-0,081$ & 0,60 & - & - \\
\hline & CA(i) & $-0,259$ & 0,09 & $-0,040$ & 0,79 & 0,01 & 0,95 & - & - \\
\hline & $\mathbf{C A}(\mathbf{c})$ & $-0,319$ & $0,03 *$ & $-0,094$ & 0,54 & $-0,09$ & 0,55 & - & - \\
\hline \multirow[t]{6}{*}{ HYS } & ST(i) & $-0,210$ & 0,17 & 0,137 & 0,37 & 0,145 & 0,34 & $-0,231$ & 0,13 \\
\hline & ST(c) & $-0,175$ & 0,25 & 0,082 & 0,59 & 0,075 & 0,62 & $-0,177$ & 0,25 \\
\hline & PU(i) & $-0,91$ & 0,55 & 0,045 & 0,77 & 0,029 & 0,85 & - & - \\
\hline & $\mathbf{P U}(\mathbf{c})$ & $-0,65$ & 0,67 & 0,208 & 0,17 & 0,233 & 0,12 & - & - \\
\hline & CA(i) & $-0,218$ & 0,15 & 0,196 & 0,20 & 0,195 & 0,20 & - & - \\
\hline & $\mathbf{C A}(\mathbf{c})$ & $-0,245$ & 0,11 & $-0,027$ & 0,86 & $-0,062$ & 0,69 & - & - \\
\hline \multirow[t]{6}{*}{ UPDRS-3 } & ST(i) & $-0,305$ & $0,04 *$ & $-0,047$ & 0,76 & $-0,033$ & 0,83 & $-0,262$ & 0,08 \\
\hline & ST(c) & $-0,183$ & 0,23 & $-0,62$ & 0,68 & $-0,074$ & 0,63 & $-0,171$ & 0,26 \\
\hline & $\mathbf{P U}(\mathbf{i})$ & $-0,155$ & 0,31 & $-0,121$ & 0,43 & $-0,123$ & 0,42 & - & - \\
\hline & $\mathbf{P U}(\mathbf{c})$ & $-0,121$ & 0,43 & $-0,072$ & 0,64 & $-0,043$ & 0,78 & - & - \\
\hline & CA(i) & $-0,329$ & $0,02 *$ & 0,037 & 0,81 & 0,083 & 0,59 & - & - \\
\hline & $\mathbf{C A}(\mathbf{c})$ & $-0,239$ & 0,11 & $-0,050$ & 0,74 & $-0,064$ & 0,68 & - & - \\
\hline
\end{tabular}

Legenda: $\mathrm{R}=$ coeficiente de correlação; $\mathrm{ST}$ = estriado; $\mathrm{PU}=$ putâmen; $\mathrm{CA}=$ caudado; $(\mathrm{i})=$ ipsilateral; $(\mathrm{c})=$ contralateral. ${ }^{*} p$-value $<0,05$

Considerando apenas o método manual, foi observada uma correlação negativa entre os valores de potencial de ligação no corpo estriado com o UPDRS-3, HYS e tempo de duração de doença. Em outras palavras, casos mais avançados e com sintomas motores mais exuberantes, definidos respectivamente por HYS e UPDRS-3, bem como casos com maior tempo de evolução, mostraram uma tendência de se apresentar com um déficit de captação do TRODAT-1 mais evidente. Para UPDRS-3, foi encontrada significância estatística para os índices de BPI do ST(i) e do CA(i), embora o nível de correlação seja pobre, enquanto que para o HYS, nenhum dos índices semiquantitativos avaliados apresentou correlação significante ( $p$-value > 0,05). Os gráficos de dispersão (figura 24) mostram essa tendência de redução do BPI com o aumento de pontuação no UPDRS-3 e na HYS. 

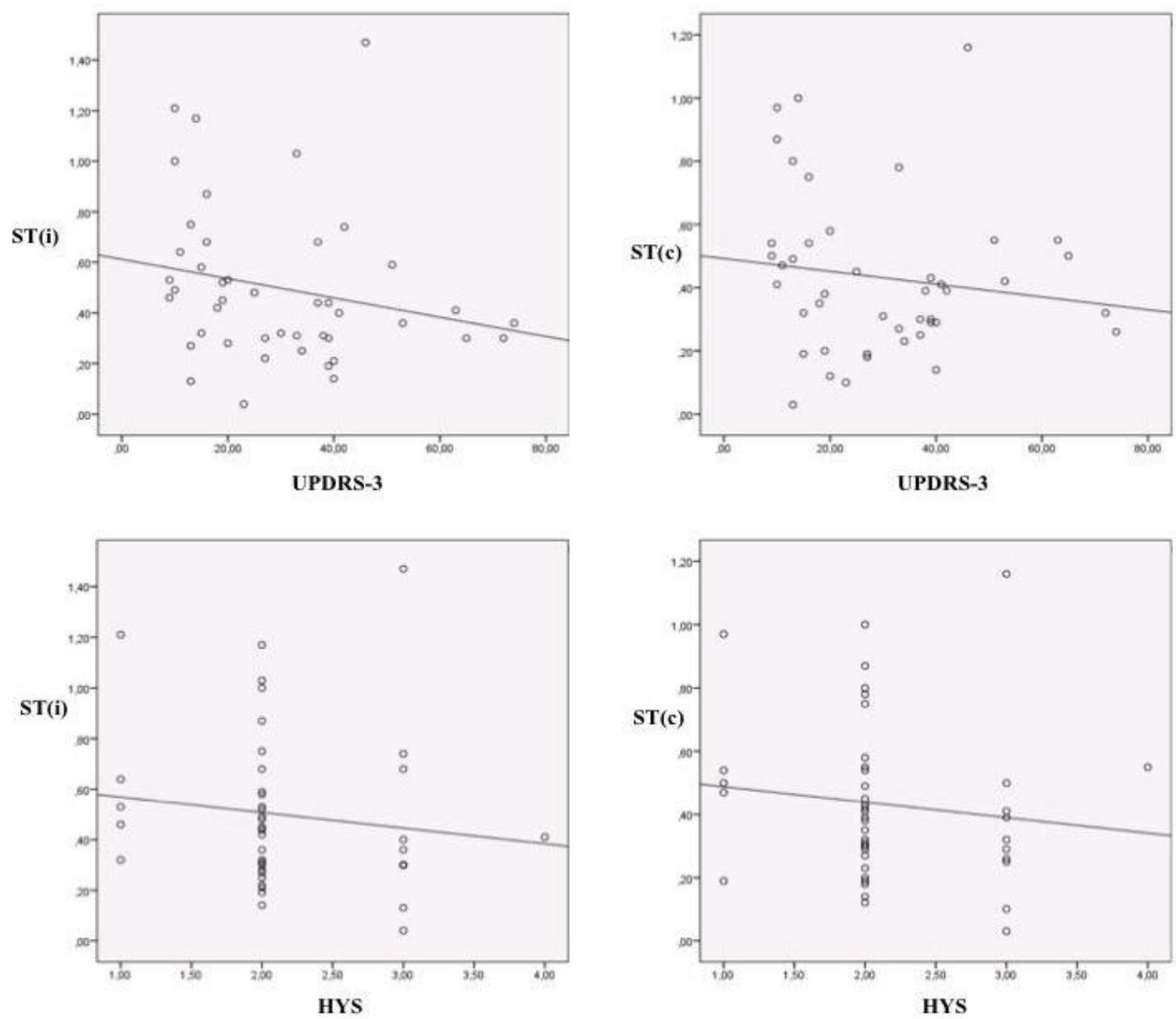

Figura 24: Correlação entre BPI de ST(i) e ST(c) obtidos pelo método manual com o UPDRS-3 e HYS.

No caso dos índices obtidos pela RM e RM-corrigida, apenas foi encontrada correlação significante entre PU(i) e o tempo de duração da doença. Os coeficientes de correlação (R) foram inferiores aos obtidos pelo método manual. A tendência de correlação foi a mesma da apresentada pelo método manual, exceto no caso da variável HYS. O método Two Box, por sua vez, seguiu a mesma tendência do método manual, com valores de R semelhantes, embora com valor- $p>0,05$ em todos os casos.

Considerando este cenário, foi proposta a aplicação de teste de correlação linear entre a escala dos sintomas motores (UPDRS-3) e BPI obtidos pelo método manual, porém dividindo a amostra em 2 grupos, um deles com pacientes em estágios iniciais da doença (HYS I e II), e outro com pacientes em estágios mais avançados (HYS III e IV). Pacientes com HYS I/II apresentavam UPDRS-3 médio de 23,9 \pm 12,6, e pacientes com HYS III/IV apresentavam UPDRS-3 médio de 46,8 \pm 19,7. Os resultados estão dispostos na tabela 29. 
Tabela 29: Correlação entre UPDRS-3 e o BPI em subgrupos (HYS I/II) e (HYS III/IV).

\begin{tabular}{lllll}
\hline & \multicolumn{2}{l}{ HYS I/II } & \multicolumn{2}{l}{ HYS III/IV } \\
\hline & R & valor-p & R & valor-p \\
ST(i) & $-0,5$ & $0,02 *$ & 0,2 & 0,4 \\
ST(c) & $-0,4$ & $0,02 *$ & 0,56 & 0,07 \\
PU(i) & $-0,39$ & $0,03 *$ & 0,31 & 0,3 \\
PU(c) & $-0,38$ & $0,03 *$ & 0,4 & 0,14 \\
CA(i) & $-0,57$ & $0,01 *$ & 0,4 & 0,5 \\
CA(c) & $-0,4$ & $0,02 *$ & 0,54 & 0,08 \\
\hline
\end{tabular}

Legenda: $\mathrm{R}$ = coeficiente de correlação; $\mathrm{ST}$ = estriado; $\mathrm{PU}=$ putâmen; $\mathrm{CA}=$ caudado; $(\mathrm{i})=$ ipsilateral; $(\mathrm{c})=$ contralateral. *p-value $<0,05$

Os dados evidenciam correlação linear significante entre BPI do estriado e subestruturas com os sintomas motores avaliados por UPDRS-3 no grupo de doentes em fase inicial. No grupo com doença avançada a correlação não esteve presente em nenhum dos índices. O comportamento do gráfico a seguir (figura 25) evidencia a correlação negativa, que foi maior do que considerando toda a amostra.
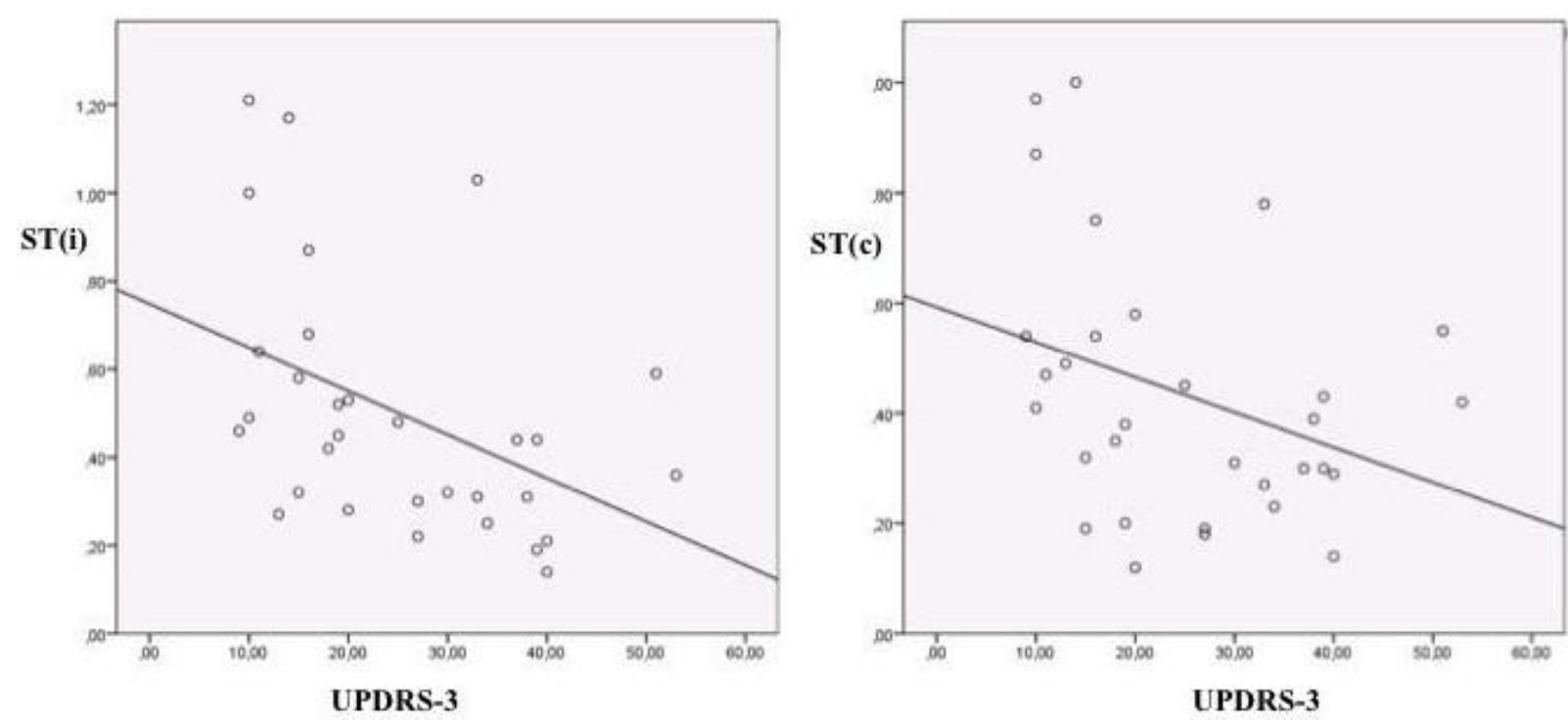

Figura 25: Gráficos de dispersão do BPI do corpo estriado correlacionado ao UPDRS-3 em grupo com doença de Parkinson em fase inicial (HYS I e II). 


\subsection{Comparação da densidade de DAT nos grupos com e sem discinesia}

Considerando os 44 pacientes com DP submetidos ao SPECT com $\left[{ }^{99 \mathrm{~m}}\right.$ Tc]-TRODAT1, 21 apresentavam discinesia induzida por levodopa (LID), enquanto 23 não apresentaram qualquer movimento anormal involuntário (AIM).

Dentre as variáveis independentes indicadas na tabela 30, foram explanatórias para a ocorrência de discinesia $(p<0,05)$ : tempo de duração da doença, idade do aparecimento dos sintomas, dosagem da levodopa, número de doses administradas ao longo do dia, duração do efeito da levodopa, UPDRS e HYS. Não foi encontrada diferença estatisticamente significante entre os grupos para as variáveis sexo, idade e escolaridade.

Tabela 30: Comparação entre médias de variáveis clínicas entre os grupos com e sem discinesia.

\begin{tabular}{|c|c|c|c|c|c|c|}
\hline & LIDpos & LIDneg & $\begin{array}{l}\text { LIDneg - } \\
\text { LIDpos }\end{array}$ & $\begin{array}{c}\text { LI } \\
\text { IC95 }\end{array}$ & $\begin{array}{c}\text { LS } \\
\text { IC95 }\end{array}$ & valor-p \\
\hline $\operatorname{Sexo}(F / M)$ & $9 / 12$ & $6 / 17$ & - & - & - & 0,94 \\
\hline Idade (anos) & $\begin{array}{c}59,29 \pm 6.05 \\
(49-68)\end{array}$ & $\begin{array}{c}60,70 \pm 8,80( \\
44-73)\end{array}$ & 1,41 & $-3,22$ & 6,04 & 0,54 \\
\hline $\begin{array}{l}\text { Escolaridade } \\
\text { (anos) }\end{array}$ & $\begin{array}{l}6,48 \pm 3,75 \\
\quad(2-16)\end{array}$ & $\begin{array}{l}5,52 \pm 4,44 \\
\quad(0-20)\end{array}$ & $-0,95$ & $-3,46$ & 1,55 & 0,45 \\
\hline $\begin{array}{l}\text { Idade de início dos } \\
\text { sintomas (anos) }\end{array}$ & $\begin{array}{c}46,62 \pm 7,30 \\
(35-60)\end{array}$ & $\begin{array}{c}53,65 \pm 11,32 \\
(33-70)\end{array}$ & 7,03 & 1,17 & 12,89 & $0,01 *$ \\
\hline $\begin{array}{l}\text { Tempo de duração } \\
\text { da doença }\end{array}$ & $\begin{array}{c}12,76 \pm 4,95( \\
3-21)\end{array}$ & $\begin{array}{c}6,96 \pm 4,61 \\
(1-17)\end{array}$ & $-5,8$ & $-8,71$ & $-2,9$ & $<0,01 * *$ \\
\hline $\begin{array}{l}\text { Dose diária de } \\
\text { levodopa }\end{array}$ & $\begin{array}{c}994,05 \pm 410,02 \\
(500-2250)\end{array}$ & $\begin{array}{c}526,19 \pm 313,70 \\
(150-1200)\end{array}$ & $-0,72$ & $-1,03$ & $-0,42$ & $<0,01 * *$ \\
\hline $\begin{array}{l}\text { Número de doses } \\
\text { ao dia }\end{array}$ & $6,00 \pm 1,79(3-9)$ & $\begin{array}{c}3,95 \pm 1,43 \\
(3-8)\end{array}$ & $-0,42$ & $-0,61$ & $-0,22$ & $<0,01 * *$ \\
\hline $\begin{array}{l}\text { Duração do efeito } \\
\text { da levodopa (h) }\end{array}$ & $3,62 \pm 1,80(2-9)$ & $\begin{array}{l}6,14 \pm 2,83 \\
\quad(2-12)\end{array}$ & 0,51 & 0,24 & 0,79 & $<0,01 * *$ \\
\hline HYS & $\begin{array}{l}2,48 \pm 0,6 \\
\quad(2-4)\end{array}$ & $\begin{array}{c}1,86 \pm 0,56 \\
\quad(1-3)\end{array}$ & $-0,61$ & $-0,95$ & $-0,25$ & $0,01^{*}$ \\
\hline UPDRS & $\begin{array}{c}35,57 \pm 16,2 \\
(13-74)\end{array}$ & $\begin{array}{c}24,83 \pm 17,54 \\
(9-72)\end{array}$ & $-10,74$ & $-21,0$ & $-0,46$ & $0,04 *$ \\
\hline
\end{tabular}

Legenda: LIDpos = discinesia induzida por levodopa positiva; LIDneg = discinesia induzida por levodopa negativa; F= sexo feminino; $\mathrm{M}$ = sexo masculino; $\mathrm{LI}=$ limite inferior; $\mathrm{LS}=$ limite superior; $\mathrm{IC}=$ intervalo de confiança. Os valores foram descritos como média \pm desvio padrão (intervalo). *valor- $p<0,05 ; * *$ valor- $p<0,01$ 
A mesma análise foi realizada para o potencial de ligação nos corpos estriados, putâmens e núcleos caudados (tabela 31).

Tabela 31: Comparação entre médias dos potenciais de ligação dos grupos com e sem discinesia.

\begin{tabular}{|c|c|c|c|c|c|c|}
\hline & LIDpos & LIDneg & $\begin{array}{l}\text { LIDneg - } \\
\text { LIDpos }\end{array}$ & LI IC95 & LS IC95 & valor-p \\
\hline ST(i) & $\begin{array}{l}0,4 \pm 0,25 \\
(0,04-1,03)\end{array}$ & $\begin{array}{c}0,58 \pm 0,34 \\
(0,19-1,47)\end{array}$ & 0,18 & $-0,004$ & 0,37 & $0,02 *$ \\
\hline ST(c) & $\begin{array}{c}0,34 \pm 0,20 \\
(0,03-0,78)\end{array}$ & $\begin{array}{c}0,49 \pm 0,27 \\
(0,19-1,16)\end{array}$ & 0,15 & 0,004 & 0,30 & $0,02 *$ \\
\hline PU(i) & $\begin{array}{c}0,33 \pm 0,22 \\
(0,03-0,96)\end{array}$ & $\begin{array}{c}0,48 \pm 0,37 \\
(0,13-1,47)\end{array}$ & 0,15 & $-0,3$ & 0,34 & 0,06 \\
\hline $\mathbf{P U}(\mathbf{c})$ & $\begin{array}{c}0,29 \pm 0,18 \\
(0,01-0,61)\end{array}$ & $\begin{array}{c}0,42 \pm 0,28 \\
(0,08-1,10)\end{array}$ & 0,12 & $-0,02$ & 0,27 & 0,06 \\
\hline CA(i) & $\begin{array}{c}0,49 \pm 0,34 \\
(0,01-1,20)\end{array}$ & $\begin{array}{c}0,73 \pm 0,33 \\
(0,32-1,51)\end{array}$ & 0,23 & 0,023 & 0,44 & $0,01 *$ \\
\hline $\mathbf{C A}(\mathbf{c})$ & $\begin{array}{c}0,42 \pm 0,29 \\
(0,02-1,30)\end{array}$ & $\begin{array}{c}0,59 \pm 0,29 \\
(0,21-1,28)\end{array}$ & 0,16 & $-0,13$ & 0,35 & $0,01 *$ \\
\hline
\end{tabular}

Legenda: LIDpos = discinesia induzida por levodopa positiva; LIDneg = discinesia induzida por levodopa negativa; $\mathrm{LI}=$ limite inferior; $\mathrm{LS}=$ limite superior; $\mathrm{IC}=$ intervalo de confiança; $\mathrm{ST}=$ estriado; $\mathrm{PU}=$ putâmen; $\mathrm{CA}=$ caudado; (i) $=$ ipsilateral; (c) = contralateral. Os valores foram descritos como média \pm desvio padrão (intervalo). *valor-p $<0,05$

Os resultados mostram diferença entre os grupos para as seguintes variáveis independentes: ST(i), ST(c), CA (i) e CA(c). Quanto ao potencial de ligação dos putâmens, representados como PU(i) e PU(c), foi observada uma diferença entre as médias dos grupos, sendo menor no grupo com discinesia, contudo não houve comprovação estatística (valor-p > $0,05)$. 


\section{Discussão}

A Medicina Nuclear é uma especialidade médica que se ocupa do diagnóstico, tratamento e investigação médica mediante o uso de radioisótopos como fontes radioativas abertas. Na rotina prática, habitualmente são administradas pequenas quantidades de materiais radioativos, conhecidos como radiofármacos, com o objetivo de avaliar uma função fisiológica específica ou detectar condições patológicas (SIEGEL; THAKUR, 2004). Para a detecção de qualquer condição patológica é fundamental conhecer a biodistribuição normal do radiofármaco após sua administração no indivíduo, ou seja, conhecer o padrão de imagem normal.

Na última década, o campo de imagem molecular (SPECT e PET) entrou em uma nova era de exploração de doenças neurológicas e provou ser uma ferramenta poderosa para a investigação do cérebro humano, que se caracteriza por regiões e redes altamente interconectadas, envolvidas com funções motoras, cognitivas e comportamentais. Várias das recentes abordagens no campo das imagens moleculares ainda estão em desenvolvimento e provavelmente não são capazes de fornecer respostas definitivas, mas representam ferramentas valiosas para melhorar nossa compreensão dos mecanismos moleculares básicos e fisiopatológicos de processos subjacentes a distúrbios parkinsonianos. Um atual desafio é identificar biomarcadores que possam precocemente predizer a doença, prognosticar a progressão da doença e predizer manifestações relacionadas ao parkinsonismo (STRAFELLA et al., 2017).

A degeneração dos neurônios nigroestriatais é responsável pela maioria das manifestações motoras clássicas na DP inicial. Embora os níveis de dopamina não possam ser medidos diretamente utilizando métodos de imagens, várias abordagens podem ser utilizadas para avaliar a função neuronal terminal do sistema nigroestriatal. A técnica mais amplamente aplicada consiste no uso de marcador para transportador de dopamina. Esses traçadores variam em termos farmacocinéticos e em grau de seletividade para DAT (STRAFELLA et al., 2017). O presente trabalho foi realizado através da aplicação de [ ${ }^{99 \mathrm{~m}} \mathrm{Tc}$ \}-TRODAT-1 para avaliação da densidade de DAT no corpo estriado, único radiofármaco disponível no Brasil para esta finalidade.

\subsection{Densidade de DAT no grupo controle saudável}

Os protocolos estabelecidos para definir a metodologia de realização e interpretação 
dos estudos de DAT caracterizam a imagem do corpo estriado como em formato de ponto e vírgula ou em crescente no plano axial É descrita uma alta relação de contraste entre o órgão alvo e não alvo (background) em todas as escalas de cores e em todas as faixas etárias. A captação deve ser simétrica ou levemente assimétrica, e deve ser semelhante entre o putâmen e o caudado (DJANG et al., 2012). Estes guidelines entretanto, não estabelecem de forma objetiva o grau de assimetria entre as estruturas que pode ser considerado normal, assim como não padronizam a razão entre putâmen e caudado para um grupo saudável.

Em todos os casos incluídos no grupo controle, qualitativamente foi possível observar uma boa relação alvo (corpo estriado) e não alvo (occipital). A relação entre a captação média

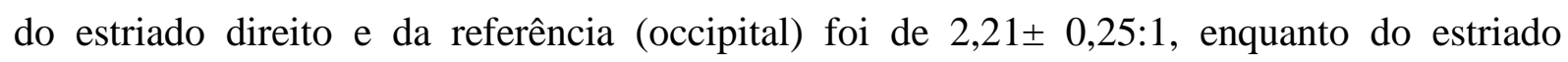
esquerdo foi de 2,18 \pm 0,21:1. Em modelos pré-clínicos com [ $\left.{ }^{99 \mathrm{~m}} \mathrm{Tc}\right\}$-TRODAT, em média, a relação entre o corpo estriado e a estrutura de referência foi maior, de 3,5:1 (MOZLEY et al., 1998).

Os valores de semiquantificação encontrados de BPI estão inseridos dentro de uma faixa de resultados obtidos por outros estudos na literatura. Para um grupo saudável, a média encontrada de BPI do ST nesses trabalhos, que tratam especificamente de SPECT com $\left[{ }^{99 \mathrm{~m}} \mathrm{Tc}\right.$ ]-TRODAT, variou entre 0,82 a 4,71 (BADIAVAS et al., 2011; BOR-SENG-SHU et al., 2014; DAVID MOZLEY et al., 2000; GENG et al., 2005; HUANG et al., [s.d.]; HWANG et al., 2004; YIN et al., 2014), considerando apenas cálculos manuais. Um estudo com população brasileira avaliou 9 pacientes controles saudáveis, 6 homens, 3 mulheres, com média de 51 anos de idade (43-57), utilizando protocolo de aquisição semelhante, porém com método de reconstrução de retroprojeção filtrada, filtro Butterworth de 0,45, e evidenciou os seguintes valores das medianas de BPI para ST, CA e PU, respectivamente: 1,18 $(1,03 ; 1,41)$; $1,64(1,55 ; 2,18)$; e $1,22(0,92 ; 1,36)$ (BOR-SENG-SHU et al., 2014). Estes valores se aproximam dos obtidos pelo nosso estudo, mantendo um padrão de maior captação no caudado em relação ao putâmen, porém mais proeminente do que o obtido no presente trabalho.

Esta variabilidade de valores de referência entre serviços faz com que seja necessário uma referência de normalidade própria, adequada à metodologia aplicada na aquisição das imagens e no seu processamento, bem como adequada ao equipamento em uso, de tal forma a evitar erros na interpretação dos exames.

Quanto aos demais índices (IA e PU/CA), são menos utilizados na prática clínica, e menos frequentemente avaliados pelos estudos científicos. Caracterizar esses índices num grupo saudável pode ser relevante para padronizar de uma forma objetiva a interpretação de 
uma imagem de SPECT com [ $\left.{ }^{99 \mathrm{~m}} \mathrm{Tc}\right]-$ TRODAT-1 normal, e pode servir como base para comparar com exames de pacientes com DP e outras desordens de movimento, que cursam com alterações no sistema dopaminérgico. O estudo de Hwang e colaboradores descreve uma captação simétrica do [ ${ }^{99 \mathrm{~m}} \mathrm{Tc}$ - - TRODAT, portanto com IA próximo a 0 (zero) (WENG et al., 2004). Por outro lado, o PU/CA apresentou uma média inferior a 1, visto que o CA tende a apresentar maior BPI em relação ao PU. A razão entre PU/CA girou em torno de $0.63 \pm 0.05$ (WENG et al., 2004), enquanto no presente estudo variou entre $0,85 \pm 0,18$ a 0,87 $\pm 0,17$. Naturalmente, esta diferença era esperada tendo em visto a variabilidade entre estudos, causada por diversos fatores já citados.

\subsubsection{Correlação com classe social, gênero e idade}

Atualmente, pouco é conhecido sobre o papel da condição socioeconômica em relação ao risco para o desenvolvimento da DP e ao impacto que pode causar na mortalidade desses indivíduos (YANG et al., 2016). Sabe-se entretanto, que o nível de escolaridade e a classe socioeconômica podem interferir em avaliações neuropsicológicas (FOSS; VALE; SPECIALI, 2005) e até mesmo no desenvolvimento de habilidades motoras (JULIUS et al., 2016). Em geral, os autores não comparam médias de potencial de ligação no corpo estriado entre diferentes classes sociais. No presente estudo foi evidenciado não haver diferença entre as classes, considerando o Critério Brasil de avaliação socioeconômica (PILLI et al., 2016), e deste modo, o padrão de imagem e os índices semiquantitativos do SPECT com [ ${ }^{99 \mathrm{~m}} \mathrm{Tc}$ ]TRODAT-1 desses pacientes devem ser avaliados da mesma forma.

Em relação a comparação de médias de BPI entre gêneros, no presente estudo não foi encontrada qualquer diferença significante dos índices entre o sexo masculino e feminino. A maioria dos estudos com DAT-SPECT na literatura reportam não haver diferença estatisticamente significante ou descrevem densidade maior nas mulheres (KAASINEN et al., 2015). Um estudo com [ ${ }^{99 \mathrm{~m}} \mathrm{Tc}$ ]-TRODAT de Weng e colaboradores com 40 indivíduos não encontrou diferença estatística entre gêneros (WENG et al., 2004). Por outro lado, em estudo de Chen e colaboradores, com 112 indivíduos, houve diferença significante, com BPI 2,8\% maior nas mulheres do que nos homens (CHEN et al., 2011). No presente estudo não foi encontrada qualquer diferença significante dos índices entre o sexo masculino e feminino. Como se vê, mesmo que exista alguma diferença, esta é percentualmente pequena e com pouco significado clínico na prática clínica.

A influência da idade no potencial de ligação do corpo estriado em estudos de DAT- 
SPECT tem sido constantemente descrita como tendo uma correlação negativa, ou seja, com o aumento da idade ocorre uma redução na BPI (KAASINEN et al., 2015). Já no final da década de 90, Mozley e colaboradores descreveram uma queda percentual do BPI ao SPECT com [ $\left.{ }^{99 \mathrm{~m}} \mathrm{Tc}\right]-T R O D A T$ correlacionada com a idade. A redução do índice variou entre $2,9 \%$ a 10,9\% por década de vida. Este estudo com 55 pacientes considerou pacientes saudáveis entre 18 e 73 anos. A queda por faixa etária foi notadamente maior nos adultos jovens, a partir da segunda década até meados dos 30 anos de idade. A partir do fim da terceira década até o fim dos 60 anos foi descrita uma relativa estabilidade biológica, com uma redução percentual pequena no BPI (inferior a 3,0 \%). Esta estabilidade é consistente com o fato de encontrarmos valores de BPI em indivíduos com mais de 70 anos similares a de indivíduos próximos a 30 anos (DAVID MOZLEY et al., 1999, 2000).

Em nosso estudo foram incluídos pacientes a partir de 40 anos de idade. Embora tenha sido observada tendência para uma queda dos índices de potencial de ligação por década de vida até o final dos 60 anos, não houve significância estatística. Este dado corrobora com a hipótese de uma relativa estabilidade da densidade dos transportadores dopaminérgicos a partir de 40 anos de idade e, portanto, os valores de referência de normalidade podem ser utilizados para este grupo de pacientes. Para indivíduos mais jovens, entretanto, outro estudo com população específica deve ser realizado para a definição de limiares de normalidade mais adequados.

\subsection{Análise qualitativa do SPECT com $\left[{ }^{99 \mathrm{~m}}\right.$ Tc]-TRODAT-1}

O padrão de imagem cerebral com $\left[{ }^{99 \mathrm{~m}} \mathrm{Tc}\right]-T R O D A T-1$ em pacientes com DP é habitualmente descrito como uma redução da densidade de transportadores dopaminérgicos no corpo estriado preferencialmente do lado contralateral ao predomínio dos sintomas, iniciando a partir do putâmen para o caudado, ou seja, com um gradiente rostrocaudal (BOOTH et al., 2015a; MEYER; FRINGS; HELLWIG, 2014; MEYER; HELLWIG, 2014; STRAFELLA et al., 2017). Todos os marcadores pré-sinápticos de função dopaminérgica apresentam um padrão muito parecido na DP. Observações post-mortem descrevem que a maioria das mudanças no putamen ocorre tipicamente dentro dos primeiros 5 anos de doença (STRAFELLA et al., 2017).

Apesar da crescente importância da aplicação de métodos quantitativos na medicina nuclear, a inspeção visual do DAT-SPECT mostra ótimos resultados em leitores treinados, 
visto que um substancial número de sinapses estriatais devem estar degeneradas quando o paciente se torna sintomático (DJANG et al., 2012).

Acton e colaboradores realizaram um estudo para determinar a acurácia do SPECT com [ ${ }^{99 \mathrm{~m}} \mathrm{Tc}$ \}-TRODAT para o diagnóstico de DP, comparando-se a avaliação manual semiquantitativa com a avaliação visual. A amostra foi composta por 81 pacientes e 94 controles saudáveis. A avaliação qualitativa mostrou desempenho diagnóstico similar à da quantificação, com AUC média de 0,89 (ACTON et al., 2006).

No presente trabalho foram encontrados elevados parâmetros de acurácia diagnóstica para a DP por meio da avaliação qualitativa isoladamente. Considerando as 3 leituras realizadas, a sensibilidade variou entre $90,91 \%$ a $95,45 \%$, especificidade entre $91,3 \%$ a 100 $\%$, e a acurácia entre 95,52\% a 92,54 \% . A concordância intraobservador foi alta, porém, a concordância interobservador apresentou resultados moderados, considerando a interpretação binária (positivo versus negativo), e reduziu de forma importante (baixa correlação) quando as imagens foram graduadas pela classificação de Benamer (BENAMER et al., 2000) e por escala modificada. Deve-se ressaltar que ambos os avaliadores do estudo apresentavam experiência em neuroimagem e, portanto, entre médicos inexperientes, o esperado é uma divergência maior nas leituras. Uma possível explicação para esta variabilidade interobservador consiste na pior relação alvo/não alvo nas imagens dos portadores de DP, fato que dificulta a individualização das estruturas.

Por fim, ao contrário de trabalhos anteriores (HUANG et al., 2004; OTTAVIANI et al., 2006), que descreveram uma boa ou satisfatória correlação entre o grau de alteração na avaliação qualitativa com HYS e com o UPDRS-3, nosso estudo encontrou apenas uma tendência de correlação negativa, não significante. Somente foi identificada uma associação negativa fraca entre o tempo de duração da doença e a avaliação qualitativa do tipo III (Benamer-modificado).

Os resultados reforçam a idéia que a avaliação qualitativa deve ser aplicada e é acurada quando se tem conhecimento dos padrões de imagem, já que a análise visual é observador dependente. Sua interpretação é mais variável quando se busca graduar o nível de déficit de DAT, ao invés de apenas definir o diagnóstico. Sendo assim, para o diagnóstico diferencial a avaliação qualitativa é na maioria das vezes suficiente e resolutiva. Todavia, para o acompanhamento da doença, esta variabilidade associada a não correlação com dados clínicos torna questionável sua aplicação. 


\subsection{Análise e comparação dos métodos quantitativos}

Em um contexto de rotina clínica, uma análise qualitativa da captação estriatal é a abordagem mais comum para a elaboração de um laudo médico. A maioria dos exames pode ser facilmente analisaa e descrita por um médico experiente. No entanto, em exames duvidosos, caracterizados por uma alta discrepância interobservador, ou quando uma avaliação de progressão da doença é requerida, a avaliação semiquantitativa pode ser útil (SKANJETI et al., 2015). Uma análise quantitativa pode fornecer um valor de referência para expressar a ampla variabilidade clínica, pode auxiliar no monitoramento de tratamentos neuroprotetores e realizar diagnósticos mais precoces, visualmente não identificáveis. Por todas estas razões, a semiquantificação tem sido encorajada pela Associação Europeia de Medicina Nuclear e Imagem Molecular (EANM) (DJANG et al., 2012; SKANJETI et al., 2015).

A análise das neurotransmissões dopaminérgicas por imagens de SPECT e PET cerebrais adquiridas em um tempo ótimo, para obter uma simples razão entre a ligação a tecido específico e outro não específico, é um método validado clinicamente (HOLTBERND; EIDELBERG, 2014; SHIH et al., 2006a). Definir uma região de interesse (ROI) de um tecido alvo e outro não alvo (não relacionado ao sistema dopaminérgico, ex., região occipital ou cerebelo) é necessário neste tipo de método baseado em proporções. Os ROIs podem ser delineados por vários métodos: manual, uso de um limiar de contagem máxima dentro da área estriatal, posicionamento de formas geométricas, uso de modelos padrões, corregistro ou desenho manual em imagens de CT ou RM, e ainda através do uso mapeamento estatístico paramétrico (SPM; Wellcome Trust Center for Neuroimaging) (YIN et al., 2014).

Os métodos quantitativos na medicina nuclear têm como principal prerrogativa a redução da subjetividade e da variabilidade interobservadores nas interpretações. Porém, conforme o método utilizado, graus diversos de dependência do observador ainda podem ser encontrados, como por exemplo no desenho manual de uma área de interesse a ser quantificada, suscetível a influência das habilidades e da experiência do avaliador.

O desenvolvimento de protocolos de quantificação aplicados a medicina nuclear como o Two Box ou métodos automáticos de corregistro com RM e CT visa minimizar a subjetividade do profissional especialista na avaliação quantitativa, aumentando a acurácia do estudo, ao mesmo tempo que simplifica este processo. Alguns vieses podem estar presentes, como a baixa resolução espacial e o efeito de volume parcial (SCHERFLER et al., 2005; SEPPI; SCHOCKE, 2005; TOSSICI-BOLT et al., 2006, 2011; VERHOEFF et al., 1993). 


\subsubsection{Comparação entre médias dos grupos DP e controle}

A diferença nos níveis de BPI entre os grupos de controles saudáveise com DP é bem estabelecido na literatura. Estudo brasileiro de 2014, com 20 pacientes (13 homens, 7 mulheres), idade média de 62,5 anos (54-67,5), utilizando método de semiquantificação manual, mostrou diferença estatisticamente significante entre os potenciais de ligação do ST, PU e CA entre os grupos com e sem DP, com valores respectivamente de 0.58 (0.47-0.67) e $1.18(1.03-1.41)(\mathrm{p}<0.05), 0.81(0.58-0.94)$ e $1.64(1.55-2.18)(\mathrm{p}<0.05)$, e $0.45(0.34-0.50)$ e $1.22(0.92-1.36)(\mathrm{p}<0.05)$. Outro estudo com 29 pacientes com DP inicial (HYS médio de 1,4 $\pm 0,5$ ), mostrou redução média da atividade em relação aos controles normais de $42 \%$ no PU posterior, $31 \%$ no PU anterior e $12 \%$ no CA, com significância estatística, menos robusta no CA. Resultados semelhantes foram encontrados por Weng e col., 2004; Acton e col., 2006; Booth e col., 2015; Mozley e col., 2000; Meyer e col., 2014.

O presente trabalho sustentou achados prévios na literatura de que a semiquantificação de DAT através de imagens adquiridas por SPECT com [ ${ }^{99 \mathrm{~m}} \mathrm{Tc}$-TRODAT-1 é capaz de distinguir os dois grupos, saudável e com DP. Nosso estudo estendeu a investigação semiquantitativa, aplicando não somente o método manual de semiquantificação, mas também outros baseados em corregistro (RM e RM-corrigida) e em template padronizado (Two Box). Todos os métodos avaliados foram capazes de diferenciar os grupos com e sem DP. O parâmetro BPI para essa distinção entre grupos não sofreu influência de sexo, idade e escolaridade, incluídos na análise estatística como covariáveis.

Deve-se observar que os valores obtidos através dos diferente métodos semiquantitativos foram distintos entre si, e não são comparáveis em uma rotina clínica. Um estudo com 84 adultos saudáveis, sendo 35 homens, 49 mulheres, com média de idade de 35,7 anos $\pm 12,5$ anos, obteve o BPI do corpo estriado a partir de 3 métodos manuais, 7 semiautomáticos e 8 automáticos, e comparou o declínio por década de vida. Os valores encontrados foram significantemente diferentes entre os métodos. O tamanho do ROI, o posicionamento, o processo de normalização e de recuperação de sinal por correção de volume parcial, são algumas das causas dessa diferença. Este estudo específico considerou que, para a pesquisa clínica, métodos baseados em templates padronizados com correção de volume parcial seriam os preferíveis (YIN et al., 2014).

Em relação aos índices menos explorados na literatura (IA e PU/CA), os dados obtidos mostraram que os índices de assimetria do ST e de PU foram capazes de distinguir os dois 
grupos, com e sem DP. Essa diferença não foi significante para IA(CA), o que pode ser decorrente da perda seletiva de DAT característica da DP, sendo mais tardia nos caudados, e portanto mantendo uma relação de simetria mais próxima de controles normais.

Estudo com 78 pacientes, 38 mulheres, 40 homens; média de idade 61 anos (51-77 anos); HYS médio de 2,5 \pm 1,2 (1-5); UPDRS-3 médio de 50,6 \pm 27,4; descreveu um IA para grupo com DP de 65\%, 0,3 e 0,11, para ST, PU e CA, respectivamente (WENG et al., 2004). Esses valores foram nitidamente superiores em relação aos encontrados em nosso estudo, que em média obteve IA para o grupo com DP de até $15 \%$, com um desvio padrão elevado. O mesmo estudo descreveu uma diferença significante para PU/CA ipsilateral e contralateral (WENG et al., 2004), o que não ocorreu em nosso estudo, embora tenhamos observado uma tendência de menor relação PU/CA nos pacientes com DP. A diferença na metodologia de quantificação utilizada pelo autor (corregistro com RM seguido de ajuste manual) pode justificar essa variação nos resultados, mesmo na presença de populações com características semelhantes.

\subsubsection{Definição de limiar de normalidade dos índices}

Embora resultados satisfatórios tenham sido frequentemente obtidos pelos métodos de semiquantificação quando comparados a análise visual (BADIAVAS et al., 2011), algumas limitações são encontradas. Particularmente em casos com déficit importante de captação no corpo estriado, com perda de referencial anatômico, e em pacientes com variação anatômica, os resultados podem ser inconsistentes e variáveis (BADIAVAS et al., 2011). Além disso, outros fatores podem interferir na quantificação, tais como o tipo de gama-câmera, a calibração, os colimadores, o procedimento de aquisição e as correções (atenuação, dispersão e efeito de volume parcial) e, portanto, a comparação com bancos de dados de referência de outros centros, ou o uso de valores de controle publicados, produz resultados válidos apenas quando os valores de referência foram obtidos exatamente com a mesma técnica ou quando estes centros foram calibrados transversalmente usando um fantoma (DJANG et al., 2012).

A padronização da aquisição, dos métodos de reconstrução e dos protocolos de avaliação semiquantitativa do DAT-SPECT desempenha um papel fundamental para que os resultados entre os centros de medicina nuclear sejam comparáveis (SKANJETI et al., 2015). Padronização é primariamente requerida para melhorar a qualidade diagnóstica e para compartilhar informação entre os serviços de medicina nuclear, e ainda é útil na tentativa de minimizar os problemas relacionados ao uso de diferentes equipamentos, inclusive dentro de 
um mesmo serviço. (SKANJETI et al., 2015).

Com o objetivo de comparar métodos de semiquantificação em uma situação controlada, estudo foi realizado no HCRP utilizando um fantoma nigroestriatal. Os resultados semiquantitativos foram comparados com os valores reais de preenchimento utilizados no simulador antropomórfico para avaliar a acurácia e precisão. Neste caso o padrão ouro é a atividade de radiofármaco conhecida dentro do corpo estriado, portanto uma boa correlação entre esse dado com os índices semiquantitativos sugere acurácia elevada. Houve uma excelente correlação entre os resultados semiquantitativos e os reais valores de preenchimento para todos os métodos, com destaque para o método Two Box (SANTOS, 2015).

Considerando que os mesmos métodos foram aplicados no presente trabalho em população saudável e em portadores de DP, era esperado bons resultados entre os métodos com menor influência do avaliador. Os resultados obtidos, entretanto, mostraram maiores sensibilidade e especificidade na identificação de pacientes com DP a partir do método manual. Para o método manual, o cutoff do BPI de ST e PU estabelecido variou entre 0,73 a 0,78. A partir deste limiar a sensibilidade variou entre $95 \%$ a $100 \%$ e a especificidade variou entre $84 \%$ a $88 \%$. Isto significa que praticamente todos os pacientes com BPI de ST e PU inferior a 0,7 eram portadores de DP. Para CA o limiar estabelecido foi maior, variando entre 0,8 a 0,88 , sendo mantida sensibilidade de até $100 \%$ e especificidade entre $77 \%$ a $84 \%$. A AUC do método manual foi elevada para todos os índices de BPI, variando entre 0,92 a 0,98. Esses valores de desempenho do teste foram consistentes com dados da literatura (BADIAVAS et al., 2011; BOR-SENG-SHU et al., 2014; HUANG et al., 2004).

O impacto dos métodos semiquantitativos em reduzir falsos positivos e negativos quando aplicados em conjunto com a avaliação qualitativa é pouco abordado na literatura. Em nosso estudo, levando-se em consideração as 3 avaliações qualitativas (A1, A2 e B1), foram obtidos ao todo 3 resultados falsos positivos e 9 resultados falsos negativos. Se aplicados os limiares de potencial de ligação de 0,7 para ST e PU, e 0,8 para CA, o método semiquantitativo manual potencialmente iria reduzir os casos falsos positivos de 3 para 0 (100\% dos casos) e os casos falsos negativos de 9 para 7 (22\% dos casos).

Em relação ao corregistro com RM, os valores de limiar de normalidade foram nitidamente menores comparando-se ao método manual, e variáveis na RM-corrigida. Os resultados foram inferiores ao método manual. Para RM os valores de sensibilidade variaram entre $73 \%$ a $82 \%$, enquanto a especificidade manteve-se entre $79 \%$ a 95\%, com área sob a curva inferior a 0,9 . No método de corregistro com RM-corrigida, era esperado uma melhora dos resultados, visto que o efeito de volume parcial é minimizado, porém os resultados foram 
mantidos. Um discreto desalinhamento observado na convergência de alguns estudos de SPECT com [ $\left.{ }^{99 \mathrm{~m}} \mathrm{Tc}\right]$-TRODAT-1 com a RM justifica esses achados. Alternativas como ajuste manual do posicionamento da ROI ou alteração no tamanho da ROI poderiam interferir no resultado final, porém, a primeira alternativa estaria em desencontro com o objetivo deste estudo, que é o de avaliar método sem qualquer interferência humana, enquanto que a segunda alternativa poderia prejudicar a análise de subestruturas.

A performance do método Two Box foi discretamente superior ao de corregistro com RM, corrigida ou não corrigida. Quando considerado cutoff de 1,1 para ST, a AUC obtida foi de 0,88 a 0,93, com maior sensibilidade (até 0,87), porém com menor especificidade, em torno de 0,80. A vantagem desse método com aplicação de ROIs geométricas é de ser capaz de coletar toda densidade de contagem originada dos compartimentos de interesse, de modo a não apresentar perda de sinal significativa por PVE, além de utilizar como fator ponderador a razão entre os volumes do corpo estriado e o volume relativo da ROI geométrica construída (SANTOS, 2015). O resultado obtido, entretanto, foi inferior ao encontrado na literatura. Um trabalho com 55 pacientes, sendo 25 com DP e 30 sem DP, submetidos a SPECT com [ $\left.{ }^{123} \mathrm{I}\right]-$ FP-CIT, propôs e aplicou método semiquantitativo para separar os grupos. Trata-se da mesma metodologia aplicada no Two Box. Além de altamente reprodutível, com coeficiente de variação interobservador de $2,5 \%$, a técnica apresentou alta sensibilidade e especificidade (97\% e 92\%, respectivamente), além de uma concordância clínica de 95\% (TOSSICI-BOLT et al., 2006). Deve-se ressaltar que neste estudo os pacientes considerados normais eram na realidade não portadores de DP, portanto os resultados estão enviesados.

Em relação aos índices de assimetria e da relação putâmen pelo caudado, aferidos somente pelo método manual, os resultados foram claramente inferiores a quantificação do potencial de ligação, com AUC inferior 0,70. Nossos achados foram contrários ao relatado por Weng e colaboradores, que descreveram uma sensibilidade e especificidade de até $100 \%$ para PU/CA(c) (WENG et al., 2004). Estes resultados desfavoráveis do presente estudo devem-se ao frequente acometimento bilateral no corpo estriado dos portadores de DP observado em cerca de $95 \%$ dos casos em nosso estudo, bem como ao frequente envolvimento dos caudados (cerca de $84 \%$ dos casos), aproximando as relações de IA e PU/CA dos controles normais.

Apesar de o desempenho de IA e PU/CA não ter sido satisfatório, estes índices foram capazes de excluir DP nos casos com maior assimetria, representados por IA > 0,2; IA(PU) > 0,22; e IA(CA) > 0,3, e nos casos com menor razão entre putâmen e núcleo caudado, com $\mathrm{PU} / \mathrm{CA}(\mathrm{i})<0,65$ e $\mathrm{PU} / \mathrm{CA}(\mathrm{c})<0,57$. Deste modo, estes índices podem ter alguma 
aplicabilidade clínica futura. Além disso, a caracterização do padrão de acometimento no SPECT com [ $\left.{ }^{99 \mathrm{~m}} \mathrm{Tc}\right]-T R O D A T-1$ em DP, considerando não apenas grau de acometimento, como também a relação entre as subestruturas que compõe o corpo estriado, pode ser útil como base para diferenciação de outras doenças motoras, em especial síndromes parkinsonianas atípicas. $\mathrm{O}$ acometimento reportado na atrofia de múltiplos sistemas (AMS) costuma ser menos assimétrico, podendo existir acometimento preferencial dos caudados dependendo da forma da doença (FREY, 2017; LU et al., 2004; STRAFELLA et al., 2017). $\mathrm{Na}$ paralisia supranuclear progressiva o fenótipo também depende da forma da doença, podendo ser assimétrico ou simétrico, em geral com um envolvimento mais homogêneo entre caudado e putâmen (FREY, 2017; LIN et al., 2010; STRAFELLA et al., 2017). Por fim, na degeneração corticobasal é descrita uma assimetria do estriado e acometimento semelhante do putâmen e caudado (relação putâmen/caudado maior comparando-se a DP) (BOOTH et al., 2015a, 2015b; FREY, 2017; STRAFELLA et al., 2017). Embora existam algumas distinções fenotípicas entre DP, AMS, PSP e DCB, é necessário estabelecer outras técnicas mais acuradas e sensíveis para o diagnóstico diferencial das síndromes parkinsonianas atípicas com base em endofenótipos de imagem molecular (FREY, 2017).

\subsubsection{Análise da confiabilidade}

A demonstração de reprodutibilidade e confiabilidade do SPECT com [ $\left.{ }^{99 \mathrm{~m}} \mathrm{Tc}\right]-$ TRODAT-1 é importante e crítico para o seu uso na prática clínica. Um estudo com 20 pacientes com DP precoce, 13 homens, 7 mulheres, idade média de 62,1 anos (42-79 anos), evidenciou uma excelente reprodutibilidade teste/reteste no cálculo de BPI do corpo estriado, com ICC de 0,95. Para IA estriatal, por outro lado, foi observado maior variabilidade e uma reprodutibilidade menos satisfatória, com ICC de 0,86 (YEH et al., 2012).

Em dissertação de mestrado, Santos, LA, avaliou de forma experimental a reprodutibilidade e acurácia de 5 métodos semiquantitativos baseados em ROI (manual, corregistro com CT e RM, e métodos baseados em template padrão), desenvolvidos para a investigação de imagens de SPECT do corpo estriado. Os métodos semiquantitativos abordados foram de natureza automatizada ou com ações interventivas do avaliador durante a construção e/ou posicionamento das ROIs, sendo realizado em um ambiente controlado por meio de simulador antropomórfico estriatal. Ao avaliar a reprodutibilidade dos métodos foi observada uma maior variabilidade no método manual (até 12,7\%). A variabilidade chegou a 
cerca de $3 \%$ para o Two Box, e foi de pequena amplitude para corregistro com RM (até 0,3\%). A variabilidade interobservador foi mais elevada, de $17,59 \%$ a 22,9\% para o método manual; $1,09 \%$ a 2,83 \% para o Two Box; e praticamente nenhuma alteração significativa para os métodos estruturais (SANTOS, 2015).

A literatura é limitada na comparação de métodos semiquantitativos em populações com DP. Em geral esta investigação é feita para um grupo de pacientes normais ou em pacientes com DP avaliados por um método específico.

No presente trabalho, optou-se por avaliar a confiabilidade dos métodos de quantificação através do coeficiente de correlação intra-classe (ICC) (YEN; LO, 2002). Em ambas as análises, intraobservador e interobservador, os resultados da literatura têm mostrado resultados excelentes, apresentando ICC para as avaliações de BPI superior a 0,75 (FLEISS; LEVIN; PAIK, 2013). Conforme o esperado, na análise interobservador o ICC foi menor comparado a análise intraobservador. Praticamente não houve diferença entre os métodos na avaliação intraobservador, sugerindo que apesar da maior subjetividade na construção e/ou posicionamento das ROIs de forma não automática, o responsável pela avaliação do exame aplica conceitos e experiência neste campo de uma forma sistemática.

Por sua vez, na avaliação interobservador a distância entre os métodos em termos de confiabilidade foi maior, particularmente entre o método manual e os demais, sendo menor no método manual. A seleção das imagens axiais para composição $2 \mathrm{D}$, desenho e ajustes das áreas de interesse, posicionamento, são etapas passíveis de influência do avaliador. No caso do Two Box essa questão é minimizada por uma característica fundamental, que diz respeito ao tamanho da ROI. A ROI de grandes dimensões, tal qual aplicado no método Two Box, garante que todo o estriado esteja compreendido dentro da sua área, e portanto não há perda de informação, mesmo que o posicionamento manual pelos avaliadores seja diferente.

Por fim, quanto ao IA e PU/CA, particularmente a confiabilidade interobservador foi insatisfatória. Uma possível justificativa para este achado diz respeito aos baixos valores absolutos encontrados, ou seja, pequenas variações são percentualmente elevadas. Deste modo, em especial para fins de seguimento, a aplicabilidade destes parâmetros fica limitada.

\subsubsection{Correlação com parâmetros clínicos}

Para desenvolver terapias capazes de modificar a história natural da doença, é necessário ter uma métrica apropriada para avaliar a progressão da doença. As medidas 
clínicas da progressão da DP são subjetivas, e podem ser enviesadas por efeitos sintomáticos da intervenção ou terapias concomitantes. Assim, biomarcadores que possam refletir com precisão a gravidade da perda neuronal nigrostriatal apresentam grande valor para o desenvolvimento deste tipo de intervenção terapêutica (KARIMI et al., 2013).

Vários autores relatam que a progressão nos estádios de HYS correlaciona-se com o declínio motor e com a deterioração da qualidade de vida (BHIDAYASIRI; TARSY, 2012; SCHENKMAN et al., 2001). Por sua vez, estudos de neuroimagem frequentemente sugerem que a redução de potenciais de ligação do corpo estriado e nas subregiões significantemente se correlacionam com a gravidade da doença, representada pela HYS e pela gravidade dos sintomas motores estabelecida pela escala UPDRS (ASENBAUM et al., 1997; GENG et al., 2005; HUANG et al., 2004; WENG et al., 2004). Estudo com 188 pacientes evidenciou em uma análise semiquantitativa, diferenças significantes entre pacientes com DP em graus variados e controles normais, com uma correlação negativa significante entre BPI estriatal e do putâmen com HYS ( $\rho=-0.89$ e -0.93 , respectivamente) (HUANG et al., 2004). Esses autores sustentam a idéia de que o SPECT com [ ${ }^{99 \mathrm{~m}} \mathrm{Tc}$ ]-TRODAT-1 poderia ser útil no monitoramento da progressão da doença ou para avaliar terapia neuroprotetora (WENG et al., 2004). Contudo os dados disponíveis na literatura são inconsistentes no que diz respeito à aplicação da neuroimagem para seguimento de DP (KARIMI et al., 2013).

Um interessante modelo experimental não humano provocou hemiparkinsonismo estável em 16 macacos, submetidos a PET com 6-[ $\left.{ }^{18} \mathrm{~F}\right]$-flúor-dopa (FD primariamente reflete a atividade da enzima descarboxilase), $\left[{ }^{11} \mathrm{C}\right]$-dihidrotetrabenazina (DTBZ reflete transportador monoamina vesicular tipo II, VMAT2), e 2-beta- $\left[{ }^{11} \mathrm{C}\right]$-carbometoxi-3-beta-4-flúorfeniltropano (CFT reflete DAT), basal e após 3 semanas do procedimento (KARIMI et al., 2013). Este estudo indicou que a captação de todos esses radiofármacos se correlacionou com a perda neuronal nigroestriatal enquanto esta ainda estava abaixo de $50 \%$. Após uma perda maior do que $50 \%$, não houve correlação com os estudos de neuroimagem.

Nosso trabalho, tal como na avaliação qualitativa, não mostrou uma correlação satisfatória entre a semiquantificação e dados clínicos de HYS ou UPDRS considerando a amostra global, contradizendo trabalhos prévios com DAT-SPECT ou DAT-PET. Entretanto, quando os grupos foram divididos em portadores de DP em estágio inicial (HYS I e II) e tardio (HYS III e IV), foi encontrada clara correlação negativa dos potenciais de ligação no grupo de DP inicial com a gravidade dos sintomas motores, avaliados por UPDRS-3. Por outro lado, não houve correlação entre UPDRS-3 e BPI nos portadores de DP em estágios mais tardios, o que sustenta a hipótese de Karimi e colaboradores de ausência de correlação 
entre neuroimagem e perda neuronal mais significativa (KARIMI et al., 2013).

Considerando os resultados obtidos, é possível questionar se ao menos em quadros clínicos iniciais estaríamos autorizados a utilizar SPECT com [ $\left.{ }^{99 m} \mathrm{Tc}\right]-T R O D A T-1$ para seguimento de DP. Essa indicação está limitada principalmente pelo fato de os sintomas surgirem muito tempo após o início da degeneração nigroestriatal. De la Fuente-Fernandes e colaboradores estimam que os sintomas motores apareçam até 13 anos após o início da alteração em exames de avaliação de DAT (STRAFELLA et al., 2017). Estudos com múltiplos marcadores revelam que em DP precoce deve existir um déficit de $29 \%$ a $44 \%$ de captação em DAT-SPECT para o aparecimento de sintomas relacionados. Em nossa casuística

apenas 5 pacientes apresentavam sintomas motores unilaterais (HYS I). Entretanto, dentre estes pacientes, 4 apresentaram déficit de captação bilateral. Um envolvimento mais grave de captação no DAT-SPECT em relação aos sintomas pode ser em parte decorrente de um processo de downregulation de DAT (STRAFELLA et al., 2017). Ou seja, uma redução da expressão do DAT na tentativa de aumentar a disponibilidade de dopamina na fenda sináptica, fato condizente com nosso achado de não correlação com sintomas nos casos mais graves.

\subsection{Comparação da densidade de DAT nos grupos com e sem discinesia}

A administração de levodopa ainda é o tratamento farmacológico mais efetivo para o controle dos sintomas motores da DP (FERNANDEZ, 2015; THANVI; LO; ROBINSON, 2007b). Embora a levodopa possa produzir uma melhora dramática nos sintomas da DP, sua aplicação clínica a longo prazo é frequentemente limitada por movimentos coreiformes involuntários irreversíveis anormais, denominados discinesia induzida por levodopa (CENCI, 2014; FIGGE; ESKOW JAUNARAJS; STANDAERT, 2016; MOSHAROV; BORGKVIST; SULZER, 2015b; THANVI; LO; ROBINSON, 2007a). Estas discinesias são observadas em aproximadamente $50 \%$ dos pacientes dentro de 5 anos do início do tratamento com levodopa, com diversas formas de apresentação (FIGGE; ESKOW JAUNARAJS; STANDAERT, 2016; POEWE, 2009). Estudos em modelos animais mostraram que é fundamental para a LID um "efeito de iniciação", em que administrações iniciais de levodopa desencadeiam uma resposta bioquímica e transcricional sensibilizada no corpo estriado após a estimulação dopaminérgica subsequente, resultando em comportamentos discinéticos progressivos e persistentes (CENCI, 2014; FIGGE; ESKOW JAUNARAJS; STANDAERT, 2016).

Uma variedade de alterações na função estriatal foram descritas como contribuinte 
para a sensibilização celular observada durante a expressão de LID, incluindo aumento da sinalização glutamatérgica, aumento da atividade de ERK/CREB, expressão de genes dependentes de levodopa e atividade de tradução aumentada (FIGGE; ESKOW JAUNARAJS; STANDAERT, 2016). As hipóteses pré-sinápticas tentam explicar a fisiopatologia da LID relacionando à desregulação do controle pré-sináptico do armazenamento vesicular, liberação não controlada e diminuição da recaptação da dopamina (CENCI, 2014; MOSHAROV; BORGKVIST; SULZER, 2015b; THANVI; LO; ROBINSON, 2007a).

Os resultados na literatura são variáveis, predominando uma associação da LID com o déficit de captação no corpo estriados nos SPECTs e PETs com marcadores de DAT. Estudo retrospectivo com 127 pacientes submetidos a PET com $\left[{ }^{18} \mathrm{~F}\right]$-FP-CIT, seguidos por pelo menos 2 anos após início do tratamento dopaminérgico, mostrou que a captação no putâmen anterior, posterior e na estrutura como um todo foi preditora de desenvolvimento de LID (HONG et al., 2014). O BPI do corpo estriado e do caudado não foram preditores para LID (HONG et al., 2014).

Uma revisão sobre a aplicação do PET na avaliação do desenvolvimento de LID em pacientes com DP apontou diversos estudos relacionados à hipótese pré-sináptica na fisiopatologia da LID. Dentre estes trabalhos, foi mostrada associação do déficit de captação no putâmen em PET com $\left[{ }^{11} \mathrm{C}\right]-\mathrm{MP}$ com LID no pico da dose e com flutuações motoras (NICCOLINI; LOANE; POLITIS, 2014; TROIANO et al., 2009). Este achado corrobora o conceito de que uma perda gradual da disponibilidade de DAT pode resultar na perda de mecanismos compensatórios quando os níveis de dopamina aumentam substancialmente após uma dose de levodopa (NICCOLINI; LOANE; POLITIS, 2014). Em outro trabalho com $\left[{ }^{18} \mathrm{~F}\right]$-fluorodopa, os pacientes com DP com flutuações motoras apresentaram redução de $12 \%$ de captação no caudado e $28 \%$ no putâmen em comparação com aqueles com uma resposta estável à levodopa (DE LA FUENTE-FERNANDEZ et al., 2000). Esses achados indicaram um papel de redução da capacidade de armazenamento de dopamina estriatal no desenvolvimento de flutuações motoras (NICCOLINI; LOANE; POLITIS, 2014).

Nosso estudo sustenta as hipóteses pré-sinápticas. Foi observado uma diferença significante entre médias de BPI do ST(i), ST(c), CA (i) e CA(c) entre os portadores de DP com e sem discinesia, sendo menor no grupo com discinesia. Por outro lado, não houve diferença significante para o BPI dos putâmens (valor-p > 0,05). Embora não tenha sido observada diferença estatisticamente significante do BPI nos putâmens, a média deste índice foi cerca de $31 \%$ menor no grupo com discinesia em relação ao grupo sem discinesia. Os 
resultados podem sugerir que há necessidade de um maior acometimento pré-sináptico dopaminérgico para o desenvolvimento de LID, visto que em DP o déficit de captação no corpo estriado se dá primeiramente nos putâmens. Outra explicação para estes dados é a ocorrência frequente de déficit de captação nos putâmens encontrada em nossa amostra total, na qual a maioria dos pacientes já se encontravam com sintomatologia motora bilateral $(88,6$ $\%$ dos casos), mesmo que destes casos, a maior parte corresponda a estadio II na HYS.

Outros parâmetros clínicos também foram avaliados de forma independente, e se mostraram associados a LID. A LID foi associada com um tempo maior de duração de doença, uma idade menor no aparecimento dos sintomas, dosagem maior da levodopa, número maior de doses administradas ao longo do dia, menor duração do efeito da levodopa e maiores valores na UPDRS e HYS. De uma forma geral, essas variáveis clínicas associadas a LID apresentam relação com o aumento da desregulação do sistema dopaminérgico, maior tempo de exposição a levodopa e aumento da disponibilidade de levodopa na fenda sináptica, e deste modo, apresentam potencial para aumentar o estímulo para iniciar o processo patológico da LID. O mesmo racional é aplicável ao déficit de DAT no corpo estriado, que reduz a recaptação da dopamina liberada na fenda sináptica. Considerando este cenário, fica claro que a associação de LID com outros fatores além do déficit de BPI do corpo estriado, evidenciado pelo SPECT com [ ${ }^{99 \mathrm{~m}} \mathrm{Tc}$ ]-TRODAT-1, sugere um aspecto multifatorial para o desenvolvimento de LID. 


\section{Limitações do estudo}

O SPECT com [ $\left.{ }^{99 \mathrm{~m}} \mathrm{Tc}\right]-T R O D A T-1$ ainda é pouco difundido no Brasil, havendo assim pouca experiência dos médicos nucleares com o método, gerando um número maior de incertezas e insegurança na definição diagnóstica. Os resultados do presente trabalho valorizam a aplicação do SPECT com [ ${ }^{99 \mathrm{~m}} \mathrm{Tc}$ ]-TRODAT-1 como ferramenta diagnóstica em um importante campo de atuação. Entretanto, é justo apresentarmos algumas limitações do nosso estudo:

1. A avaliação clínica foi considerada o padrão ouro para a comparação dos dados. $\mathrm{O}$ único diagnóstico definitivo de DP é a avaliação anatomopatológica, inviável em um estudo desta natureza. O diagnóstico clínico está sujeito a erros (HUGHES et al., 1992; RAJPUT; ROZDILSKY; RAJPUT, 1991), contudo todos os casos incluídos em nosso trabalho apresentavam critérios clássicos para a DP, e foram diagnosticados por médico especialista na área. Deste modo, a possibilidade de falso positivo está minimizada.

2. Os pacientes não realizaram de forma sistemática RM para excluir lesões orgânicas detectáveis ao método. Foi realizada avaliação clínica criteriosa para excluir antecedentes descritos na metodologia e checados em prontuário estudos anatômicos e/ou funcionais prévios. Devido a necessidade de financiamento, não foi inserida nos critérios de inclusão a necessidade de RM do crânio.

3. A terapêutica em uso pelos pacientes era heterogênea, com respostas sintomatológicas diversas, inclusive no momento da avaliação clínica. Apesar de este fato não interferir na captação de $\left[{ }^{99 m} \mathrm{Tc}\right.$-TRODAT-1 no corpo estriado (DJANG et al., 2012), pode influenciar a pontuação da escala motora UPDRS.

4. Este estudo aplicou de forma arbitrária alguns métodos de semiquantificação de natureza distinta, com a finalidade de comparar e avaliar desde o método totalmente manual e, portanto, dependente de avaliador, até métodos quase integralmente automatizados, sem influência significativa de avaliador. $O$ método de semiquantificação ideal não é estabelecido na literatura, e possivelmente deve envolver e combinação de metodologias, algo como um método automatizado com ajuste fino manual. 


\section{Conclusões}

Este estudo criou um banco de dados de imagens de SPECT com [ $\left.{ }^{99 \mathrm{~m}} \mathrm{Tc}\right]-\mathrm{TRODAT}-1$ com 23 pacientes saudáveis com idade superior a 40 anos e 44 pacientes com diagnóstico clínico confirmado de DP, e portanto ampliou perspectivas de novos estudos nesta linha de pesquisa, ao passo que aprimorou o conhecimento e habilidades dos profissionais da Seção de Medicina do HCRP envolvidos neste processo.

Quanto aos demais objetivos, conclui-se que:

1. O padrão de imagem do SPECT cerebral com [ $\left.{ }^{99 m} \mathrm{Tc}\right]-T R O D A T-1$ no grupo de pacientes saudáveis foi caracterizado por captação nos corpos estriados com elevada relação alvo/não-alvo, de padrão simétrico e potencial de ligação discretamente maior (cerca de 15\%) nos núcleos caudados em relação aos putâmens.

2. O potencial de ligação não sofreu redução significante entre faixas etárias de 40 a 79 anos de idade, e deste modo não houve impacto clinicamente relevante na interpretação dos estudos de SPECT com [ $\left.{ }^{99 \mathrm{~m}} \mathrm{Tc}\right]$-TRODAT-1. A classe socioeconômica e o gênero não influenciaram de forma significante a densidade de DAT. Novos estudos devem ser realizados para estabelecer o padrão normal para jovens adultos com idade inferior a 40 anos.

3. A avaliação qualitativa do SPECT cerebral com $\left[{ }^{99 \mathrm{~m}} \mathrm{Tc}\right]-T R O D A T-1$ apresentou excelente desempenho na distinção entre controles saudáveis e pacientes com DP, com sensibilidade, especificidade e acurácia, respectivamente, de 90.9-95.4\%, 91.3-100\% e 92.5-95.5\%.

4. A avaliação qualitativa do SPECT com [ $\left.{ }^{99 \mathrm{~m}} \mathrm{Tc}\right]-T R O D A T-1$ apresentou uma correlação insatisfatória com o tempo de duração da doença, UPDRS-3 e HYS, com tendência a correlação negativa.

5. A concordância intraobservador na avaliação qualitativa foi alta, porém, a concordância interobservador foi moderada, considerando a interpretação binária (positivo versus negativo), ou pobre, considerando a classificação de Benamer e por escala modificada.

6. O potencial de ligação do ST, PU e CA foi capaz de diferenciar indivíduos saudáveis de pacientes com DP em todos os métodos semiquantitativos. O método semiquantitativo manual apresentou melhor desempenho. O método Two Box apresentou a segunda maior AUC. 
7. A concordância intraobservador e interobservador na semiquantificação do BPI foi excelente em todos os métodos semiquantitativos. A concordância interobservador foi menor no método manual.

8. Em todos os métodos semiquantitativos não houve correlação significante de BPI com tempo de doença, UPDRS-3 e HYS, ou esta correlação foi fraca. Quando o grupo com DP foi subdividido em HYS I/II e HYS III/IV, foi observada correlação significante negativa entre BPI e UPDRS-3 e o primeiro subgrupo (casos menos avançados).

9. O desempenho dos índices de assimetria e da relação putâmen/caudado foi inferior ao dos potenciais de ligação, bem como sua confiabilidade intraobservador e interobservador.

10. Pacientes portadores de DP com discinesia apresentaram médias de BPI menores do que o grupo sem discinesia, sendo estatisticamente significante para ST(i), ST(c), CA (i) e $\mathrm{CA}(\mathrm{c})$. 


\section{Perspectivas futuras}

Este estudo integra uma linha de pesquisa nova de trabalho no HCRP, iniciada com a avaliação de formas de aquisição, processamento e quantificação de SPECT com [ ${ }^{99 \mathrm{~m}} \mathrm{Tc}$ ]TRODAT-1 através de duas dissertações de mestrado utilizando um fantoma antropomórfico estriatal (SANTOS, 2015; TREVISAN, 2015). A experiência obtida será aplicada em novos trabalhos.

O primeiro trabalho proposto, já aprovado pelo Comitê de Ética em Pesquisa (CEP) dentro do mesmo projeto desenvolvido para esta dissertação, consiste na comparação e correlação da densidade de transportadores dopaminérgicos com imagens de perfusão cerebral obtidas a partir de SPECT com [ $\left.{ }^{99 \mathrm{~m}} \mathrm{Tc}\right]-\mathrm{ECD}$, e com dados clínicos, particularmente sintomas não-motores de DP. Foram realizados SPECTs com [ $\left.{ }^{99 \mathrm{~m}} \mathrm{Tc}\right]-\mathrm{ECD}$ em 20 pacientes, dos quais todos realizaram SPECT com $\left[{ }^{99 \mathrm{~m}} \mathrm{Tc}\right]-\mathrm{TRODAT}$.

$\mathrm{Na}$ instituição ainda foi proposto estudo com SPECT com [ $\left.{ }^{99 \mathrm{~m}} \mathrm{Tc}\right]-\mathrm{ECD}$ em população obesa. Baseado na literatura prévia, sabe-se que a insulina promove o trafficking do receptor DAT pré-formado resultando em aumento da expressão de DAT na membrana pré-sináptica. Como obesos apresentam resistência à insulina, é provável que este mecanismo não funcione adequadamente. Desta forma, o objetivo é verificar se pessoas obesas apresentam menor densidade do DAT após ingestão de glicose, Este estudo já foi aprovado pelo CEP e conta com fomento do CNPq (Universal) recentemente aprovado, processo ${ }^{\circ} 425775 / 2016-0$. 


\section{REFERÊNCIAS BIBLIOGRÁFICAS}

ACTON, P. D. et al. Comparison of region-of-interest analysis and human observers in the diagnosis of Parkinson's disease using [99mTc] TRODAT-1 and SPECT. Physics in medicine and biology, v. 51, n. 3, p. 575, 2006.

ASENBAUM, S. et al. Imaging of Dopamine Transporters with Iodine-123- ̃̃Ÿ-CITand SPECT in Parkinson's Disease. Journal of Nuclear Medicine, v. 38, p. 1-6, 1997.

BADIAVAS, K. et al. SPECT imaging evaluation in movement disorders: far beyond visual assessment. European journal of nuclear medicine and molecular imaging, v. 38, n. 4, p. 764-773, abr. 2011.

BAGLIERI, A. et al. Differences between conventional and non conventional MRI techniques in Parkinson' diseas. Functional Neurology, v. 28(2), p. 73-82, 2013.

BARBOSA, E. R.; SALLEM, F. Diagnosis, Parkinsons Disease. Revista de Neurociências, v. 13, n. 3, p. 158-165, 2005.

BENAMER, T. S. et al. Accurate differentiation of parkinsonism and essential tremor using visual assessment of [123I]-FP-CIT SPECT imaging: the [123I]-FP-CIT study group. Movement disorders: official journal of the Movement Disorder Society, v. 15, n. 3, p. 503-510, maio 2000.

BHIDAYASIRI, R.; TARSY, D. Parkinson's Disease: Hoehn and Yahr Scale. In: Movement Disorders: A Video Atlas. Current Clinical Neurology. [s.1.] Humana Press, 2012. p. 4-5.

BOOIJ, J.; KEMP, P. Dopamine transporter imaging with [123I] FP-CIT SPECT: potential effects of drugs. European journal of nuclear medicine and molecular imaging, v. 35, n. 2, p. 424-438, 2008.

BOOTH, T. C. et al. The role of functional dopamine-transporter SPECT imaging in parkinsonian syndromes, part 1. AJNR. American journal of neuroradiology, v. 36, n. 2, p. 229-235, fev. 2015a.

BOOTH, T. C. et al. The role of functional dopamine-transporter SPECT imaging in parkinsonian syndromes, part 2. AJNR. American journal of neuroradiology, v. 36, n. 2, p. 236-244, fev. 2015 b.

BOR-SENG-SHU, E. et al. Dopamine transporter imaging using 99mTc-TRODAT-1 SPECT in Parkinson's disease. Medical science monitor: international medical journal of experimental and clinical research, v. 20, p. 1413-1418, 11 ago. 2014.

BOURZAC, K. Diagnosis: Warning signs. Nature, v. 538, n. 7626, p. S5-S7, 27 out. 2016.

BRAAK, H. et al. Stages in the development of Parkinson's disease-related pathology. Cell and tissue research, v. 318, n. 1, p. 121-134, out. 2004.

BRAVO, P. A. F.; NASSIF, M. C. DOENÇA DE PARKINSON: TERAPÊUTICA ATUAL E AVANÇADA. Infarma, v. 18, p. 25-29, 2006.

BRETT, M. et al. Region of interest analysis using the MarsBar toolbox for SPM 99. NeuroImage, v. 16, n. 2, p. S497, 2002.

BROOKS, D. J. Parkinson's disease: diagnosis. Parkinsonism \& related disorders, v. 18 Suppl 1, p. S31-3, jan. 2012.

BROOKS, D. J. Molecular imaging of dopamine transporters. Ageing research reviews, v. 30, p. 114-121, set. 2016. 
BROOKS, D. J.; PAVESE, N. Imaging biomarkers in Parkinson's disease. Progress in neurobiology, v. 95, n. 4, p. 614-628, dez. 2011.

BRUCKI, S. M. D. et al. [Suggestions for utilization of the mini-mental state examination in Brazil]. Arquivos de neuro-psiquiatria, v. 61, n. 3B, p. 777-781, set. 2003.

CENCI, M. A. Presynaptic Mechanisms of 1-DOPA-Induced Dyskinesia: The Findings, the Debate, and the Therapeutic Implications. Frontiers in neurology, v. 5, 2014.

CHEN, K. C. et al. Striatal Dopamine Transporter Availability in Drug-Naive Patients With Schizophrenia: A Case-Control SPECT Study With [99mTc]-TRODAT-1 and a Meta-analysis. Schizophrenia Bulletin, p. 1-9, 2011.

COT SANZ, A. Absolute quantification in brain SPECT imaging. [s.1.] Universitat Politècnica de Catalunya, 2003.

CRITS-CHRISTOPH, P. et al. Dopamine transporter levels in cocaine dependent subjects. Drug and alcohol dependence, v. 98, n. 1-2, p. 70-76, 1 nov. 2008.

DAVID MOZLEY, P. et al. Effects of Age on Dopamine Transporters in Healthy Humans. THE JOURNALOF NUCLEAR MEDICINE, v. 40, p. 1812-1819, 1999.

DAVID MOZLEY, P. et al. Binding of [99mTc]TRODAT@ 1 to Dopamine Transporters in Patients with Parkinson's Disease and in Healthy Volunteers. The Journal of Nuclear Medicine, v. 41, n. 4, p. 584-589, 2000.

DE LA FUENTE-FERNANDEZ, R. et al. Evidence for impaired presynaptic dopamine function in parkinsonian patients with motor fluctuations. Journal of neural transmission , v. 107, n. 1, p. 49$57,2000$.

DICKSON, J. C. et al. The impact of reconstruction method on the quantification of DaTSCAN images. European journal of nuclear medicine and molecular imaging, v. 37, n. 1, p. 23-35, jan. 2010 .

DJANG, D. S. W. et al. SNM practice guideline for dopamine transporter imaging with 123I-ioflupane SPECT 1.0. Journal of nuclear medicine: official publication, Society of Nuclear Medicine, v. 53, n. 1, p. 154-163, jan. 2012.

DREW, L. Two hundred steps. Nature, v. 538, n. 7626, p. S2-S3, 27 out. 2016.

EHGOETZ MARTENS, K. A.; LEWIS, S. J. G. Pathology of behavior in PD: What is known and what is not? Journal of the neurological sciences, 29 dez. 2016.

ENGELENDER, S.; ISACSON, O. The Threshold Theory for Parkinson's Disease. Trends in neurosciences, v. 40, n. 1, p. 4-14, jan. 2017.

FERNAGUT, P.-O. et al. Dopamine transporter binding is unaffected by L-DOPA administration in normal and MPTP-treated monkeys. PloS one, v. 5, n. 11, p. e14053, 22 nov. 2010.

FERNANDEZ, H. H. 2015 Update on Parkinson disease. Cleveland Clinic journal of medicine, v. 82 , n. 9 , p. $563-568$, set. 2015.

FIGGE, D. A.; ESKOW JAUNARAJS, K. L.; STANDAERT, D. G. Dynamic DNA Methylation Regulates Levodopa-Induced Dyskinesia. The Journal of neuroscience: the official journal of the Society for Neuroscience, v. 36, n. 24, p. 6514-6524, 15 jun. 2016.

FLEISS, J. L.; LEVIN, B.; PAIK, M. C. Statistical Methods for Rates and Proportions. [s.1.] John 
Wiley \& Sons, 2013.

FOSS, M. P.; VALE, F. DE A. C. DO; SPECIALI, J. G. [Influence of education on the neuropsychological assessment of the elderly: application and analysis of the results from the Mattis Dementia Rating Scale (MDRS)]. Arquivos de neuro-psiquiatria, v. 63, n. 1, p. 119-126, mar. 2005.

FREY, K. A. Molecular Imaging of Extrapyramidal Movement Disorders. Seminars in nuclear medicine, v. 47, n. 1, p. 18-30, jan. 2017.

GAZEWOOD, J. D.; RICHARDS, D. R.; CLEBAK, K. Parkinson disease: an update. American family physician, v. 87, n. 4, p. 267-273, 15 fev. 2013.

GENG, Y. et al. Investigating the role of 99mTc-TRODAT-1 SPECT imaging in idiopathic Parkinson's disease. Journal of Zhejiang University. Science. B, v. 6, n. 1, p. 22-27, jan. 2005.

GIRAUDEAU, B. Negative values of the intraclass correlation coefficient are not theoretically possible. Journal of clinical epidemiology, v. 49, n. 10, p. 1205-1206, out. 1996.

GOETZ, C. G. et al. Movement Disorder Society-sponsored revision of the Unified Parkinson's Disease Rating Scale (MDS-UPDRS): scale presentation and clinimetric testing results. Movement disorders: official journal of the Movement Disorder Society, v. 23, n. 15, p. 2129-2170, 15 nov. 2008.

GOETZ, C. G. Unified Parkinson's Disease Rating Scale (UPDRS) and Movement Disorder Society Revision of the UPDRS (MDS-UPDRS). In: Rating Scales in Parkinson's Disease. [s.l: s.n.]. p. 62 83.

GRAYSON, M. Nature Outlook. Parkinson's Disease. Nature, v. 538, 27 out. 2016.

HARIKRISHNA REDDY, D.; MISRA, S.; MEDHI, B. Advances in drug development for Parkinson's disease: present status. Pharmacology, v. 93, n. 5-6, p. 260-271, 1 ago. 2014.

HOEXTER, M. Q. et al. Higher striatal dopamine transporter density in PTSD: an in vivo SPECT study with [(99m)Tc]TRODAT-1. Psychopharmacology, v. 224, n. 2, p. 337-345, nov. 2012.

HOLTBERND, F.; EIDELBERG, D. The utility of neuroimaging in the differential diagnosis of parkinsonian syndromes. Seminars in neurology, v. 34, n. 2, p. 202-209, abr. 2014.

HONG, J. Y. et al. Presynaptic dopamine depletion predicts levodopa-induced dyskinesia in de novo Parkinson disease. Neurology, v. 82, n. 18, p. 1597-1604, 6 maio 2014.

HOU, H. et al. Reduced striatal dopamine transporters in people with internet addiction disorder. Journal of biomedicine \& biotechnology, v. 2012, p. 854524, 13 mar. 2012.

HUANG, W.-S. et al. Usefulness of brain 99mTc-TRODAT-1 SPET for the evaluation of Parkinson's disease. European journal of nuclear medicine and molecular imaging, v. 31, n. 2, p. 155-161, fev. 2004.

HUANG, W.-S. et al. Crossover Study of 99mTc-TRODAT-1 SPECT and 18F-FDOPA PET in Parkinson's Disease Patients. [s.d.].

HUGHES, A. J. et al. Accuracy of clinical diagnosis of idiopathic Parkinson's disease: a clinicopathological study of 100 cases. Journal of neurology, neurosurgery, and psychiatry, v. 55, n. 3, p. 181-184, mar. 1992.

HUGHES, A. J. et al. What features improve the accuracy of clinical diagnosis in Parkinson's disease: a clinicopathologic study. 1992. Neurology, v. 57, n. 10 Suppl 3, p. S34-8, nov. 2001. 
HUGHES, A. J. et al. The accuracy of diagnosis of parkinsonian syndromes in a specialist movement disorder service. Brain: a journal of neurology, v. 125, n. Pt 4, p. 861-870, abr. 2002.

HUGHES, A. J.; DANIEL, S. E.; LEES, A. J. Improved accuracy of clinical diagnosis of Lewy body Parkinson's disease. Neurology, v. 57, n. 8, p. 1497-1499, 23 out. 2001.

HWANG, W. J. et al. Reproducibility of 99mTc-TRODAT-1 SPECT measurement of dopamine transporters in Parkinson's disease. Journal of nuclear medicine: official publication, Society of Nuclear Medicine, v. 45, n. 2, p. 207-213, fev. 2004.

JON STOESSL, A. Neuroimaging in Parkinson's Disease. Neurotherapeutics: the journal of the American Society for Experimental NeuroTherapeutics, v. 8, n. 1, p. 72-81, 1 jan. 2011.

JULIUS, M. S. et al. Children's ability to learn a motor skill is related to handwriting and reading proficiency. Learning and individual differences, v. 51, p. 265-272, 1 out. 2016.

KAASINEN, V. et al. Effects of aging and gender on striatal and extrastriatal [123I]FP-CIT binding in Parkinson's disease. Neurobiology of aging, v. 36, n. 4, p. 1757-1763, abr. 2015.

KARIMI, M. et al. Validation of nigrostriatal positron emission tomography measures: critical limits. Annals of neurology, v. 73, n. 3, p. 390-396, mar. 2013.

KRAUSE, J. et al. Influence of striatal dopamine transporter availability on the response to methylphenidate in adult patients with ADHD. European archives of psychiatry and clinical neuroscience, v. 255, n. 6, p. 428-431, dez. 2005.

KRAUSE, K. H. et al. The dopamine transporter and neuroimaging in attention deficit hyperactivity disorder. Neuroscience and biobehavioral reviews, v. 27, n. 7, p. 605-613, nov. 2003.

LEE, J.-D. et al. An automatic MRI/SPECT registration algorithm using image intensity and anatomical feature as matching characters: application on the evaluation of Parkinson's disease. Nuclear medicine and biology, v. 34, n. 4, p. 447-457, maio 2007.

LIN, C.-Y. et al. Dose-response relationship between cumulative mercury exposure index and specific uptake ratio in the striatum on Tc-99m TRODAT SPECT. Clinical nuclear medicine, v. 36, n. 8, p. 689-693, ago. 2011.

LIN, W.-Y. et al. Preliminary studies of differential impairments of the dopaminergic system in subtypes of progressive supranuclear palsy. Nuclear medicine communications, v. 31, n. 11, p. 974 980, nov. 2010.

LIU, H. et al. Evaluation of Tourette's syndrome by (99m)Tc-TRODAT-1 SPECT/CT imaging. Annals of nuclear medicine, v. 24, n. 7, p. 515-521, ago. 2010.

LIZARRAGA, K. J. et al. Molecular imaging of movement disorders. World journal of radiology, v. 8, n. 3, p. 226-239, 28 mar. 2016.

LU, C.-S. et al. 99mTc-TRODAT-1 imaging of multiple system atrophy. Journal of nuclear medicine: official publication, Society of Nuclear Medicine, v. 45, n. 1, p. 49-55, jan. 2004.

MARRAS, C.; TANNER, C. M. Chapter 10. Epidemiology of Parkinson's Disease. In: WATTS RL, S. D. G. (Ed.). . Movement Disorders. 3. New York, NY: McGraw-Hill, 2012. v. 3.

MCHUGH, M. L. Interrater reliability: the kappa statistic. Biochemia medica: casopis Hrvatskoga drustva medicinskih biokemicara / HDMB, v. 22, n. 3, p. 276-282, 2012.

MELO, L. M.; BARBOSA, E. R.; CARAMELLI, P. Declínio cognitivo e demência associados à 
doença de Parkinson: características clínicas e tratamento. Revista de Psiquiatria Clínica, v. 34, n. 4, p. 176-183, 2007.

MEYER, P. T.; FRINGS, L.; HELLWIG, S. Update on SPECT and PET in parkinsonism - part 2. Current opinion in neurology, v. 27, n. 4, p. 398-404, 2014.

MEYER, P. T.; HELLWIG, S. Update on SPECT and PET in parkinsonism - part 1: imaging for differential diagnosis. Current opinion in neurology, v. 27, n. 4, p. 390-397, ago. 2014.

MIZUNO, Y.; HATTORI, N.; MOCHIZUKI, H. Chapter 12. Etiology of Parkinson's Disease. In: WATTS RL, S. D. G. (Ed.). . Movement Disorders. 3. New York, NY: McGraw-Hill, 2012. v. 3.

MOSHAROV, E. V.; BORGKVIST, A.; SULZER, D. Presynaptic effects of levodopa and their possible role in dyskinesia. Movement disorders: official journal of the Movement Disorder Society, v. 30, n. 1, p. 45-53, jan. 2015a.

MOSHAROV, E. V.; BORGKVIST, A.; SULZER, D. Presynaptic effects of levodopa and their possible role in dyskinesia. Movement disorders: official journal of the Movement Disorder Society, v. 30, n. 1, p. 45-53, jan. 2015b.

MOZLEY, P. D. et al. Biodistribution and dosimetry of TRODAT-1: a technetium-99m tropane for imaging dopamine transporters. Journal of nuclear medicine: official publication, Society of Nuclear Medicine, v. 39, n. 12, p. 2069-2076, dez. 1998.

MUNHOZ, R. P. et al. Non-motor signs in Parkinson's disease: a review. Arquivos de NeuroPsiquiatria, v. 73, n. 5, p. 454-462, 2015.

NEMA Standards Publication NU 1-2007: Performance Measurements of Gamma Cameras. [s.l.] National Electrical Manufacturers Association, 2007.

NICARETTA, D. H.; PEREIRA, J. S.; PIMENTEL, M. L. V. Distúrbios autonômicos na doença de Parkinson. Revista da Associação Médica Brasileira, v. 44, n. 2, p. 120-122, 1998.

NICCOLINI, F.; LOANE, C.; POLITIS, M. Dyskinesias in Parkinson's disease: views from positron emission tomography studies. European journal of neurology: the official journal of the European Federation of Neurological Societies, v. 21, n. 5, p. 694-9, e39-43, maio 2014.

NIETHAMMER, M.; FEIGIN, A.; EIDELBERG, D. Functional neuroimaging in Parkinson's disease. Cold Spring Harbor perspectives in medicine, v. 2, n. 5, p. a009274, maio 2012.

OTTAVIANI, S. et al. Comparative analysis of visual and semi-quantitative assessment of striatal [123I]FP-CIT-SPET binding in Parkinson's disease. Neurological sciences: official journal of the Italian Neurological Society and of the Italian Society of Clinical Neurophysiology, v. 27, n. 6, p. 397-401, dez. 2006.

OUNG, Q. W. et al. Technologies for Assessment of Motor Disorders in Parkinson's Disease: A Review. Sensors, v. 15, n. 9, p. 21710-21745, 31 ago. 2015.

PAVESE, N.; BROOKS, D. J. Imaging neurodegeneration in Parkinson's disease. Biochimica et biophysica acta, v. 1792, n. 7, p. 722-729, jul. 2009.

PEDROSO, J. L. et al. Sleep disorders in Machado-Joseph disease: A dopamine transporter imaging study. Journal of the neurological sciences, v. 324, n. 1, p. 90-93, 15 jan. 2013.

PICILLO, M. et al. The relevance of gender in Parkinson's disease: a review. Journal of neurology, p. 1-25, 4 jan. 2017. 
PILLI, L. et al. Critério Brasil 2015 e atualização da distribuição de classes para 2016. [s.1.] Associação Brasileira de Empresas de Pesquisa - APEP, 2016.

POEWE, W. Treatments for Parkinson disease - past achievements and current clinical needs. Neurology, v. 72, n. 7 Supplement 2, p. S65-S73, 17 fev. 2009.

POEWE, W.; MAHLKNECHT, P. Chapter 15. Pharmacological Treatment of Parkinson's Disease. In: POEWE, W.; MAHLKNECHT, P. (Eds.). . Movement Disorders. 3. New York, NY: McGrawHill, 2012. v. 3.

QAMHAWI, Z. et al. Clinical correlates of raphe serotonergic dysfunction in early Parkinson's disease. Brain: a journal of neurology, v. 138, n. Pt 10, p. 2964-2973, out. 2015.

RAJPUT, A. H.; ROZDILSKY, B.; RAJPUT, A. Accuracy of clinical diagnosis in parkinsonism-a prospective study. The Canadian journal of neurological sciences. Le journal canadien des sciences neurologiques, v. 18, n. 3, p. 275-278, 1991.

RITT, P. et al. Absolute quantification in SPECT. European journal of nuclear medicine and molecular imaging, v. 38 Suppl 1, p. S69-77, maio 2011.

RIZZO, G. et al. Accuracy of clinical diagnosis of Parkinson disease: A systematic review and metaanalysis. Neurology, v. 86, n. 6, p. 566-576, 9 fev. 2016.

ROSSO, A. et al. Recomendações para o tratamento da fase inicial da doença de Parkinson. In: DIASTOSTA, E. et al. (Eds.). . Doença de Parkinson. Recomendações. [s.1.] Omnifarma, 2010. p. 21-139.

SANTOS, L. A. Avaliação comparativa dos diferentes métodos de quantificação de imagens de SPECT com 99mTc: um estudo de validação utilizando um fantoma antropomórfico estriatal. [s.l.] Universidade de São Paulo, 2015.

SCHENKMAN, M. L. et al. Spinal movement and performance of a standing reach task in participants with and without Parkinson disease. Physical therapy, v. 81, n. 8, p. 1400-1411, ago. 2001.

SCHERFLER, C. et al. Voxel-wise analysis of [123I]beta-CIT SPECT differentiates the Parkinson variant of multiple system atrophy from idiopathic Parkinson's disease. Brain: a journal of neurology, v. 128, n. Pt 7, p. 1605-1612, jul. 2005.

SCHMITT, G. J. E. et al. Dual-isotope SPECT imaging of striatal dopamine: a comparative study between never-treated and haloperidol-treated first-episode schizophrenic patients. European archives of psychiatry and clinical neuroscience, v. 262, n. 3, p. 183-191, abr. 2012.

SCHNEIDER, C. A.; RASBAND, W. S.; ELICEIRI, K. W. NIH Image to ImageJ: 25 years of image analysis. Nature methods, v. 9, n. 7, p. 671-675, jul. 2012.

SEPPI, K.; SCHOCKE, M. F. H. An update on conventional and advanced magnetic resonance imaging techniques in the differential diagnosis of neurodegenerative parkinsonism. Current opinion in neurology, v. 18, n. 4, p. 370-375, ago. 2005.

SHIH, M. C. et al. Parkinson s disease and dopamine transporter neuroimaging: a critical review. Sao Paulo medical journal = Revista paulista de medicina, v. 124, n. 3, p. 168-175, 2006 a

SHIH, M. C. et al. Parkinson's disease and dopamine transporter neuroimaging: a critical review. Sao Paulo medical journal $=$ Revista paulista de medicina, v. 124, n. 3, p. 168-175, 4 maio 2006 b.

SIEGEL, J. A.; THAKUR, M. What is nuclear medicine? Disponível em:

<http://interactive.snm.org/docs/whatisnucmed2.pdf>. Acesso em: 2017. 
SKANJETI, A. et al. Multicenter Semiquantitative Evaluation of (123)I-FP-CIT Brain SPECT.

Journal of neuroimaging: official journal of the American Society of Neuroimaging, v. 25, n. 6, p. 1023-1029, nov. 2015.

SOUZA, C. et al. Parkinson's disease and the Process of Aging Motor: Literature Review. Rev Neurocienc, v. 19, n. 4, p. 718-723, 2011.

STANDAERT, D.; GALANTER, J. M. Farmacologia da neurotransmissão dopaminérgica. In: GOLAN, D. E. (Ed.). . Princípios de Farmacologia: A Base Fisiopatologia da Farmacoterapia. [s.1.] Guanabara Koogan, 2009. p. 166-185.

STEBBINS, G. T.; GOETZ, C. G. Factor structure of the Unified Parkinson's Disease Rating Scale: Motor Examination section. Movement disorders: official journal of the Movement Disorder Society, v. 13, n. 4, p. 633-636, jul. 1998.

STRAFELLA, A. P. et al. Molecular imaging to track Parkinson's disease and atypical parkinsonisms: New imaging frontiers. Movement disorders: official journal of the Movement Disorder Society, v. 32, n. 2, p. 181-192, fev. 2017.

SZOBOT, C. M. et al. Molecular imaging genetics of methylphenidate response in ADHD and substance use comorbidity. Synapse, v. 65, n. 2, p. 154-159, fev. 2011.

TATSCH, K. Imaging of the dopaminergic system in differential diagnosis of dementia. European journal of nuclear medicine and molecular imaging, v. 35, n. S1, p. 51-57, 2008.

TEIVE, H. O Papel de Charcot na Doença de Parkinson. Arq Neuropsiquiatria, v. 56, n. 1, p. 141145, 1998.

THANVI, B.; LO, N.; ROBINSON, T. Levodopa-induced dyskinesia in Parkinson's disease: clinical features, pathogenesis, prevention and treatment. Postgraduate medical journal, v. 83, n. 980, p. 384-388, 2007a.

THANVI, B.; LO, N.; ROBINSON, T. Levodopa-induced dyskinesia in Parkinson's disease: clinical features, pathogenesis, prevention and treatment. Postgraduate medical journal, v. 83, n. 980, p. 384-388, jun. 2007b.

TOSSICI-BOLT, L. et al. Quantification of [123I]FP-CIT SPECT brain images: an accurate technique for measurement of the specific binding ratio. European journal of nuclear medicine and molecular imaging, v. 33, n. 12, p. 1491-1499, dez. 2006.

TOSSICI-BOLT, L. et al. Calibration of gamma camera systems for a multicentre European 123I-FPCIT SPECT normal database. European journal of nuclear medicine and molecular imaging, v. 38, n. 8, p. 1529-1540, 2011.

TREVISAN, A. C. Avaliação de diferentes métodos de reconstrução de imagens no processamento de SPECT cerebral com simulador antropomórfico estriatal. MSc - [s.l.] EESC Esc Engenharia de São Carlo, 2015.

TROIANO, A. R. et al. PET demonstrates reduced dopamine transporter expression in PD with dyskinesias. Neurology, v. 72, n. 14, p. 1211-1216, 7 abr. 2009.

VAN LAERE, K. et al. Dual-tracer dopamine transporter and perfusion SPECT in differential diagnosis of parkinsonism using template-based discriminant analysis. Journal of nuclear medicine: official publication, Society of Nuclear Medicine, v. 47, n. 3, p. 384-392, mar. 2006.

VAN LAERE, K. et al. EANM procedure guidelines for brain neurotransmission SPECT/PET using dopamine D2 receptor ligands, version 2. European journal of nuclear medicine and molecular 
imaging, v. 37, n. 2, p. 434-442, fev. 2010.

VERHOEFF, N. P. et al. Estimation of dopamine D2 receptor binding potential in the striatum with iodine-123-IBZM SPECT: technical and interobserver variability. Journal of nuclear medicine: official publication, Society of Nuclear Medicine, v. 34, n. 12, p. 2076-2084, dez. 1993.

WEBSITE, T. F. P. James Parkinson. Disponível em: <www.thefamouspeople.com/profiles/jamesparkinson-4855.php.>.

WENG, Y.-H. et al. Sensitivity and specificity of 99mTc-TRODAT-1 SPECT imaging in differentiating patients with idiopathic Parkinson's disease from healthy subjects. Journal of nuclear medicine: official publication, Society of Nuclear Medicine, v. 45, n. 3, p. 393-401, mar. 2004.

WERNECK, A. L. Doença de Parkinson: Etiopatogenia , Clínica e Terapêutica. Revista Hospital Universitário Pedro Ernesto, v. 9, p. 10-19, 2010.

WILKINSON, J. R.; WEINTRAUB, D.; STERN, M. B. Movement Disorders. Chapter 13. Clinical Manifestations of Parkinson's Disease. New York, NY: McGraw-Hill, 2012a. v. 3

WILKINSON, J. R.; WEINTRAUB, D.; STERN, M. B. Chapter 13. Clinical Manifestations of Parkinson's Disease. In: WATTS RL, S. D. G. (Ed.). . Movement Disorders. 3. New York, NY: McGraw-Hill, 2012b. v. 3.

YANG, F. et al. Socioeconomic status in relation to Parkinson's disease risk and mortality: A population-based prospective study. Medicine, v. 95, n. 30, p. e4337, jul. 2016.

YEH, C.-B. et al. Reproducibility of brain dopamine transporter binding with Tc-99m TRODAT-1 SPECT in healthy young men. Psychiatry Research: Neuroimaging, v. 201, n. 3, p. 222-225, 2012.

YEN, M.; LO, L.-H. Examining test-retest reliability: an intra-class correlation approach. Nursing research, v. 51, n. 1, p. 59-62, jan. 2002.

YIN, T.-K. et al. Differences of Various Region-of-Interest Methods for Measuring Dopamine Transporter Availability Using -TRODAT-1 SPECT. The Scientific World Journal, v. 2014, 1 jul. 2014. 


\section{ANEXOS}

ANEXO A

Critérios para Diagnóstico de DP do Banco de Cérebro de Londres (UK Parkinson's Disease Society Brain Bank clinical diagnostic criteria) (HUGHES et al., 1992).

\section{Primeira etapa - Diagnóstico da Síndrome Parkinsoniana}

- Bradicinesia (lentidão no início do movimento voluntário com redução progressiva da velocidade e da amplitude de ações repetitivas) associada a pelo menos uma das seguintes manifestações: rigidez muscular, tremor de repouso de 4 a $6 \mathrm{~Hz}$ ou instabilidade postural não causada por disfunção visual primária, vestibular, cerebelar ou proprioceptiva.

\section{Segunda etapa - Critérios de Exclusão da DP}

- História de acidentes vasculares encefálicos de repetição com progressão em degraus dos sintomas

- História de traumas cranianos repetidos

- Antecedente comprovado de encefalite

- Crises Oculógiras

- Uso de neuroléptico desde o início dos sintomas da doença

- Mais do que um caso de acometimento familiar

- Remissão sustentada de sintomas

- Persistência de acometimento unilateral após três anos

- Paralisia ocular supranuclear

- Sinais Cerebelares

- Acometimento autonômico precoce e acentuado

- Demência severa precoce com distúrbios de memória, linguagem e praxia

- Sinal de Babinski

- Presença de tumores cerebrais ou hidrocefalia comunicante à neuroimagem

- Exposição ao MPTP

- Resposta terapêutica ruim a altas doses de levodopa

Terceira etapa - Critérios de sustentação para o diagnóstico da DP (três ou mais para o diagnóstico definitivo)

- Início unilateral, acometimento assimétrico

- Presença de tremor de repouso

- Doença progressiva

- Assimetria persistente afetando principalmente o lado de início da doença

- Resposta excelente à levodopa (melhora de 70 a 100\%)

- Resposta à levodopa por cinco anos ou mais

- Discinesia (corea) induzida pela terapia com levodopa

- Evolução clínica de dez anos ou mais 


\begin{abstract}
ANEXO B
ESCALA DE HOEHN E YAHR (BHIDAYASIRI; TARSY, 2012).
\end{abstract}

\begin{tabular}{|c|c|}
\hline Escala de Hoehn e Yahr & Escala de Hoehn e Yahr modificada \\
\hline 0 - Nenhum sinal da doença & $\mathbf{0}$ - Nenhum sinal da doença \\
\hline \multirow{2}{*}{$\begin{array}{l}1 \text { - Doença unilateral, usualmente } \\
\text { com mínima ou sem incapacidade }\end{array}$} & 1 - Doença unilateral \\
\hline & 1,5 - Envolvimento unilateral e axial. \\
\hline \multirow[t]{2}{*}{$\begin{array}{l}2 \text { - Doença bilateral sem déficit } \\
\text { de equilíbrio }\end{array}$} & $\begin{array}{l}2 \text { - Doença bilateral sem déficit de equilíbrio (recupera o } \\
\text { equilíbrio dando três passos para trás ou menos). }\end{array}$ \\
\hline & $\begin{array}{l}\text { 2,5 - Doença bilateral leve, com recuperação no "teste do } \\
\text { empurrão"(empurra-se bruscamente o paciente para trás a partir } \\
\text { dos ombros, o paciente dá mais que três passos, mas recupera o } \\
\text { equilíbrio sem ajuda). }\end{array}$ \\
\hline $\begin{array}{l}3 \text { - Doença bilateral leve a } \\
\text { moderada; com instabilidade } \\
\text { postural; capacidade para viver } \\
\text { independente. }\end{array}$ & $\begin{array}{l}3 \text { - Doença bilateral leve a moderada; alguma instabilidade } \\
\text { postural; capacidade para viver independente. }\end{array}$ \\
\hline $\begin{array}{l}4 \text { - Incapacidade grave, ainda } \\
\text { capaz de caminhar ou permanecer } \\
\text { de pé sem ajuda. }\end{array}$ & $\begin{array}{l}4 \text { - Incapacidade grave, ainda capaz de caminhar ou permanecer } \\
\text { de pé sem ajuda. }\end{array}$ \\
\hline $\begin{array}{l}5 \text { - Confinado à cama ou cadeira } \\
\text { de rodas a não ser que receba } \\
\text { ajuda. }\end{array}$ & $\begin{array}{l}5 \text { - Confinado à cama ou cadeira de rodas a não ser que receba } \\
\text { ajuda. }\end{array}$ \\
\hline
\end{tabular}




\author{
ANEXO C

HOSPITAL DAS CLÍNICAS DA
FACULDADE DE MEDICINA DE Q Plotorforma
RIBEIRÃO PRETO DA USP - \\ PARECER CONSUBSTANCIADO DO CEP

\section{DADOS DO PROJETO DE PESQUISA} \\ Título da Pesqulsa: Avaliaçáo Quantitativa e Qualitativa da Densidade de Transportadores Pré-Sinápticos \\ de Dopamina em Pacientes Saudáveis e em Portadores de Doença de Parkinson: Um \\ estudo de SPECT com 99mTc-TRODAT-1. \\ Pesqulsador: FELIPE ARRIVA PITELLA \\ Área Temátlca: \\ Versão: 2 \\ CAAE: 47359715.5 .0000 .5440 \\ Instltulção Proponente: Faculdade de Medicina de Ribeiráo Preto da Universidade de Sáo Paulo \\ Patrocinador Princlpal: Financiamento Proprio

\section{DADOS DO PARECER}

Número do Parecer: 1.239.855

\title{
Apresentação do Projeto:
}

A Doença de Parkinson (DP) é uma doença degenerativa progressiva do Sistema Nervoso Central. Estudos recentes evidenciam que a doença nao envolve somente substância nigra compacta (SNc), mas também outras regioes cerebrais. O SPECT cerebral com [99mTc]-TRODAT-1 e o SPECT com [99mTc]-ECD permitem, respectivamente, estudar a perda de terminaçбes dos neurônios dopaminérgicos no corpo estriado e as alteraçбes perfusionais nas demais regioes do encéfalo de pacientes com DP. O estudo tem como objetivos: (a) Correlacionar as imagens de SPECT [99mTc]-TRODAT-1 e de SPECT [ 99mTc]-ECD em Voluntários Saudáveis e em pacientes com DP, procurando-se estabelecer um limiar quantitativo entre a normalidade e a doença; (b) Correlacionar fenótipos clínicos da DP inicial ou avançada com os SPECTs com [99mTc]-ECD e [99mTc]-TRODAT-1; (c) Determinar a Sensibilidade, Especificidade, VPP, VPN do SPECT com [99mTc]-TRODAT-1 (d) Avaliar a reprodutibilidade inter e intra-sujeito na quantificaça de Iesరes presentes no corpo estriado; (e) Em direça paralela, realizaremos pesquisas tecnologicas para avaliar a aquisiçáo e processamento de SPECT com 99mTc-TRODAT-1, intencionando definir um protocolo de fácil uso pela maioria dos centros de medicina nuclear, com boa reprodutibilidade intra e intersujeito e com acurácia validada através de ferramentas físicas e clínicas. Para tanto seráo incluídos neste estudo retrospectivo 60 pacientes voluntários, sendo 20 saudáveis, 20

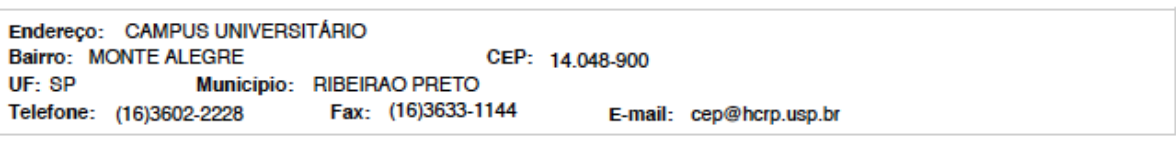




\section{HOSPITAL DAS CLÍNICAS DA FACULDADE DE MEDICINA DE Q Platoformo RIBEIRÃO PRETO DA USP -}

Continuaçăo do Parecer: 1.239 .855

portadores de Parkinson em grau inicial e 20 com doença avançada. Os mesmos será subdivididos por faixa etária para posterior análise (18 a 60 anos e maiores do que 60 anos). Destes pacientes, 60 foram submetidos previamente ao SPECT-CT com [99mTc]-TRODAT-1 para avaliar os transportadores dopaminergicos. Vinte pacientes com Parkinson foram submetidos ao SPECT com [99mTc]-ECD para avaliar o Fluxo Sanguíneo Cerebral regional (FSCr) em repouso. Todos os pacientes assinaram consentimento livre e informado para a realizaçao dos exames. Para o uso das imagens dos pacientes, estes deveráo assinar novo termo de consentimento para garantir a privacidade dos mesmos. Vale ressaltar que todos sáo pacientes e fazem seguimento junto ao Hospital das Clínicas da FMRP - USP e o estudo será realizado junto ao Serviço de Medicina Nuclear (SMN) deste hospital. O pós-processamento das imagens e a análise estatística compreenderá inicialmente a segmentaçáo de regiøes de interesse (ROI) para posterior quantificaçáo. Os métodos de segmentaçáo descritos pela literatura sugerem alguns softwares (softwares Analyze 10.0, 3D-Slicer e 3D-SSP) de processamento de imagens que auxiliam no estabelecimento destas ROIs, fornecendo templates padronizados e auxiliando na segmentaçá semiautomatizada através de transformaçðes rígidas e nao rígidas. Serao definidas as seguintes regiøes: caudado, putâmen, corpo estriado (caudado e putâmen) e regioes frontal e occipital. Depois de aplicada as segmentaçбes sobre as imagens de SPECT, serao realizadas as quantificaçбes, estabelecendo seus respectivos valores de SUV e valores de $\mathrm{p}$ dos clusters de atividade a partir de software de processamento estatístico Statistical Parametric Mapping. Os índices encontrados seráo comparados a variáveis clínicas (idade, sexo, faixa etária, índice de massa corpórea, etnia, nivel educacional e PSQI score) e relacionado à análise qualitativa e semiquantitativa da perfusáo sanguineo com SPECT-CT com [99mTc]-ECD, quando aplicável. As imagens será avaliadas e quantificadas por 2 observadores médicos nucleares experientes. Um destes fará a análise por 2 vezes com pelo menos um intervalo de 1 semana entre as leituras, para fins de avaliaçá intra-observador.

\section{Objetlvo da Pesqulsa:}

O estudo tem como objetivos: (a) Correlacionar as imagens de SPECT [99mTc]-TRODAT-1 e de SPECT [ 99mTc]-ECD em Voluntários Saudáveis e em pacientes com DP, procurando-se estabelecer um limiar quantitativo entre a normalidade e a doença; (b) Correlacionar fenótipos clínicos da DP inicial ou avançada com os SPECTs com [99mTc]-ECD e [99mTc]-TRODAT-1; (c) Determinar a Sensibilidade, Especificidade, VPP, VPN do SPECT com [99mTc]-TRODAT-1 (d) Avaliar a reprodutibilidade inter e intra-sujeito na quantificaçăo de lesరes presentes no corpo estriado; (e) Em direçăo paralela, realizaremos pesquisas tecnológicas para avaliar a aquisiçáo e processamento

Endereço: CAMPUS UNIVERSITÁRIO

Bairro: MONTE ALEGRE

UF: SP Municipio: RIBEIRAO PRETO

Telefone: (16)3602-2228 Fax: (16)3633-1144 E-mail: cep@hcrp.usp.br 


\section{HOSPITAL DAS CLÍNICAS DA
FACULDADE DE MEDICINA DE
USIBEIRÃO PRETO DA USP - USP - RIBEIRÃO}

Continuaçắlo do Parecer: 1.239 .855

de SPECT com 99mTc-TRODAT-1, intencionando definir um protocolo de fácil uso pela maioria dos centros de medicina nuclear, com boa reprodutibilidade intra e intersujeito e com acurácia validada através de ferramentas físicas e clínicas.

\section{Avallação dos Rlscos e Benefíclos:}

Năo há riscos diretos aos envolvidos visto que utilizarăo exames já realizados e em relaçáo aos riscos de privacidade dos pacientes asseguram que essa será garantida. Quanto aos benefícios nao haverá benefícios para os participantes com este projeto, mas esta pesquisa irá ajudar a melhorar as técnicas de imagens para futuros pacientes com Doença de Parkinson, ajudando os médicos no laudo. Náo haverá qualquer benefício financeiro pela a participaça dos pacientes nesta pesquisa.

\section{Comentárlos e Conslderações sobre a Pesqulsa:}

Sinaliza relevância cientifica e social podendo contribuir com a compreensăo e melhor intervençăo junto à patologia estudada.

\section{Considerações sobre os Termos de apresentação obrlgatórla:}

Apresenta toda a documentaçáo necessária.

\section{Recomendações:}

\section{Conclusões ou Pendênclas e Llsta de Inadequações:}

Diante do exposto e à luz da Resoluçao CNS 466/2012, o projeto de pesquisa versáo 2 de 01/09/2015, assim como os Termos de Consentimento Livre e Esclarecido (saudáveis, Parkinson leve e Parkinson avançado) versáo 2 de 01/09/2015, podem ser enquadrados na categoria APROVADO.

\section{ConsIderações FInals a critérlo do CEP:}

Projeto Aprovado: Tendo em vista a legislaçáo vigente, devem ser encaminhados ao CEP, relatórios parciais anuais referentes ao andamento da pesquisa e relatório final ao término do trabalho. Qualquer modificaçá do projeto original deve ser apresentada a este CEP em nova versá, de forma objetiva e com justificativas, para nova apreciaçå.

Este parecer fol elaborado baseado nos documentos abalxo relaclonados:

\begin{tabular}{|l|l|c|c|c|}
\hline \multicolumn{1}{|c|}{ Tipo Documento } & \multicolumn{1}{|c|}{ Arquivo } & Postagem & Autor & Situaçăo \\
\hline TCLE / Termos de & TERMO DE CONSENTIMENTO LIVRE & $28 / 06 / 2015$ & & Aceito \\
Assentimento / & E ESCLARECIDO.pdf & $19: 21: 51$ & & \\
\hline
\end{tabular}

Endereço: CAMPUS UNIVERSITÁRIO

Bairro: MONTE ALEGRE

CEP: $14.048-900$

UF: SP Municipio: RIBEIRAO PRETO

Telefone: (16)3602-2228 $\quad$ Fax: (16)3633-1144 E-mail: cep@hcrp.usp.br 


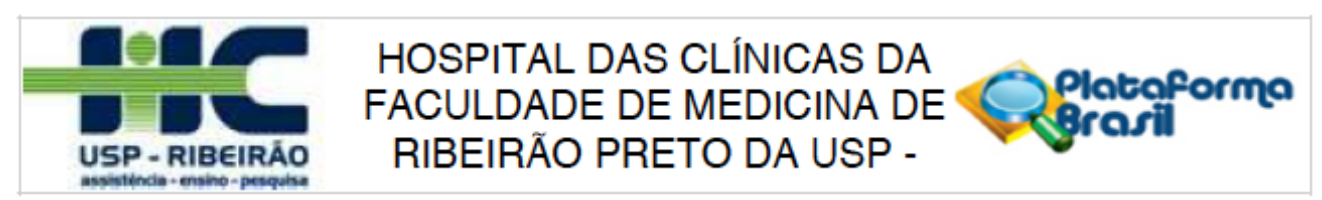

Continuaçălo do Parecer: 1.239.855

\begin{tabular}{|c|c|c|c|c|}
\hline $\begin{array}{l}\text { Justificativa de } \\
\text { Ausência }\end{array}$ & $\begin{array}{l}\text { TERMO DE CONSENTIMENTO LIVRE } \\
\text { E ESCLARECIDO.pdf }\end{array}$ & $\begin{array}{c}28 / 06 / 2015 \\
19: 21: 51\end{array}$ & & Aceito \\
\hline $\begin{array}{l}\text { Projeto Detalhado / } \\
\text { Brochura } \\
\text { Investigador }\end{array}$ & $\begin{array}{l}\text { PROJETO - CEP - FELIPE ARRIVA } \\
\text { PITELLA.pdf }\end{array}$ & $\begin{array}{c}05 / 07 / 2015 \\
18: 11: 31\end{array}$ & & Aceito \\
\hline Folha de Rosto & FOLHA DE ROSTO ASSINADA.pdf & $\begin{array}{c}05 / 07 / 2015 \\
18: 10: 50 \\
\end{array}$ & & Aceito \\
\hline Outros & UPC.pdf & $\begin{array}{c}07 / 07 / 2015 \\
22: 59: 54\end{array}$ & & Aceito \\
\hline $\begin{array}{l}\text { Projeto Detalhado / } \\
\text { Brochura } \\
\text { Investigador }\end{array}$ & PROJETO_modificado_01092015.docx & $\begin{array}{c}01 / 09 / 2015 \\
23: 56: 21\end{array}$ & $\begin{array}{l}\text { FELIPE ARRIVA } \\
\text { PITELLA }\end{array}$ & Aceito \\
\hline $\begin{array}{l}\text { TCLE / Termos de } \\
\text { Assentimento / } \\
\text { Justificativa de } \\
\text { Ausencia }\end{array}$ & $\begin{array}{l}\text { TCLE_grupo_pacientes_saudaveis_mod } \\
\text { ificado_01092015.docx }\end{array}$ & $\begin{array}{c}01 / 09 / 2015 \\
23: 58: 28\end{array}$ & $\begin{array}{l}\text { FELIPE ARRIVA } \\
\text { PITELLA }\end{array}$ & Aceito \\
\hline $\begin{array}{l}\text { TCLE / Termos de } \\
\text { Assentimento / } \\
\text { Justificativa de } \\
\text { Ausência }\end{array}$ & $\begin{array}{l}\text { TCLE_grupo_Parkinson_leve_modificad } \\
\text { o_01092015.docx }\end{array}$ & $\begin{array}{c}01 / 09 / 2015 \\
23: 58: 51\end{array}$ & $\begin{array}{l}\text { FELIPE ARRIVA } \\
\text { PITELLA }\end{array}$ & Aceito \\
\hline $\begin{array}{l}\text { TCLE / Termos de } \\
\text { Assentimento / } \\
\text { Justificativa de } \\
\text { Ausencia }\end{array}$ & $\begin{array}{l}\text { TCLE_Parkinson_avancado_modificado } \\
\text { _01092015.docx }\end{array}$ & $\begin{array}{c}02 / 09 / 2015 \\
00: 00: 17\end{array}$ & $\begin{array}{l}\text { FELIPE ARRIVA } \\
\text { PITELLA }\end{array}$ & Aceito \\
\hline Outros & Carta.pdf & $\begin{array}{c}02 / 09 / 2015 \\
00: 05: 55\end{array}$ & $\begin{array}{l}\text { FELIPE ARRIVA } \\
\text { PITELLA }\end{array}$ & Aceito \\
\hline $\begin{array}{l}\text { Informaçoes Básicas } \\
\text { do Projeto }\end{array}$ & $\begin{array}{l}\text { PB_INFORMAÇC̄ESS_BÁSICAS_DO_P } \\
\text { ROJETO 272762.pdf }\end{array}$ & $\begin{array}{c}02 / 09 / 2015 \\
00: 06: 20\end{array}$ & & Aceito \\
\hline
\end{tabular}

Sltuação do Parecer:

Aprovado

Necesslta Apreclação da CONEP:

Năo

RIBEIRAO PRETO, 22 de Setembro de 2015

Assinado por:

MARCIA GUIMARÄES VILLANOVA

(Coordenador)

Endereço: CAMPUS UNIVERSITÁRIO

Bairro: MONTE ALEGRE

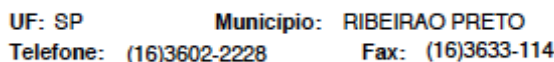

EP: $14.048-900$

Telefone: (16)3602-22

ax: (16)3633-1144 E-mail: cep@hcrp.usp.br

Pagina 04 de 04 


\section{APÊNDICES}

\section{APÊNDICE 1: Termo de Consentimento Livre Esclarecido - grupo saudável}

Você está sendo convidado(a) a participar, como voluntário em uma pesquisa. Após ser esclarecido(a) sobre as informações a seguir, no caso de aceitar a fazer parte do estudo, assine ao final deste documento de 2 páginas, que está em duas vias. Uma delas é sua e a outra é do pesquisador responsável.

Caso você não aceite participar da pesquisa, você não será penalizado(a) de forma alguma. Em caso de dúvidas você pode procurar qualquer pesquisador envolvido na pesquisa. Se você tiver dúvidas sobre os aspectos éticos desta pesquisa, você pode entrar em contato com o Comitê de Ética do Hospital das Clínicas da faculdade de Medicina de Ribeirão Preto, pelo telefone (16) 3602-2228.

Título do projeto: "Avaliação Quantitativa e Qualitativa da Densidade de Transportadores PréSinápticos de Dopamina em Pacientes Saudáveis e em Portadores de Doença de Parkinson: Um estudo de SPECT com ${ }^{99 \mathrm{~m}}$ Tc-TRODAT-1."

Pesquisador responsável:

Prof. Dr. Lauro Wichert Ana

Telefone para contato - (16) 3602-2596; e-mail: lwichert@ fmrp.usp.br

\section{Felipe Arriva Pitella}

Telefone para contato - (16) 3602-2596; e-mail: pitella.fa@gmail.com

Este projeto de pesquisa tem a finalidade de ajudar os médicos a analisarem a função e a forma de estruturas do cérebro de pacientes com Doença de Parkinson, chamados Gânglios da Base. Queremos saber como estas estruturas funcionam em pessoas saudáveis e em participantes portadores de Doença de Parkinson.

Esta pesquisa incluirá as imagens já realizadas de 60 pacientes. Se o(a) $\operatorname{Sr}(a)$. concordar em participar desta pesquisa, você fará parte do grupo de pacientes saudáveis (sem doença de Parkinson), e sua participação consistirá em permitir o uso dos seus dados da história clínica, exame médico e do exame cintilográfico chamado de SPECT Cerebral com o medicamento ${ }^{99 \mathrm{~m}}$ Tc-TRODAT-1, que você realizou no Hospital das Clínicas de Ribeirão Preto, e para o qual o(a) senhor(a) já assinou termo de consentimento prévio permitindo a sua realização.

Sua contribuição para este projeto de pesquisa será apenas em contribuir com as suas informações e exame acima, não precisando retornar a este serviço para coleta de outros dados ou realização de outros exames. Informamos que o(a) $\operatorname{Sr}(a)$. poderá nos solicitar toda e qualquer informação relativa ao projeto e ao SPECT cerebral, posto que será garantido a você o acesso às informações clínicas e de imagem resultantes da pesquisa na qual o(a) senhor(a) está participando.

RISCOS: Não haverá riscos para o participante. A privacidade do mesmo estará garantida.

CUSTOS: Não haverá nenhum custo pela pesquisa ao senhor(a).

\section{BENEFÍCIOS QUE SE PODE OBTER}


Não haverá benefícios para o(a) senhor(a) com este projeto de pesquisa atual, mas sua participação irá ajudar a melhorar as técnicas de imagens para futuros participantes com Doença de Parkinson, ajudando os médicos no laudo. Não haverá qualquer benefício financeiro pela sua participação ou de seu dependente nesta pesquisa.

\section{PRIVACIDADE DO PARTICIPANTE}

As informações coletadas neste estudo serão anexadas ao seu prontuário no Hospital das Clínicas e somente médicos e outros profissionais autorizados terão acesso. Haverá a necessidade de consultar os seus dados de prontuário médico, mas a sua privacidade será respeitada, ou seja, seu nome ou qualquer outro dado que possa de alguma forma identificá-lo serão mantidos em segredo.

\section{DO CONSENTIMENTO DO PARTICIPANTE}

Fui informado(a) de todos os detalhes necessários para o entendimento do estudo "Avaliação Quantitativa e Qualitativa da Densidade de Transportadores Pré-Sinápticos de Dopamina em Pacientes Saudáveis e em Portadores de Doença de Parkinson: Um estudo de SPECT com ${ }^{99 \mathrm{~m}}$ TcTRODAT-1". Fui informado(a) que posso me recusar a participar deste estudo ou retirar meu consentimento a qualquer momento sem precisar me justificar. Caso queira sair da pesquisa, não sofrerei qualquer prejuízo.

Também fui informado(a) que a mim, ou ao meu acompanhante, é assegurada a assistência durante toda a pesquisa, assim como é garantido o livre acesso a todas as informações e esclarecimentos adicionais sobre este estudo e suas consequências antes, durante e depois da minha participação.

Ribeirão Preto, de de

Nome do voluntário da pesquisa

Nome do responsável legal

Nome do pesquisador
Assinatura do voluntário da pesquisa

Assinatura do responsável legal

Assinatura do pesquisador 


\section{APÊNDICE 2: Termo de Consentimento Livre Esclarecido - grupo DP leve}

Você está sendo convidado(a) a participar, como voluntário em uma pesquisa. Após ser esclarecido(a) sobre as informações a seguir, no caso de aceitar a fazer parte do estudo, assine ao final deste documento de 2 páginas, que está em duas vias. Uma delas é sua e a outra é do pesquisador responsável.

Caso você não aceite participar da pesquisa, você não será penalizado(a) de forma alguma. Em caso de dúvidas você pode procurar qualquer pesquisador envolvido na pesquisa. Se você tiver dúvidas sobre os aspectos éticos desta pesquisa, você pode entrar em contato com o Comitê de Ética do Hospital das Clínicas da faculdade de Medicina de Ribeirão Preto, pelo telefone (16) 3602-2228.

Título do projeto: "Avaliação Quantitativa e Qualitativa da Densidade de Transportadores PréSinápticos de Dopamina em Pacientes Saudáveis e em Portadores de Doença de Parkinson: Um estudo de SPECT com ${ }^{99 \mathrm{~m}}$ Tc-TRODAT-1."

Pesquisador responsável:

Prof. Dr. Lauro Wichert Ana

Telefone para contato - (16) 3602-2596; e-mail: lwichert@ fmrp.usp.br

\section{Felipe Arriva Pitella}

Telefone para contato - (16) 3602-2596; e-mail: pitella.fa@gmail.com

Este projeto de pesquisa tem a finalidade de ajudar os médicos a analisarem a função e a forma de estruturas do cérebro de pacientes com Doença de Parkinson, chamados Gânglios da Base. Queremos saber como estas estruturas funcionam em pessoas saudáveis e em participantes portadores de Doença de Parkinson.

Esta pesquisa incluirá as imagens já realizadas de 60 pacientes. Se o(a) $\operatorname{Sr}(a)$. concordar em participar desta pesquisa, você fará parte do grupo de pacientes portadores de doença de Parkinson inicial (com sinais e sintomas mais leves), e sua participação consistirá em permitir o uso dos seus dados da história clínica, exame médico e dos exames cintilográficos chamados de SPECT Cerebral com o medicamento ${ }^{99 \mathrm{~m}}$ Tc-TRODAT-1 e SPECT Cerebral com o medicamento ${ }^{99 \mathrm{~m}} \mathrm{Tc}-\mathrm{ECD}$, que você realizou no Hospital das Clínicas de Ribeirão Preto, e para o qual o(a) senhor(a) já assinou termo de consentimento prévio permitindo a sua realização.

Sua contribuição para este projeto de pesquisa será apenas em contribuir com as suas informações e exame acima, não precisando retornar a este serviço para coleta de outros dados ou realização de outros exames. Informamos que o(a) $\operatorname{Sr}(a)$. poderá nos solicitar toda e qualquer informação relativa ao projeto e aos SPECTs cerebrais, posto que será garantido a você o acesso às informações clínicas e de imagem resultantes da pesquisa na qual o(a) senhor(a) está participando.

RISCOS: Não haverá riscos para o participante. A privacidade do mesmo estará garantida.

CUSTOS: Não haverá nenhum custo pela pesquisa ao senhor(a).

\section{BENEFÍCIOS QUE SE PODE OBTER}

Não haverá benefícios para o(a) senhor(a) com este projeto de pesquisa atual, mas sua participação irá ajudar a melhorar as técnicas de imagens para futuros participantes com Doença de Parkinson, ajudando os médicos no laudo. Não haverá qualquer benefício financeiro pela sua participação ou de seu dependente nesta pesquisa. 


\section{PRIVACIDADE DO PARTICIPANTE}

As informações coletadas neste estudo serão anexadas ao seu prontuário no Hospital das Clínicas e somente médicos e outros profissionais autorizados terão acesso. Haverá a necessidade de consultar os seus dados de prontuário médico, mas a sua privacidade será respeitada, ou seja, seu nome ou qualquer outro dado que possa de alguma forma identificá-lo serão mantidos em segredo.

\section{DO CONSENTIMENTO DO PARTICIPANTE}

Fui informado(a) de todos os detalhes necessários para o entendimento do estudo "Avaliação Quantitativa e Qualitativa da Densidade de Transportadores Pré-Sinápticos de Dopamina em Pacientes Saudáveis e em Portadores de Doença de Parkinson: Um estudo de SPECT com ${ }^{99 \mathrm{~m}} \mathrm{Tc}$ TRODAT-1". Fui informado(a) que posso me recusar a participar deste estudo ou retirar meu consentimento a qualquer momento sem precisar me justificar. Caso queira sair da pesquisa, não sofrerei qualquer prejuízo à assistência que venho recebendo.

Também fui informado(a) que a mim, ou ao meu acompanhante, é assegurada a assistência durante toda a pesquisa, assim como é garantido o livre acesso a todas as informações e esclarecimentos adicionais sobre este estudo e suas consequências antes, durante e depois da minha participação.

Ribeirão Preto, de de

Nome do voluntário da pesquisa

Nome do responsável legal

Nome do pesquisador
Assinatura do voluntário da pesquisa

Assinatura do responsável legal

Assinatura do pesquisador 


\section{APÊNDICE 3: Termo de Consentimento Livre Esclarecido - grupo DP avançado}

Você está sendo convidado(a) a participar, como voluntário em uma pesquisa. Após ser esclarecido(a) sobre as informações a seguir, no caso de aceitar a fazer parte do estudo, assine ao final deste documento de 2 páginas, que está em duas vias. Uma delas é sua e a outra é do pesquisador responsável.

Caso você não aceite participar da pesquisa, você não será penalizado(a) de forma alguma. Em caso de dúvidas você pode procurar qualquer pesquisador envolvido na pesquisa. Se você tiver dúvidas sobre os aspectos éticos desta pesquisa, você pode entrar em contato com o Comitê de Ética do Hospital das Clínicas da faculdade de Medicina de Ribeirão Preto, pelo telefone (16) 3602-2228.

Título do projeto: "Avaliação Quantitativa e Qualitativa da Densidade de Transportadores PréSinápticos de Dopamina em Pacientes Saudáveis e em Portadores de Doença de Parkinson: Um estudo de SPECT com ${ }^{99 \mathrm{~m}}$ Tc-TRODAT-1."

Pesquisador responsável:

Prof. Dr. Lauro Wichert Ana

Telefone para contato - (16) 3602-2596; e-mail: lwichert@ fmrp.usp.br

\section{Felipe Arriva Pitella}

Telefone para contato - (16) 3602-2596; e-mail: pitella.fa@gmail.com

Este projeto de pesquisa tem a finalidade de ajudar os médicos a analisarem a função e a forma de estruturas do cérebro de pacientes com Doença de Parkinson, chamados Gânglios da Base. Queremos saber como estas estruturas funcionam em pessoas saudáveis e em participantes portadores de Doença de Parkinson.

Esta pesquisa incluirá as imagens já realizadas de 60 pacientes. Se o(a) $\operatorname{Sr}(a)$. concordar em participar desta pesquisa, você fará parte do grupo de pacientes portadores de doença de Parkinson já mais evoluído, e sua participação consistirá em permitir o uso dos seus dados da história clínica, exame médico e dos exames cintilográficos chamados de SPECT Cerebral com o medicamento ${ }^{99 \mathrm{~m}} \mathrm{Tc}$ TRODAT-1 e SPECT Cerebral com o medicamento ${ }^{99 \mathrm{~m}} \mathrm{Tc}-\mathrm{ECD}$, que você realizou no Hospital das Clínicas de Ribeirão Preto, e para o qual o(a) senhor(a) já assinou termo de consentimento prévio permitindo a sua realização.

Sua contribuição para este projeto de pesquisa será apenas em contribuir com as suas informações e exame acima, não precisando retornar a este serviço para coleta de outros dados ou realização de outros exames. Informamos que o(a) $\operatorname{Sr}(a)$. poderá nos solicitar toda e qualquer informação relativa ao projeto e aos SPECTs cerebrais, posto que será garantido a você o acesso às informações clínicas e de imagem resultantes da pesquisa na qual o(a) senhor(a) está participando.

RISCOS: Não haverá riscos para o participante. A privacidade do mesmo estará garantida.

CUSTOS: Não haverá nenhum custo pela pesquisa ao senhor(a).

\section{BENEFÍCIOS QUE SE PODE OBTER}

Não haverá benefícios para o(a) senhor(a) com este projeto de pesquisa atual, mas sua participação irá ajudar a melhorar as técnicas de imagens para futuros participantes com Doença de Parkinson, ajudando os médicos no laudo. Não haverá qualquer benefício financeiro pela sua participação ou de seu dependente nesta pesquisa. 


\section{PRIVACIDADE DO PARTICIPANTE}

As informações coletadas neste estudo serão anexadas ao seu prontuário no Hospital das Clínicas e somente médicos e outros profissionais autorizados terão acesso. Haverá a necessidade de consultar os seus dados de prontuário médico, mas a sua privacidade será respeitada, ou seja, seu nome ou qualquer outro dado que possa de alguma forma identificá-lo serão mantidos em segredo.

\section{DO CONSENTIMENTO DO PARTICIPANTE}

Fui informado(a) de todos os detalhes necessários para o entendimento do estudo "Avaliação Quantitativa e Qualitativa da Densidade de Transportadores Pré-Sinápticos de Dopamina em Pacientes Saudáveis e em Portadores de Doença de Parkinson: Um estudo de SPECT com ${ }^{99 \mathrm{~m}}$ TcTRODAT-1". Fui informado(a) que posso me recusar a participar deste estudo ou retirar meu consentimento a qualquer momento sem precisar me justificar. Caso queira sair da pesquisa, não sofrerei qualquer prejuízo à assistência que venho recebendo.

Também fui informado(a) que a mim, ou ao meu acompanhante, é assegurada a assistência durante toda a pesquisa, assim como é garantido o livre acesso a todas as informações e esclarecimentos adicionais sobre este estudo e suas consequências antes, durante e depois da minha participação.

Ribeirão Preto, de de

Nome do voluntário da pesquisa

Nome do responsável legal

Nome do pesquisador
Assinatura do voluntário da pesquisa

Assinatura do responsável legal

Assinatura do pesquisador 


\title{
APÊNDICE 4: Procedimento Operacional
}

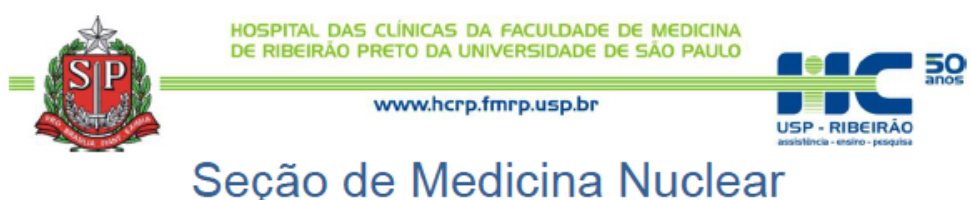

\section{Procedimento Operacional TRODAT-1}

\author{
Procedimentos Operacionais \\ Neste protocolo estão descritos os seguintes procedimentos para a "DAT \\ SPECT Imaging" \\ 1. Dados do Paciente \\ 2. Preparação do Radiofármaco - Preparação e Controle de Qualidade \\ 3. Injeção \\ 4. Parâmetros de pré-aquisição \\ 5. Parâmetros de Aquisição \\ 6. Parametros de Reconstrução \\ 7. Métodos de Aquisição Disponíveis
}




\section{Dados do Paciente}

ID:

Idade:

Gênero:

Nome:

OBSERVAÇÕES:

\section{Preparação do Radiofármaco - Marcação e Controle de Qualidade.}

As orientação para marcação e controle de qualidade seguem recomendações fornecidas pelo fabricante - Radiopharmacos. Recomendamos que a bula seja novamente consultada a cada lote para que as devidas alteração no protocolo de marcação sejam rigidamente aplicadas.

Lote do kit:____ Lote do Gerador de ${ }^{99 m} \mathrm{Tc}$ :

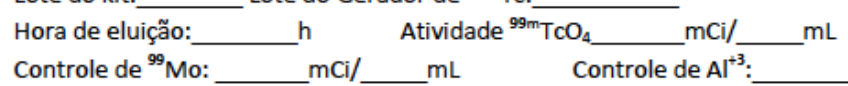

Controle de ${ }^{99} \mathrm{Mo}$ : $\mathrm{mCl} / \mathrm{mL} \quad$ Controle de $\mathrm{Al}^{+3}$ :

Procedimento:

a. Retirar o frasco de TRODAT-1 do refrigerador e deixar atingir a temperatura ambiente. Realizar assepssia nas tampas.

b. Adicionar de 1 a $2 \mathrm{~mL}$ de solução de ${ }^{99 m} \mathrm{TcO}_{4}$, recém eluida (menos de um $1 \mathrm{~h}$ ) de um gerador ${ }^{99} \mathrm{Mo} /{ }^{99 \mathrm{~m}} \mathrm{Tc}$.

Atividade máxima: $50 \mathrm{mCi}$.

c. Agitar até completa dissolução;

d. Levar a banho mariana a $100^{\circ} \mathrm{C}$ por $30 \mathrm{~min}$;

e. Esperar esfriar a temperatura ambiente ( 5 minutos)

f. Verificar atividade final. $\mathrm{mL}$

Controle de qualide do TRODAT-1 marcado com ${ }^{99 \mathrm{~m}} \mathrm{Tc}$ : Hora: $\mathrm{h}$

PROTOCOLO OPERACIONAL - TRODAT 
Procedimento:

Cromatografia ascendente:

Suportes: papel Whatman $3 \mathrm{MM}(1,5 \times 8,0 \mathrm{~cm})$

Solvente: solução de bicarbonato de sódio (saturada)

$\underline{\text { Resultados: }}$

O sistema corte a $2 \mathrm{~cm}$ do fim da fita;

Sistema1: Papel Whatman 3MM em acetona

Atividade do segmento1:

Atividade do segmento2:

Cálculo:

A = Atividade. Seg, $2 \times 100 /$ Atividade. $\operatorname{Seg}(1+2)=$ $\% \mathrm{de}^{99 m} \mathrm{TCO}_{4}$;

Pureza Radioquímica $=100-\mathrm{A}=$ \%TRODAT- ${ }^{99 m}$ TC $\quad$ (REFERÊNCIA: $>90 \%$ )

$\mathrm{pH}=$

(REFERÊNCIA: recomendações na bula)

\section{Controle de Extração de Solventes}

-Colocar num tubo cônico $3 \mathrm{~mL}$ de clorofórmio e $3 \mathrm{~mL}$ de salina $0.9 \%$;

-Adicionar 0,1 -0,5mL de TRODAT- $1^{99 \mathrm{~m}} \mathrm{Tc}$;

-Agitar 1 minuto;

-Retirar $1 \mathrm{~mL}$ da fase superior-1, com uma seringa de $1 \mathrm{~mL}$;

-Retirar $2 \mathrm{~mL}$ da fase superior-1, com uma seringa de $1 \mathrm{~mL}$;

-Cotar a atividadade no calibrador de dose;

\section{Calcular o rendimento:}

Atividade da fase1:

Atividade da fase 2:

Ativ. da fase $2 \times 100 /$ Atividade da fases $(1+2)=$ $\%$ TRODAT $-1^{99 \mathrm{~m}} \mathrm{TC}$ 


\title{
3. Injeção
}

Para de injeção do radiofármaco devidamente preparado é de fundamental importância ter o conhecimento da atividade real contida na instrumentação utilizada antes e após a injeção no paciente.

Atividade real antes:

Hora:

Atividade real após:

Hora:

Qualquer imprevisto que possar ocorrer durante este procedimento deve ser devidademente relatado em súmula, comunicando de forma imediata o Responsável Técnico e Supervisor de Radioproteção do setor.

Observações:

\section{Parâmetros de pré-aquisição}

Conforme sugerido por Guidelines ICANL (The Intersocietal Commission for the Accreditation of Nuclear Medicine Laboratories), alguns controles de qualidade são impreterivelmente necessários para obter melhores resultados nas análises qualitativas.

i. Pico de Energia: diariamente;

Verificado $\square \quad$ Não Verificado

ii. Uniformidade Extrinsica (Intrinsica*): diariamente;

\author{
Verificado $\square$ Não Verificado
}

iii. Resolução Espacial e Linearidade: semanal; Verificado $\square \quad$ Não Verificado

iv. Calibração de Uniformidade: mensal; Verificado $\square \quad$ Não Verificado

v. Alinhamento do Centro de Rotação: mensal; Verificado $\square \quad$ Não Verificado

*Não obrigatório; 


\section{Parâmetros de Aquisição}

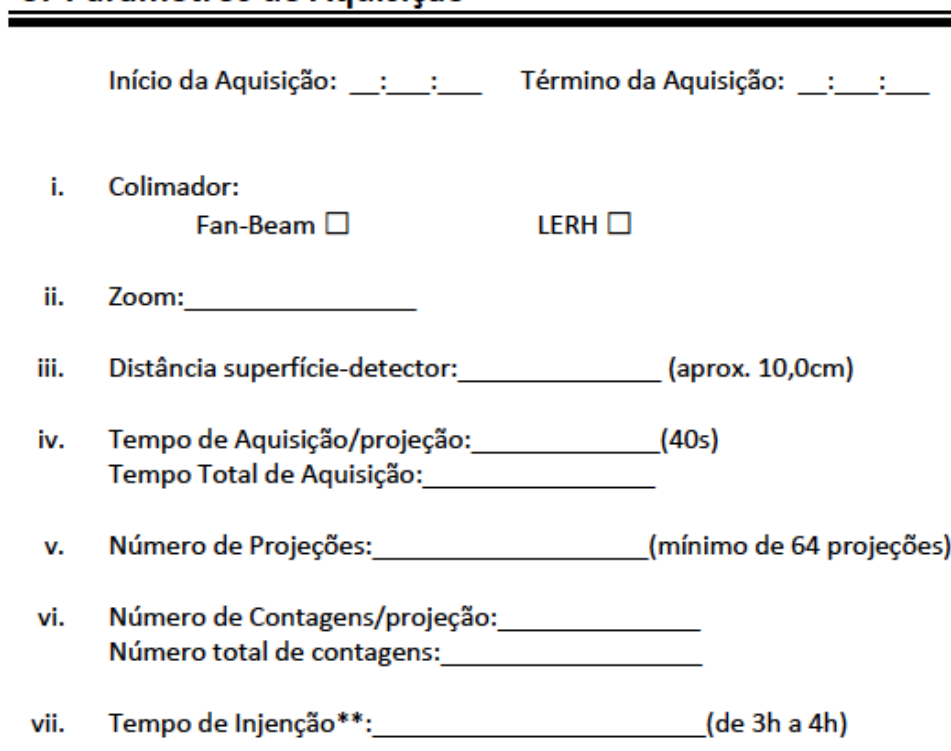

\section{Parâmetros de Reconstrução}

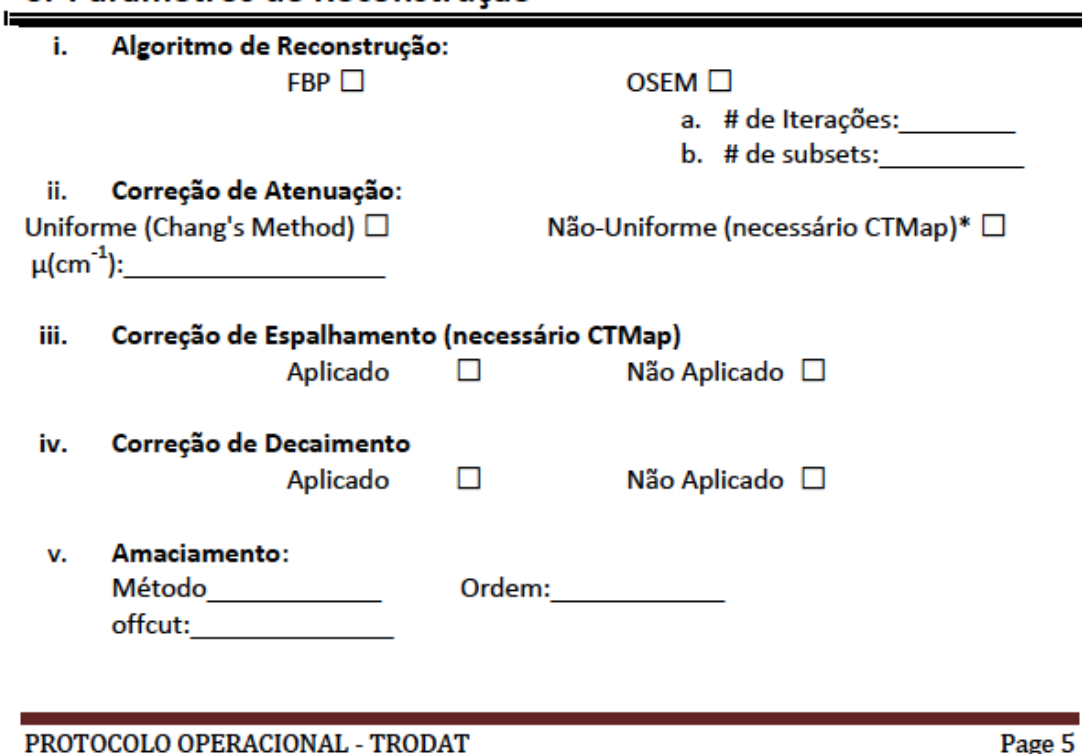




\section{Métodos de Aquisição Disponíveis}

zTodas as quantificações serão baseadas no fatos de BP (binding potencial) (1) para o corpo estriado, putamen e núcleo caudado. Indices de Assimetria (2) de capitação também poderá ser calculado quando necessário.

$$
\begin{aligned}
B P_{D / E}^{S T}=\frac{\left(\overline{S T}_{D V E}-\overline{O C}\right)}{\overline{O C}} \quad B P_{D V E}^{P U} & =\frac{\left(\overline{P U}_{D I E}-\overline{O C}\right)}{\overline{O C}} \quad B P_{D / E}^{C A}=\frac{\left(\overline{C A}_{D I E}-\overline{O C}\right)}{\overline{O C}} \\
A I & =\frac{(\text { ipslateral }- \text { contralateral })}{\underline{\text { (ipslateral }+ \text { contralateral })}} \times 100 \%
\end{aligned}
$$

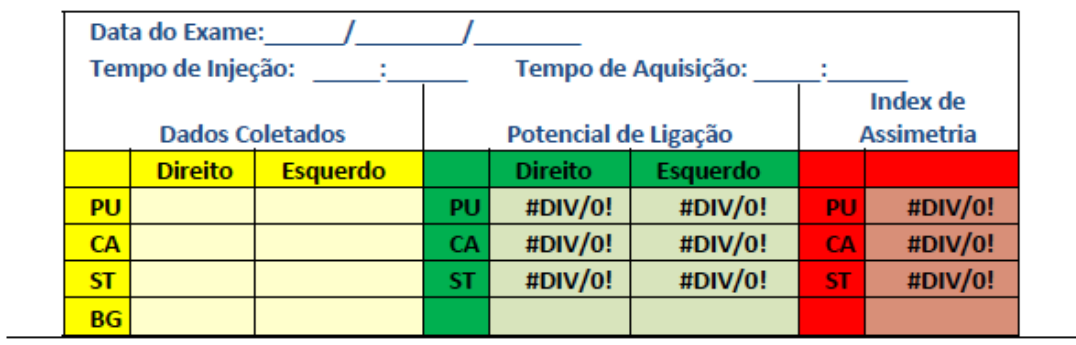

Protocolo Elaborado por: 


\section{APÊNDICE 5: ARTIGO 1}

\section{Evaluation of the dopamine transporter density with ${ }^{99} \mathrm{~m}$ Tc-TRODAT-1 in Parkinson's disease patients with levodopa-induced dyskinesias.}

Felipe Arriva Pitella ${ }^{1}$, Vitor Tumas ${ }^{2}$, Leonardo Alexandre-Santos ${ }^{1}$, Ana Carolina Trevisan 1,3, Manuelina Mariana Capellari Macruz ${ }^{2}$, Julieta Seixas-Moizes ${ }^{1}$,Emerson Nobuyuki Itikawa $^{1,3}$, Mery Kato ${ }^{1}$, Jose Henrique Silvah ${ }^{1}$, Anneke A. Boerlage ${ }^{6}$, Dick Tibboel ${ }^{6}$, Marcus Vinícius Simões ${ }^{1}$, Carlos Alberto Buchpiguel ${ }^{5}$, Lauro Wichert-Ana ${ }^{1,3,5}$.

${ }^{1}$ Department of Internal Medicine, Section of Nuclear Medicine, and ${ }^{2}$ Department of Neuroscience and Behavioral Sciences. Ribeirão Preto Medical School, University of São Paulo. Ribeirão Preto, SP, Brazil.

${ }^{3}$ Interunits Post-Graduation Program on Bioengineering. São Carlos School of Engineering, University of São Paulo, São Carlos, Brazil.

${ }^{4}$ Center of Nuclear Medicine, University of Sao Paulo, University of Sao Paulo Medical School, Sao Paulo, Brazil.

${ }^{5}$ The Center for Interdisciplinary Research on Applied Neurosciences - NAPNA - University of São Paulo (USP).

${ }^{6}$ Intensive Care and Pediatric Surgery Department, Erasmus Medical Center, Sophia Children's Hospital. Erasmus University. Rotterdam, The Netherlands.

Running Title: ${ }^{99 m}$ Tc-TRODAT-1 SPECT in levodopa-induced dyskinesia Word Count (Title: 14 Running Title: 5 Abstract: 253; Text: 3237).

Manuscript includes: 26 references, 2 Color Figures, 3 Tables.

Disclosure: The authors report no conflicts of interest.

\section{ADDRESS CORRESPONDENCE TO:}

Dr. Felipe Arriva Pitella, MD, PhD

Seção de Medicina Nuclear, Hospital das Clínicas - FMRP - USP. Av. Bandeirantes, 3900.

CEP: 14048-900. Ribeirão Preto - SP - Brasil. Phone/FAX: +55 1636022596.

E-mail: pitella.fa@gmail.com 


\begin{abstract}
RATIONALE: Levodopa is the most efficient and common drug for treating Parkinson's disease (PD). However, its long-term use is associated with disabling fluctuations and levodopa-induced dyskinesia (LID) in $9-80 \%$ of the patients. The risk factors for LID include the age of PD onset, disease severity, duration of L-DOPA treatment and dose used, indicating that both the progressive loss of DA neurons and L-DOPA exposure are involved. OBJECTIVE: Using ${ }^{99 \mathrm{~m}}$ Tc-TRODAT-1, this study compared the dopamine transporter (DAT) density with other risk factors for LID in PD patients with and without dyskinesias. MATERIAL AND METHODS: Sixty-seven patients, 23 healthy (8 male; mean \pm SD age $59 \pm 11$ years old) and 44 age-matched patients with various degrees of severity of idiopathic PD (29 male; mean \pm SD age 59 \pm 7 years old; mean \pm SD duration of symptoms $10 \pm 6$ years; HYS: mean \pm SD 2.16 \pm 0.65 ; UPDRS III: mean \pm SD 29.74 \pm 17.79$)$. All patients performed ${ }^{99 \mathrm{~m}}$ Tc-TRODAT-1 SPECT. Specific uptake ratios or binding potentials (BPI) in the striatum were calculated. RESULTS: The quantification of either ipsilateral or contralateral striatum was statistically lower in the PD group with and without dyskinesias than in the healthy control group. Among the independent variables, age of symptoms onset, disease duration, levodopa dosage, doses per day, levodopa effect duration time, HYS and UPDRS explained the occurrence of dyskinesia $(\mathrm{p}<0.05)$. The quantification of either ipsilateral or contralateral striatum and caudate nucleus was statistically lower in the patients with dyskinesia than in those without dyskinesia ( $\mathrm{p}<0.05)$. CONCLUSION: The present results provide evidence that presynaptic dopaminergic denervation in PD plays a role in the development of LID.
\end{abstract}

KEYWORDS: Parkinson; levodopa; dyskinesia; dopamine; TRODAT 


\section{INTRODUCTION}

Parkinson disease (PD) is a progressive neurodegenerative disease that affects approximately $1 \%$ of persons older than 60 years, and up to $4 \%$ of those older than 80 years [1]. PD diagnosis is primarily based on neurological findings and relies on the presence of the cardinal features of bradykinesia, rigidity, tremor and postural instability, coupled with gradual symptom progression and a sustained response to therapy with levodopa. Nonmotor symptoms, such as constipation, cardiac arrhythmias, sleep disorders, and cognitive deficits are also observed in the disease [1,2].

The pathophysiology underlying PD is not fully understood. The main hallmark is the loss of dopaminergic neurons in the substantia nigra pars compacta, leading to depletion of dopamine (DA) in the striatum and accumulation of $\alpha$-synuclein protein in the brain in the form of Lewy bodies [3]. Various other mechanisms were implicated in dopaminergic cell death in PD: oxidative stress, excitotoxicity, mitochondrial dysfunction, neuroinflammation, protein aggregation, phosphorylation, genetic defects and toxins [3].

Carbidopa-levodopa combination therapy remains the most effective treatment; if it is not effective, another diagnosis need to be considered [4]. Carbidopa-levodopa improves tremor, rigidity and bradykinesia, particularly in the early stages of PD. It is well tolerated, has a rapid onset, reduces the risk of death, and is the least expensive of the medications used for this condition. However, long-term use of levodopa is often associated with significantly disabling fluctuations and dyskinesias [4,5]. The reported incidence rates of levodopa-induced dyskinesia (LID) show a wide range, from 9-80\% [4,5]. LID are clinically heterogeneous and commonly presents as chorea or choreoathetosis, though myoclonus, akathisia, ballism and other forms of abnormal movements have also been described. LID first appear on the most affected side by PD and in legs before arms [5]. The risk factors for LID include the age of PD onset, disease severity, duration of L-DOPA treatment and dose used, indicating that both the progressive loss of DA neurons and levodopa (L-DOPA) exposure are involved [6]. In fact, some authors have shown evidence that presynaptic dopaminergic denervation in PD plays a role in LID [5].

The underlying mechanisms for LID are also unclear. It is suggested that pulsatile stimulation of the postsynaptic receptors due to intermittent administration of levodopa leads to downstream changes in proteins and genes, causing alterations in striatal output in a way that promotes dyskinesias [5]. 
The dopamine transporter (DAT) has been considered a marker of dopamine terminal innervations. DAT is a protein in the presynaptic membrane on the terminal of dopaminergic projections that regulates the extracellular dopamine concentration [7]. Several DAT SPECT agents based on cocaine or the closely related tropane derivatives have been reported. They have been applied to investigate striatal dopamine terminal function in typical and atypical PD. Reductions in the striatal uptake of these tracers provide a useful marker of functional dopaminergic loss in that region and potentially provides a valuable means of supporting or rejecting a diagnosis of parkinsonism associated with striatal dopamine deficiency (BROOKS, 2012). Since ${ }^{99 \mathrm{~m}}$ Tc-TRODAT-1 binds DAT, this radiolabeled tropane has been used to evaluate the transporter density [8-11].

Using ${ }^{99 \mathrm{~m}}$ Tc-TRODAT-1, this study aimed to compare DAT density with other risk factors for LID in PD patients with and without dyskinesias.

\section{MATERIAL AND METHODS}

\section{Study Design}

Upon inclusion in the study, the patients were allocated in two groups (healthy subjects and PD group, subdivided in PD with and without dyskinesias) prospectively balanced in terms of age, educational level and sex. The data were analyzed in blinded fashion, after a computergenerated randomization designed to yield groups.

\section{Subjects}

This study included prospectively 67 patients. Twenty-three healthy controls ( 8 male; 15 female; mean \pm SD age $59 \pm 11$ years old) and 44 age-matched patients with various degrees of severity of idiopathic PD (29 male; 15 female; mean \pm SD age $59 \pm 7$ years old; mean \pm SD duration of symptoms $10 \pm 6$ years; range of symptoms duration 1-21 years). All subjects have been treated at the Clinical Hospital of the Ribeirão Preto Medical School, University of São Paulo (HC-FMRP-USP) and provided written informed consent before the study. The study was approved by the institution's Ethics Committee. An expert neurologist in extrapyramidal disease evaluated the patients. PD was diagnosed according to generally accepted criteria (UK Parkinson's Disease Society Brain Bank Clinical Diagnostic Criteria)[12,13].

Eleven patients were on carbidopa-levodopa monotherapy, one was on dopamine agonist monotherapy, while 32 were receiving combination therapy; all patients responded to treatment with good motor benefit. Patients were not taking any medication that might have 
interfered with striatal ${ }^{99 \mathrm{~m}}$ Tc-TRODAT-1 uptake. All PD patients were scored with the Hoehn and Yahr Scale (HYS), which ranges from HYS I to HYS IV (mean \pm SD 2,16 $\pm 0,65$; range 14), and with the Unified Parkinson's Disease Rating Scale motor score (UPDRS III: mean \pm SD 29,74 $\pm 17,79$; range 9-74) [12,13]. All patients underwent brain SPECT with ${ }^{99 \mathrm{~m}}$ Tc-TRODAT1.

\section{Radiopharmaceutical}

The ${ }^{99 \mathrm{~m}}$ Tc-TRODAT-1 was prepared from a preformulated lyophilized kit provided by the Institute of Nuclear Energy Research (Lung-Tan, Taiwan). The kit was reconstituted with $1,110 \mathrm{MBq}(44 \mathrm{mCi})$ of freshly eluted ${ }^{99 \mathrm{~m}} \mathrm{Tc}$-sodium pertechnetate in $5 \mathrm{~mL}$ of saline solution and was incubated at $100^{\circ} \mathrm{C}$ for $30 \mathrm{~min}$ to complete the labelling. After cooling to room temperature, ${ }^{99 \mathrm{~m}} \mathrm{Tc}-\mathrm{TRODAT}-1$ with a radiochemical purity $>90 \%$ (determined by a dualstrip instant thin-layer chromatography method) was obtained in a neutral solution ( $\mathrm{pH} 7.0$ $7.5)$.

\section{Image acquisition}

All ${ }^{99 \mathrm{~m}}$ Tc-TRODAT-1 SPECTs were performed 4 hours after injection of 740-1,110 MBq (mean \pm SD $865,8 \pm 74$ ) of ${ }^{99 m}$ Tc-TRODAT-1 using a dual-head camera. Data were acquired in a $128 \times 128$ matrix with a 1.2 zoom through a $360^{\circ}$ rotation $\left(180^{\circ}\right.$ for each head) at $3^{\circ}$ intervals, for 30 seconds per angle step. Images were reconstructed using the iterative method and Butterworth filter (order 2.00, cut-off 0.22). Transverse, coronal and sagittal orbitomeatal oriented slices ( $4.7 \mathrm{~mm}$ thick) were created. Chang's attenuation correction method was applied using a coefficient of $0.12 / \mathrm{cm}$.

\section{Semi-quantitative assessment}

Five adjacent transaxial slices with the highest radiotracer uptake in the basal ganglia were summed for semi-quantitative analysis of striatal specific DAT binding of ${ }^{99 \mathrm{~m}}$ Tc-TRODAT-1 using an image analysis package (JETpack; Philips Medical Systems). Fixed regions of interest (ROI) were drawn manually over the summed transaxial slice of each hemisphere on the whole striatum, on putamen and caudate. An irregular ROI was drawn manually on occipital cortex (Figure 1). Specific uptake ratios or binding potential (BPI) in the striatum were calculated by subtracting the mean counts per pixel in the occipital lobe (background) from the mean counts per pixel in the whole striatum and dividing the result by the mean counts per pixel in the background [14]. In the PD group, the striatum located opposite the 
side with dominant symptoms was defined as the contralateral. In the control group, the right striatum was defined as the contralateral and the ipsilateral was the left striatum [14].

Images of ${ }^{99 m}$ Tc-TRODAT-1 were semi-quantitatively analysed by two experienced nuclear medicine physicians blinded to the diagnosis of Parkinson's disease and to clinical conditions.

\section{INSERT FIGURE 1}

\section{Statistical analysis}

A simple linear regression model was adjusted for comparison of striatum, caudate nucleus and putamen BPI of healthy subjects and PD group. In PD group, relationships among dyskinesia and clinical findings was evaluated by an adjusted simple linear regression model. The following variables were analyzed: gender, age (years), schooling (years), disease duration (years), age of onset of symptoms (years), UPDRS, levodopa daily dose (mg), number of doses per day and levodopa effect duration time (hours). Concerning the DAT BPI in the striatum, caudate nucleus, and putamen, for intergroup comparisons (PD group with and without dyskinesia), an adjusted simple linear regression model was also used. The software used was SAS 9.3.

\section{RESULTS}

Visual inspection frequently revealed clear differences between the uptake of TRODAT-1 in patients with DP versus healthy volunteers, as shown in Figure 2.

\section{INSERT FIGURE 2}

The mean \pm SD BP in the healthy group was $1.18 \pm 0.22$ (ipsilateral striatum); $1.21 \pm 0.25$ (contralateral striatum); $1.14 \pm 0.28$ (contralateral putamen); $1.09 \pm 0.23$ (putamen ipsilateral); $1.33 \pm 0.29$ (caudate contralateral); and $1.31 \pm 0.27$ (caudate ipsilateral). The quantification of either ipsilateral or contralateral striatum (total and subregions) was statistically lower in the PD group than in the healthy control group (table 1). The reduction of uptake was most pronounced in the contralateral striatum than in the dominant symptomatic side. 


\section{INSERT TABLE 1}

Forty-four patients with PD were screened for this study (29 male; 15 female). Twenty-one patients had dyskinesia while 23 did not show any AIM (abnormal involuntary movement). Among the independent clinical variables indicated in table 2, age of symptoms onset, disease duration, levodopa dosage, doses per day, levodopa effect duration time, HYS and UPDRS, were explanatory to the occurrence of dyskinesia $(\mathrm{p}<0.05)$.

\section{INSERT TABLE 2}

We also found that the quantification of either ipsilateral or contralateral striatum and caudate nucleus was statistically lower in the patients with dyskinesia than in those without dyskinesia (Table 2).

\section{INSERT TABLE 3}

Otherwise, despite DAT density in the contralateral and ipsilateral putamen was lower in the patients with dyskinesia than in those without dyskinesia, we not found statistically difference.

\section{DISCUSSION}

The main pathological hallmark of PD is the loss of dopaminergic neurons in the substantia nigra pars compacta. Imaging of the dopaminergic system with PET or SPECT has proved to be valuable for understanding and diagnosing neurodegenerative diseases, such as PD. Loss of dopamine neurons in the striatum in PD has been imaged using various markers of dopaminergic function. Groups of PD patients have been separated from groups of agematched healthy control subjects in numerous imaging studies [4,13,15-19]. The administration of levodopa is still the most effective pharmacological treatment for the control of the motor symptoms of Parkinson's disease. [20,21]. Although L-dopa may produce a dramatic improvement in PD symptoms, its long-term clinical application is often limited by abnormal irreversible and involuntary choreiform movements called levodopainduced dyskinesia [22-25]. These are observed in approximately 50\% of patients within 5 years of initiation of L-dopa treatment, with various forms of presentation [25,26]. Studies in 
animal models have shown that an "initiation effect" is central to the LID, in which early administrations of levodopa trigger a biochemical and transcriptional response sensitized in the striatum following subsequent dopaminergic stimulation, resulting in progressive and persistent dyskinetic behaviors [24,25].

A variety of changes in striatal function have been described as contributing to cellular sensitization observed during LID expression, including increased glutamatergic signaling, increased ERK / CREB activity, expression of L-dopa-dependent genes and increased translation activity [25]. The pre-synaptic hypotheses attempt to explain the pathophysiology of the LID by relating to presynaptic control dysregulation of vesicular storage, uncontrolled release and decreased dopamine reuptake [22-24].

The results in the literature are variable, but an association of LID with the uptake deficit in the striatum in SPECTs and PET with DAT markers is described. A retrospective study of 127 patients undergoing PET with $\left[{ }^{18} \mathrm{~F}\right]$-FP-CIT, followed for at least 2 years after initiation of dopaminergic treatment, showed that uptake in the anterior and posterior putamen and in the striatum was a predictor of LID development [27]. The BPI of the striatum and caudate were not predictors for LID [27].

A review focused on the application of PET in the evaluation of the development of LID in patients with PD, pointed out several studies related to the presynaptic hypothesis in the pathophysiology of LID. Among these studies, the association of the uptake deficit in the putamen in PET with $\left[{ }^{11} \mathrm{C}\right]-\mathrm{MP}$ with LID at peak dose and with motor fluctuations was shown. This finding corroborates the concept that a gradual loss of DAT availability may result in the loss of compensatory mechanisms when dopamine levels increase substantially after a dose of levodopa [28,29]. In another study with $\left[{ }^{18} \mathrm{~F}\right]$-dopa, patients with PD with motor fluctuations had a $12 \%$ reduction in caudate uptake and $28 \%$ in putamen compared to those with a stable response to levodopa [30]. These findings have indicated a role of reducing the storage capacity of striatal dopamine in the development of motor fluctuations [28].

Our study supports presynaptic hypotheses. A significant difference was observed between BPI means of ST(i), ST(c), CA(i) and CA(c) among patients with PD with and without dyskinesia, being lower in the group with dyskinesia. On the other hand, there was no significant difference for BPI of the putamen ( $p$-value > 0.05). Although there was no statistically significant difference in BPI in the putamen, the mean of this index was about $31 \%$ lower in the group with dyskinesia compared to the group without dyskinesia. The results suggest that a greater pre-synaptic dopaminergic involvement is needed for the 
development of LID, since in Parkinson's disease the uptake deficit in the striatum occurs primarily in the putamen. Another explanation for these data is the frequent occurrence of uptake deficit in the putamen found in our total sample, in which the majority of patients already had bilateral motor symptomatology (88.6\% of the cases), although most of the cases were at an early stage (stage II in HYS).

Other clinical parameters were also evaluated independently. Statistical differences were observed between groups for the following variables: duration of disease, age at onset of symptoms, levodopa dosage, number of doses administered throughout the day, duration of levodopa effect, UPDRS and HYS. In general, these clinical variables associated with LID are related to the increase in dopaminergic system dysregulation, longer exposure to levodopa, and increased availability of levodopa.

\section{CONCLUSIONS}

Until nowadays, there isn't a complete understanding of the mechanisms behind the development of LID. The present results provide evidence that presynaptic dopaminergic denervation in Parkinson's disease plays a role in the development of levodopa-induced dyskinesias. The uptake deficit may represent a predictor of the development of LID and could be used to devise new preventive strategies, which may represent the best approach to this medical problem.

\section{ACKNOWLEDGEMENTS}

The authors gratefully acknowledge financial support from: (a) Grant/Project \# 049/2013 (AUXPE No. 2880/2013, LWA) from CAPES / NUFFIC, Brazil Netherlands International Cooperation; (b) Grant\# 2013/25.987-2 (LWA) and Grant\# 2015/50089-3 FAPESP SPRINT (LWA) from The State of São Paulo Research Foundation - FAPESP. None of these funding agencies played a role in the design, data collection, management, analysis, interpretation of the data, and preparation, review or approval of the manuscript. We confirm that we have read the Journal's position on issues involved in ethical publication and affirm that this report has the approval of our institutional ethics committee. We also thank John Carpenter, Ribeirão Preto, Brazil, for the English revision.

\section{CONFLICT OF INTEREST}

All authors have no financial arrangement or affiliation with industry. Two authors received MSc and PhD scholarships while both paper or research were done: ACT (CAPES 
2012/14152-4), ENI (FAPESP 2012/14152-4). No funding agencies played any/a role in the design or conduct of the study, in the analysis of data and the writing of the manuscript.

\section{STATEMENT OF AUTHORSHIP}

FAP, LWA, VT designed the research; FAP, ACT, LAS, MK conducted the research; LAS conducted the analysis through SPM software; LAS, ENI conducted additional statistical analyses; MMCM and VT performed clinical evaluation, JHS critically reviewed the manuscript, LWA and VT had primary responsibility for final content. All authors contributed towards, read and approved the final manuscript.

\section{REFERENCES}

1. Gazewood JD, Richards DR, Clebak K. Parkinson disease: an update. Am. Fam. Physician. 2013;87:267-73.

2. Munhoz RP, Moro A, Silveira-Moriyama L, Teive HA. Non-motor signs in Parkinson's disease: a review. Arq. Neuropsiquiatr. 2015;73:454-62.

3. Harikrishna Reddy D, Reddy DH, Misra S, Medhi B. Advances in Drug Development for Parkinson's Disease: Present Status. Pharmacology. 2014;93:260-71.

4. Fernandez HH. 2015 Update on Parkinson disease. Cleve. Clin. J. Med. 2015;82:563-8.

5. Thanvi B, Lo N, Robinson T. Levodopa-induced dyskinesia in Parkinson's disease: clinical features, pathogenesis, prevention and treatment. Postgrad. Med. J. 2007;83:384-8.

6. Mosharov EV, Borgkvist A, Sulzer D. Presynaptic effects of levodopa and their possible role in dyskinesia. Mov. Disord. 2015;30:45-53.

7. Huang W-S, Chiang Y-H, Lin J-C, Chou Y-H, Cheng C-Y, Liu R-S. Crossover study of (99m)Tc-TRODAT-1 SPECT and (18)F-FDOPA PET in Parkinson's disease patients. J. Nucl. Med. 2003;44:999-1005.

8. Pavese N, Brooks DJ. Imaging neurodegeneration in Parkinson's disease. Biochim. Biophys. Acta. 2009;1792:722-9.

9. Meyer PT, Frings L, Hellwig S. Update on SPECT and PET in parkinsonism - part 2: biomarker imaging of cognitive impairment in Lewy-body diseases. Curr. Opin. Neurol. 2014;27:398-404.

10. Brooks DJ. 1.7.2 DIAGNOSIS OF PD. Parkinsonism Relat. Disord. 2012;18:S4.

11. Marshall V, Grosset D. Role of dopamine transporter imaging in routine clinical practice. Mov. Disord. 2003;18:1415-23.

12. Goetz CG. Unified Parkinson's Disease Rating Scale (UPDRS) and Movement Disorder 
Society Revision of the UPDRS (MDS-UPDRS). Rating Scales in Parkinson's Disease. 2012. p. $62-83$.

13. Hughes AJ, Daniel SE, Kilford L, Lees AJ. Accuracy of clinical diagnosis of idiopathic Parkinson's disease: a clinico-pathological study of 100 cases. J. Neurol. Neurosurg.

Psychiatry. 1992;55:181-4.

14. Weng Y-H, Yen T-C, Chen M-C, Kao P-F, Tzen K-Y, Chen R-S, et al. Sensitivity and specificity of 99mTc-TRODAT-1 SPECT imaging in differentiating patients with idiopathic Parkinson's disease from healthy subjects. J. Nucl. Med. 2004;45:393-401.

15. Yeh C-B, Chou Y-H, Cheng C-Y, Lee M-S, Wang J-J, Lee C-H, et al. Reproducibility of brain dopamine transporter binding with Tc-99m TRODAT-1 SPECT in healthy young men. Psychiatry Res. 2012;201:222-5.

16. Chou KL, Hurtig HI, Stern MB, Colcher A, Ravina B, Newberg A, et al. Diagnostic accuracy of [99mTc]TRODAT-1 SPECT imaging in early Parkinson's disease. Parkinsonism Relat. Disord. 2004;10:375-9.

17. Tatsch K. Imaging of the dopaminergic system in parkinsonism with SPET. Nucl. Med. Commun. 2001;22:819-27.

18. Shih MC, Hoexter MQ, Andrade LAF de, Bressan RA. Parkinson's disease and dopamine transporter neuroimaging: a critical review. Sao Paulo Med. J. 2006;124:168-75.

19. Oung QW, Muthusamy H, Lee HL, Basah SN, Yaacob S, Sarillee M, et al. Technologies for Assessment of Motor Disorders in Parkinson's Disease: A Review. Sensors . 2015;15:21710-45.

20. Fernandez HH. 2015 Update on Parkinson disease. Cleve. Clin. J. Med. 2015;82:563-8.

21. Thanvi B, Lo N, Robinson T. Levodopa-induced dyskinesia in Parkinson's disease:

clinical features, pathogenesis, prevention and treatment. Postgrad. Med. J. 2007;83:384-8.

22. Thanvi B, Lo N, Robinson T. Levodopa-induced dyskinesia in Parkinson's disease:

clinical features, pathogenesis, prevention and treatment. Postgrad. Med. J. 2007;83:384-8.

23. Mosharov EV, Borgkvist A, Sulzer D. Presynaptic effects of levodopa and their possible role in dyskinesia. Mov. Disord. 2015;30:45-53.

24. Cenci MA. Presynaptic Mechanisms of 1-DOPA-Induced Dyskinesia: The Findings, the Debate, and the Therapeutic Implications. Front. Neurol. [Internet]. Frontiers; 2014 [cited 2017 Jan 28];5. Available from:

http://journal.frontiersin.org/article/10.3389/fneur.2014.00242/full

25. Figge DA, Eskow Jaunarajs KL, Standaert DG. Dynamic DNA Methylation Regulates Levodopa-Induced Dyskinesia. J. Neurosci. 2016;36:6514-24.

26. Poewe W. Treatments for Parkinson disease - past achievements and current clinical needs. Neurology. 2009;72:S65-73.

27. Hong JY, Oh JS, Lee I, Sunwoo MK, Ham JH, Lee JE, et al. Presynaptic dopamine 
depletion predicts levodopa-induced dyskinesia in de novo Parkinson disease. Neurology. 2014;82:1597-604.

28. Niccolini F, Loane C, Politis M. Dyskinesias in Parkinson's disease: views from positron emission tomography studies. Eur. J. Neurol. 2014;21:694-9, e39-43.

29. Troiano AR, de la Fuente-Fernandez R, Sossi V, Schulzer M, Mak E, Ruth TJ, et al. PET demonstrates reduced dopamine transporter expression in PD with dyskinesias. Neurology. 2009;72:1211-6.

30. De La Fuente-Fernandez R, Pal PK, Vingerhoets F, Kishore A, Schulzer M, Mak EK, et al. Evidence for impaired presynaptic dopamine function in parkinsonian patients with motor fluctuations. J. Neural Transm. Springer; 2000;107:49-57. 


\section{FIGURES}

\section{FIGURE 1}

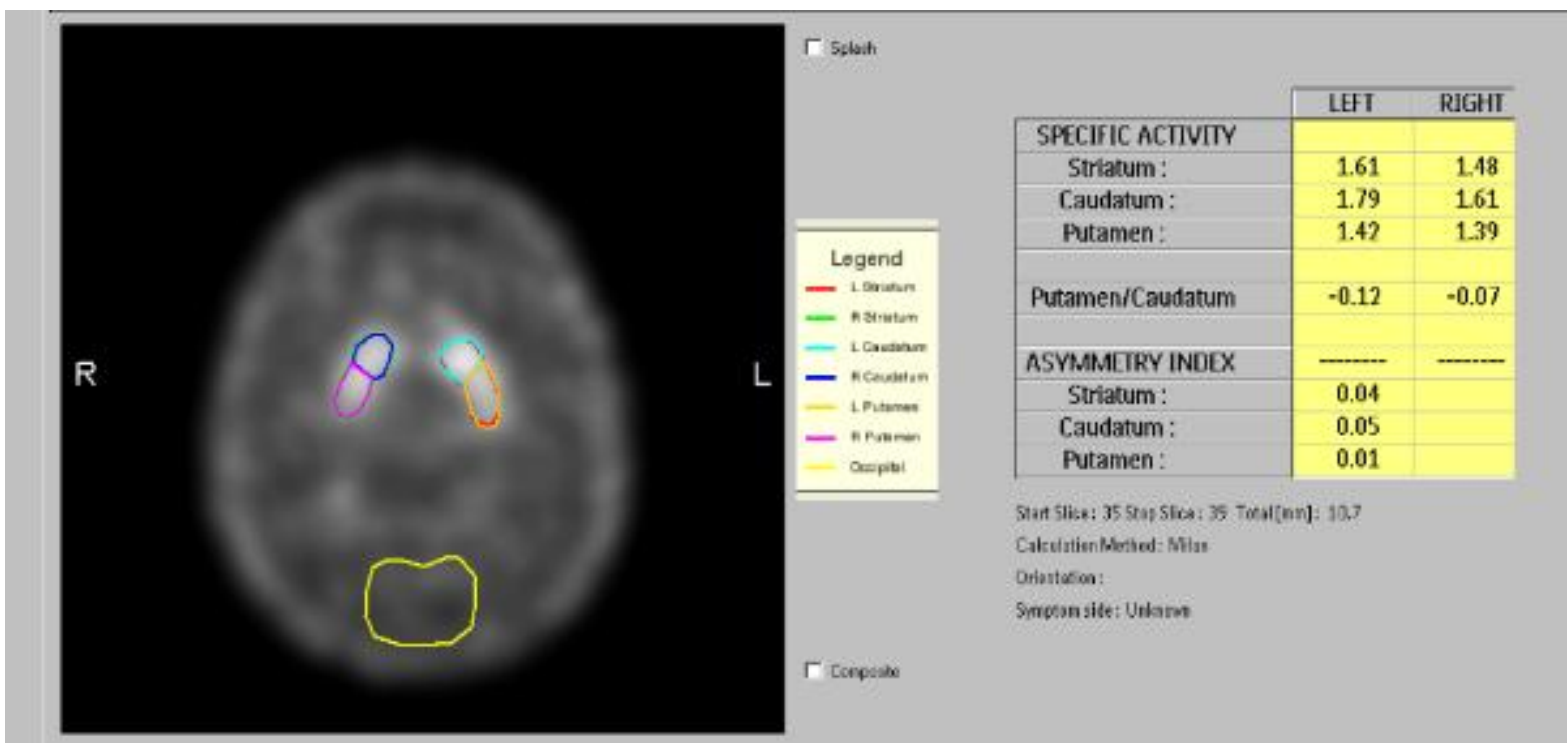

\section{FIGURE 2}

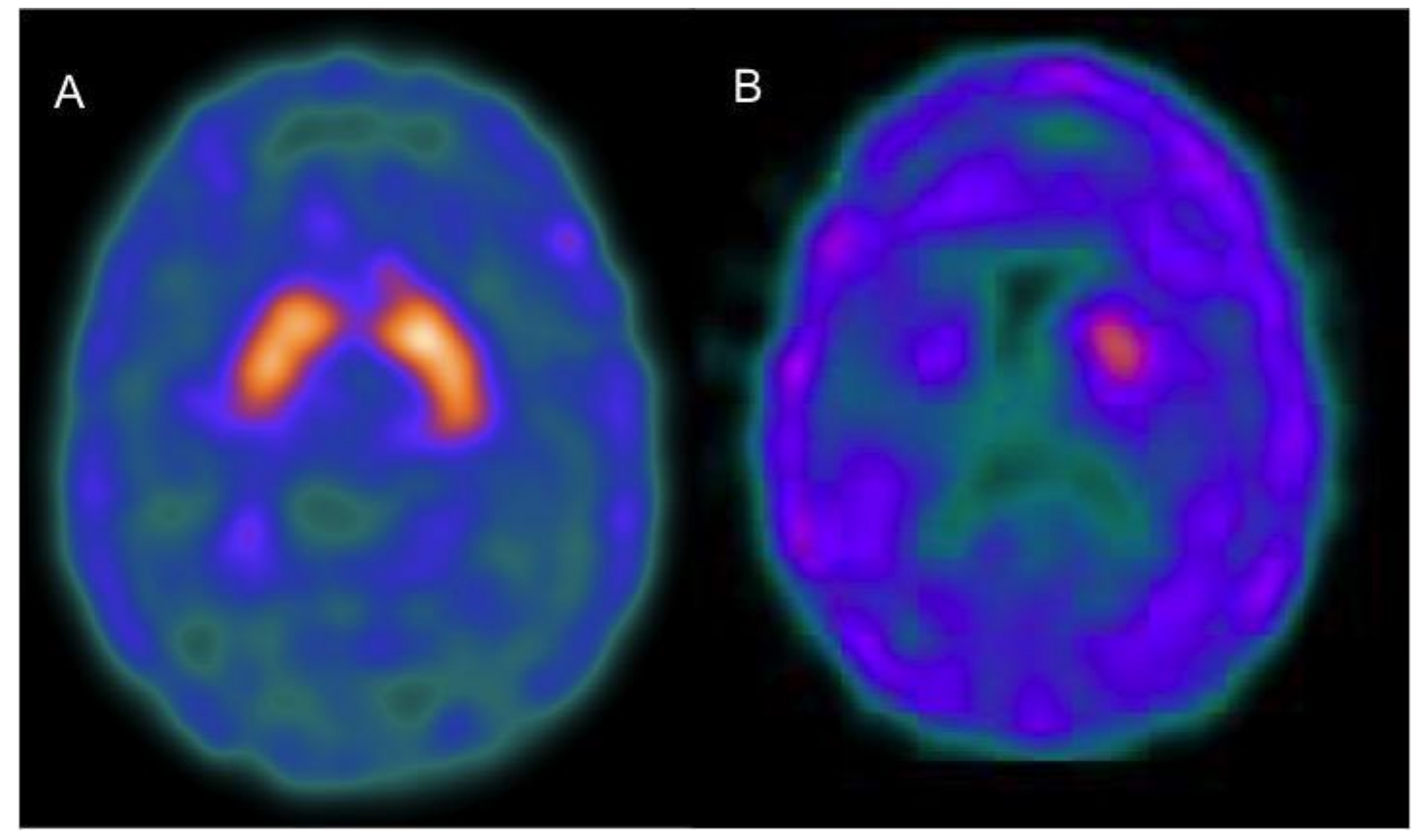




\section{LEGENDS}

Figure 1: Quantification of the binding potential in the striatum, performed in a healthy volunteer: Fixed regions of interest (ROI) were drawn manually over the summed transaxial slice of each hemisphere on the whole striatum, on putamen and caudate

Figure 2: ${ }^{99 \mathrm{~m}}$ Tc-TRODAT-1 SPECT images of a healthy subject (left) and a PD patient H-Y stage III (right). There is a marked decrease in ${ }^{99 m}$ Tc-TRODAT-1 uptake in the striatum of the PD patient. The reduction of uptake was most pronounced in the contralateral striatum than in the dominant symptomatic side. 


\section{TABLES}

Table 1 - Quantification of striatum and subregions between healthy and PD groups $(\mathrm{n}=67$ patients).

\begin{tabular}{|c|c|c|c|c|c|c|}
\hline & PD & $\begin{array}{l}\text { Healthy } \\
\text { subjects }\end{array}$ & $\begin{array}{l}\text { (PD - } \\
\text { healthy }\end{array}$ & $\begin{array}{l}\text { IL } \\
\text { CI95 }\end{array}$ & $\begin{array}{l}\text { SL } \\
\text { CI95 }\end{array}$ & $p$-value \\
\hline ST(i) & $\begin{array}{l}0.50 \pm 0.31 \\
(0.04-1.47)\end{array}$ & $\begin{array}{l}1.18 \pm 0.22 \\
(0.78-1.68)\end{array}$ & -0.68 & -0.82 & -0.53 & $<0.01 * *$ \\
\hline ST(c) & $\begin{array}{l}0.43 \pm 0.25 \\
(0.03-1.16)\end{array}$ & $\begin{array}{l}1.21 \pm 0.25 \\
(0.74-1.77)\end{array}$ & -0.77 & -0.90 & -0.64 & $<0.01 * *$ \\
\hline PU(i) & $\begin{array}{l}0.42 \pm 0.31 \\
(0.03-1.47)\end{array}$ & $\begin{array}{l}1.09 \pm 0.23 \\
(0.71-1.55)\end{array}$ & -0.67 & -0.82 & -0.52 & $<0.01^{* *}$ \\
\hline $\mathbf{P U}(\mathbf{c})$ & $\begin{array}{l}0.37 \pm 0.25 \\
(0.01-1.10)\end{array}$ & $\begin{array}{l}1.14 \pm 0.28 \\
(0.73-1.91)\end{array}$ & -0.77 & -0.90 & -0.63 & $<0.01 * *$ \\
\hline CA(i) & $\begin{array}{l}0.62 \pm 0.35 \\
(0.01-1.51)\end{array}$ & $\begin{array}{l}1.31 \pm 0.27 \\
(0.88-1.84)\end{array}$ & -0.69 & -0.86 & -0.52 & $<0.01 * *$ \\
\hline $\mathrm{CA}(\mathrm{c})$ & $\begin{array}{l}0.52 \pm 0.30 \\
(0.02-1.30)\end{array}$ & $\begin{array}{l}1.33 \pm 0.29 \\
(0.80-1.95)\end{array}$ & -0.81 & -0.96 & -0.65 & $<0.01 * *$ \\
\hline
\end{tabular}

Legend: $\mathrm{PD}=$ Parkinson disease; $\mathrm{ST}=$ striatum; $\mathrm{CA}=$ caudate $\mathrm{PU}=$ putamen $; \mathrm{i}=$ ipsilateral; $\mathrm{c}=$ contralateral; $\mathrm{IL}=$ inferior limit; $\mathrm{SL}=$ superior limit; $\mathrm{CI}=$ confidence interval. The values were described as mean \pm standard deviation (range)

**p-value $<0.01$ 
Table 2 - Mean and standard deviation of clinical variables on groups of dyskinesia and without dyskinesia ( $\mathrm{n}=44$ patients).

\begin{tabular}{|c|c|c|c|c|c|c|}
\hline & LIDpos & LIDneg & $\begin{array}{l}\text { LIDneg - } \\
\text { LIDpos }\end{array}$ & $\begin{array}{c}\text { IL } \\
\text { CI95 }\end{array}$ & $\begin{array}{c}\text { SL } \\
\text { CI95 }\end{array}$ & $p$-value \\
\hline Gender (F/M) & $9 / 12$ & $6 / 17$ & - & - & - & 0.94 \\
\hline Age (years) & $\begin{array}{l}59.29 \pm 6.05 \\
\quad(49-68)\end{array}$ & $\begin{array}{l}60.70 \pm 8.80 \\
\quad(44-73)\end{array}$ & 1.41 & -3.22 & 6.04 & 0.54 \\
\hline $\begin{array}{l}\text { Schooling } \\
\text { (years) }\end{array}$ & $\begin{array}{c}6.48 \pm 3.75(2- \\
16)\end{array}$ & $\begin{array}{c}5.52 \pm 4.44(0- \\
20)\end{array}$ & -0.95 & -3.46 & 1.55 & 0.45 \\
\hline $\begin{array}{l}\text { Age of } \\
\text { symptoms onset } \\
\text { (years) }\end{array}$ & $\begin{array}{c}46.62 \pm 7.30 \\
\quad(35-60)\end{array}$ & $\begin{array}{c}53.65 \pm 11.32 \\
(33-70)\end{array}$ & 7.03 & 1.17 & 12.89 & $0.01 *$ \\
\hline $\begin{array}{l}\text { Disease duration } \\
\text { (years) }\end{array}$ & $\begin{array}{l}12.76 \pm 4.95 \\
\quad(3-21)\end{array}$ & $\begin{array}{c}6.96 \pm 4.61(1- \\
17)\end{array}$ & -5.8 & -8.71 & -2.9 & $<0.01 * *$ \\
\hline $\begin{array}{l}\text { Levodopa } \\
\text { dosage (mg) }\end{array}$ & $\begin{array}{l}994.05 \pm 410.02 \\
\quad(500-2250)\end{array}$ & $\begin{array}{c}526.19 \pm 313.70 \\
(150-1200)\end{array}$ & -0.72 & -1.03 & -0.42 & $<0.01 * *$ \\
\hline Doses per day & $\begin{array}{c}6.00 \pm 1.79(3- \\
9)\end{array}$ & $3.95 \pm 1.43(3-8)$ & -0.42 & -0.61 & -0.22 & $<0.01 * *$ \\
\hline $\begin{array}{l}\text { Levodopa effect } \\
\text { duration time } \\
\text { (hours) }\end{array}$ & $\begin{array}{c}3.62 \pm 1.80(2- \\
9)\end{array}$ & $\begin{array}{c}6.14 \pm 2.83(2- \\
12)\end{array}$ & 0.51 & 0.24 & 0.79 & $<0.01 * *$ \\
\hline HYS & $2.48 \pm 0.6(2-4)$ & $1.86 \pm 0.56(1-3)$ & -0.61 & -0.95 & -0.25 & $0.01 *$ \\
\hline UPDRS & $\begin{array}{c}35.57 \pm 16.2 \\
(13-74)\end{array}$ & $\begin{array}{c}24.83 \pm 17.54 \\
(9-72)\end{array}$ & -10.74 & -21.02 & -0.46 & $0.04 *$ \\
\hline
\end{tabular}

Legend: LIDpos = levodopa induced dyskinesia positive; LIDneg = levodopa induced dyskinesia negative; $F=$ female; $M$ $=$ male; $\mathrm{IL}=$ inferior limit $\mathrm{SL}=$ superior limit $\mathrm{CI}=$ confidence interval. The values were described as mean \pm standard deviation (range). *p-value $<0 . .05 * * p$-value $<0 . .01$ 
Table 3 - Quantification of striatum and subregions between dyskinesia and non-dyskinesia groups.

\begin{tabular}{|c|c|c|c|c|c|c|}
\hline & LIDpos & LIDneg & LIDneg - LIDpos & IL CI95 & SL CI95 & p-value \\
\hline ST(i) & $\begin{array}{l}0.4 \pm 0.25 \\
(0.04-1.03)\end{array}$ & $\begin{array}{l}0.58 \pm 0.34 \\
(0.19-1.47)\end{array}$ & 0.18 & -0.004 & 0.37 & $0.02 *$ \\
\hline ST(c) & $\begin{array}{l}0.34 \pm 0.20 \\
(0.03-0.78)\end{array}$ & $\begin{array}{l}0.49 \pm 0.27 \\
(0.19-1.16)\end{array}$ & 0.15 & 0.004 & 0.30 & $0.02 *$ \\
\hline PU(i) & $\begin{array}{l}0.33 \pm 0.22 \\
(0.03-0.96)\end{array}$ & $\begin{array}{l}0.48 \pm 0.37 \\
(0.13-1.47)\end{array}$ & 0.15 & -0.3 & 0.34 & 0.06 \\
\hline $\mathbf{P U}(\mathbf{c})$ & $\begin{array}{l}0.29 \pm 0.18 \\
(0.01-0.61)\end{array}$ & $\begin{array}{l}0.42 \pm 0.28 \\
(0.08-1.10)\end{array}$ & 0.12 & -0.02 & 0.27 & 0.06 \\
\hline $\mathbf{C A}(\mathbf{i})$ & $\begin{array}{l}0.49 \pm 0.34 \\
(0.01-1.20)\end{array}$ & $\begin{array}{l}0.73 \pm 0.33 \\
(0.32-1.51)\end{array}$ & 0.23 & 0.023 & 0.44 & $0.01 *$ \\
\hline $\mathbf{C A}(\mathbf{c})$ & $\begin{array}{l}0.42 \pm 0.29 \\
(0.02-1.30)\end{array}$ & $\begin{array}{l}0.59 \pm 0.29 \\
(0.21-1.28)\end{array}$ & 0.16 & -0.13 & 0.35 & $0.01 *$ \\
\hline
\end{tabular}

Legend: PD = Parkinson disease; $\mathrm{ST}=$ striatum; $\mathrm{CA}=$ caudate $\mathrm{PU}=$ putamen $; \mathrm{i}=$ ipsilateral $; \mathrm{c}=$ contralateral; $\mathrm{IL}=$ inferior limit; $\mathrm{SL}=$ superior limit $\mathrm{CI}=$ confidence interval. The values were described as mean \pm standard deviation (range). *p-value $<0 . .05 * *$-value $<0 . .01$ 


\section{APÊNDICE 6: ARTIGO 2}

\section{Evaluation of semiquantitative indexes in Parkinson's disease and healthy subjects - a study with [ ${ }^{99 \mathrm{~m}}$ Tc]-TRODAT-1.}

Felipe Arriva Pitella ${ }^{1}$, Vitor Tumas ${ }^{2}$, Leonardo Alexandre Santos ${ }^{1}$, Ana Carolina Trevisan

${ }^{1,3}$, Manuelina Mariana Capellari Macruz ${ }^{2}$, Emerson Nobuyuki Itikawa ${ }^{1,3}$, Mery Kato ${ }^{1}$, Jose Henrique Silvah ${ }^{1}$, Anneke A. Boerlage ${ }^{6}$, Dick Tibboel ${ }^{6}$, Marcus Vinícius Simões ${ }^{1}$, Carlos Alberto Buchpiguel ${ }^{5}$, Lauro Wichert-Ana ${ }^{1,3,5}$.

${ }^{1}$ Department of Internal Medicine, Section of Nuclear Medicine, and ${ }^{2}$ Department of Neuroscience and Behavioral Sciences. Ribeirão Preto Medical School, University of São Paulo. Ribeirão Preto, SP, Brazil.

${ }^{3}$ Interunits Post-Graduation Program on Bioengineering. São Carlos School of Engineering, University of São Paulo, São Carlos, Brazil.

${ }^{4}$ Center of Nuclear Medicine, University of Sao Paulo, University of Sao Paulo Medical School, Sao Paulo, Brazil.

${ }^{5}$ The Center for Interdisciplinary Research on Applied Neurosciences - NAPNA - University of São Paulo (USP).

${ }^{6}$ Intensive Care and Pediatric Surgery Department, Erasmus Medical Center, Sophia Children's Hospital. Erasmus University. Rotterdam, The Netherlands.

\section{ADDRESS CORRESPONDENCE TO:}

Dr. Felipe Arriva Pitella, MD, PhD

Seção de Medicina Nuclear, Hospital das Clínicas - FMRP - USP. Av. Bandeirantes, 3900.

CEP: 14048-900. Ribeirão Preto - SP - Brasil. Phone/FAX: +55 1636022596.

E-mail: pitella.fa@gmail.com 


\begin{abstract}
OBJECTIVE: Using [ $\left.{ }^{99 \mathrm{~m}} \mathrm{Tc}\right]-T R O D A T-1$, this study aimed to evaluate different quantitative indexes in healthy subjects and patients with PD. MATERIAL AND METHODS: Sixty-seven patients, 23 healthy ( 8 male; mean \pm SD age $59 \pm 11$ years old) and 44 age-matched patients with various degrees of severity of idiopathic PD (29 male; age: $59 \pm 7$ years old; duration of symptoms: $10 \pm 6$ years; HYS: 2.16 \pm 0.65 ; UPDRS III: 29.74 \pm 17.79$)$. All patients performed [ $\left.{ }^{99 \mathrm{~m}} \mathrm{Tc}\right]-$ TRODAT-1 SPECT. Binding potentials (BPI) of striatum and subregions, asymmetry index (AI) and putamen/caudate ratio (P/C) were calculated. RESULTS: BPI was statistically lower in the PD group than in the healthy control group. A BPI cutoff for striatum and putamen ranging from 0.73 to 0.78 showed a sensitivity of $95 \%-100 \%$ and specificity of $84 \%$ $88 \%$. For caudate nucleus, a BPI threshold of 0.8 to 0.88 revealed sensitivity up to $100 \%$ and specificity of $77 \%-84 \%$. The BPIs respective areas under the curve (AUC) ranged from 0.92 to 0.98 . For $\mathrm{AI}$ and $\mathrm{P} / \mathrm{C}$, the AUC was less than 0.70 . BPI ICC was close to 1.0 in the intraobserver evaluation, and 0.76 to 0.87 in the interobserver assessment. ICC for AI and P/C was inferior to 0.75 in the intraobserver and interobserver evaluation. CONCLUSION: Different semiquantitative indices show applicability in the differentiation between PD and healthy individuals and add information to the differential diagnosis of other entities involving the dopaminergic system. The performances of the $\mathrm{AI}$ and $\mathrm{P} / \mathrm{C}$ were lower than those of the BPI, as well as their intraobserver and interobserver reliability, and therefore should be used with caution.
\end{abstract}

KEYWORDS: Parkinson; dopamine; TRODAT 


\section{INTRODUCTION}

Parkinsonism is a clinical syndrome characterized by specific motor deficits, referred as cardinal symptoms in Parkinson's disease: akinesia/bradykinesia, rigidity, tremor and postural instability [1]. Several entities can cause signs and symptoms of parkinsonism and all have in common the disorder of the nigrostriatal dopaminergic pathway, which plays a central role in the control of voluntary movements [2]. The causes of parkinsonism can be grouped into primary (or idiopathic), secondary, parkinsonism-plus or atypical syndromes, and hereditary neurodegenerative diseases [2].

Parkinson's disease (PD) is a progressive neurodegenerative disease that affects approximately $1 \%$ of persons older than 60 years and up to $4 \%$ of those older than 80 years (GAZEWOOD; RICHARDS; CLEBAK, 2013). The main aspect of the pathophysiology is the loss of dopaminergic neurons in the substantia nigra pars compacta, with depletion of dopamine (DA) in the striatum and deposition of $\alpha$-synuclein protein in the form of Lewy bodies in the brain [3]. The nigral neuronal loss in PD occurs slowly over the decades preceding the onset of symptoms. Up to $80 \%$ of dopaminergic neurons are lost before the onset of cardinal signs and symptoms of Parkinson's disease [2].

The clinical diagnostic accuracy is variable (76-90\%) and depends on the physician's experience [4,5][6,7]. In a recent meta-analysis the diagnostic accuracy was 80.6\% (95\% CI, $75.2 \%-85.3 \%$ ) for specialists and $73.8 \%$ (95\% CI, 67.8\% -79.6\%) for non-specialists in the area. When the diagnosis was made by specialists in movement disorders, the accuracy increased to $79.6 \%(95 \% \mathrm{CI}, 46 \%-95.1 \%)$ at baseline, and to $83.9 \%$ (95\% CI, 69, $7 \%$ 92.6\%) after follow-up [8]. Considering this scenario, the application of biomarkers and imaging tests becomes relevant, especially in doubtful cases, as for example in patients with poor treatment response with levodopa.

Single photon emission computed tomography (SPECT) with [ $\left.{ }^{99 m} \mathrm{Tc}\right]-T R O D A T-1$, a radiolabeled tropane that binds dopamine transporters (DAT), has been proposed to evaluate the integrity of the nigrostriatal dopaminergic system. In clinical routine, visual interpretation of DAT-SPECT and semiquantification techniques can be applied [9-12]. Many quantitative methods have been developed in order to improve the diagnosis, which is currently mainly based on the observer's experience in visual assessment of the SPECT images. Moreover, guidelines used for conducting and interpreting studies of dopaminergic transporters do not objectively establish the degree of asymmetry between structures that can be considered normal, nor do they standardize the ratio between putamen and caudate for a normal group [13]. 
Using [ $\left.{ }^{99 \mathrm{~m}} \mathrm{Tc}\right]-$ TRODAT-1, this study aimed to evaluate the diagnostic accuracy of different quantitative indexes in healthy subjects and patients with PD and to correlate these indexes with clinical data.

\section{MATERIAL AND METHODS}

\section{Study Design}

Upon inclusion in the study, the patients were allocated in two groups (healthy subjects and PD group) prospectively balanced in terms of age, schooling, and gender. The data were analyzed in blinded fashion, after a computer-generated randomization designed to yield groups. The images were analyzed by qualitative and manual semiquantitative methods by two evaluators, in order to establish accuracy, sensitivity, specificity, and reproducibility of the methods.

\section{Subjects}

This study included prospectively 67 patients. Twenty-three healthy controls ( 8 male; 15 female; mean \pm SD age $59 \pm 11$ years old) and 44 age-matched patients with various degrees of severity of idiopathic PD (29 male; 15 female; mean \pm SD age $59 \pm 7$ years old; mean \pm SD duration of symptoms $10 \pm 6$ years; range of symptoms duration 1-21 years). All subjects have been treated at the Clinical Hospital of the Ribeirão Preto Medical School, University of São Paulo (HC-FMRP-USP) and provided written informed consent before the study. The study was approved by the institution's Ethics Committee.

In the group of healthy volunteers were excluded: patients with moderately severe and severe dementia; Parkinson's disease or parkinsonian syndrome; neuropsychiatric disorders (schizophrenia, hyperactivity and attention deficit, symptomatic depressions and others that may occur with alterations in the dopaminergic system); abusive use of alcohol or drugs; organic brain lesions; cerebral vascular accidents; claustrophobia; chronic use of psychotropic medications; use of medications known to interfere with TRODAT-1 binding to DAT; history of trauma with loss of consciousness; smoking. The patients were submitted to a summary clinical evaluation.

Parkinson's patients necessarily presented clinical diagnosis confirmed by a specialist neurologist in the area. We used the diagnostic criteria of the London Brain Bank (UK-PDS Brain Bank Society-Sponsored Revision of the Unified Parkinson's Disease Rating Scale) 
$[14,15]$. Eleven patients were on carbidopa-levodopa monotherapy, one was on dopamine agonist monotherapy, while 32 were receiving combination therapy; all patients responded to treatment with good motor benefit. Patients were not taking any medication that might have interfered with striatal [ $\left.{ }^{99 \mathrm{~m}} \mathrm{Tc}\right]-$ TRODAT-1 uptake. All PD patients were scored with the Hoehn and Yahr Scale (HYS), which ranges from HYS I to HYS IV (mean \pm SD 2.16 \pm 0.65 ; range 1-4), and with the Unified Parkinson's Disease Rating Scale motor score (UPDRS III: mean \pm SD 29.74 \pm 17.79 ; range 9-74) $[16,17]$. All patients underwent brain SPECT with $\left[{ }^{99 \mathrm{~m}} \mathrm{Tc}\right]-\mathrm{TRODAT}-1$.

\section{Radiopharmaceutical}

The $\left[{ }^{99 \mathrm{~m}} \mathrm{Tc}\right]-$ TRODAT-1 was prepared from a pre formulated lyophilized kit provided by the Institute of Nuclear Energy Research (Lung-Tan, Taiwan). The kit was reconstituted with $1110 \mathrm{MBq}(44 \mathrm{mCi})$ of freshly eluted sodium [ $\left.{ }^{99 \mathrm{~m}} \mathrm{Tc}\right]$-pertechnetate in $5 \mathrm{ml}$ of saline and incubated at $100^{\circ} \mathrm{C}$ for 30 minutes to complete labeling. After cooling to room temperature, quality control of radiochemical purity $(>90 \%)$, determined by the chromatographic method, was performed.

\section{Image acquisition}

All [ $\left.{ }^{99 \mathrm{~m}} \mathrm{Tc}\right]-T R O D A T-1$ SPECT were performed 4 hours after injection of 740-1110 $\mathrm{MBq}(\mathrm{mean} \pm \mathrm{SD} 865.8 \pm 74)$ of $\left[{ }^{99 \mathrm{~m}} \mathrm{Tc}\right]-\mathrm{TRODAT}-1$. The scintigraphic images were obtained in a circular camera series model BrightView XCT (Philips Medical Systems Inc., Cleveland, OH, USA) composed of two detector heads. The data were collected using a low energy high resolution (LEHR) collimator, in a symmetric window with a $15 \%$ width, centered on a 140 $\mathrm{keV}$ photopeak. In a step-and-shoot acquisition mode, 64 projections were collected, with a circular orbit of $180^{\circ}$ per head and with a projection acquisition time of $30 \mathrm{~s}$, a radius of rotation of less than $20 \mathrm{~cm}$, a matrix of $128 \times 128$ pixels, a magnification factor of $x 1$ and with isotropic pixels of $2.13 \mathrm{~mm}$. Images were reconstructed using the iterative method and Butterworth filter (order 2.00, cut-off 0.22). Chang's attenuation correction method was applied using a coefficient of $0.12 / \mathrm{cm}$.

The adequate conditions for SPECT and final image quality were guaranteed by parameters indicated by the manufacturer and by the performance of quality controls established by international protocols. The tests of intrinsic and extrinsic uniformity, center of rotation, spatial resolution, tomographic sensitivity and other quality control tests of monthly and semester intervals had their results analyzed and adapted to the values recommended by 
NEMA [18].

\section{Semiquantitative assessment}

The five adjacent transaxial slices with the highest radiotracer uptake in the basal ganglia were summed for semiquantitative analysis of striatal specific DAT binding of $\left[{ }^{99 m}\right.$ Tc]-TRODAT-1 using an image analysis package (JETpack; Philips Medical Systems). Fixed regions of interest (ROI) were drawn manually over the summed transaxial slice of each hemisphere on the whole striatum, on putamen and caudate. An irregular ROI was drawn manually on occipital cortex (figure 1). In the control group, the right striatum was defined as the contralateral and the ipsilateral was the left striatum (WENG et al., 2004).

Specific uptake ratios or binding potential (BPI) in the striatum were calculated by subtracting the mean counts per pixel in the occipital lobe (background) from the mean counts per pixel in the whole striatum and dividing the result by the mean counts per pixel in the background [19]. In the PD group, the striatum located opposite the side with dominant symptoms was defined as the contralateral.

Images of [ $\left.{ }^{99 \mathrm{~m}} \mathrm{Tc}\right]-$ TRODAT-1 were semiquantitatively analyzed by two experienced nuclear medicine physicians blinded to the diagnosis of Parkinson's disease and to clinical conditions.

\section{INSERT FIGURE 1}

After calculating the mean values of counts per pixel for each area of interest, we calculated each structure binding potential (BPI), ipsilateral and contralateral to the side of motor symptoms; the asymmetry index (AI) of the striatum (ST), putamen (PU) and caudate nucleus (CA); and the ratio between putamen and caudate $(\mathrm{P} / \mathrm{C})$, ipsilateral and contralateral to the side of motor symptoms. The indexes were calculated by the following formulas [20]:

$$
B P I=\frac{R O I-\text { ROIref }}{\text { ROIref }}
$$

Where ROI and ROIref are the average counts per pixel found by the ROIs of interest and reference ROI, respectively.

$$
A I=2 X \frac{R O I i-R O I c}{R O I i+R O I C}
$$


Where ROIi and ROIc are the means of counts per pixel found in the ROIs that are ipsilateral and contralateral to the predominance of motor symptoms, respectively.

$$
\frac{P U}{C A}=\frac{(P U-R O I r e f)}{(C A-\text { ROIref })}
$$

Where PU and CA are the mean counts per pixel found in the putamen and caudate nucleus ROIs, respectively. ROIref is the mean of counts per pixel in the occipital lobe.

\section{Statistical analysis}

Normal distribution was checked by the Shapiro-Wilk test. To compare the healthy controls and PD groups, the Mann-Whitney and Kruskal-Wallis tests were used for variables not normally distributed, such as the binding potential in healthy subjects, gender, age and socioeconomics class. The other indices (P/C and $\mathrm{AI})$ were tested by t-test for independent groups or ANOVA. Age-related changes in the striatal ROI tracer binding were analyzed with linear regression.

Simple and multiple linear regression models were adjusted to compare the striatum, caudate nucleus and putamen BPI, AI and P/C between the healthy subjects and PD groups. In the multiple regression models, gender, age and schooling were used as covariables. The BPI was correlated with UPDRS and HYS using the nonparametric correlation of Spearman. The softwares used were SAS 9.3 (SAS Institute Inc., Cary, NC, USA) and SPSS v17.0 (IBM Corporation, Armonk, NY, USA).

ROC curves were generated using $\mathrm{R}$ version 3.3.3 software to compare the sensitivity and specificity of the diagnosis of each index based on the area under the curve (AUC). The threshold was established after defining the best relationship between sensitivity and specificity among the points generated by the ROC curve. The reliability of the quantification methods was evaluated by the Intraclass Correlation Coefficient (ICC).

\section{RESULTS}

\section{Evaluation of healthy subjects}

The mean \pm SD BPI in the healthy group was $1.18 \pm 0.22$ (ipsilateral striatum); $1.21 \pm 0.25$ (contralateral striatum); $1.14 \pm 0.28$ (contralateral putamen); $1.09 \pm 0.23$ (ipsilateral putamen); $1.33 \pm 0.29$ (contralateral caudate); and 1.31 \pm 0.27 (ipsilateral caudate). The mean BPI was about $18 \%$ higher in the caudate nucleus than in the putamen, with a mean P/C range 
0.85 to 0.87 . The AI observed for both striatum and related subregions was variable, ranging from -0.19 to 0.19 for $\mathrm{ST}$, with a maximum negative value of -0.38 for PU and a maximum positive value of 0.27 for CA. Negative AI values show higher BPI in the right structure, while positive AI values indicate higher BPI on the left one. The results showed that there was no predominance on either side.

Compared to the subgroup with 40-49 years old, the mean striatal BPI was found to be reduced in $8 \%$ and 13\% (left and right, respectively) in the subgroup with 50-59 years old. Moreover, the subgroup with 60-69 years old had an additional BPI reduction of $8 \%$ and 6\% (left and right sides, respectively). This tendency did not remain between the 60-69 and 70-79 age groups, where a slight percentage increase (about 1\%) was observed in those with more advanced age. The scatter plots for striatum BPI (figure 2) corroborate the descriptive analysis of discrete reduction with increasing age, but with no statistical significance in this sample. The analysis by gender and socioeconomic class did not find differences between the subgroups $(p$-value $>0.05)$.

\section{INSERT FIGURE 2}

\section{Comparison between healthy subjects and the PD group}

The quantification of either ipsilateral or contralateral striatum (total and subregions) was statistically lower in the PD group than in the healthy control group (table 1). The reduction of uptake was most pronounced in the contralateral striatum than in the dominant symptomatic side. The pattern was maintained in the multiple models, considering gender, age and schooling as covariates.

\section{TABLE 1}

The mean BPI reduction observed between the control and PD groups ranged from $53 \%$ (in the ipsilateral caudate) to $68 \%$ (in the contralateral putamen). The standard deviation of the calculated indexes was higher in the PD group due to higher heterogeneity in the images of this group.

A statistically significant difference was observed for $\mathrm{AI}(\mathrm{ST})$ and $\mathrm{AI}(\mathrm{PU})$ between the groups (table 2). The same was not observed for the caudate nucleus. On the other hand, although an average lower value of $\mathrm{P} / \mathrm{C}(\mathrm{i})$ and $\mathrm{P} / \mathrm{C}(\mathrm{c})$ was observed in the PD group, this result was not accompanied by statistical significance. 


\section{TABLE 2}

\section{Indexes performance}

The threshold, sensitivity, specificity and the area under the curve for each BPI can be seen at table 3. For BPI of ST and PU, the established cutoff ranged from 0.73 to 0.78 . From this threshold, the sensitivity ranged from $95 \%$ to $100 \%$ and the specificity ranged from $84 \%$ to $88 \%$. This means that virtually all patients with BPI of ST and PU less than 0.7 had PD. For CA, the established threshold was higher, ranging from 0.8 to 0.88 , with sensitivity up to $100 \%$ and specificity of $77 \%$ to $84 \%$. The areas under the curve described were high, ranging from 0.92 to 0.98 .

\section{TABLE 3}

The results were clearly lower for AI and P/C (table 4) than for BPI, with AUC less than 0.70 .

\section{TABLE 4}

The ROC curves in figure 3 show the difference in BPI performance compared to AI and $\mathrm{P} / \mathrm{C}$.

\section{INSERT FIGURE 3}

\section{Reliability of the semiquantitative indexes}

The reliability of the semiquantification was evaluated by the intra-class correlation coefficient (table 5). Considering BPI, an ICC was found close to 1.0 in the intraobserver evaluation. In the interobserver assessment, the reliability was lower, but still high, with ICC ranging from 0.76 in the CA(i) quantification to 0.87 for ST(i), ST(c) and PU(i). On the other hand, considering $\mathrm{P} / \mathrm{C}$ and $\mathrm{AI}$, the intraobserver reliability was satisfactory, except for the calculation of $\mathrm{AI}(\mathrm{PU})$, and was poor in the interobserver evaluation. 


\section{TABLE 5}

Negative ICC values, although not theoretically possible, can be observed in practice as a result of statistical analysis. The interpretation in these cases is poor correlation [21].

\section{Binding potential correlation with clinical data in PD group}

A negative correlation between UPDRS-3 and BPI of ST(i) $(\mathrm{R}=-0.305$; $p$-value $=$ $0.04)$ and $\mathrm{CA}(\mathrm{i})(\mathrm{R}=-0.329$; $p$-value $=0.02)$ was found, but the level of correlation was poor. There was no statistically significant correlation between the BPI of the other structures and UPDRS-3 (p-value > 0.05). None of the semiquantitative indexes evaluated showed a significant correlation with HYS. Considering this scenario, a linear correlation test between UPDRS-3 and BPI was applied in two subgroups of patients with PD: patients in the initial stages of the disease (HYS I/II; mean UPDRS-3 of $23.9 \pm 12.6$ ) and in advanced stages (HYS III/IV, $46.8 \pm 19.7)$. The results are shown in table 6 .

\section{TABLE 6}

The data show a significant linear correlation between BPI of striatum and substructures with motor symptoms assessed by UPDRS-3 in patients with PD with HYS I and II. In the group with advanced disease (HYS III/IV), a correlation was not present in any of the indexes. The behavior of the dispersion graph (figure 4) shows the negative correlation.

\section{INSERT FIGURE 4}

\section{DISCUSSION}

The semiquantification values of BPI found in our study were inserted within a range of results obtained by other studies in the literature. For a healthy group, the mean BPI of ST in these studies, which specifically treats SPECT with [ $\left.{ }^{99 m} \mathrm{Tc}\right]-$ TRODAT, ranged from 0.82 to 4.71 , based on the results obtained manual method [22-28]. This variability of reference values between services makes it necessary a reference of normality of its own, appropriate to the methodology applied in the acquisition of images and their processing, as well as adequate to the equipment in use, avoiding errors in the interpretation of the exams.

Although little is known about the role of socioeconomic status in relation to the risk 
for the development of Parkinson's disease and the impact that can cause in mortality of these individuals [29], in the present study it was evidenced that there was no difference between the socioeconomic classes in DAT density. That way, the image pattern and semiquantitative DAT-SPECT indices of such patients should be evaluated in the same way. Regarding the comparison of means of BPI among genders, in the present study, no significant difference was found between male and female. Most DAT-SPECT studies in the literature report no statistically significant difference or describe higher DAT density in women [30]. In practical terms, this possible difference between gender seems to have little clinical significance.

The influence of age on the BPI of the striatum in DAT-SPECT studies has been consistently described and a negative correlation has been reported [30]. Our study found a relative stability of density of DAT from 40 years of age, and therefore reference values of normality can be used for this group of patients. For younger individuals, however, another study with a specific population should be performed to define an adequate threshold of normality.

The difference in BPI levels between groups of healthy and PD patients is well established in the literature. The present work supported previous findings that DAT semiquantification through SPECT with [ ${ }^{99 \mathrm{~m}} \mathrm{Tc}$ ] -TRODAT-1 is able to distinguish between a group with a confirmed clinical diagnosis of PD and a group of healthy individuals, with high sensitivity, specificity, and accuracy. The performance that we found it is consistent with data from the literature $[22,28,31]$.

Neuroimaging studies often suggest that the reduction of BPI of the striatum and the sub regions significantly correlate with the severity of the disease, represented by HYS, and by the severity of the motor symptoms, established by the UPDRS [20,25,31,32]. Some of these authors support the idea that SPECT with [ $\left.{ }^{99 \mathrm{~m}} \mathrm{Tc}\right]-T R O D A T-1$ could be useful in monitoring disease progression or assessing neuroprotective [20]. However, the data available in the literature are inconsistent [33]. Our work did not show a satisfactory correlation between semiquantification and clinical data of HYS or UPDRS considering the global sample, contradicting previous work with DAT-SPECT or DAT-PET. However, when the PD patients were divided into early stage (HYS I and II) and late stage (HYS III and IV), there was a clear negative correlation of the BPI of PD group in the early stage with the severity of motor symptoms, evaluated by UPDRS-3. On the other hand, there was no correlation between UPDRS-3 and BPI in patients with PD at later stages. This finding supported the hypothesis of Karimi and collaborators of the absence of correlation between neuroimaging and more significant neuronal loss [33]. Considering the results obtained, it is possible to 
question if at least in initial cases we would be allowed to use DAT-SPECT for PD follow-up. The fact that the symptoms appear long after the onset of nigrostriatal degeneration [34] makes this application difficult.

About the least explored indexes in the literature ( $\mathrm{AI}$ and $\mathrm{P} / \mathrm{C}$ ratio), the obtained data showed that the ST and PU asymmetry indices were able to distinguish the two groups, with and without PD. This difference was not significant for $\mathrm{AI}(\mathrm{CA})$, which may be due to the selective loss of DAT characteristic of PD, being later in the caudate nucleus, and therefore maintaining a symmetry relation closer to healthy subjects. On the other hand, although we observed a trend of lower $\mathrm{P} / \mathrm{C}$ ratio in patients with $\mathrm{PD}$, this finding did not present statistical difference, contrary to what was described in the literature [20]. These unfavorable results of the present study could be due to the frequent bilateral involvement in the striatum of PD patients, observed in about $95 \%$ of the cases in our study, as well as to the frequent involvement of the caudate nucleus (about $84 \%$ of the cases). Although the performance of AI and $\mathrm{P} / \mathrm{C}$ was not satisfactory, these indices were able to exclude $\mathrm{PD}$ when $\mathrm{AI}(\mathrm{ST})>0.2$; $\mathrm{AI}(\mathrm{PU})>0.22$; and $\mathrm{AI}(\mathrm{CA})>0.3$; and still when $\mathrm{P} / \mathrm{C}(\mathrm{i})<0.65$ and $\mathrm{P} / \mathrm{C}(\mathrm{c})<0.57$. Thus, these indices may have applicability. In addition, the characterization of the pattern of involvement in DAT-SPECT in PD, considering not only degree of involvement, but also the relationship between the substructures that compose the striatum, can be useful as a basis for differentiation of other motor diseases, especially atypical parkinsonian syndromes.

Regarding indexes reliability, it was excellent for BPI [35]. On the other hand, it was unsatisfactory for $\mathrm{AI}$ and $\mathrm{P} / \mathrm{C}$, particularly interobserver. A possible justification for this finding concerns the low absolute values found, in which small variations could cause high percentual variations. Thus, for follow-up purposes, the applicability of $\mathrm{AI}$ and $\mathrm{P} / \mathrm{C}$ ratio is limited.

\section{CONCLUSIONS}

The DAT density is symmetrical in the striatum, with a higher binding potential in the caudate nucleus compared to the putamen (about 18\% higher). The binding potential does not suffer clinically significant reduction between 40 years of age and the end of 70 years, thus there is no impact on the interpretation of the DAT-SPECT studies. Further studies should be performed to establish the normal pattern for young adults under the age of 40 years. Socioeconomic class and gender do not significantly influence DAT density. Different semiquantitative indexes show applicability in the differentiation between PD and healthy individuals and potentially may aid information to the differential diagnosis of other entities 
involving the dopaminergic system. The performances of the AI and P/C are lower than those of the BPI, as well as their intraobserver and interobserver reliability, and therefore should be used with caution. Finally, DAT-SPECT has little utility in the control of PD progression. The application can be considered in initial cases with discrete image findings identified in a baseline study.

\section{ACKNOWLEDGEMENTS}

The authors gratefully acknowledge financial support from: (a) Grant/Project \# 049/2013 (AUXPE No. 2880/2013, LWA) from CAPES / NUFFIC, Brazil Netherlands International Cooperation; (b) Grant\# 2013/25.987-2 (LWA) and Grant\# 2015/50089-3 FAPESP SPRINT (LWA) from The State of São Paulo Research Foundation - FAPESP. None of these funding agencies played a role in the design, data collection, management, analysis, interpretation of the data, and preparation, review or approval of the manuscript. We confirm that we have read the Journal's position on issues involved in ethical publication and affirm that this report has the approval of our institutional ethics committee. We also thank John Carpenter, Ribeirão Preto, Brazil, for the English revision.

\section{CONFLICT OF INTEREST}

All authors have no financial arrangement or affiliation with industry. Two authors received MSc and Ph.D scholarships while both paper or research were done: ACT (CAPES 2012/14152-4), ENI (FAPESP 2012/14152-4). No funding agencies played any/a role in the design or conduct of the study, in the analysis of data and the writing of the manuscript.

\section{STATEMENT OF AUTHORSHIP}

FAP, LWA, VT designed the research; FAP, ACT, LAS, MK conducted the research; LAS conducted the analysis through SPM software; LAS, ENI conducted additional statistical analyses; MMCM and VT performed clinical evaluation, JHS critically reviewed the manuscript, LWA and VT had primary responsibility for final content. All authors contributed towards, read and approved the final manuscript.

\section{REFERENCES}

1. Barbosa ER, Sallem F. Diagnosis, Parkinsons Disease. Revista de Neurociências. 2005;13:158-65. 
2. Wilkinson JR, Weintraub D, Stern MB. Movement Disorders. Chapter 13. Clinical Manifestations of Parkinson's Disease. Watts R1 SDG, editor. New York, NY: McGraw-Hill; 2012.

3. Harikrishna Reddy D, Reddy DH, Misra S, Medhi B. Advances in Drug Development for Parkinson's Disease: Present Status. Pharmacology. 2014;93:260-71.

4. Rajput AH, Rozdilsky B, Rajput A. Accuracy of clinical diagnosis in parkinsonism - a prospective study. Can. J. Neurol. Sci. 1991;18:275-8.

5. Hughes AJ, Daniel SE, Kilford L, Lees AJ. Accuracy of clinical diagnosis of idiopathic Parkinson's disease: a clinico-pathological study of 100 cases. J. Neurol. Neurosurg. Psychiatry. 1992;55:181-4.

6. Hughes AJ, Daniel SE, Lees AJ. Improved accuracy of clinical diagnosis of Lewy body Parkinson's disease. Neurology. 2001;57:1497-9.

7. Hughes AJ, Ben-Shlomo Y, Daniel SE, Lees AJ. What features improve the accuracy of clinical diagnosis in Parkinson's disease: a clinicopathologic study. 1992. Neurology. 2001;57:S34-8.

8. Rizzo G, Copetti M, Arcuti S, Martino D, Fontana A, Logroscino G. Accuracy of clinical diagnosis of Parkinson disease: A systematic review and meta-analysis. Neurology.

2016;86:566-76.

9. Pavese N, Brooks DJ. Imaging neurodegeneration in Parkinson's disease. Biochim. Biophys. Acta. 2009; 1792:722-9.

10. Meyer PT, Frings L, Hellwig S. Update on SPECT and PET in parkinsonism - part 2: biomarker imaging of cognitive impairment in Lewy-body diseases. Curr. Opin. Neurol. 2014;27:398-404.

11. Brooks DJ. 1.7.2 DIAGNOSIS OF PD. Parkinsonism Relat. Disord. 2012;18:S4.

12. Marshall V, Grosset D. Role of dopamine transporter imaging in routine clinical practice. Mov. Disord. 2003;18:1415-23.

13. Djang DSW, Janssen MJR, Bohnen N, Booij J, Henderson TA, Herholz K, et al. SNM practice guideline for dopamine transporter imaging with 123I-ioflupane SPECT 1.0. J. Nucl. Med. 2012;53:154-63.

14. Goetz CG. Unified Parkinson's Disease Rating Scale (UPDRS) and Movement Disorder Society Revision of the UPDRS (MDS-UPDRS). Rating Scales in Parkinson's Disease. 2012. p. $62-83$.

15. Goetz CG, Tilley BC, Shaftman SR, Stebbins GT, Fahn S, Martinez-Martin P, et al. Movement Disorder Society-sponsored revision of the Unified Parkinson's Disease Rating Scale (MDS-UPDRS): scale presentation and clinimetric testing results. Mov. Disord. 2008;23:2129-70.

16. Goetz CG. Unified Parkinson's Disease Rating Scale (UPDRS) and Movement Disorder Society Revision of the UPDRS (MDS-UPDRS). Rating Scales in Parkinson's Disease. 2012. 
p. $62-83$.

17. Hughes AJ, Daniel SE, Kilford L, Lees AJ. Accuracy of clinical diagnosis of idiopathic Parkinson's disease: a clinico-pathological study of 100 cases. J. Neurol. Neurosurg.

Psychiatry. 1992;55:181-4.

18. NEMA Standards Publication NU 1-2007: Performance Measurements of Gamma Cameras. National Electrical Manufacturers Association; 2007.

19. Weng Y-H, Yen T-C, Chen M-C, Kao P-F, Tzen K-Y, Chen R-S, et al. Sensitivity and specificity of 99mTc-TRODAT-1 SPECT imaging in differentiating patients with idiopathic Parkinson's disease from healthy subjects. J. Nucl. Med. 2004;45:393-401.

20. Weng Y-H, Yen T-C, Chen M-C, Kao P-F, Tzen K-Y, Chen R-S, et al. Sensitivity and specificity of 99mTc-TRODAT-1 SPECT imaging in differentiating patients with idiopathic Parkinson's disease from healthy subjects. J. Nucl. Med. 2004;45:393-401.

21. Giraudeau B. Negative values of the intraclass correlation coefficient are not theoretically possible. J. Clin. Epidemiol. 1996;49:1205-6.

22. Badiavas K, Molyvda E, Iakovou I, Tsolaki M, Psarrakos K, Karatzas N. SPECT imaging evaluation in movement disorders: far beyond visual assessment. Eur. J. Nucl. Med. Mol. Imaging. 2011;38:764-73.

23. Yin T-K, Lee B-F, Yang YK, Chiu N-T. Differences of Various Region-of-Interest Methods for Measuring Dopamine Transporter Availability Using -TRODAT-1 SPECT. The Scientific World Journal [Internet]. Hindawi Publishing Corporation; 2014 [cited 2017 Jan 28];2014. Available from: https://www.hindawi.com/journals/tswj/2014/837439/

24. David Mozley P, Schneider JS, Acton PD, PIÃ K, Stem MB, Siderowf A, et al. Binding of [99mTc]TRODAT@1 to Dopamine Transporters in Patients with Parkinson's Disease and in Healthy Volunteers. The Journal of Nuclear Medicine. 2000;41:584-9.

25. Geng Y, Shi G-H, Jiang Y, Xu L-X, Hu X-Y, Shao Y-Q. Investigating the role of 99mTcTRODAT-1 SPECT imaging in idiopathic Parkinson's disease. J. Zhejiang Univ. Sci. B. 2005;6:22-7.

26. Hwang WJ, Yao WJ, Wey SP, Ting G. Reproducibility of 99mTc-TRODAT-1 SPECT measurement of dopamine transporters in Parkinson's disease. J. Nucl. Med. 2004;45:207-13.

27. Huang W-S, Chiang Y-H, Lin J-C, Chou Y-H, Cheng C-Y, Liu R-S. Crossover Study of 99mTc-TRODAT-1 SPECT and 18F-FDOPA PET in Parkinson's Disease Patients.

28. Bor-Seng-Shu E, Felicio AC, Braga-Neto P, Batista IR, Paiva WS, de Andrade DC, et al. Dopamine transporter imaging using 99mTc-TRODAT-1 SPECT in Parkinson's disease.

Med. Sci. Monit. 2014;20:1413-8.

29. Yang F, Johansson ALV, Pedersen NL, Fang F, Gatz M, Wirdefeldt K. Socioeconomic status in relation to Parkinson's disease risk and mortality: A population-based prospective study. Medicine . 2016;95:e4337.

30. Kaasinen V, Joutsa J, Noponen T, Johansson J, Seppänen M. Effects of aging and gender 
on striatal and extrastriatal [123I]FP-CIT binding in Parkinson's disease. Neurobiol. Aging. 2015;36:1757-63.

31. Huang W-S, Lee M-S, Lin J-C, Chen C-Y, Yang Y-W, Lin S-Z, et al. Usefulness of brain 99mTc-TRODAT-1 SPET for the evaluation of Parkinson's disease. Eur. J. Nucl. Med. Mol. Imaging. 2004;31:155-61.

32. Asenbaum S, Brucke T, Pirker W, Podreka I, Angelberger P, Wenger S, et al. Imaging of Dopamine Transporters with Iodine-123- ÄŸ-CITand SPECT in Parkinson's Disease. Journal of Nuclear Medicine. 1997;38:1-6.

33. Karimi M, Tian L, Brown CA, Flores HP, Loftin SK, Videen TO, et al. Validation of nigrostriatal positron emission tomography measures: critical limits. Ann. Neurol.

2013;73:390-6.

34. Strafella AP, Bohnen NI, Perlmutter JS, Eidelberg D, Pavese N, Van Eimeren T, et al. Molecular imaging to track Parkinson's disease and atypical parkinsonisms: New imaging frontiers. Mov. Disord. 2017;32:181-92.

35. Fleiss JL, Levin B, Paik MC. Statistical Methods for Rates and Proportions. John Wiley \& Sons; 2013.

\section{FIGURES}

\section{FIGURE 1}

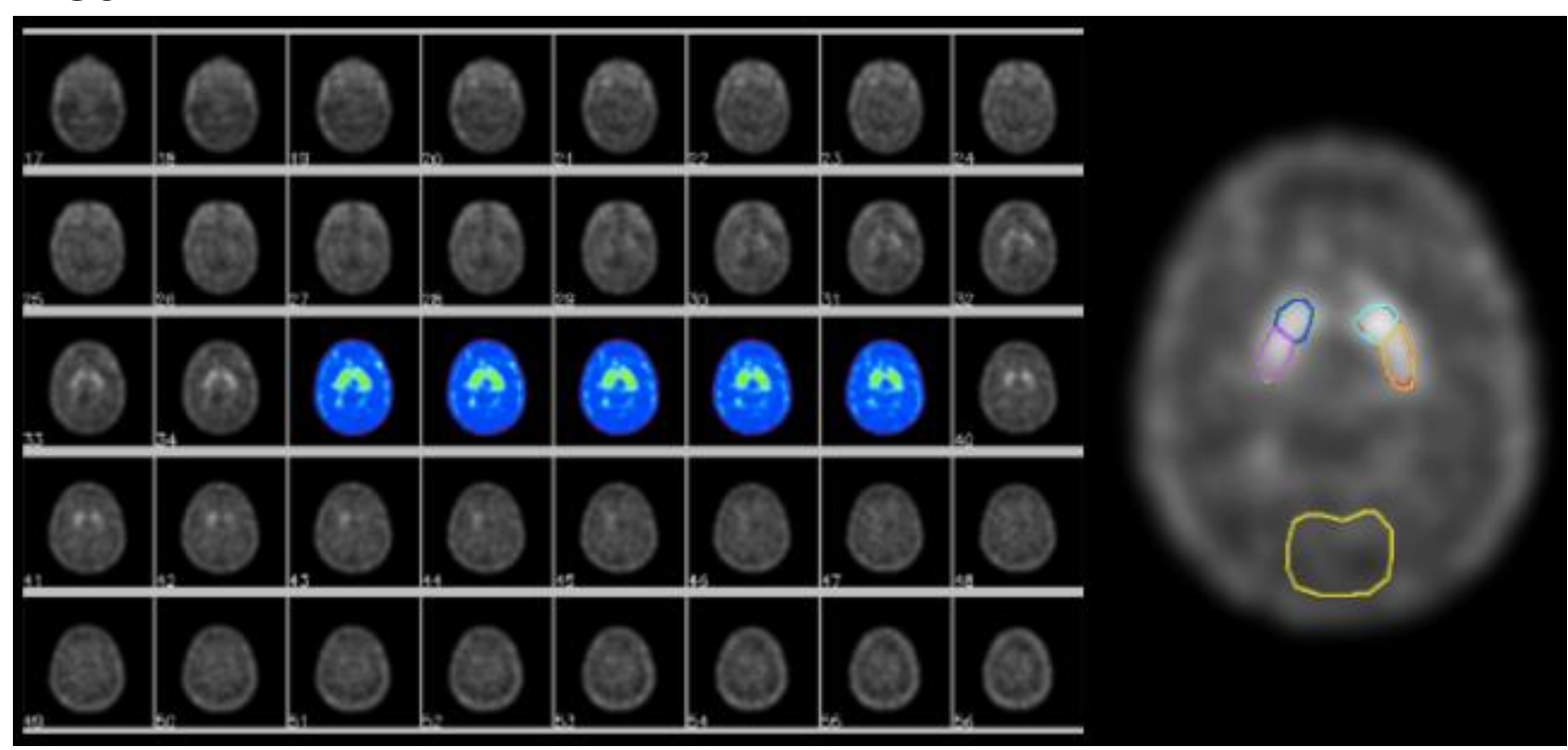


FIGURE 2
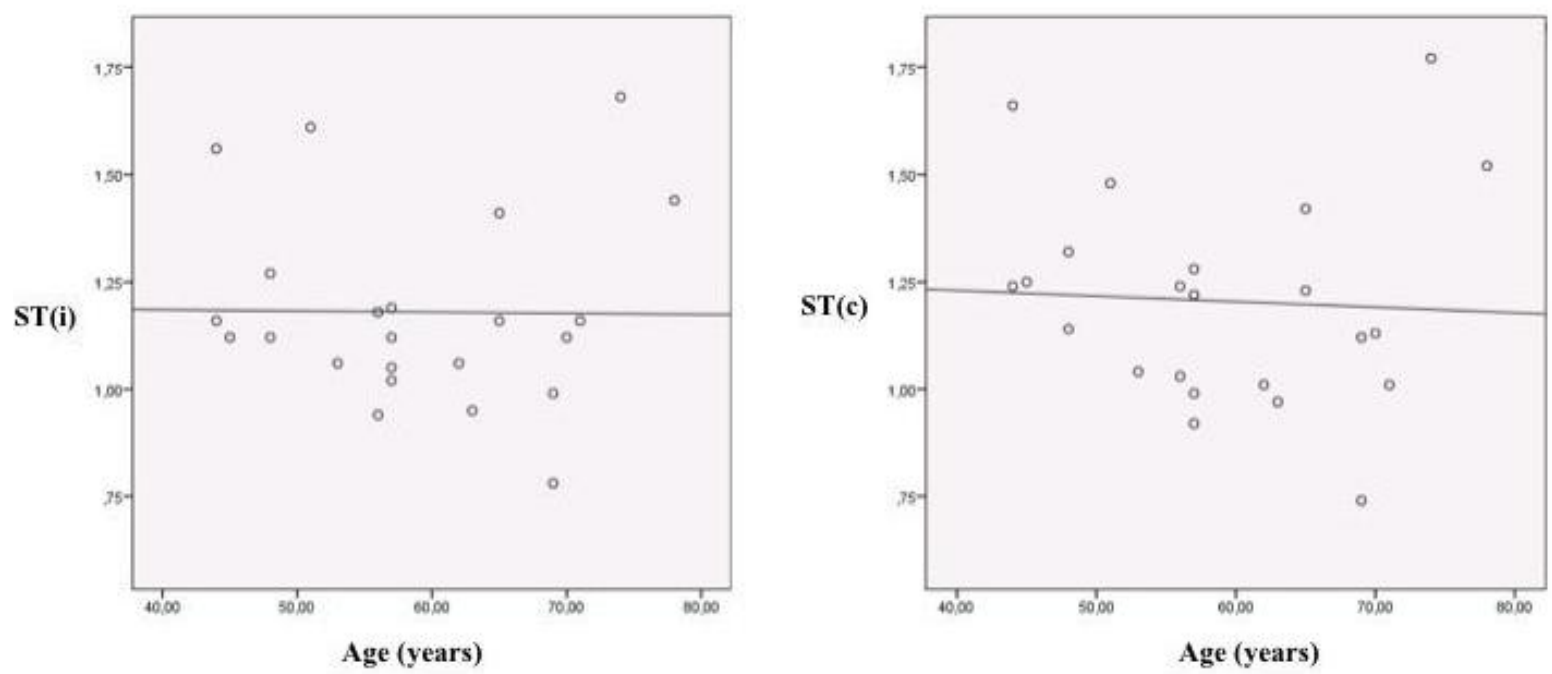

FIGURE 3
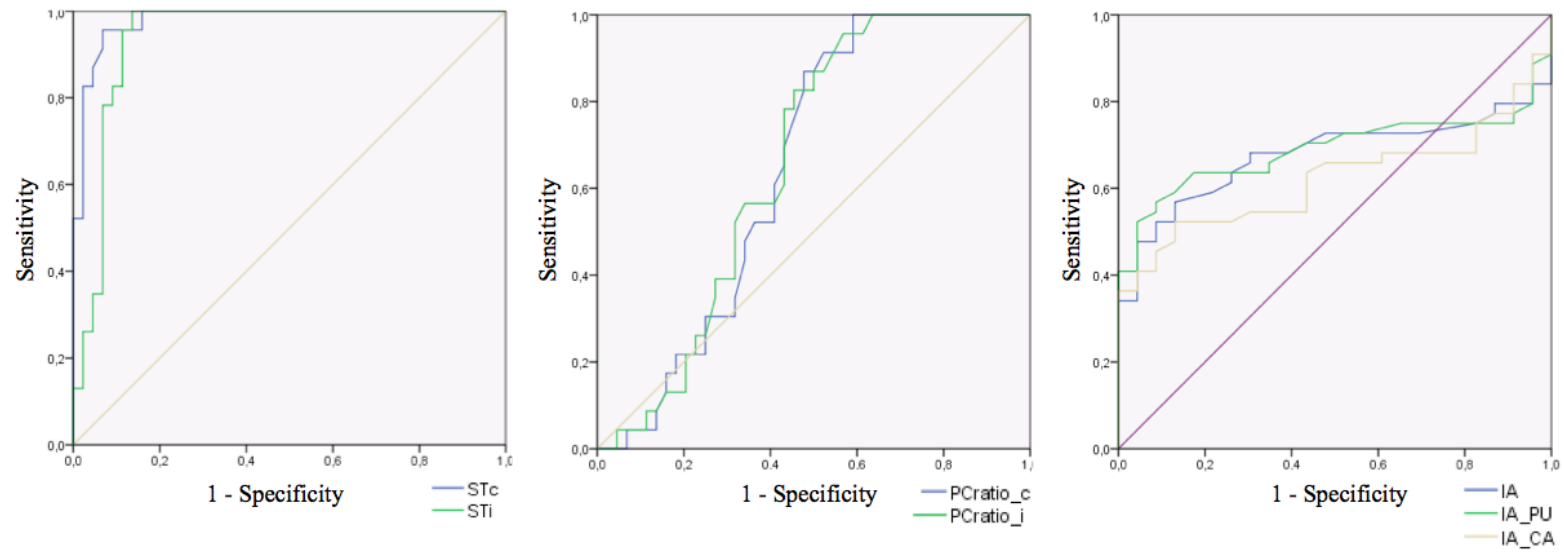

FIGURE 4
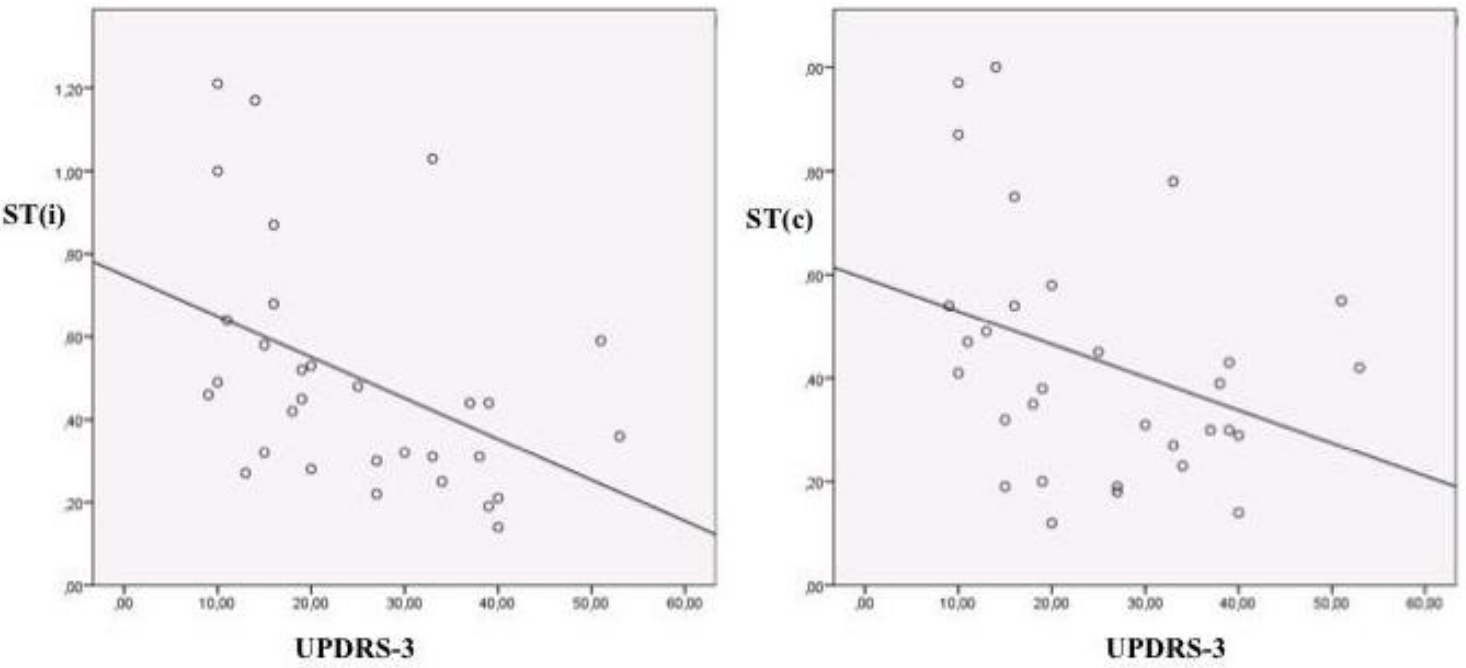


\section{LEGENDS}

Figure 1 - Manual semiquantification performed in a healthy volunteer: Fixed regions of interest (ROI) were drawn manually over the five summed transaxial slice of each hemisphere on the whole striatum, on putamen and caudate nucleus.

Figura 2: Age plotted against ST(i) and ST(c) BPI in healthy subjects group by age.

Figure 3: ROC curves for BPI, $\mathrm{AI}$ and $\mathrm{P} / \mathrm{C}$.

Figure 4: UPDRS-3 plotted against ST(i) and ST(c) BPI in PD subgroup (HYS I/II).

\section{TABLES}


Table 1: Semiquantification of striatum BPI and subregions in healthy and PD groups $(n=67$ patients).

\begin{tabular}{|c|c|c|c|c|c|c|c|c|c|c|}
\hline & \multicolumn{6}{|c|}{ Simple regression model } & \multicolumn{4}{|c|}{ Adjusted regression model (age, sex, schooling) } \\
\hline & PD & Healthy subjects & $\begin{array}{c}\text { PD - } \\
\text { healthy } \\
\text { subjects }\end{array}$ & $\begin{array}{c}\text { IL } \\
\text { IC95 }\end{array}$ & $\begin{array}{c}\text { SL } \\
\text { IC95 }\end{array}$ & p-value & $\begin{array}{l}\text { PD - healthy } \\
\text { subjects }\end{array}$ & $\underset{\text { IC95 }}{\text { IL }}$ & $\begin{array}{c}\text { SL } \\
\text { IC95 }\end{array}$ & p-value \\
\hline ST(i) & $\begin{array}{c}0.50 \pm 0.31 \\
(0.04-1.47)\end{array}$ & $\begin{array}{l}1.18 \pm 0.22 \\
(0.78-1.68)\end{array}$ & -0.68 & -0.82 & -0.53 & $<0.01 * *$ & -0.70 & -0.86 & -0.54 & $<0.01 * *$ \\
\hline $\mathbf{S T}(\mathbf{c})$ & $\begin{array}{l}0.43 \pm 0.25 \\
(0.03-1.16)\end{array}$ & $\begin{array}{l}1.21 \pm 0.25 \\
(0.74-1.77)\end{array}$ & -0.77 & -0.90 & -0.64 & $<0.01 * *$ & -0.81 & -0.95 & -0.67 & $<0.01 * *$ \\
\hline PU(i) & $\begin{array}{l}0.42 \pm 0.31 \\
(0.03-1.47)\end{array}$ & $\begin{array}{l}1.09 \pm 0.23 \\
(0.71-1.55)\end{array}$ & -0.67 & -0.82 & -0.52 & $<0.01 * *$ & -0.69 & -0.85 & -0.53 & $<0.01 * *$ \\
\hline $\mathbf{P U}(\mathbf{c})$ & $\begin{array}{l}0.37 \pm 0.25 \\
(0.01-1.10)\end{array}$ & $\begin{array}{l}1.14 \pm 0.28 \\
(0.73-1.91)\end{array}$ & -0.77 & -0.90 & -0.63 & $<0.01 * *$ & -0.81 & -0.95 & -0.67 & $<0.01 * *$ \\
\hline $\mathbf{C A}(\mathbf{i})$ & $\begin{array}{l}0.62 \pm 0.35 \\
(0.01-1.51)\end{array}$ & $\begin{array}{l}1.31 \pm 0.27 \\
(0.88-1.84)\end{array}$ & -0.69 & -0.86 & -0.52 & $<0.01 * *$ & -0.71 & -0.81 & -0.53 & $<0.01 * *$ \\
\hline $\mathbf{C A}(\mathbf{c})$ & $\begin{array}{c}0.52 \pm 0.30 \\
(0.02-1.30)\end{array}$ & $\begin{array}{l}1.33 \pm 0.29 \\
(0.80-1.95)\end{array}$ & -0.81 & -0.96 & -0.65 & $<0.01 * *$ & -0.84 & -1.00 & -0.67 & $<0.01 * *$ \\
\hline
\end{tabular}

Legend: PD: Parkinson's disease; IL = inferior limit; $\mathrm{SL}=$ superior limit $\mathrm{CI}=$ confidence interval; $\mathrm{ST}=$ striatum; $\mathrm{PU}=$ putamen; $\mathrm{CA}=\mathrm{caudate}$ nucleus; (i) = ipsilateral; $(\mathrm{c})=$ contralateral. The values were described at mean \pm standard deviation (range). $* p$-value $<0.05 * * p$-value $<0.01$ 
Table 2: Semiquantification of AI and P/C in healthy and PD groups with the manual method ( $\mathrm{n}=67$ patients).

\begin{tabular}{|c|c|c|c|c|c|c|c|c|c|c|}
\hline & \multicolumn{6}{|c|}{ Simple regression model } & \multicolumn{4}{|c|}{ Adjusted regression model (age, sex, schooling) } \\
\hline & PD & Healthy subjects & $\begin{array}{c}\text { PD - } \\
\text { healthy } \\
\text { subjects }\end{array}$ & $\begin{array}{l}\text { IL } \\
\text { IC95 }\end{array}$ & $\begin{array}{l}\text { SL } \\
\text { IC95 }\end{array}$ & p-value & $\begin{array}{l}\text { PD - healthy } \\
\text { subjects }\end{array}$ & $\begin{array}{c}\text { IL } \\
\text { IC95 }\end{array}$ & $\begin{array}{l}\text { SL } \\
\text { IC95 }\end{array}$ & $p$-value \\
\hline $\mathbf{P} / \mathbf{C}(\mathbf{i})$ & $\begin{array}{c}0.74 \pm 0.38 \\
(0.23-2.33)\end{array}$ & $\begin{array}{c}0.85 \pm 0.18 \\
(0.57-1.33)\end{array}$ & -0.11 & -0.28 & 0.05 & 0.20 & -0.11 & -0.30 & 0.06 & 0.20 \\
\hline $\mathbf{P} / \mathbf{C}(\mathbf{c})$ & $\begin{array}{c}0.76 \pm 0.46 \\
(0.14-2.88)\end{array}$ & $\begin{array}{c}0.87 \pm 0.17 \\
(0.65-1.36)\end{array}$ & 0.10 & -0.30 & 0.09 & 0.30 & -0.16 & -0.37 & 0.04 & 0.11 \\
\hline AI & $\begin{array}{c}0.12 \pm 0.40 \\
(0.09-1.19)\end{array}$ & $\begin{array}{c}-0.01 \pm 0.08 \\
(-0.19-0.19)\end{array}$ & 0.14 & 0.01 & 0.27 & $0.02 *$ & 0.18 & 0.01 & 0.36 & $<0.04 *$ \\
\hline AI (PU) & $\begin{array}{c}0.13 \pm 0.48 \\
(-0.87-1.64)\end{array}$ & $\begin{array}{c}-0.03 \pm 0.12 \\
(-0.38-0.22)\end{array}$ & 0.17 & 0.01 & 0.32 & $0.03 *$ & 0.25 & 0.03 & 0.46 & $<0.02 *$ \\
\hline AI (CA) & $\begin{array}{c}0.15 \pm 0.53 \\
(-1.69-1.59)\end{array}$ & $\begin{array}{c}-0.01 \pm 0.14 \\
(-0.30-0.27)\end{array}$ & 0.16 & -0.01 & 0.33 & 0.06 & 0.16 & -0.08 & 0.42 & 0.1 \\
\hline
\end{tabular}

Legend: $\mathrm{ICC}=$ Intraclass Correlation Coefficient; $\mathrm{IL}=$ inferior limit; $\mathrm{SL}=$ superior limit; $\mathrm{CI}=$ confidence interval; $\mathrm{AI}=$ asymmetry index; $\mathrm{P} / \mathrm{C}=\mathrm{P} / \mathrm{C}$ ratio; $(\mathrm{i})=$ ipsilateral; $(\mathrm{c})=$ contralateral. The values were described at mean \pm standard deviation (range). ${ }^{*} p$-value $<0.05 * * p$-value $<0.01$ 
Table 3: Results of the ROC curve for the BPI of the striatum and sub regions obtained by the semiquantitative manual method.

\begin{tabular}{lllllll}
\hline & ST(c) & ST(i) & PU(c) & PU(i) & CA(c) & CA(i) \\
\hline Cutoff & 0.74 & 0.78 & 0.73 & 0.74 & 0.8 & 0.88 \\
Sensitivity & 1 & 1 & 1 & 0.96 & 1 & 1 \\
Specificity & 0.84 & 0.86 & 0.89 & 0.89 & 0.84 & 0.77 \\
& & & & & & \\
$\begin{array}{l}\text { AUC } \\
\text { (CI 95\%) }\end{array}$ & $\begin{array}{l}0.98 \\
(0.94 ; 1.00)\end{array}$ & $\begin{array}{l}0.94 \\
(0.87 ; 0.99)\end{array}$ & $\begin{array}{l}0.97 \\
(0.93 ; 1.00)\end{array}$ & $\begin{array}{l}0.93 \\
(0.86 ; 0.99)\end{array}$ & $\begin{array}{l}0.96 \\
(0.92 ; 0.99)\end{array}$ & $\begin{array}{l}0.92 \\
(0.86 ; 0.98)\end{array}$ \\
\hline
\end{tabular}

Legend: $\mathrm{ST}=$ striatum $\mathrm{CA}=$ caudate $\mathrm{PU}=$ putamen $; \mathrm{i}=$ ipsilateral $; \mathrm{c}=$ contralateral; $\mathrm{AUC}=$ area under the curve

Table 4: Results of the ROC curve for the BPI of the striatum and sub regions obtained by the semiquantitative manual method.

\begin{tabular}{llllll}
\hline & $\mathbf{A I}(\mathbf{S T})$ & $\mathbf{A I}(\mathbf{P U})$ & $\mathbf{A I}(\mathbf{C A})$ & $\mathbf{P} / \mathbf{C}(\mathbf{i})$ & $\mathbf{P} / \mathbf{C}(\mathbf{c})$ \\
\cline { 2 - 5 } Cutoff & 0.2 & 0.22 & 0.3 & 0.65 & 0.57 \\
& & & & & \\
Sensitivity & 0.34 & 0.49 & 0.36 & 1 & 1 \\
& & & & & \\
Specificity & 1 & 1 & 1 & 0.41 & 0.36 \\
& & & & & \\
AUC & $0.67(0.54 ;$ & $0.68(0.56 ;$ & $0.62(0.49 ;$ & $0.65(0.52 ;$ & $0.66(0.53 ;$ \\
(CI 95\%) & $0.80)$ & $0.81)$ & $0.75)$ & $0.77)$ & $0.78)$ \\
\hline
\end{tabular}

Legend: $\mathrm{CA}=$ caudate $\mathrm{PU}=$ putamen $; \mathrm{i}=$ ipsilateral $; \mathrm{c}=$ contralateral $; \mathrm{P} / \mathrm{C}=$ putamen $/$ caudade ratio $; \mathrm{AI}=$ asymmetry index.; AUC = area under the curve 
Table 5: Evaluation of the reliability of the semiquantitative indexes.

\begin{tabular}{|c|c|c|c|c|c|c|}
\hline & \multicolumn{3}{|c|}{ Interobserver evaluation } & \multicolumn{3}{|c|}{ Intraobserver evaluation } \\
\hline & ICC & $\underset{\text { CIS5\% }}{\text { IL }}$ & $\begin{array}{c}\text { SL } \\
\text { CI95\% }\end{array}$ & ICC & $\underset{\text { CI95\% }}{\text { IL }}$ & $\begin{array}{c}\text { SL } \\
\text { CI95\% }\end{array}$ \\
\hline ST(i) & 0.87 & 0.8 & 0.92 & 0.98 & 0.97 & 0.99 \\
\hline ST(c) & 0.87 & 0.79 & 0.92 & 0.98 & 0.96 & 0.99 \\
\hline $\mathbf{P U}(\mathbf{i})$ & 0.87 & 0.8 & 0.92 & 0.98 & 0.96 & 0.99 \\
\hline $\mathbf{P U}(\mathbf{c})$ & 0.86 & 0.78 & 0.91 & 0.97 & 0.94 & 0.98 \\
\hline $\mathbf{C A}(\mathbf{i})$ & 0.76 & 0.64 & 0.84 & 0.96 & 0.94 & 0.98 \\
\hline $\mathbf{C A}(\mathbf{c})$ & 0.81 & 0.71 & 0.88 & 0.96 & 0.94 & 0.98 \\
\hline $\mathbf{P} / \mathbf{C}(\mathbf{i})$ & 0.12 & -0.12 & 0.35 & 0.66 & 0.51 & 0.78 \\
\hline $\mathbf{P} / \mathrm{C}(\mathrm{c})$ & -0.03 & -0.27 & 0.21 & 0.49 & 0.28 & 0.65 \\
\hline $\mathbf{A I}(\mathbf{S T})$ & 0.35 & -0.05 & 0.60 & 0.73 & 0.56 & 0.83 \\
\hline $\mathbf{A I}(\mathbf{P U})$ & 0.47 & 0.14 & 0.67 & 0.02 & -0.61 & 0.38 \\
\hline $\mathbf{A I}(\mathbf{C A})$ & 0.20 & -0.28 & 0.51 & 0.51 & 0.20 & 0.70 \\
\hline \multicolumn{7}{|c|}{$\begin{array}{l}\text { Legend: } \mathrm{IL}=\text { inferior limit; } \mathrm{SL}=\text { superior limit } ; \mathrm{CI}=\text { confidence interval; } \mathrm{ICC}=\text { intra- } \\
\text { class correlation coefficient; } \mathrm{ST}=\text { striatum; } \mathrm{CA}=\text { caudate; } \mathrm{PU}=\text { putamen; } \mathrm{i}=\text { ipsilateral; } \mathrm{c} \\
=\text { contralateral; } \mathrm{P} / \mathrm{C}=\text { putamen/caudade ratio } ; \mathrm{AI}=\text { asymmetry index.; } \mathrm{AUC}=\text { area under } \\
\text { the curve }\end{array}$} \\
\hline
\end{tabular}

Tabela 6: Correlation between UPDRS-3 and BPI in PD subgroups (HYS I/II; HYS III/IV).

\begin{tabular}{lllll}
\hline & HYS I/II & \multicolumn{2}{l}{ HYS III/IV } \\
\hline & R & p-valor & R & p-valor \\
ST(i) & -0.5 & $0.02 *$ & 0.2 & 0.4 \\
ST(c) & -0.4 & $0.02 *$ & 0.56 & 0.07 \\
PU(i) & -0.39 & $0.03 *$ & 0.31 & 0.3 \\
PU(c) & -0.38 & $0.03 *$ & 0.4 & 0.14 \\
CA(i) & -0.57 & $0.01 *$ & 0.4 & 0.5 \\
CA(c) & -0.4 & $0.02 *$ & 0.54 & 0.08 \\
\hline $\begin{array}{l}\text { Legend: R = correlation coefficient; ST = striatum; PU = } \\
\text { putamen; CA = caudate nucleus; (i) = ipsilateral; (c) }= \\
\text { contralateral. *p-value < } 0.05\end{array}$ & \\
\hline
\end{tabular}




\section{APÊNDICE 7: ARTIGO 3}

\section{Semiquantitative evaluation of DAT-SPECT with [ ${ }^{99 \mathrm{~m}}$ Tc]-TRODAT-1 in Parkinson's disease - comparison of different methods.}

Felipe Arriva Pitella ${ }^{1}$, Vitor Tumas ${ }^{2}$, Leonardo Alexandre Santos ${ }^{1}$, Ana Carolina Trevisan

${ }^{1,3}$, Manuelina Mariana Capellari Macruz ${ }^{2}$, Emerson Nobuyuki Itikawa ${ }^{1,3}$, Mery Kato ${ }^{1}$, Jose Henrique Silvah ${ }^{1}$, Anneke A. Boerlage ${ }^{6}$, Dick Tibboel ${ }^{6}$, Marcus Vinícius Simões ${ }^{1}$, Carlos Alberto Buchpiguel ${ }^{5}$, Lauro Wichert-Ana ${ }^{1,3,5}$.

${ }^{1}$ Department of Internal Medicine, Section of Nuclear Medicine, and ${ }^{2}$ Department of Neuroscience and Behavioral Sciences. Ribeirão Preto Medical School, University of São Paulo. Ribeirão Preto, SP, Brazil.

${ }^{3}$ Interunits Post-Graduation Program on Bioengineering. São Carlos School of Engineering, University of São Paulo, São Carlos, Brazil.

${ }^{4}$ Center of Nuclear Medicine, University of Sao Paulo, University of Sao Paulo Medical School, Sao Paulo, Brazil.

${ }^{5}$ The Center for Interdisciplinary Research on Applied Neurosciences - NAPNA - University of São Paulo (USP).

${ }^{6}$ Intensive Care and Pediatric Surgery Department, Erasmus Medical Center, Sophia Children's Hospital. Erasmus University. Rotterdam, The Netherlands.

\section{ADDRESS CORRESPONDENCE TO:}

Dr. Felipe Arriva Pitella, MD, PhD

Seção de Medicina Nuclear, Hospital das Clínicas - FMRP - USP. Av. Bandeirantes, 3900.

CEP: 14048-900. Ribeirão Preto - SP - Brasil. Phone/FAX: +55 1636022596.

E-mail: pitella.fa@gmail.com 


\section{ABSTRACT}

RATIONALE: The use of quantification methods in nuclear medicine for the purpose of enhancing diagnostic accuracy is increasing. The semiquantification process based on areas of interest (ROI) has as main challenge the construction of these ROIs in order to present adequate dimensions and correct positioning on the striatum. OBJECTIVE: To evaluate semiquantitative methods applied in DAT-SPECT with [ $\left.{ }^{99 \mathrm{~m}} \mathrm{Tc}\right]-$ TRODAT-1. MATERIAL AND METHODS: Sixty-seven patients, 23 healthy ( 8 male; mean \pm SD age $59 \pm 11$ years old) and 44 age-matched patients with various degrees of severity of idiopathic PD (29 male; age: $59 \pm 7$ years old; duration of symptoms: $10 \pm 6$ years; HYS: $2.16 \pm 0.65$; UPDRS III: 29.74 \pm 17.79$)$. All patients performed [ ${ }^{99 \mathrm{~m}} \mathrm{Tc}$ ]-TRODAT-1 SPECT. Specific uptake ratios or binding potentials (BPI) in the striatum were calculated using four different semiquantitative methods: manual, magnetic resonance imaging (MR), magnetic resonance corrected for partial volume effect, Two Box. RESULTS: There was a significant reduction ( $p$-value <0.05) of the binding potential in the striatum and substructures in the group of patients with PD. The AUC proved to be satisfactory for all indexes, especially with the application of the manual method. The corrected-MR method presented slightly lower results. In the intraobserver evaluation, for all methods an ICC near 1.0 was found. In the interobserver assessment the agreement was also excellent, with a discrete advantage for the Two Box. The manual method presented a lower reliability among the methods. CONCLUSION: Semiquantitative assessment can contribute in diagnosis of PD. The methods present advantages and disadvantages to each other regarding applicability, reliability and accuracy. The manual method is still an accessible tool, easy to handle and with excellent results. For disease follow-up, if applicable, methods that associate high accuracy with minor interobserver disagreement should be considered, such as the Two Box.

KEYWORDS: Parkinson;TRODAT; semiquantification; binding potential. 


\section{INTRODUCTION}

Parkinson's disease (PD) is a progressive neurodegenerative disease that affects approximately $1 \%$ of persons older than 60 years (GAZEWOOD; RICHARDS; CLEBAK, 2013). The main aspect of the pathophysiology is the loss of dopaminergic neurons in the substantia nigra pars compacta [1]. PD diagnosis is primarily based on neurological findings, such as bradykinesia, rigidity, tremor and postural instability $[2,3]$.

In addition to the diagnostic value, the functional images of positron emission tomography (PET) and single photon emission computed tomography (SPECT) help to understand the pathophysiology underlying the parkinsonian syndromes and provide a sensitive means to detect subclinical diseases and evaluate the degree and evolution of the disease [4]. Molecular imaging techniques use dopaminergic biomarkers as the main tool in the clinical investigation of movement disorders [5-8].

The SPECT with 99m Tc-TRODAT-1, a radiolabeled tropane that binds dopamine transporters (DAT), has been proposed to evaluate the integrity of the nigrostriatal dopaminergic system [9-12]. The imaging pattern in patients with PD on visual inspection is usually described as a reduction of the density of dopaminergic transporters in the striatum body preferentially on the contralateral side to the predominance of the symptoms, with a rostrocaudal gradient $[5,6,13,14]$.

The use of quantification methods in nuclear medicine for the purpose of enhancing diagnostic accuracy is increasing. The semiquantification process based on areas of interest (ROI) has as main challenge the construction of these ROIs in order to present adequate dimensions and correct positioning on the striatum. The evaluator's experience becomes a determining factor in the construction of these ROIs for quantification $[15,16]$.

The manual semiquantitative method is one of the most widely used due to its versatility and practicality [17-19], however others methods are postulated. The construction of ROIs templates can be based on standardized geometric models with size and shape similar to structures of the striatum [20] or using ROIs with regular geometries and large dimensions, such as the semiquantitative method Two Box [19]. Another approach is based on the construction of ROIs from structural images of magnetic resonance imaging (MRI) or computed tomography (CT). The construction of ROIs or volumes of interest (VOI) from these structural images provides a method of quantification that is many times more accurate $[15,16]$.

Using [ $\left.{ }^{99 \mathrm{~m}} \mathrm{Tc}\right]-$ TRODAT-1, this study aimed to evaluate and compare semiquantitative methods. 


\section{MATERIAL AND METHODS}

\section{Study Design}

Upon inclusion in the study, the patients were allocated in two groups (healthy subjects and PD group) prospectively balanced in terms of age, schooling, and gender. The data were analyzed in blinded fashion, after a computer-generated randomization designed to yield groups. The images were analyzed by four semiquantitative methods by two evaluators, in order to establish accuracy, sensitivity, specificity, and reproducibility of the methods.

\section{Subjects}

This study included prospectively 67 patients. Twenty-three healthy controls ( 8 male; 15 female; mean \pm SD age 59 \pm 11 years old) and 44 age-matched patients with various degrees of severity of idiopathic PD (29 male; 15 female; mean \pm SD age $59 \pm 7$ years old; mean \pm SD duration of symptoms $10 \pm 6$ years; range of symptoms duration 1-21 years). All subjects have been treated at the Clinical Hospital of the Ribeirão Preto Medical School, University of São Paulo (HC-FMRP-USP) and provided written informed consent before the study. The study was approved by the institution's Ethics Committee.

In the group of healthy volunteers were excluded: patients with moderately severe and severe dementia; Parkinson's disease or parkinsonian syndrome; neuropsychiatric disorders (schizophrenia, hyperactivity and attention deficit, symptomatic depressions and others that may occur with alterations in the dopaminergic system); abusive use of alcohol or drugs; organic brain lesions; cerebral vascular accidents; claustrophobia; chronic use of psychotropic medications; use of medications known to interfere with TRODAT-1 binding to DAT; history of trauma with loss of consciousness; smoking. The patients were submitted to a summary clinical evaluation.

Parkinson's patients necessarily presented clinical diagnosis confirmed by a specialist neurologist in the area. We used the diagnostic criteria of the London Brain Bank (UK-PDS Brain Bank Society-Sponsored Revision of the Unified Parkinson's Disease Rating Scale) $[21,22]$. Eleven patients were on carbidopa-levodopa monotherapy, one was on dopamine agonist monotherapy, while 32 were receiving combination therapy; all patients responded to treatment with good motor benefit. Patients were not taking any medication that might have interfered with striatal $\left[{ }^{99 \mathrm{~m}} \mathrm{Tc}\right]-$ TRODAT-1 uptake. All PD patients were scored with the Hoehn and Yahr Scale (HYS), which ranges from HYS I to HYS IV (mean \pm SD 2.16 \pm 0.65 ; 
range 1-4), and with the Unified Parkinson's Disease Rating Scale motor score (UPDRS III: mean \pm SD 29.74 \pm 17.79 ; range 9-74) [23,24]. All patients underwent brain SPECT with $\left[{ }^{99 \mathrm{~m}} \mathrm{Tc}\right]-\mathrm{TRODAT}-1$.

\section{Radiopharmaceutical}

The $\left[{ }^{99 \mathrm{~m}} \mathrm{Tc}\right]-T R O D A T-1$ was prepared from a pre formulated lyophilized kit provided by the Institute of Nuclear Energy Research (Lung-Tan, Taiwan). The kit was reconstituted with $1110 \mathrm{MBq}(44 \mathrm{mCi})$ of freshly eluted sodium $\left[{ }^{99 \mathrm{~m}} \mathrm{Tc}\right]$-pertechnetate in $5 \mathrm{ml}$ of saline and incubated at $100^{\circ} \mathrm{C}$ for 30 minutes to complete labeling. After cooling to room temperature, quality control of radiochemical purity ( $>90 \%$ ), determined by the chromatographic method, was performed.

\section{Image acquisition}

DAT-SPECT with [ ${ }^{99 m} \mathrm{Tc}$ ]-TRODAT-1 was performed using a dual-head camera 4 hours after injection of 740-1,110 MBq (mean \pm SD $865,8 \pm 74)$ of [ $\left.{ }^{99 m} \mathrm{Tc}\right]-T R O D A T-1$. The scintigraphic images were obtained in a circular camera series model BrightView XCT (Philips Medical Systems Inc., Cleveland, OH, USA) composed of two detector heads. The data were collected using a low energy high resolution (LERH) collimator, in a symmetric window with a $15 \%$ width, centered on a $140 \mathrm{keV}$ photopeak. In a step-and-shoot acquisition mode, 64 projections were collected, with a circular orbit of $180^{\circ}$ per head and with a projection acquisition time of $30 \mathrm{~s}$, a radius of rotation of less than $20 \mathrm{~cm}$, a matrix of $128 \mathrm{x}$ 128 pixels, a magnification factor of $\mathrm{x} 1$ and with isotropic pixels of $2.13 \mathrm{~mm}$. Images were reconstructed using the iterative method and Butterworth filter (order 2.00, cut-off 0.22). Chang's attenuation correction method was applied using a coefficient of $0.12 / \mathrm{cm}$.

\section{Image evaluation}

Semiquantitative analyzes were performed by two nuclear physicians with neuroimaging experience (observer A and B). Previous training was performed since the evaluators were not familiar with all softwares of semiquantification. Both observers had experience with visual interpretation with the SPECT with $\left[{ }^{99 m} \mathrm{Tc}\right]-T R O D A T-1$. One of them performed two readings at least 1 week apart (evaluation A1 and A2). The second observer reading was called B1 for comparison purposes. For the analysis the patients were randomized, being identified by a random number (1 to 67). For the purposes of inter-observer evaluation, automatic methods (MR and corrected-MR) were performed on separate computers. 
The methods of quantification applied in this study were chosen by data from the literature and previous application in a study with anthropomorphic phantom performed in the Nuclear Medicine Section of HC-FMRP-USP [25,26]. The selection criteria were essentially based on the feasibility of the methods in a practical routine, with potential good results, using opensource software.

\section{Semiquantitative assessment}

Specific uptake ratios or binding potential (BPI) in the striatum were calculated by subtracting the mean counts per pixel in the occipital lobe (background) from the mean counts per pixel in the whole striatum and dividing the result by the mean counts per pixel in the background [27]. In the PD group, the striatum located opposite the side with dominant symptoms was defined as the contralateral. In the control group, the right striatum was defined as the contralateral and the ipsilateral was the left striatum (WENG et al., 2004).

Manual method: Five adjacent transaxial slices with the highest radiotracer uptake in the basal ganglia were summed for semiquantitative analysis of striatal specific DAT binding of $\left[{ }^{99 m}\right.$ Tc]-TRODAT-1 using an image analysis package (JETpack; Philips Medical Systems). Fixed regions of interest (ROI) were drawn manually over the summed transaxial slice of each hemisphere on the whole striatum, on putamen and caudate. An irregular ROI was drawn manually on occipital cortex (Figure 1).

\section{INSERT FIGURE 1}

Two Box: The Two Box method proposed by Tossici-Bolt and colleagues (TOSSICI-BOLT et al., 2006) is based on the use of a standardized ROI template in the collection of quantification parameters in two-dimensional SPECT images of the striatum (figure 2). The main steps of this method include the construction of a two-dimensional (2D) image from the sum of the cross-sections containing counts of the striatum (I); The construction of the reference ROI (II); The positioning of the pre-constructed trapezoidal ROIs on the striatum in the 2D image (III); and the calculation of the semi-quantization parameter Specific Binding Ratio (SBR) (IV), an analogue of the binding potential, defined as a ratio between the counts in the area of interest and the reference area [19].

\section{INSERT FIGURE 2}


Magnetic nuclear resonance (with and without partial volume effect correction): The main steps involved in this process correspond to obtaining a standard MR template from the Atlases of the Montreal Neurological Institute (MNI) (I); convergence of SPECT images with the MR template (figure 3) (II); extraction of the mean values of counts per voxel, recorded for each striatal VOI offered by the Automated Anatomical Labeling - AAL atlas and automated quantification of BPI values (III); partial volume effect (PVE) correction for each VOI analyzed (IV).

\section{INSERT FIGURE 3}

\section{Statistical analysis}

Simple and multiple linear regression models were adjusted to compare the striatum, caudate nucleus and putamen BPI between the healthy subjects and PD groups. In the multiple regression models, gender, age and schooling were used as covariables. The softwares used were SAS 9.3 (SAS Institute Inc., Cary, NC, USA) and SPSS v17.0 (IBM Corporation, Armonk, NY, USA). ROC curves were generated using R version 3.3.3 software to compare the sensitivity and specificity of the diagnosis of each index based on the area under the curve (AUC). The threshold was established after defining the best relationship between sensitivity and specificity among the points generated by the ROC curve. The reliability of the quantification methods was evaluated by the Intraclass Correlation Coefficient (ICC).

\section{RESULTS}

The regression models showed a statistically significant reduction ( $\mathrm{p}$-value $<0.05$ ) of the binding potential in the striatum and substructures in the group of patients with PD in relation to the healthy group in all applied methods (manual, MRI, MRI And Two Box). The results were maintained when multiple regression models were used, where sex, age and schooling were considered as covariates. Tables 1-4 show the comparison in the BPI of the groups (PD and healthy subjects) evaluated for each method.

INSERT TABLE 1 


\section{INSERT TABLE 2}

\section{INSERT TABLE 3}

\section{INSERT TABLE 4}

The threshold, sensitivity and specificity determined by the threshold and area under the curve for each BPI can be seen at table 5. In manual method, for BPI of ST and PU, the established cutoff ranged from 0.73 to 0.78 . From this threshold, the sensitivity ranged from $95 \%$ to $100 \%$ and the specificity ranged from $84 \%$ to $88 \%$. This means that virtually all patients with BPI of ST and PU less than 0.7 had PD. For CA, the established threshold was higher, ranging from 0.8 to 0.88 , with sensitivity up to $100 \%$ and specificity of $77 \%$ to $84 \%$. The areas under the curve described were high, ranging from 0.92 to 0.98 .

\section{INSERT TABLE 5}

The sensitivity was lower in the automatic methods (MR and corrected-MR) considering the adopted cutoff, being in general less than $80 \%$. The AUC obtained from the ROC curves, which translates the performance of the test, proved to be satisfactory for all indexes, especially with the application of the manual method. The performance of the BPI indexes was good for semiquantification with MR and Two Box, with a slight superiority for the second, ranging from 0.77 to 0.88 and 0.88 to 0.93 , respectively. The corrected-MR method presented slightly lower results, ranging from 0.74 to 0.81 .

In the intraobserver evaluation (table 6), for all methods an ICC near 1.0 was found. In the interobserver assessment the agreement was also excellent, with ICC for the analyzed indexes similar between the corrected methods with MR, corrected-MR and Two Box, with a discrete advantage for the Two Box. The manual method presented a lower reliability among the methods, with ICC ranging from 0.76 in the quantification of CA (i) to 0.87 for ST(i), ST(c) and PU(i) (Table 7).

INSERT TABLE 6

INSERT TABLE 7 


\section{DISCUSSION}

All the evaluated semiquantitative methods were able to differentiate the groups with and without PD. The BPI parameter for this distinction between groups was not influenced by sex, age and schooling. The percentage reduction in the BPI of PD group and healthy patients was variable between methods and structures, but over $50 \%$ in all, with a predominance of contralateral deficit, higher on the putamen. It should be noted that the values obtained are distinct from each other, and are not comparable in a clinical routine. A study of 84 healthy adults, 35 men, 49 women, with mean age of 35.7 years \pm 12.5 years, obtained BPI of the striatum from 3 manual, 7 semi-automatic and 8 automatic methods, and compared the decline per decade of life. The values found were significantly different among the methods. The size of the ROI, the positioning, normalization process and signal recovery by partial volume correction are some of the causes of this difference. This specific study considered that, for clinical research, methods based on standardized templates with partial volume correction would be preferable [28].

Although satisfactory results have often been obtained by semiquantification methods when compared to visual analysis [29], some limitations are found. In particular, in cases with significant uptake deficit in the striatum, with loss of anatomic referential, and in patients with anatomical variation, the results may be inconsistent and variable [29]. In addition, other factors may interfere with quantification, such as gamma-camera type, calibration, collimators, acquisition procedure and corrections (attenuation, scattering and partial volume effect), and therefore, comparison with other centers or the use of published control values produces valid results only when the reference values were obtained with exactly the same technique or when these centers were calibrated transversally using a phantom [30].

Among the semiquantitative methods, the manual method presented a higher sensitivity and specificity in the identification of patients with PD. A slight misalignment observed in the convergence of some studies of SPECT with [ $\left.{ }^{99 \mathrm{~m}} \mathrm{Tc}\right]-T R O D A T-1$ with MR justifies the inferior results obtained by this technique. Alternatives such as manual adjustment of ROI positioning or change in size of ROI could interfere with the final result, however, the first alternative would be in disagreement with the objective of this study, which was to evaluate method without any human interference. On the other hand, the second alternative could undermine the analysis of substructures. The performance of the Two Box was slightly better than that of MR. The advantage of this method with the application of geometric ROIs is to be able to collect all counting densities originating from the compartments of interest, without significant signal loss due to PVE, besides using as a 
weight factor the ratio between the striated body volumes and the relative volume of the constructed geometric ROI [25]. The results obtained, however, were lower than those found in the literature [19].

The impact of semiquantitative methods on reducing false positives and negatives when applied in conjunction with qualitative assessment is little discussed in the literature. In our study, taking into account the 3 qualitative evaluations (A1, A2 and B1), we obtained 3 false-positive results and 9 false-negative results. If BPI threshold of 0.7 for ST and PU and 0.8 for AC was applied, the manual semiquantitative method would potentially reduce false positive cases from 3 to 0 (100\% of cases) and false negative cases from 9 to 7 (22\% of cases).

At last, regarding intraobserver and interobserver agreement in semiquantitative methods, the results were excellent, with ICC for BPI scores higher than 0.75 (FLEISS; LEVIN; PAIK, 2013). As expected, in the interobserver analysis the ICC was lower compared to the intraobserver analysis. There was practically no difference between the methods in the intraobserver evaluation, suggesting that despite the greater subjectivity in the construction and positioning of the ROIs in a non-automatic way, the observer applies the tool systematically and following well-established previous concepts. On the other hand, in the interobserver evaluation the distance between the methods in terms of reliability was greater, particularly between the manual method and the others, being smaller in the manual method. The selection of axial images for 2D composition, design and adjustments of the areas of interest, positioning, are steps that can be influenced by the evaluator. In the case of Two Box this issue is minimized by a fundamental feature, which relates to the size of the ROI. The large ROI, as applied in the Two Box method, ensures that there is no loss of information, even if the manual positioning by the evaluators is different.

\section{CONCLUSIONS}

Semiquantitative assessment can contribute in diagnosis of PD. The methods present advantages and disadvantages to each other regarding applicability, reliability and accuracy. Possibly a combination of methods, such as by manually adjusting the ROI position after anatomical study convergence with SPECT with TRODAT-1, may yield better results. Among the semiquantitative methods, the manual method is still an accessible tool, easy to handle and with excellent results. For disease follow-up, if applicable, methods that associate high accuracy with minor interobserver disagreement should be considered, such as the Two Box. The application of semiquantitative methods should be encouraged as it can minimize 
misdiagnoses, especially among inexperienced professionals.

\section{ACKNOWLEDGEMENTS}

The authors gratefully acknowledge financial support from: (a) Grant/Project \# 049/2013 (AUXPE No. 2880/2013, LWA) from CAPES / NUFFIC, Brazil Netherlands International Cooperation; (b) Grant\# 2013/25.987-2 (LWA) and Grant\# 2015/50089-3 FAPESP SPRINT (LWA) from The State of São Paulo Research Foundation - FAPESP. None of these funding agencies played a role in the design, data collection, management, analysis, interpretation of the data, and preparation, review or approval of the manuscript. We confirm that we have read the Journal's position on issues involved in ethical publication and affirm that this report has the approval of our institutional ethics committee. We also thank John Carpenter, Ribeirão Preto, Brazil, for the English revision.

\section{CONFLICT OF INTEREST}

All authors have no financial arrangement or affiliation with industry. Two authors received MSc and Ph.D scholarships while both paper or research were done: ACT (CAPES 2012/14152-4), ENI (FAPESP 2012/14152-4). No funding agencies played any/a role in the design or conduct of the study, in the analysis of data and the writing of the manuscript.

\section{STATEMENT OF AUTHORSHIP}

FAP, LWA, VT designed the research; FAP, ACT, LAS, MK conducted the research; LAS conducted the analysis through SPM software; LAS, ENI conducted additional statistical analyses; MMCM and VT performed clinical evaluation, JHS critically reviewed the manuscript, LWA and VT had primary responsibility for final content. All authors contributed towards, read and approved the final manuscript.

\section{REFERENCES}

1. Harikrishna Reddy D, Reddy DH, Misra S, Medhi B. Advances in Drug Development for Parkinson's Disease: Present Status. Pharmacology. 2014;93:260-71.

2. Gazewood JD, Richards DR, Clebak K. Parkinson disease: an update. Am. Fam. Physician. 2013;87:267-73.

3. Munhoz RP, Moro A, Silveira-Moriyama L, Teive HA. Non-motor signs in Parkinson's disease: a review. Arq. Neuropsiquiatr. 2015;73:454-62. 
4. Brooks DJ. Parkinson's disease: diagnosis. Parkinsonism Relat. Disord. 2012;18 Suppl $1:$ S31-3.

5. Meyer PT, Hellwig S. Update on SPECT and PET in parkinsonism - part 1: imaging for differential diagnosis. Curr. Opin. Neurol. 2014;27:390-7.

6. Meyer PT, Frings L, Hellwig S. Update on SPECT and PET in parkinsonism - part 2. Curr. Opin. Neurol. 2014;27:398-404.

7. Oung QW, Muthusamy H, Lee HL, Basah SN, Yaacob S, Sarillee M, et al. Technologies for Assessment of Motor Disorders in Parkinson's Disease: A Review. Sensors .

$2015 ; 15: 21710-45$.

8. Niethammer M, Feigin A, Eidelberg D. Functional neuroimaging in Parkinson's disease. Cold Spring Harb. Perspect. Med. 2012;2:a009274.

9. Pavese N, Brooks DJ. Imaging neurodegeneration in Parkinson's disease. Biochim. Biophys. Acta. 2009;1792:722-9.

10. Meyer PT, Frings L, Hellwig S. Update on SPECT and PET in parkinsonism - part 2: biomarker imaging of cognitive impairment in Lewy-body diseases. Curr. Opin. Neurol. 2014;27:398-404.

11. Brooks DJ. 1.7.2 DIAGNOSIS OF PD. Parkinsonism Relat. Disord. 2012;18:S4.

12. Marshall V, Grosset D. Role of dopamine transporter imaging in routine clinical practice. Mov. Disord. 2003;18:1415-23.

13. Booth TC, Nathan M, Waldman AD, Quigley A-M, Schapira AH, Buscombe J. The role of functional dopamine-transporter SPECT imaging in parkinsonian syndromes, part 1. AJNR Am. J. Neuroradiol. 2015;36:229-35.

14. Strafella AP, Bohnen NI, Perlmutter JS, Eidelberg D, Pavese N, Van Eimeren T, et al. Molecular imaging to track Parkinson's disease and atypical parkinsonisms: New imaging frontiers. Mov. Disord. 2017;32:181-92.

15. Scherfler C, Seppi K, Donnemiller E, Goebel G, Brenneis C, Virgolini I, et al. Voxel-wise analysis of [123I]beta-CIT SPECT differentiates the Parkinson variant of multiple system atrophy from idiopathic Parkinson's disease. Brain. 2005;128:1605-12.

16. Seppi K, Schocke MFH. An update on conventional and advanced magnetic resonance imaging techniques in the differential diagnosis of neurodegenerative parkinsonism. Curr. Opin. Neurol. 2005;18:370-5.

17. Verhoeff NP, Kapucu O, Sokole-Busemann E, van Royen EA, Janssen AG. Estimation of dopamine D2 receptor binding potential in the striatum with iodine-123-IBZM SPECT: technical and interobserver variability. J. Nucl. Med. 1993;34:2076-84.

18. Tossici-Bolt L, Dickson JC, Sera T, de Nijs R, Bagnara MC, Jonsson C, et al. Calibration of gamma camera systems for a multicentre European 123I-FP-CIT SPECT normal database. Eur. J. Nucl. Med. Mol. Imaging. 2011;38:1529-40. 
19. Tossici-Bolt L, Hoffmann SMA, Kemp PM, Mehta RL, Fleming JS. Quantification of [123I]FP-CIT SPECT brain images: an accurate technique for measurement of the specific binding ratio. Eur. J. Nucl. Med. Mol. Imaging. 2006;33:1491-9.

20. Van Laere K, Casteels C, De Ceuninck L, Vanbilloen B, Maes A, Mortelmans L, et al. Dual-tracer dopamine transporter and perfusion SPECT in differential diagnosis of parkinsonism using template-based discriminant analysis. J. Nucl. Med. 2006;47:384-92.

21. Goetz CG. Unified Parkinson's Disease Rating Scale (UPDRS) and Movement Disorder Society Revision of the UPDRS (MDS-UPDRS). Rating Scales in Parkinson's Disease. 2012. p. $62-83$.

22. Goetz CG, Tilley BC, Shaftman SR, Stebbins GT, Fahn S, Martinez-Martin P, et al. Movement Disorder Society-sponsored revision of the Unified Parkinson's Disease Rating Scale (MDS-UPDRS): scale presentation and clinimetric testing results. Mov. Disord. 2008;23:2129-70.

23. Goetz CG. Unified Parkinson's Disease Rating Scale (UPDRS) and Movement Disorder Society Revision of the UPDRS (MDS-UPDRS). Rating Scales in Parkinson's Disease. 2012. p. $62-83$.

24. Hughes AJ, Daniel SE, Kilford L, Lees AJ. Accuracy of clinical diagnosis of idiopathic Parkinson's disease: a clinico-pathological study of 100 cases. J. Neurol. Neurosurg.

Psychiatry. 1992;55:181-4.

25. Santos LA. Avaliação comparativa dos diferentes métodos de quantificação de imagens de SPECT com 99mTc: um estudo de validação utilizando um fantoma antropomórfico estriatal [Internet]. Universidade de São Paulo; 2015. Available from: http://www.teses.usp.br/teses/disponiveis/17/17138/tde-07012016-160245/en.php

26. Trevisan AC. Avaliação de diferentes métodos de reconstrução de imagens no processamento de SPECT cerebral com simulador antropomórfico estriatal [MSc]. WichertAna L, editor. EESC - Esc Engenharia de São Carlo; 2015.

27. Weng Y-H, Yen T-C, Chen M-C, Kao P-F, Tzen K-Y, Chen R-S, et al. Sensitivity and specificity of 99mTc-TRODAT-1 SPECT imaging in differentiating patients with idiopathic Parkinson's disease from healthy subjects. J. Nucl. Med. 2004;45:393-401.

28. Yin T-K, Lee B-F, Yang YK, Chiu N-T. Differences of Various Region-of-Interest Methods for Measuring Dopamine Transporter Availability Using -TRODAT-1 SPECT. The Scientific World Journal [Internet]. Hindawi Publishing Corporation; 2014 [cited 2017 Jan 28];2014. Available from: https://www.hindawi.com/journals/tswj/2014/837439/

29. Badiavas K, Molyvda E, Iakovou I, Tsolaki M, Psarrakos K, Karatzas N. SPECT imaging evaluation in movement disorders: far beyond visual assessment. Eur. J. Nucl. Med. Mol. Imaging. 2011;38:764-73.

30. Djang DSW, Janssen MJR, Bohnen N, Booij J, Henderson TA, Herholz K, et al. SNM practice guideline for dopamine transporter imaging with 123I-ioflupane SPECT 1.0. J. Nucl. Med. 2012;53:154-63. 


\section{FIGURES}

FIGURE 1

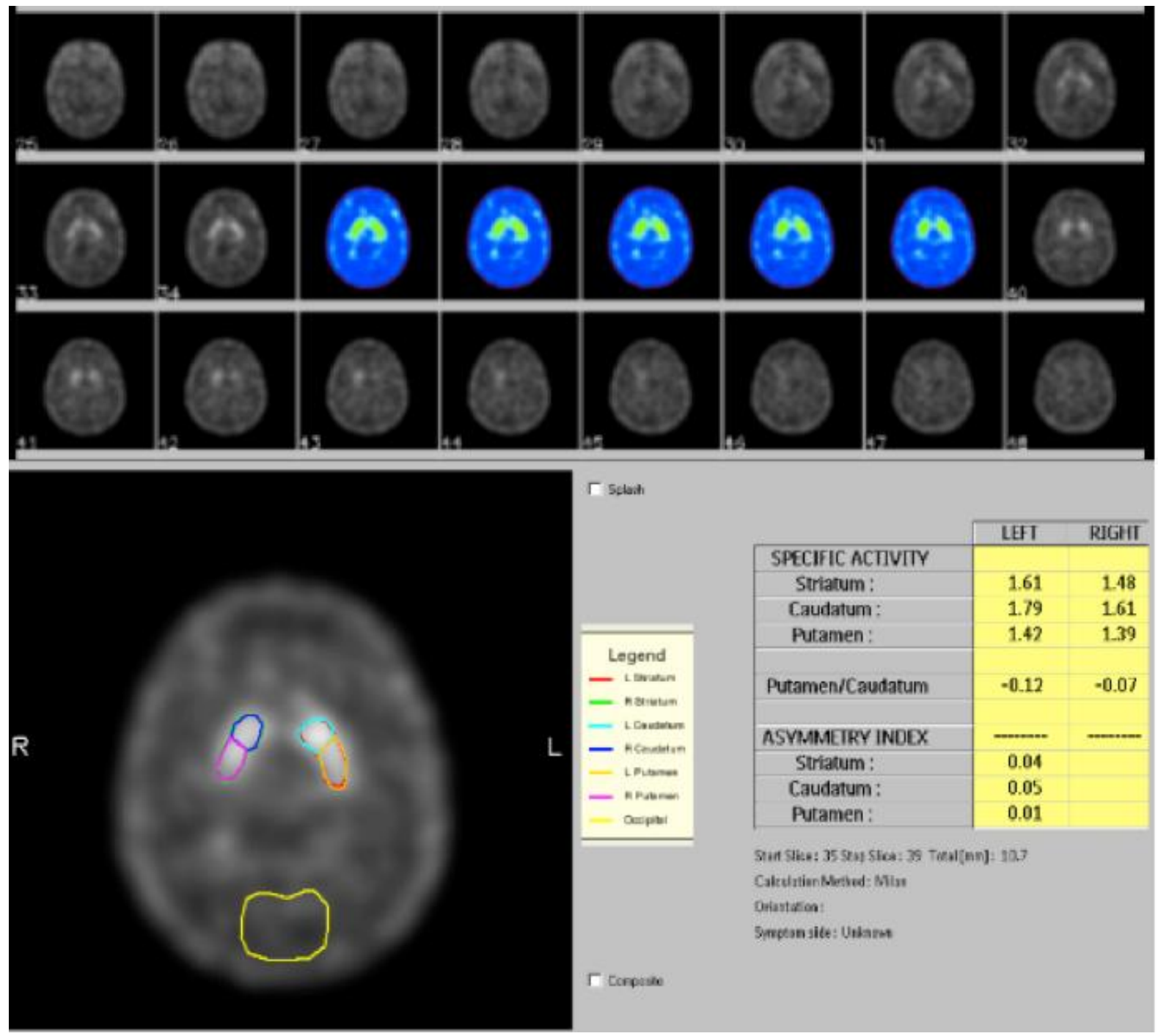




\section{FIGURE 2}

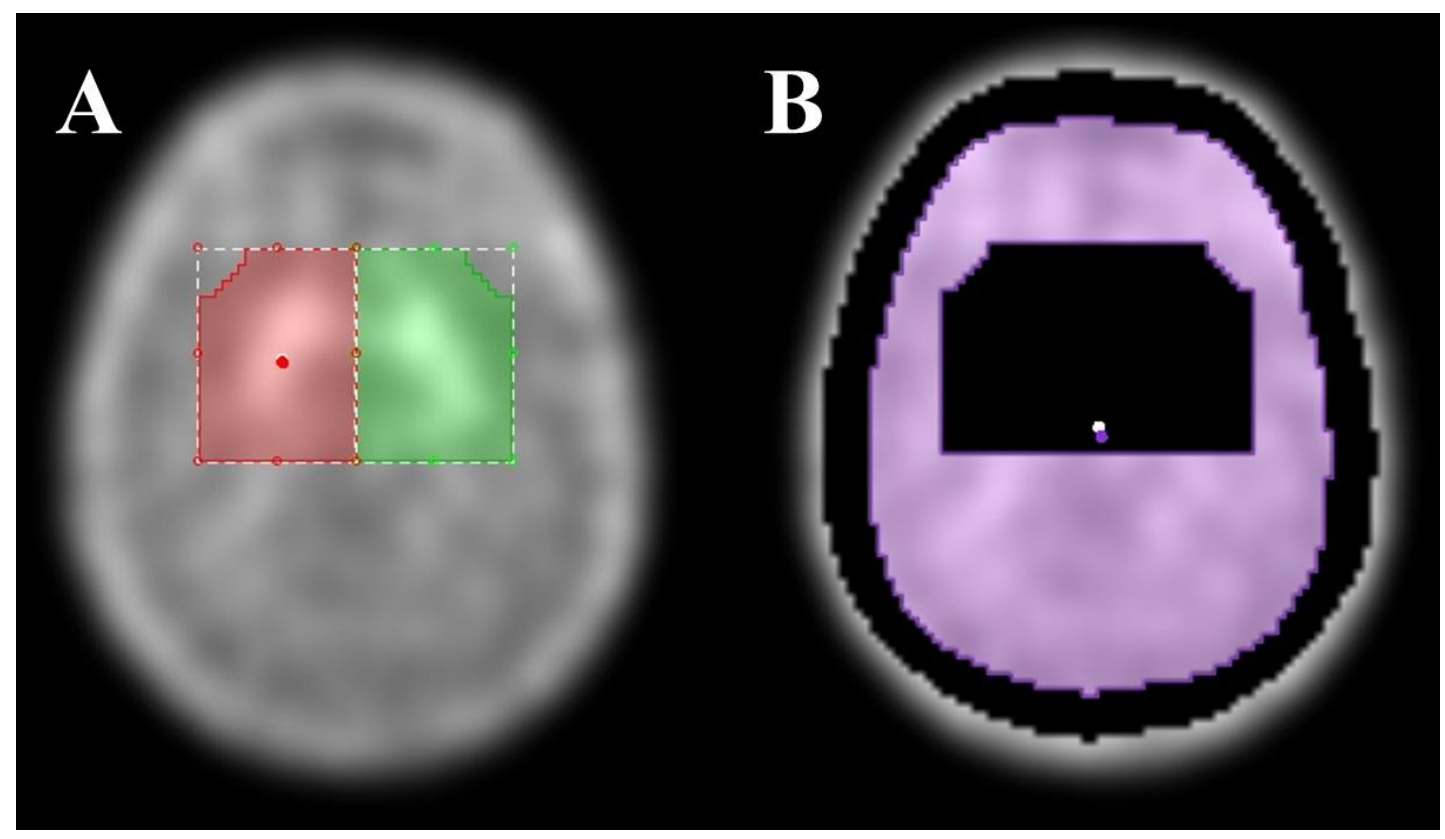

\section{FIGURE 3}
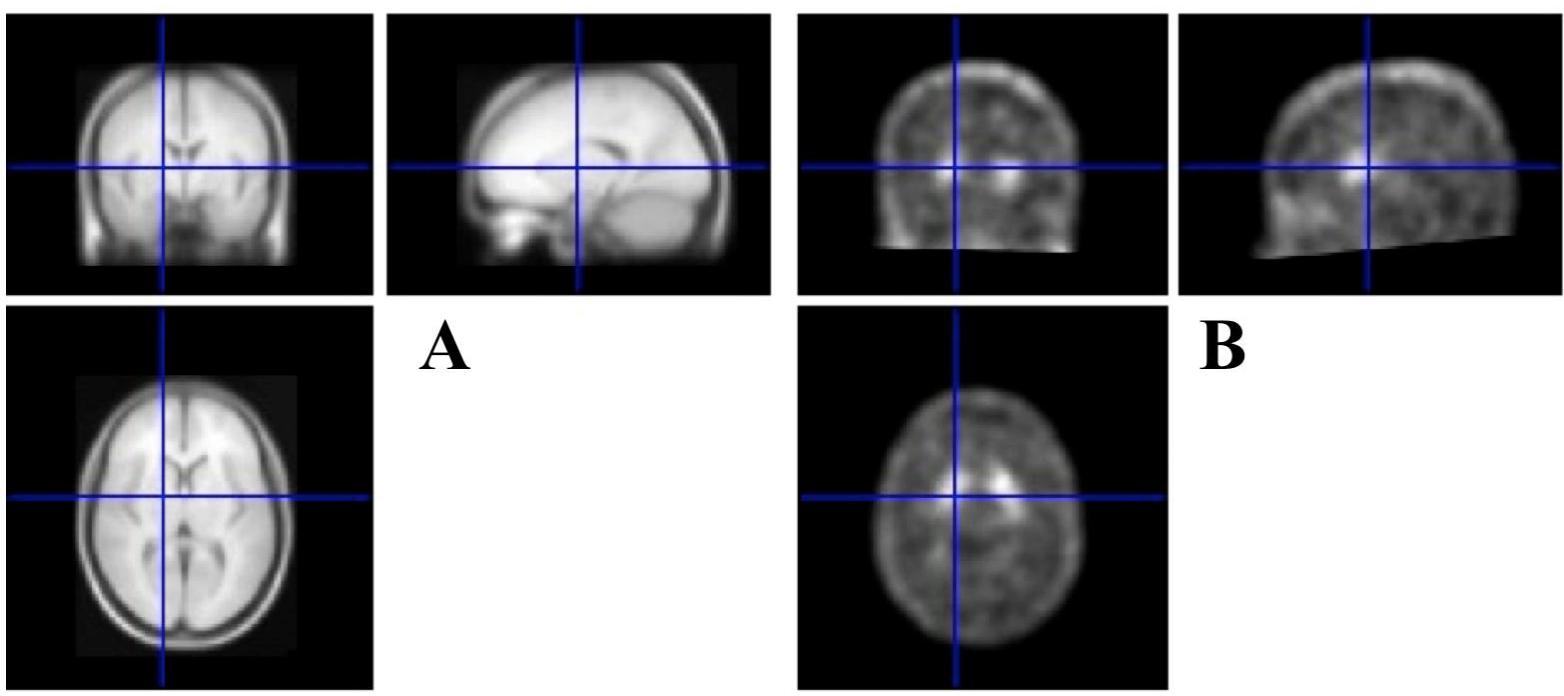

A

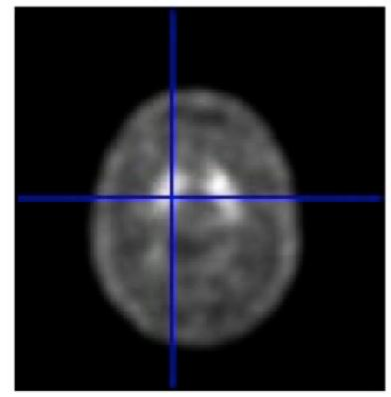

B

\section{LEGEND}

Figure 1: Quantification of the binding potential in the striatum, performed in a healthy volunteer.

Figure 2: Positioning of the right and left striatal ROIs (A) and establishment of the reference ROI (B) in the Two Box method.

Figure 3: Alignment between the MNI305 template from the Montreal Neurological Institute Atlases (A) and the SPECT with [ $\left.{ }^{99 \mathrm{~m}} \mathrm{Tc}\right]-T R O D A T-1$ from a healthy patient.

\section{TABLES}


Table 1: Semiquantification of striatum BPI and sub regions in healthy and PD groups with the manual method ( $\mathrm{n}=67$ patients).

\begin{tabular}{|c|c|c|c|c|c|c|c|c|c|c|}
\hline & \multicolumn{6}{|c|}{ Simple regression model } & \multicolumn{4}{|c|}{ Adjusted regression model (age, sex, schooling) } \\
\hline & PD & Healthy subjects & $\begin{array}{c}\text { PD - } \\
\text { healthy } \\
\text { subjects }\end{array}$ & $\begin{array}{c}\text { IL } \\
\text { IC95 }\end{array}$ & $\begin{array}{c}\text { SL } \\
\text { IC95 }\end{array}$ & $p$-value & $\begin{array}{l}\text { PD - healthy } \\
\text { subjects }\end{array}$ & $\begin{array}{c}\text { IL } \\
\text { IC95 }\end{array}$ & $\begin{array}{l}\text { SL } \\
\text { IC95 }\end{array}$ & $p$-value \\
\hline ST(i) & $\begin{array}{l}0.50 \pm 0.31 \\
(0.04-1.47)\end{array}$ & $\begin{array}{l}1.18 \pm 0.22 \\
(0.78-1.68)\end{array}$ & -0.68 & -0.82 & -0.53 & $<0.01 * *$ & -0.70 & -0.86 & -0.54 & $<0.01 * *$ \\
\hline $\mathbf{S T}(\mathbf{c})$ & $\begin{array}{l}0.43 \pm 0.25 \\
(0.03-1.16)\end{array}$ & $\begin{array}{l}1.21 \pm 0.25 \\
(0.74-1.77)\end{array}$ & -0.77 & -0.90 & -0.64 & $<0.01 * *$ & -0.81 & -0.95 & -0.67 & $<0.01 * *$ \\
\hline $\mathbf{P U}(\mathbf{i})$ & $\begin{array}{l}0.42 \pm 0.31 \\
(0.03-1.47)\end{array}$ & $\begin{array}{l}1.09 \pm 0.23 \\
(0.71-1.55)\end{array}$ & -0.67 & -0.82 & -0.52 & $<0.01 * *$ & -0.69 & -0.85 & -0.53 & $<0.01 * *$ \\
\hline $\mathbf{P U}(\mathbf{c})$ & $\begin{array}{l}0.37 \pm 0.25 \\
(0.01-1.10)\end{array}$ & $\begin{array}{l}1.14 \pm 0.28 \\
(0.73-1.91)\end{array}$ & -0.77 & -0.90 & -0.63 & $<0.01 * *$ & -0.81 & -0.95 & -0.67 & $<0.01 * *$ \\
\hline CA(i) & $\begin{array}{l}0.62 \pm 0.35 \\
(0.01-1.51)\end{array}$ & $\begin{array}{l}1.31 \pm 0.27 \\
(0.88-1.84)\end{array}$ & -0.69 & -0.86 & -0.52 & $<0.01 * *$ & -0.71 & -0.81 & -0.53 & $<0.01 * *$ \\
\hline $\mathrm{CA}(\mathrm{c})$ & $\begin{array}{l}0.52 \pm 0.30 \\
(0.02-1.30)\end{array}$ & $\begin{array}{l}1.33 \pm 0.29 \\
(0.80-1.95)\end{array}$ & -0.81 & -0.96 & -0.65 & $<0.01^{* *}$ & -0.84 & -1.00 & -0.67 & $<0.01^{* *}$ \\
\hline
\end{tabular}

Legend: PD: Parkinson's disease; IL = inferior limit; SL = superior limit; CI = confidence interval; $\mathrm{ST}=$ striatum; $\mathrm{PU}=$ putamen; $\mathrm{CA}=$ caudate nucleus; (i) $=$ ipsilateral $;(\mathrm{c})=$ contralateral. The values were described at mean \pm standard deviation (range). * $p$-value $<0.05 * *$-value $<0.01$ 
Table 2: Semiquantification of striatum BPI and sub regions in healthy and PD groups with the MRI method ( $\mathrm{n}=67$ patients).

\begin{tabular}{|c|c|c|c|c|c|c|c|c|c|c|}
\hline & \multicolumn{6}{|c|}{ Simple regression model } & \multicolumn{4}{|c|}{ Adjusted regression model (age, sex, schooling) } \\
\hline & PD & Healthy subjects & $\begin{array}{c}\text { PD - } \\
\text { healthy } \\
\text { subjects }\end{array}$ & $\begin{array}{c}\text { IL } \\
\text { IC95 }\end{array}$ & $\begin{array}{c}\text { SL } \\
\text { IC95 }\end{array}$ & p-value & $\begin{array}{l}\text { PD - healthy } \\
\text { subjects }\end{array}$ & $\begin{array}{c}\text { IL } \\
\text { IC95 }\end{array}$ & $\begin{array}{c}\text { SL } \\
\text { IC95 }\end{array}$ & $p$-value \\
\hline ST(i) & $\begin{array}{l}0.24 \pm 0.12 \\
(0.00-0.62)\end{array}$ & $\begin{array}{l}0.49 \pm 0.17 \\
(0.15-0.80)\end{array}$ & -0.25 & -0.32 & -0.18 & $<0.01 * *$ & -0.25 & -0.33 & -0.18 & $<0.01 * *$ \\
\hline $\mathrm{ST}(\mathrm{c})$ & $\begin{array}{l}0.22 \pm 0.10 \\
(0.05-0.58)\end{array}$ & $\begin{array}{l}0.46 \pm 0.16 \\
(0.17-0.71)\end{array}$ & -0.24 & -0.31 & -0.18 & $<0.01 * *$ & -0.25 & -0.32 & -0.19 & $<0.01 * *$ \\
\hline PU(i) & $\begin{array}{c}0.25 \pm 0.14 \\
(-0.02-0.63)\end{array}$ & $\begin{array}{l}0.55 \pm 0.21 \\
(0.19-1.10)\end{array}$ & -0.31 & -0.39 & -0.22 & $<0.01 * *$ & -0.31 & -0.40 & -0.23 & $<0.01 * *$ \\
\hline $\mathbf{P U}(\mathbf{c})$ & $\begin{array}{c}0.21 \pm 0.10 \\
(-0.01-0.45)\end{array}$ & $\begin{array}{l}0.39 \pm 0.18 \\
(0.08-0.68)\end{array}$ & -0.18 & -0.25 & -0.11 & $<0.01 * *$ & -0.19 & -0.25 & -0.12 & $<0.01 * *$ \\
\hline $\mathbf{C A}(\mathbf{i})$ & $\begin{array}{l}0.23 \pm 0.14 \\
(0.01-0.61)\end{array}$ & $\begin{array}{c}0.42 \pm 0.19 \\
(0.06-0.75)\end{array}$ & -0.19 & -0.27 & -0.11 & $<0.01 * *$ & -0.20 & -0.28 & -0.11 & $<0.01 * *$ \\
\hline $\mathbf{C A}(\mathbf{c})$ & $\begin{array}{c}0.22 \pm 0.15 \\
(-0.09-0.71)\end{array}$ & $\begin{array}{c}0.53 \pm 0.20 \\
(0.14-0.84)\end{array}$ & -0.31 & -0.39 & -0.22 & $<0.01 * *$ & -0.32 & -0.41 & -0.23 & $<0.01 * *$ \\
\hline
\end{tabular}

Legend: PD: Parkinson's disease; IL = inferior limit; $\mathrm{SL}=$ superior limit $\mathrm{CI}=$ confidence interval; $\mathrm{ST}=$ striatum; $\mathrm{PU}=$ putamen; $\mathrm{CA}=$ caudate nucleus; $\mathrm{AI}=$ asymmetry index; $\mathrm{P} / \mathrm{C}=\mathrm{P} / \mathrm{C}$ ratio; $(\mathrm{i})=$ ipsilateral; $(\mathrm{c})=$ contralateral. The values were described at mean \pm standard deviation $($ range)

*p-value $<0.05$

$* * p$-value $<0.01$ 
Table 3: Semiquantification of striatum BPI and sub regions in healthy and PD groups with the MRI-corrected ( $\mathrm{n}=67$ patients).

\begin{tabular}{|c|c|c|c|c|c|c|c|c|c|c|}
\hline & \multicolumn{6}{|c|}{ Simple regression model } & \multicolumn{4}{|c|}{ Adjusted regression model (age, sex, schooling) } \\
\hline & PD & Healthy subjects & $\begin{array}{l}\text { PD - healthy } \\
\text { subjects }\end{array}$ & $\begin{array}{c}\text { IL } \\
\text { IC95 }\end{array}$ & $\begin{array}{c}\text { SL } \\
\text { IC95 }\end{array}$ & p-value & $\begin{array}{l}\text { PD - healthy } \\
\text { subjects }\end{array}$ & $\begin{array}{c}\text { IL } \\
\text { IC95 }\end{array}$ & $\begin{array}{c}\text { SL } \\
\text { IC95 }\end{array}$ & p-value \\
\hline ST(i) & $\begin{array}{l}0.90 \pm 0.19 \\
(0.54-1.52)\end{array}$ & $\begin{array}{l}1.30 \pm 0.26 \\
(0.77-1.78)\end{array}$ & -0.40 & -0.51 & -0.28 & $<0.01 * *$ & -0.41 & -0.53 & -0.29 & $<0.01 * *$ \\
\hline $\mathbf{S T}(\mathbf{c})$ & $\begin{array}{l}0.86 \pm 0.16 \\
(0.59-1.41)\end{array}$ & $\begin{array}{l}1.22 \pm 0.24 \\
(0.77-1.62)\end{array}$ & -0.37 & -0.46 & -0.27 & $<0.01 * *$ & -0.38 & -0.48 & -0.28 & $<0.01 * *$ \\
\hline PU(i) & $\begin{array}{l}0.81 \pm 0.24 \\
(0.42-0.64)\end{array}$ & $\begin{array}{l}1.31 \pm 0.35 \\
(0.75-2.26)\end{array}$ & -0.50 & -0.64 & -0.35 & $<0.01 * *$ & -0.52 & -0.66 & -0.37 & $<0.01 * *$ \\
\hline $\mathbf{P U}(\mathbf{c})$ & $\begin{array}{l}0.74 \pm 0.18 \\
(0.40-1.07)\end{array}$ & $\begin{array}{l}0.96 \pm 0.28 \\
(0.45-1.48)\end{array}$ & -0.21 & -0.32 & -0.10 & $<0.01 * *$ & -0.22 & -0.33 & -0.11 & $<0.01 * *$ \\
\hline CA(i) & $\begin{array}{l}0.99 \pm 0.24 \\
(0.56-1.63)\end{array}$ & $\begin{array}{l}1.28 \pm 0.34 \\
(0.59-1.82)\end{array}$ & -0.29 & -0.43 & -0.14 & $<0.01 * *$ & -0.30 & -0.46 & -0.15 & $<0.01 * *$ \\
\hline $\mathbf{C A}(\mathbf{c})$ & $\begin{array}{l}0.98 \pm 0.27 \\
(0.37-1.84)\end{array}$ & $\begin{array}{l}1.50 \pm 0.37 \\
(0.76-2.06)\end{array}$ & -0.53 & -0.68 & -0.37 & $<0.01 * *$ & -0.55 & -0.72 & -0.38 & $<0.01 * *$ \\
\hline
\end{tabular}

Legend: PD: Parkinson's disease; IL = inferior limit; $\mathrm{SL}=$ superior limit $\mathrm{CI}=$ confidence interval; $\mathrm{ST}=$ striatum; $\mathrm{PU}=$ putamen; $\mathrm{CA}=$ caudate nucleus; $\mathrm{AI}=$ asymmetry index; $\mathrm{P} / \mathrm{C}=\mathrm{P} / \mathrm{C}$ ratio; (i) = ipsilateral; (c) = contralateral. The values were described at mean \pm standard deviation (range)

*p-value $<0.05$

$* * p$-value $<0.01$ 
Table 4: Semiquantification of striatum BPI and sub regions in healthy and PD groups with the Two Box ( $\mathrm{n}=67$ patients).

\begin{tabular}{|c|c|c|c|c|c|c|c|c|c|c|}
\hline & \multicolumn{5}{|c|}{ Simple regression model } & \multicolumn{5}{|c|}{ Adjusted regression model (age, sex, schooling) } \\
\hline & PD & Healthy subjects & $\begin{array}{l}\text { PD - healthy } \\
\text { subjects }\end{array}$ & $\begin{array}{c}\text { IL } \\
\text { IC95 }\end{array}$ & $\begin{array}{c}\text { SL } \\
\text { IC95 }\end{array}$ & p-value & $\begin{array}{l}\text { PD - healthy } \\
\text { subjects }\end{array}$ & $\begin{array}{c}\text { IL } \\
\text { IC95 }\end{array}$ & $\begin{array}{c}\text { SL } \\
\text { IC95 }\end{array}$ & $p$-value \\
\hline ST(i) & $\begin{array}{c}0.74 \pm 0.49 \\
(-0.38-2.02)\end{array}$ & $\begin{array}{l}1.58 \pm 0.52 \\
(0.52-2.65)\end{array}$ & -0.83 & -1.09 & -0.58 & $<0.01 * *$ & -0.83 & -1.09 & -0.56 & $<0.01 * *$ \\
\hline $\mathbf{S T}(\mathbf{c})$ & $\begin{array}{c}0.68 \pm 0.50 \\
(-0.62-1.68)\end{array}$ & $\begin{array}{l}1.65 \pm 0.50 \\
(0.62-2.65)\end{array}$ & -0.98 & -1.22 & -0.72 & $<0.01 * *$ & -1.01 & -1.27 & -0.74 & $<0.01 * *$ \\
\hline
\end{tabular}

Legend: PD: Parkinson's disease; IL = inferior limit; SL = superior limit; CI = confidence interval; $\mathrm{ST}=$ striatum; (i) = ipsilateral; $(\mathrm{c})=$ contralateral. The values were described at mean \pm standard deviation (range)

*p-value $<0.05$

** $p$-value $<0.01$ 
Table 5: Results of the ROC curve for the BPI of the striatum and sub regions obtained by the semiquantitative manual method.

\begin{tabular}{|c|c|c|c|c|c|c|c|}
\hline & & ST(c) & ST(i) & $\mathbf{P U}(\mathbf{c})$ & PU(i) & $\mathbf{C A}(\mathbf{c})$ & CA(i) \\
\hline \multirow[t]{4}{*}{ Manual } & Cutoff & 0.74 & 0.78 & 0.73 & 0.74 & 0.8 & 0.88 \\
\hline & Sensitivity & 1 & 1 & 1 & 0.957 & 1 & 1 \\
\hline & Specificity & 0.841 & 0.864 & 0.886 & 0.886 & 0.841 & 0.773 \\
\hline & $\begin{array}{l}\text { AUC } \\
\text { (CI 95\%) }\end{array}$ & $\begin{array}{l}0.98 \\
(0.94 ; 1.00)\end{array}$ & $\begin{array}{l}0.94 \\
(0.87 ; 0.99)\end{array}$ & $\begin{array}{l}0.97 \\
(0.93 ; 1.00)\end{array}$ & $\begin{array}{l}0.93 \\
(0.86 ; 0.99)\end{array}$ & $\begin{array}{l}0.96 \\
(0.92 ; 0.99)\end{array}$ & $\begin{array}{l}0.92 \\
(0.86 ; 0.98)\end{array}$ \\
\hline \multirow[t]{4}{*}{ MR } & Cutoff & 0.35 & 0.37 & 0.33 & 0.46 & 0.34 & 0.4 \\
\hline & Sensitivity & 0.783 & 0.783 & 0.739 & 0.783 & 0.826 & 0.739 \\
\hline & Specificity & 0.932 & 0.886 & 0.864 & 0.955 & 0.795 & 0.841 \\
\hline & $\begin{array}{l}\text { AUC } \\
\text { (CI 95\%) }\end{array}$ & $\begin{array}{l}0.88 \\
(0.79 ; 0.96)\end{array}$ & $\begin{array}{l}0.87 \\
(0.76 ; 0.96)\end{array}$ & $\begin{array}{l}0.80 \\
(0.65 ; 0.93)\end{array}$ & $\begin{array}{l}0.88 \\
(0.79 ; 0.96)\end{array}$ & $\begin{array}{l}0.88 \\
(0.79 ; 0.96)\end{array}$ & $\begin{array}{l}0.77 \\
(0.64 ; 0.90)\end{array}$ \\
\hline \multirow{4}{*}{$\begin{array}{l}\text { corrected- } \\
\text { MR }\end{array}$} & Cutoff & 0.72 & 1.13 & 0.83 & 1.1 & 1.21 & 1.14 \\
\hline & Sensitivity & 0.783 & 0.783 & 0.783 & 0.78 & 0.783 & 0.739 \\
\hline & Specificity & 0.909 & 0.886 & 0.682 & 0.91 & 0.841 & 0.818 \\
\hline & $\begin{array}{l}\text { AUC } \\
\text { (CI 95\%) }\end{array}$ & $\begin{array}{l}0.87 \\
(0.78 ; 0.96)\end{array}$ & $\begin{array}{l}0.87 \\
(0.78 ; 0.96)\end{array}$ & $\begin{array}{l}0.74 \\
(0.58 ; 0.96)\end{array}$ & $\begin{array}{l}0.88 \\
(0.79 ; 0.96)\end{array}$ & $\begin{array}{l}0.87(0.77 ; \\
0.95)\end{array}$ & $\begin{array}{l}0.74 \\
(0.60 ; 0.88)\end{array}$ \\
\hline \multirow[t]{4}{*}{ Two Box } & Cutoff & 1.12 & 1.13 & - & - & - & - \\
\hline & Sensitivity & 0.87 & 0.826 & - & - & - & - \\
\hline & Specificity & 0.82 & 0.795 & - & - & - & - \\
\hline & $\begin{array}{l}\text { AUC } \\
\text { (CI 95\%) }\end{array}$ & $\begin{array}{l}0.93 \\
(0.85 ; 0.98)\end{array}$ & $\begin{array}{l}0.88 \\
(0.79 ; 0.96)\end{array}$ & - & - & - & - \\
\hline
\end{tabular}

Legend: $\mathrm{ST}=$ striatum; $\mathrm{PU}=$ putamen; $\mathrm{CA}=$ caudate nucleus; $(\mathrm{i})=$ ipsilateral; $(\mathrm{c})=$ contralateral, $\mathrm{AUC}=$ Area under the curve. 
Table 6: Intraobserver assessment of the semiquantitative method

\begin{tabular}{|c|c|c|c|c|c|c|c|c|c|c|c|c|}
\hline & \multicolumn{3}{|c|}{ Manual } & \multicolumn{3}{|c|}{ MRI } & \multicolumn{3}{|c|}{ Corrected-MRI } & \multicolumn{3}{|c|}{ Two Box } \\
\hline & ICC & $\begin{array}{c}\text { IL } \\
\text { IC95\% }\end{array}$ & $\begin{array}{c}\text { SL } \\
\text { IC95\% }\end{array}$ & ICC & $\begin{array}{c}\text { IL } \\
\text { IC95\% }\end{array}$ & $\begin{array}{c}\text { SL } \\
\text { IC95\% }\end{array}$ & ICC & $\begin{array}{c}\text { IL } \\
\text { IC95\% }\end{array}$ & $\begin{array}{c}\text { SL } \\
\text { IC95\% }\end{array}$ & ICC & $\begin{array}{c}\text { IL } \\
\text { IC95\% }\end{array}$ & $\begin{array}{c}\text { SL } \\
\text { IC95\% }\end{array}$ \\
\hline ST(i) & 0.98 & 0.97 & 0.99 & 0.9994 & 0.999 & 0.9996 & 0.9996 & 0.9993 & 0.9997 & 0.972 & 0.956 & 0.983 \\
\hline ST(c) & 0.98 & 0.96 & 0.99 & 0.9995 & 0.9992 & 0.9997 & 0.9996 & 0.9993 & 0.9997 & 0.977 & 0.963 & 0.986 \\
\hline PU(i) & 0.98 & 0.96 & 0.99 & 0.9993 & 0.9989 & 0.9996 & 0.9993 & 0.9988 & 0.9995 & - & - & - \\
\hline $\mathbf{P U}(\mathbf{c})$ & 0.97 & 0.94 & 0.98 & 0.9993 & 0.9989 & 0.9996 & 0.9994 & 0.999 & 0.9996 & - & - & - \\
\hline CA(i) & 0.96 & 0.94 & 0.98 & 0.9996 & 0.9993 & 0.9997 & 0.9997 & 0.9995 & 0.9998 & - & - & - \\
\hline $\mathbf{C A}(\mathbf{c})$ & 0.96 & 0.94 & 0.98 & 0.9991 & 0.9986 & 0.9995 & 0.9991 & 0.9985 & 0.9994 & - & - & - \\
\hline
\end{tabular}

Legend: $\mathrm{ICC}=$ Intraclass Correlation Coefficient; IL = inferior limit; $\mathrm{SL}=$ superior limit $\mathrm{CI}=$ confidence interval; $\mathrm{ST}=$ striatum; $\mathrm{PU}=$ putamen; $\mathrm{CA}=$ caudate nucleus; $\mathrm{AI}=$ asymmetry index; $\mathrm{P} / \mathrm{C}=\mathrm{P} / \mathrm{C}$ ratio; $(\mathrm{i})=$ ipsilateral; $(\mathrm{c})=$ contralateral. 
Table 7: Interobserver assessment of the semiquantitative methods.

\begin{tabular}{|c|c|c|c|c|c|c|c|c|c|c|c|c|}
\hline & ICC & $\begin{array}{c}\text { IL } \\
\text { IC95\% }\end{array}$ & $\begin{array}{c}\text { SL } \\
\text { IC95\% }\end{array}$ & ICC & $\begin{array}{c}\text { IL } \\
\text { IC95\% }\end{array}$ & $\begin{array}{c}\text { SL } \\
\text { IC95\% }\end{array}$ & ICC & $\begin{array}{c}\text { IL } \\
\text { IC95\% }\end{array}$ & $\begin{array}{c}\text { SL } \\
\text { IC95\% }\end{array}$ & ICC & $\begin{array}{c}\text { IL } \\
\text { IC95\% }\end{array}$ & $\begin{array}{c}\text { SL } \\
\text { IC95\% }\end{array}$ \\
\hline ST(i) & 0.87 & 0.8 & 0.92 & 0.931 & 0.891 & 0.957 & 0.936 & 0.899 & 0.96 & 0.94 & 0.9 & 0.96 \\
\hline $\operatorname{ST}(\mathbf{c})$ & 0.87 & 0.79 & 0.92 & 0.95 & 0.919 & 0.969 & 0.946 & 0.914 & 0.967 & 0.94 & 0.9 & 0.96 \\
\hline $\mathbf{P U}(\mathbf{c})$ & 0.86 & 0.78 & 0.91 & 0.883 & 0.817 & 0.926 & 0.841 & 0.754 & 0.899 & - & - & - \\
\hline CA(i) & 0.76 & 0.64 & 0.84 & 0.929 & 0.887 & 0.955 & 0.918 & 0.87 & 0.949 & - & - & - \\
\hline $\mathrm{CA}(\mathbf{c})$ & 0.81 & 0.71 & 0.88 & 0.907 & 0.853 & 0.941 & 0.889 & 0.826 & 0.93 & - & - & - \\
\hline
\end{tabular}

Legend: ICC = Intraclass Correlation Coefficient; IL = inferior limit; $\mathrm{SL}=$ superior limit; $\mathrm{CI}=$ confidence interval; $\mathrm{ST}=$ striatum; $\mathrm{PU}=$ putamen; $\mathrm{CA}=\mathrm{caudate}$ nucleus; $\mathrm{AI}$ $=$ asymmetry index; $\mathrm{P} / \mathrm{C}=\mathrm{P} / \mathrm{C}$ ratio; $(\mathrm{i})=$ ipsilateral; $(\mathrm{c})=$ contralateral. 


\section{APÊNDICE 8: ARTIGO 4}

\section{Comparison between qualitative and semiquantitative evaluation of DAT- SPECT with [ ${ }^{99 m}$ Tc]-TRODAT-1 in Parkinson's disease.}

Felipe Arriva Pitella ${ }^{1}$, Vitor Tumas ${ }^{2}$, Leonardo Alexandre Santos ${ }^{1}$, Ana Carolina Trevisan

${ }^{1,3}$, Manuelina Mariana Capellari Macruz ${ }^{2}$, Emerson Nobuyuki Itikawa ${ }^{1,3}$, Mery Kato ${ }^{1}$, Jose Henrique Silvah ${ }^{1}$, Anneke A. Boerlage ${ }^{6}$, Dick Tibboel ${ }^{6}$, Marcus Vinícius Simões ${ }^{1}$, Carlos Alberto Buchpiguel ${ }^{5}$, Lauro Wichert-Ana ${ }^{1,3,5}$.

${ }^{1}$ Department of Internal Medicine, Section of Nuclear Medicine, and ${ }^{2}$ Department of Neuroscience and Behavioral Sciences. Ribeirão Preto Medical School, University of São Paulo. Ribeirão Preto, SP, Brazil.

${ }^{3}$ Interunits Post-Graduation Program on Bioengineering. São Carlos School of Engineering, University of São Paulo, São Carlos, Brazil.

${ }^{4}$ Center of Nuclear Medicine, University of Sao Paulo, University of Sao Paulo Medical School, Sao Paulo, Brazil.

${ }^{5}$ The Center for Interdisciplinary Research on Applied Neurosciences - NAPNA - University of São Paulo (USP).

${ }^{6}$ Intensive Care and Pediatric Surgery Department, Erasmus Medical Center, Sophia Children's Hospital. Erasmus University. Rotterdam, The Netherlands.

\section{ADDRESS CORRESPONDENCE TO:}

Dr. Felipe Arriva Pitella, MD, PhD

Seção de Medicina Nuclear, Hospital das Clínicas - FMRP - USP. Av. Bandeirantes, 3900.

CEP: 14048-900. Ribeirão Preto - SP - Brasil. Phone/FAX: +55 1636022596.

E-mail: pitella.fa@gmail.com 


\section{ABSTRACT}

RATIONALE: The visual inspection of DAT-SPECT shows excellent results in trained readers, since a substantial number of synapses may be degenerate when the patient becomes symptomatic. The use of quantification methods in nuclear medicine for the purpose of enhancing diagnostic accuracy is increasing. OBJECTIVE: Using ${ }^{99 \mathrm{~m}} \mathrm{Tc}-$ TRODAT-1, this study aimed to evaluate and compare DAT-SPECT visual interpretation and semiquantitative manual method. MATERIAL AND METHODS: Sixty-seven patients, 23 healthy (8 male; mean \pm SD age $59 \pm 11$ years old) and 44 age-matched patients with various degrees of severity of idiopathic PD (29 male; age: 59 \pm 7 years old; duration of symptoms: $10 \pm 6$ years; HYS: 2.16 \pm 0.65 ; UPDRS III: 29.74 \pm 17.79 ). All patients performed [ ${ }^{99 m} \mathrm{Tc}$ ]-TRODAT-1 SPECT. The visual interpretation and semiquantification of binding potentials (BPI) of striatum and subregions were made by two observers. RESULTS: In the qualitative evaluation, sensitivity was 90.9-95.4\%, specificity 91.3-100\%, positive predictive value 95.4-100\%, negative predictive value 84.6-91.3\%, and accuracy 92.5-95.5\%. There was a strong intraobserver agreement (kappa > 0.80) in the qualitative binary evaluation (positive versus negative), with a moderate interobserver agreement $(\mathrm{kappa}=0.60-0.79)$. There was a weak interobserver agreement when considering the qualitative classification of Benamer. BPI was statistically lower in the PD group than in the healthy control group. A BPI cutoff for striatum and putamen ranging from 0.73 to 0.78 showed a sensitivity of $95 \%-100 \%$ and specificity of $84 \%$ $88 \%$. For caudate nucleus, a BPI threshold of 0.8 to 0.88 revealed sensitivity up to $100 \%$ and specificity of $77 \%-84 \%$. The BPIs respective areas under the curve (AUC) ranged from 0.92 to 0.98 . BPI ICC was close to 1.0 in the intraobserver evaluation, and 0.76 to 0.87 in the interobserver assessment. CONCLUSION: The qualitative evaluation showed excellent performance. The semiquantitative manual method was comparable with visual interpretation, with a small advantage for visual interpretation. The semiquantitative method aid information to visual interpretation.

KEYWORDS: Parkinson; TRODAT; semiquantitative; qualitative 


\section{INTRODUCTION}

Parkinson's disease (PD) is a progressive neurodegenerative disease that affects approximately $1 \%$ of persons older than 60 years (GAZEWOOD; RICHARDS; CLEBAK, 2013). The main aspect of the pathophysiology is the loss of dopaminergic neurons in the substantia nigra pars compacta [1]. PD diagnosis is primarily based on neurological findings, such as bradykinesia, rigidity, tremor and postural instability $[2,3]$.

In addition to the diagnostic value, the functional images of positron emission tomography (PET) and single photon emission computed tomography (SPECT) help to understand the pathophysiology underlying the parkinsonian syndromes and provide a sensitive means to detect subclinical diseases and evaluate the degree and evolution of the disease [4]. Molecular imaging techniques use dopaminergic biomarkers as the main tool in the clinical investigation of movement disorders [5-8].

The SPECT with ${ }^{99 \mathrm{~m}}$ Tc-TRODAT-1, a radiolabeled tropane that binds dopamine transporters (DAT), has been proposed to evaluate the integrity of the nigrostriatal dopaminergic system. In clinical routine, visual interpretation of DAT-SPECT and several semi-quantification techniques can be applied [9-12].

The imaging pattern in patients with PD on visual inspection is usually described as a reduction of the density of dopaminergic transporters in the striatum body preferentially on the contralateral side to the predominance of the symptoms, with a rostrocaudal gradient $[5,6,13,14]$. The visual inspection of DAT-SPECT shows excellent results in trained readers, since a substantial number of synapses may be degenerate when the patient becomes symptomatic [15].

The use of quantification methods in nuclear medicine for the purpose of enhancing diagnostic accuracy is increasing. The semi-quantification process based on areas of interest (ROI) has as main challenge the construction of these ROIs in order to present adequate dimensions and correct positioning on the striatum. The evaluator's experience becomes a determining factor in the construction of these ROIs for quantification $[16,17]$. The manual semiquantitative method is one of the most widely used due to its versatility and practicality [18-20].

Using ${ }^{99 \mathrm{~m}}$ Tc-TRODAT-1, this study aimed to evaluate and compare DAT-SPECT visual interpretation and semiquantitative manual method.

\section{MATERIAL AND METHODS}




\section{Study Design}

Upon inclusion in the study, the patients were allocated in two groups (healthy subjects and PD group) prospectively balanced in terms of age, schooling, and gender. The data were analyzed in blinded fashion, after a computer-generated randomization designed to yield groups. The images were analyzed by qualitative and manual semiquantitative methods by two evaluators, in order to establish accuracy, sensitivity, specificity, and reproducibility of the methods. Both methods were correlated with clinical data.

\section{Subjects}

This study included prospectively 67 patients. Twenty-three healthy controls ( 8 male; 15 female; mean \pm SD age $59 \pm 11$ years old) and 44 age-matched patients with various degrees of severity of idiopathic PD (29 male; 15 female; mean \pm SD age $59 \pm 7$ years old; mean \pm SD duration of symptoms $10 \pm 6$ years; range of symptoms duration 1-21 years). All subjects have been treated at the Clinical Hospital of the Ribeirão Preto Medical School, University of São Paulo (HC-FMRP-USP) and provided written informed consent before the study. The study was approved by the institution's Ethics Committee.

In the group of healthy volunteers were excluded: patients with moderately severe and severe dementia; Parkinson's disease or parkinsonian syndrome; neuropsychiatric disorders (schizophrenia, hyperactivity and attention deficit, symptomatic depressions and others that may occur with alterations in the dopaminergic system); abusive use of alcohol or drugs; organic brain lesions; cerebral vascular accidents; claustrophobia; chronic use of psychotropic medications; use of medications known to interfere with TRODAT-1 binding to DAT; history of trauma with loss of consciousness; smoking. The patients were submitted to a summary clinical evaluation.

Parkinson's patients necessarily presented clinical diagnosis confirmed by a specialist neurologist in the area. We used the diagnostic criteria of the London Brain Bank (UK-PDS Brain Bank Society-Sponsored Revision of the Unified Parkinson's Disease Rating Scale) $[21,22]$. Eleven patients were on carbidopa-levodopa monotherapy, one was on dopamine agonist monotherapy, while 32 were receiving combination therapy; all patients responded to treatment with good motor benefit. Patients were not taking any medication that might have interfered with striatal [ $\left.{ }^{99 \mathrm{~m}} \mathrm{Tc}\right]-T R O D A T-1$ uptake. All PD patients were scored with the Hoehn and Yahr Scale (HYS), which ranges from HYS I to HYS IV (mean \pm SD 2.16 \pm 0.65 ; range 1-4), and with the Unified Parkinson's Disease Rating Scale motor score (UPDRS III: mean \pm SD 29.74 \pm 17.79 ; range 9-74) [23,24]. All patients underwent brain SPECT with 


\section{$\left[{ }^{99 \mathrm{~m}} \mathrm{Tc}\right]-\mathrm{TRODAT}-1$.}

\section{Radiopharmaceutical}

The $\left[{ }^{99 \mathrm{~m}} \mathrm{Tc}\right]-$ TRODAT-1 was prepared from a pre formulated lyophilized kit provided by the Institute of Nuclear Energy Research (Lung-Tan, Taiwan). The kit was reconstituted with $1110 \mathrm{MBq}(44 \mathrm{mCi})$ of freshly eluted sodium $\left[{ }^{99 \mathrm{~m}} \mathrm{Tc}\right]$-pertechnetate in $5 \mathrm{ml}$ of saline and incubated at $100^{\circ} \mathrm{C}$ for 30 minutes to complete labeling. After cooling to room temperature, quality control of radiochemical purity ( $>90 \%)$, determined by the chromatographic method, was performed.

\section{Image acquisition}

DAT-SPECT with [ ${ }^{99 \mathrm{~m}} \mathrm{Tc}$ ]-TRODAT-1 SPECT was performed using a dual-head camera 4 hours after injection of 740-1,110 MBq (mean \pm SD $865,8 \pm 74$ ) of [ $\left.{ }^{99 \mathrm{~m}} \mathrm{Tc}\right]-T R O D A T-$ 1. The scintigraphic images were obtained in a circular camera series model BrightView XCT (Philips Medical Systems Inc., Cleveland, OH, USA) composed of two detector heads. The data were collected using a low energy high resolution (LERH) collimator, in a symmetric window with a $15 \%$ width, centered on a $140 \mathrm{keV}$ photopeak. In a step-and-shoot acquisition mode, 64 projections were collected, with a circular orbit of $180^{\circ}$ per head and with a projection acquisition time of $30 \mathrm{~s}$, a radius of rotation of less than $20 \mathrm{~cm}$, a matrix of $128 \mathrm{x}$ 128 pixels, a magnification factor of $\mathrm{x} 1$ and with isotropic pixels of $2.13 \mathrm{~mm}$. Images were reconstructed using the iterative method and Butterworth filter (order 2.00, cut-off 0.22). Chang's attenuation correction method was applied using a coefficient of $0.12 / \mathrm{cm}$.

\section{Image evaluation}

The images were blindly assessed and quantified by 2 observers. Visual and semiquantitative analyzes were performed by two nuclear physicians with neuroimaging experience (observer A and B). No previous training was performed, since the evaluators were familiar with the SPECT image with [ ${ }^{99 \mathrm{~m}} \mathrm{Tc}$ ] -TRODAT-1. One of them performed two readings at least 1 week apart (evaluation A1 and A2). The second observer reading was called B1 for comparison purposes. For the analysis the patients were randomized, being identified by a random number (1 to 67$)$.

\section{Visual interpretation}

The images were evaluated in an Extended Brilliance Workspace Philips (EBW) 
workstation, dedicated to research in the Nuclear Medicine Section of HC-FMRP-USP. Two linear color scales were used: inverse (white and black) and thermal. The studies of each patient were initially defined by the observers as normal (figure 1) or abnormal (qualitative assessment 1).

\section{INSERT FIGURE 1}

The exams were classified in degrees according to the type of alteration observed: 0 normal; 1 - involvement of one of the pimples; II - bilateral involvement of the putamen; III involvement of the putamen and the caudate nucleus $[25,26]$. The evaluation considering the criteria of Benamer and collaborators was defined as qualitative evaluation 2. For future analysis, the grade 3 was subdivided into $3 a$ (involvement of one of the caudate nuclei) and $3 b$ (bilateral involvement of the caudates) (figure 2).

\section{INSERT FIGURE 2}

\section{Semi-quantitative assessment}

Specific uptake ratios or binding potential (BPI) in the striatum were calculated by subtracting the mean counts per pixel in the occipital lobe (background) from the mean counts per pixel in the whole striatum and dividing the result by the mean counts per pixel in the background [27]. In the PD group, the striatum located opposite the side with dominant symptoms was defined as the contralateral. In the control group, the right striatum was defined as the contralateral and the ipsilateral was the left striatum (WENG et al., 2004).

Five adjacent transaxial slices with the highest radiotracer uptake in the basal ganglia were summed for semi-quantitative analysis of striatal specific DAT binding of [ $\left.{ }^{99 \mathrm{~m}} \mathrm{Tc}\right]$-TRODAT1 using an image analysis package (JETpack; Philips Medical Systems). Fixed regions of interest (ROI) were drawn manually over the summed transaxial slice of each hemisphere on the whole striatum, on putamen and caudate. An irregular ROI was drawn manually on occipital cortex (Figure 3).

\section{INSERT FIGURE 3}

\section{Statistical analysis}


A 2x2 table was used to determine the sensitivity, specificity, predictive values and accuracy of the qualitative assessments for the diagnosis of Parkinson's disease. The intraobserver and interobserver agreement was measured by the kappa coefficient (0 $\leq \mathrm{k} \leq 1$ ). The softwares used were SAS 9.3 (SAS Institute Inc., Cary, NC, USA) and SPSS v17.0 (IBM Corporation, Armonk, NY, USA).

For semiquantitative manual method, simple and multiple linear regression models were adjusted to compare the striatum, caudate nucleus and putamen BPI between the healthy subjects and PD groups. In the multiple regression models, gender, age and schooling were used as covariables. The reliability of the quantification methods was evaluated by the Intraclass Correlation Coefficient (ICC). The softwares used were SAS 9.3 (SAS Institute Inc., Cary, NC, USA) and SPSS v17.0 (IBM Corporation, Armonk, NY, USA).

ROC curves were generated using $\mathrm{R}$ version 3.3.3 software to compare the sensitivity and specificity of the diagnosis of each index based on the area under the curve (AUC). The threshold was established after defining the best relationship between sensitivity and specificity among the points generated by the ROC curve.

\section{RESULTS}

\section{Qualitative evaluation}

In the qualitative evaluation, sensitivity was $90.9-95.4 \%$, specificity $91.3-100 \%$, positive predictive value 95.4-100\%, negative predictive value 84.6-91.3\%, and accuracy 92.5-95.5\%. Positive predictive values were higher than negative values (Table 1).

There was a strong intraobserver agreement (kappa > 0.80) in the qualitative binary evaluation (positive versus negative), with a moderate interobserver agreement (kappa $=0.60$ - 0.79). There was a weak interobserver agreement when considering the qualitative classification 2 (table 2).

\section{TABLE 2}

\section{Semiquantitative evaluation}


There was a statistically significant reduction ( $p$-value $<0.05)$ of the BPI in the striatum and substructures in the group of patients with PD compared to healthy group. The results were maintained when multiple regression model was applied, with gender, age and schooling as covariates. Table 3 shows the comparison in the BPI of the groups (PD and healthy subjects).

\section{TABLE 3}

The threshold, sensitivity and specificity determined by the threshold and area under the curve for each BPI can be seen at table 4. For BPI of ST and PU, the established cutoff ranged from 0.73 to 0.78 . From this threshold, the sensitivity ranged from $95 \%$ to $100 \%$ and the specificity ranged from $84 \%$ to $88 \%$. This means that virtually all patients with BPI of ST and PU less than 0.7 had PD. For CA, the established threshold was higher, ranging from 0.8 to 0.88 , with sensitivity up to $100 \%$ and specificity of $77 \%$ to $84 \%$. The areas under the curve described were high, ranging from 0.92 to 0.98 (figure 4).

\section{INSERT FIGURE 4}

Considering the 3 qualitative evaluations (A1, A2 and B1), we obtained 3 falsepositive results and 9 false-negative results. If BPI threshold of 0.7 for ST and PU and 0.8 for AC was applied, the manual semiquantitative method would reduce false positive cases from 3 to 0 (100\% of cases) and false negative cases from 9 to 7 (22\% of cases).

In the intraobserver evaluation, for all indexes an ICC near 1.0 was found. The interobserver agreement was also excellent, however, lower than intraobserver, with ICC ranging from 0.76 in the quantification of CA (i) to 0.87 for ST(i), ST(c) and PU(i) (table 4).

\section{TABLE 4}

\section{DISCUSSION}

In the present study, excellent results were found for the diagnosis of PD through qualitative evaluation alone. The interobserver agreement was excellent, but the interobserver agreement was only moderate considering the binary interpretation (positive versus negative), and significantly reduced (poor correlation) when the images were graded by the Benamer classification $[25,26]$. Both evaluators of the study had experience in neuroimaging, and therefore, among inexperienced physicians, what is expected is a greater divergence in the 
readings. One possible explanation for this interobserver variability is the poor target / nontarget ratio in the images of the DP patients, which makes it difficult to individuate the structures.

The results support that the qualitative evaluation must be applied and it is accurate. The visual interpretation presents higher variability when the DAT deficit is categorized. Therefore, for the differential diagnosis the qualitative evaluation is in most cases sufficient and resolutive.

About semi-quantification, it was able to differentiate the groups with and without PD. The BPI parameter for this distinction between groups was not influenced by gender, age and schooling. The percentage reduction in the BPI of PD group was over than $50 \%$ for all structures compared to healthy patients, with a predominance of the contralateral deficit, more evident on the putamen.

Although satisfactory results have often been obtained by semi-quantification methods when compared to visual analysis [28], some limitations are found. In particular, in cases with significant uptake deficit in the striatum, with the loss of anatomic referential, and in patients with anatomical variation, the results may be inconsistent and variable [28]. In addition, other factors may interfere with quantification, such as gamma-camera type, calibration, collimators, acquisition procedure and corrections (attenuation, scattering, and partial volume effect), and therefore, comparison with other centers or the use of published control values produces valid results only when the reference values were obtained with exactly the same technique or when these centers were calibrated transversally using a phantom [15].

The impact of semiquantitative methods on reducing false positives and negatives when applied in conjunction with qualitative assessment is little discussed in the literature. In our study, Regarding intraobserver and interobserver agreement in semi-quantitative manual method, with ICC for BPI scores higher than 0.75 (FLEISS; LEVIN; PAIK, 2013). As expected, in the interobserver analysis the ICC was lower compared to the intraobserver analysis, still, the results were excellent.

\section{CONCLUSION}

The qualitative evaluation of SPECT with $\left[{ }^{99 \mathrm{~m}} \mathrm{Tc}\right]-$ TRODAT- 1 showed excellent differential diagnosis performance among healthy and PD patients. The semiquantitative manual method was comparable with visual interpretation, with a small advantage for visual interpretation. However, the semiquantitative assessment was complementary to qualitative assessment, and reduced false negatives and false positives. Interobserver agreement was higher in the 
semiquantitative manual method compared to qualitative evaluation when it was made a classification of the uptake deficit.

\section{ACKNOWLEDGEMENTS}

The authors gratefully acknowledge financial support from: (a) Grant/Project \# 049/2013 (AUXPE No. 2880/2013, LWA) from CAPES / NUFFIC, Brazil Netherlands International Cooperation; (b) Grant\# 2013/25.987-2 (LWA) and Grant\# 2015/50089-3 FAPESP SPRINT (LWA) from The State of São Paulo Research Foundation - FAPESP. None of these funding agencies played a role in the design, data collection, management, analysis, interpretation of the data, and preparation, review or approval of the manuscript. We confirm that we have read the Journal's position on issues involved in ethical publication and affirm that this report has the approval of our institutional ethics committee. We also thank John Carpenter, Ribeirão Preto, Brazil, for the English revision.

\section{CONFLICT OF INTEREST}

All authors have no financial arrangement or affiliation with industry. Two authors received MSc and Ph.D scholarships while both paper or research were done: ACT (CAPES 2012/14152-4), ENI (FAPESP 2012/14152-4). No funding agencies played any/a role in the design or conduct of the study, in the analysis of data and the writing of the manuscript.

\section{STATEMENT OF AUTHORSHIP}

FAP, LWA, VT designed the research; FAP, ACT, LAS, MK conducted the research; LAS conducted the analysis through SPM software; LAS, ENI conducted additional statistical analyses; MMCM and VT performed clinical evaluation, JHS critically reviewed the manuscript, LWA and VT had primary responsibility for final content. All authors contributed towards, read and approved the final manuscript.

\section{REFERENCES}

1. Harikrishna Reddy D, Reddy DH, Misra S, Medhi B. Advances in Drug Development for Parkinson's Disease: Present Status. Pharmacology. 2014;93:260-71.

2. Gazewood JD, Richards DR, Clebak K. Parkinson disease: an update. Am. Fam. Physician. 2013;87:267-73.

3. Munhoz RP, Moro A, Silveira-Moriyama L, Teive HA. Non-motor signs in Parkinson's 
disease: a review. Arq. Neuropsiquiatr. 2015;73:454-62.

4. Brooks DJ. Parkinson's disease: diagnosis. Parkinsonism Relat. Disord. 2012;18 Suppl $1:$ S31-3.

5. Meyer PT, Hellwig S. Update on SPECT and PET in parkinsonism - part 1: imaging for differential diagnosis. Curr. Opin. Neurol. 2014;27:390-7.

6. Meyer PT, Frings L, Hellwig S. Update on SPECT and PET in parkinsonism - part 2. Curr. Opin. Neurol. 2014;27:398-404.

7. Oung QW, Muthusamy H, Lee HL, Basah SN, Yaacob S, Sarillee M, et al. Technologies for Assessment of Motor Disorders in Parkinson's Disease: A Review. Sensors .

2015; 15:21710-45.

8. Niethammer M, Feigin A, Eidelberg D. Functional neuroimaging in Parkinson's disease. Cold Spring Harb. Perspect. Med. 2012;2:a009274.

9. Pavese N, Brooks DJ. Imaging neurodegeneration in Parkinson's disease. Biochim.

Biophys. Acta. 2009;1792:722-9.

10. Meyer PT, Frings L, Hellwig S. Update on SPECT and PET in parkinsonism - part 2: biomarker imaging of cognitive impairment in Lewy-body diseases. Curr. Opin. Neurol. 2014;27:398-404.

11. Brooks DJ. 1.7.2 DIAGNOSIS OF PD. Parkinsonism Relat. Disord. 2012;18:S4.

12. Marshall V, Grosset D. Role of dopamine transporter imaging in routine clinical practice. Mov. Disord. 2003;18:1415-23.

13. Booth TC, Nathan M, Waldman AD, Quigley A-M, Schapira AH, Buscombe J. The role of functional dopamine-transporter SPECT imaging in parkinsonian syndromes, part 1. AJNR Am. J. Neuroradiol. 2015;36:229-35.

14. Strafella AP, Bohnen NI, Perlmutter JS, Eidelberg D, Pavese N, Van Eimeren T, et al. Molecular imaging to track Parkinson's disease and atypical parkinsonisms: New imaging frontiers. Mov. Disord. 2017;32:181-92.

15. Djang DSW, Janssen MJR, Bohnen N, Booij J, Henderson TA, Herholz K, et al. SNM practice guideline for dopamine transporter imaging with 123I-ioflupane SPECT 1.0. J. Nucl. Med. 2012;53:154-63.

16. Scherfler C, Seppi K, Donnemiller E, Goebel G, Brenneis C, Virgolini I, et al. Voxel-wise analysis of [123I]beta-CIT SPECT differentiates the Parkinson variant of multiple system atrophy from idiopathic Parkinson's disease. Brain. 2005;128:1605-12.

17. Seppi K, Schocke MFH. An update on conventional and advanced magnetic resonance imaging techniques in the differential diagnosis of neurodegenerative parkinsonism. Curr. Opin. Neurol. 2005;18:370-5.

18. Verhoeff NP, Kapucu O, Sokole-Busemann E, van Royen EA, Janssen AG. Estimation of dopamine D2 receptor binding potential in the striatum with iodine-123-IBZM SPECT: 
technical and interobserver variability. J. Nucl. Med. 1993;34:2076-84.

19. Tossici-Bolt L, Dickson JC, Sera T, de Nijs R, Bagnara MC, Jonsson C, et al. Calibration of gamma camera systems for a multicentre European 123I-FP-CIT SPECT normal database. Eur. J. Nucl. Med. Mol. Imaging. 2011;38:1529-40.

20. Tossici-Bolt L, Hoffmann SMA, Kemp PM, Mehta RL, Fleming JS. Quantification of [123I]FP-CIT SPECT brain images: an accurate technique for measurement of the specific binding ratio. Eur. J. Nucl. Med. Mol. Imaging. 2006;33:1491-9.

21. Goetz CG. Unified Parkinson's Disease Rating Scale (UPDRS) and Movement Disorder Society Revision of the UPDRS (MDS-UPDRS). Rating Scales in Parkinson's Disease. 2012. p. 62-83.

22. Goetz CG, Tilley BC, Shaftman SR, Stebbins GT, Fahn S, Martinez-Martin P, et al. Movement Disorder Society-sponsored revision of the Unified Parkinson's Disease Rating Scale (MDS-UPDRS): scale presentation and clinimetric testing results. Mov. Disord. 2008;23:2129-70.

23. Goetz CG. Unified Parkinson's Disease Rating Scale (UPDRS) and Movement Disorder Society Revision of the UPDRS (MDS-UPDRS). Rating Scales in Parkinson's Disease. 2012. p. $62-83$.

24. Hughes AJ, Daniel SE, Kilford L, Lees AJ. Accuracy of clinical diagnosis of idiopathic Parkinson's disease: a clinico-pathological study of 100 cases. J. Neurol. Neurosurg. Psychiatry. 1992;55:181-4.

25. Ottaviani S, Tinazzi M, Pasquin I, Nothdurfter W, Tomelleri G, Fincati E, et al. Comparative analysis of visual and semi-quantitative assessment of striatal [123I]FP-CITSPET binding in Parkinson's disease. Neurol. Sci. 2006;27:397-401.

26. Benamer TS, Patterson J, Grosset DG, Booij J, de Bruin K, van Royen E, et al. Accurate differentiation of parkinsonism and essential tremor using visual assessment of [123I]-FP-CIT SPECT imaging: the [123I]-FP-CIT study group. Mov. Disord. 2000;15:503-10.

27. Weng Y-H, Yen T-C, Chen M-C, Kao P-F, Tzen K-Y, Chen R-S, et al. Sensitivity and specificity of 99mTc-TRODAT-1 SPECT imaging in differentiating patients with idiopathic Parkinson's disease from healthy subjects. J. Nucl. Med. 2004;45:393-401.

28. Badiavas K, Molyvda E, Iakovou I, Tsolaki M, Psarrakos K, Karatzas N. SPECT imaging evaluation in movement disorders: far beyond visual assessment. Eur. J. Nucl. Med. Mol. Imaging. 2011;38:764-73. 


\section{FIGURES}

FIGURE 1
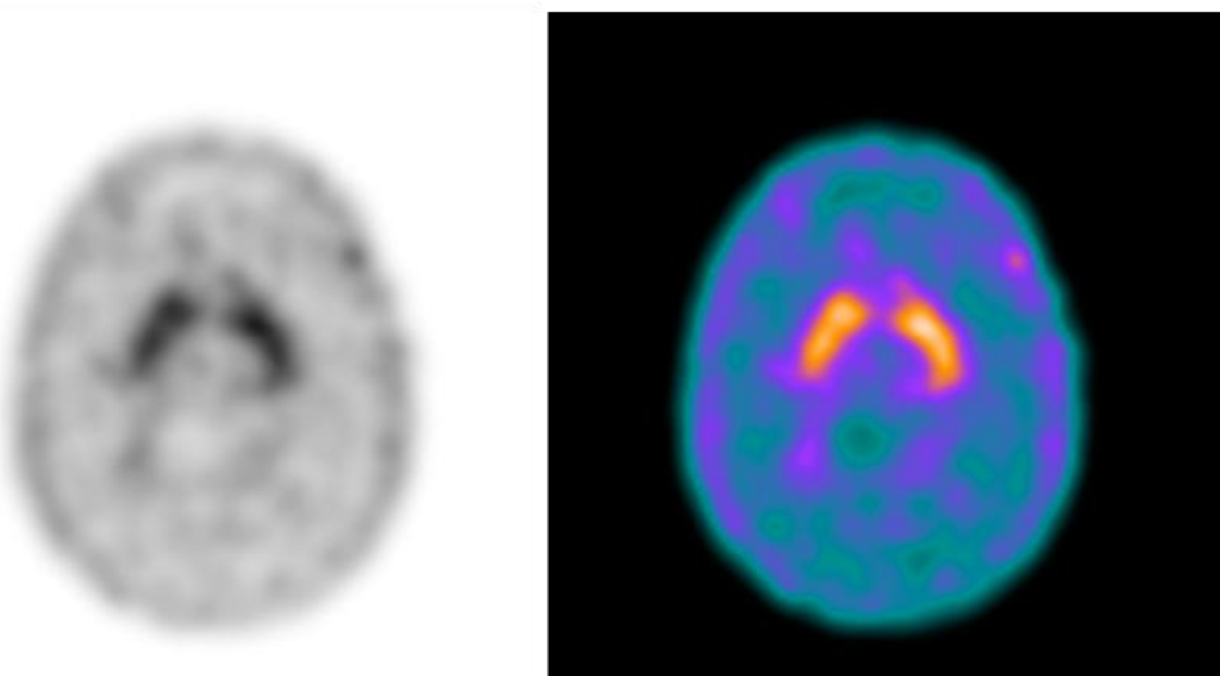

FIGURE 2

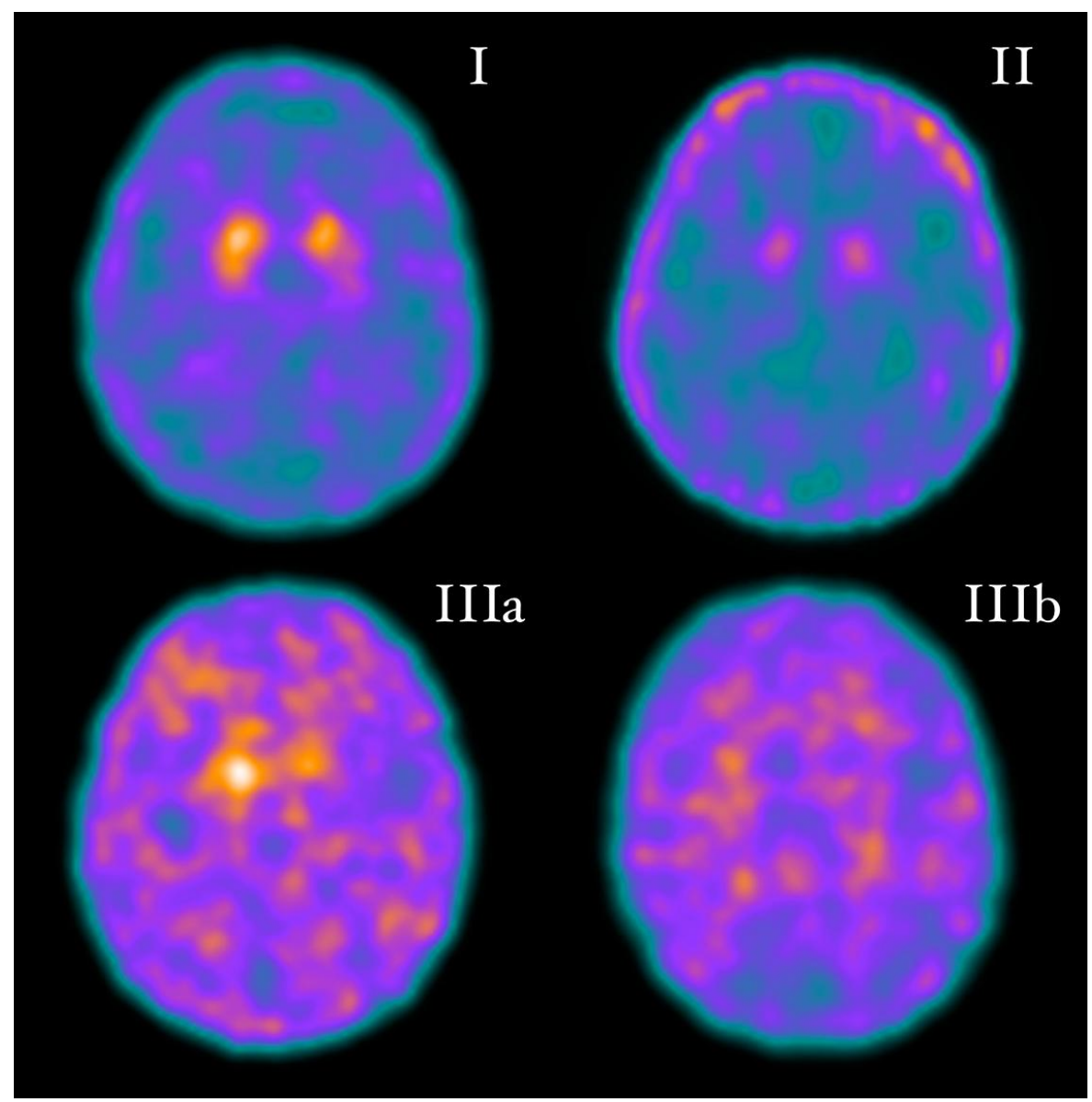


FIGURE 3

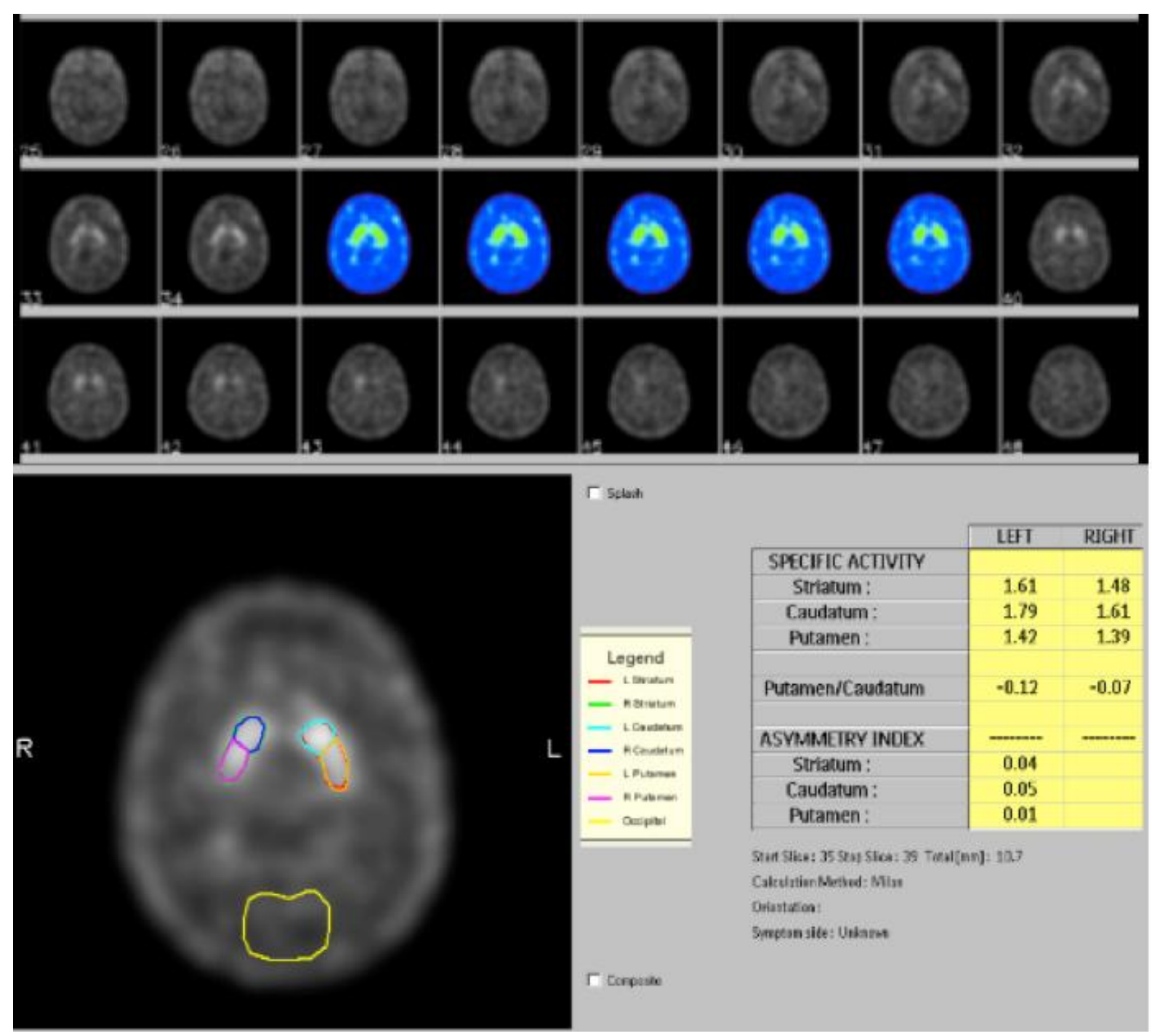




\section{FIGURE 4}

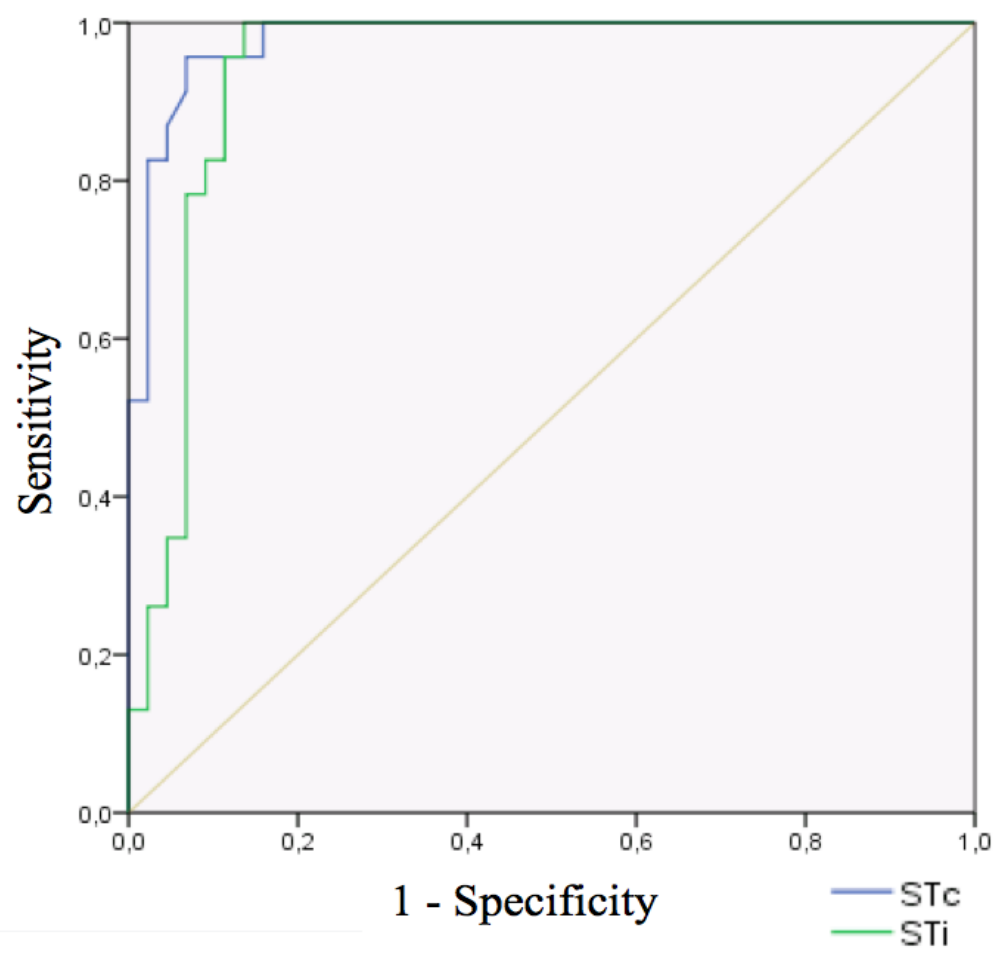

\section{LEGEND}

Figure 1: Transverse image of a SPECT with $\left[{ }^{99 \mathrm{~m}} \mathrm{Tc}\right]-$ TRODAT-1 of a healthy patient.

Figure 2: Transverse images of abnormal SPECT with $\left[{ }^{99 \mathrm{~m}} \mathrm{Tc}\right]-T R O D A T-1$ graded: Iinvolvement of one putamen; II- bilateral involvement of the putamen; IIIa - involvement of the putamen and one of the caudate nucleus; IIIb - bilateral involvement of putamen and caudate nucleus.

Figure 3: Quantification of the binding potential in the striatum, performed in a healthy volunteer.

Figure 4: ROC curve of the BPI ST(i) and ST(c). 


\section{TABLES}

Table 1: Qualitative evaluation of SPECT with [ $\left.{ }^{99 \mathrm{~m}} \mathrm{Tc}\right]-T R O D A T-1$ in PD group and healthy controls.

\begin{tabular}{llll}
\hline \multicolumn{1}{l}{ A1 } & \multicolumn{2}{l}{ A2 } & \multicolumn{1}{l}{ B1 } \\
\hline Sensitivity & $93,18 \%$ & $90,91 \%$ & $95,45 \%$ \\
Specificity & $100,00 \%$ & $95,65 \%$ & $91,30 \%$ \\
PPV & $100,00 \%$ & $97,56 \%$ & $95,45 \%$ \\
NPV & $88,46 \%$ & $84,62 \%$ & $91,30 \%$ \\
Accuracy & $95,52 \%$ & $92,54 \%$ & $94,03 \%$ \\
\hline
\end{tabular}

Legend: Legend: $\mathrm{A} 1=$ first evaluation of the observer A; $\mathrm{A} 2=$ second evaluation of the observer $\mathrm{A} ; \mathrm{B}=$ second observer evaluation; $\mathrm{PPV}=$ positive predictive value; NPV = negative predictive value.

Table 2: Analysis of interobserver and intraobserver agreement in the qualitative evaluation of SPECTs with [ $\left.{ }^{99 \mathrm{~m}} \mathrm{Tc}\right]-\mathrm{TRODAT}-1$.

\begin{tabular}{|c|c|c|c|}
\hline Visual interpretation & Coefficient & Intraobserver agreement & Interobserver agreement \\
\hline $\begin{array}{l}\text { Classification } 1 \\
\text { (positive versus } \\
\text { negative) }\end{array}$ & kappa index & $\begin{array}{l}0,87 \\
(\mathrm{CI} 95 \% 0,75 ; 0,99)\end{array}$ & $\begin{array}{l}0,77 \\
(\mathrm{CI} 95 \% 0,61 ; 0,93)\end{array}$ \\
\hline \multirow[t]{2}{*}{$\begin{array}{l}\text { Classification } 2 \\
{[26]}\end{array}$} & kappa index & $\begin{array}{l}0,82 \\
(\text { CI } 95 \% 0,71 ; 0,93)\end{array}$ & $\begin{array}{l}0,49 \\
(\text { CI } 95 \% 0,36 ; 0,63)\end{array}$ \\
\hline & $\begin{array}{l}\text { kappa index } \\
\text { weighted }\end{array}$ & $\begin{array}{l}0,92 \\
\text { (CI } 95 \% 0,87 ; 0,97)\end{array}$ & $\begin{array}{l}0,64 \\
(\mathrm{CI} 95 \% 0,51 ; 0,77)\end{array}$ \\
\hline
\end{tabular}


Table 3: Semiquantification of striatum BPI and sub regions in healthy and PD groups with the manual method ( $\mathrm{n}=67$ patients).

\begin{tabular}{|c|c|c|c|c|c|c|c|c|c|c|}
\hline & \multicolumn{5}{|c|}{ Simple regression model } & \multicolumn{5}{|c|}{ Adjusted regression model (age, sex, schooling) } \\
\hline & PD & Healthy subjects & $\begin{array}{c}\text { PD - } \\
\text { healthy } \\
\text { subjects }\end{array}$ & $\begin{array}{c}\text { IL } \\
\text { IC95 }\end{array}$ & $\begin{array}{c}\text { SL } \\
\text { IC95 }\end{array}$ & p-value & $\begin{array}{l}\text { PD - healthy } \\
\text { subjects }\end{array}$ & $\begin{array}{c}\text { IL } \\
\text { IC95 }\end{array}$ & $\begin{array}{c}\text { SL } \\
\text { IC95 }\end{array}$ & $p$-value \\
\hline ST(i) & $\begin{array}{c}0.50 \pm 0.31 \\
(0.04-1.47)\end{array}$ & $\begin{array}{l}1.18 \pm 0.22 \\
(0.78-1.68)\end{array}$ & -0.68 & -0.82 & -0.53 & $<0.01 * *$ & -0.70 & -0.86 & -0.54 & $<0.01 * *$ \\
\hline $\mathbf{S T}(\mathbf{c})$ & $\begin{array}{l}0.43 \pm 0.25 \\
(0.03-1.16)\end{array}$ & $\begin{array}{l}1.21 \pm 0.25 \\
(0.74-1.77)\end{array}$ & -0.77 & -0.90 & -0.64 & $<0.01 * *$ & -0.81 & -0.95 & -0.67 & $<0.01 * *$ \\
\hline $\mathbf{P U}(\mathbf{i})$ & $\begin{array}{l}0.42 \pm 0.31 \\
(0.03-1.47)\end{array}$ & $\begin{array}{l}1.09 \pm 0.23 \\
(0.71-1.55)\end{array}$ & -0.67 & -0.82 & -0.52 & $<0.01 * *$ & -0.69 & -0.85 & -0.53 & $<0.01 * *$ \\
\hline $\mathbf{P U}(\mathbf{c})$ & $\begin{array}{l}0.37 \pm 0.25 \\
(0.01-1.10)\end{array}$ & $\begin{array}{l}1.14 \pm 0.28 \\
(0.73-1.91)\end{array}$ & -0.77 & -0.90 & -0.63 & $<0.01 * *$ & -0.81 & -0.95 & -0.67 & $<0.01 * *$ \\
\hline CA(i) & $\begin{array}{l}0.62 \pm 0.35 \\
(0.01-1.51)\end{array}$ & $\begin{array}{l}1.31 \pm 0.27 \\
(0.88-1.84)\end{array}$ & -0.69 & -0.86 & -0.52 & $<0.01 * *$ & -0.71 & -0.81 & -0.53 & $<0.01 * *$ \\
\hline $\mathbf{C A}(\mathbf{c})$ & $\begin{array}{l}0.52 \pm 0.30 \\
(0.02-1.30)\end{array}$ & $\begin{array}{l}1.33 \pm 0.29 \\
(0.80-1.95)\end{array}$ & -0.81 & -0.96 & -0.65 & $<0.01 * *$ & -0.84 & -1.00 & -0.67 & $<0.01 * *$ \\
\hline
\end{tabular}

Legend: PD: Parkinson's disease; IL = inferior limit; $\mathrm{SL}=$ superior limit $\mathrm{CI}=$ confidence interval; $\mathrm{ST}=$ striatum; $\mathrm{PU}=$ putamen; $\mathrm{CA}=$ caudate nucleus; (i) = ipsilateral; $(\mathrm{c})=$ contralateral. The values were described at mean \pm standard deviation (range). *p-value $<0.05 * *$-value $<0.01$ 
Table 5: Agreement evaluation of the semiquantitative methods.

\begin{tabular}{lcccccc}
\hline & \multicolumn{3}{c}{ Intraobserver } & & \multicolumn{3}{c}{ Interobserver } \\
\hline & ICC & $\begin{array}{c}\text { IL } \\
\text { IC95\% }\end{array}$ & $\begin{array}{c}\text { SL } \\
\text { IC95\% }\end{array}$ & ICC & IL & SL \\
ST(i) & 0.98 & 0.97 & 0.99 & 0.87 & 0.8 & 0.92 \\
ST(c) & 0.98 & 0.96 & 0.99 & 0.87 & 0.79 & 0.92 \\
PU(i) & 0.98 & 0.96 & 0.99 & 0.87 & 0.8 & 0.92 \\
PU(c) & 0.97 & 0.94 & 0.98 & 0.86 & 0.78 & 0.91 \\
$\mathbf{C A}(\mathbf{i})$ & 0.96 & 0.94 & 0.98 & 0.76 & 0.64 & 0.84 \\
$\mathbf{C A}(\mathbf{c})$ & 0.96 & 0.94 & 0.98 & 0.81 & 0.71 & 0.88 \\
\hline
\end{tabular}

Legend: ICC = Intraclass Correlation Coefficient; IL = inferior limit; $\mathrm{SL}=$ superior limit; $\mathrm{CI}=$ confidence interval; $\mathrm{ST}=$ striatum; $\mathrm{PU}=$ putamen $; \mathrm{CA}=$ caudate nucleus; $\mathrm{AI}=$ asymmetry index; $\mathrm{P} / \mathrm{C}=\mathrm{P} / \mathrm{C}$ ratio; $(\mathrm{i})=$ ipsilateral; $(\mathrm{c})=$ contralateral. 